OAK RIDGE

NATIONAL LABORATORY

MANAGED BY UT-BATTELLE

FOR THE DEPARTMENT OF ENERGY

\title{
Aspects of the Mechanical Behavior of Stitched \\ T300 Mat/Urethane 420 IMR Composite
}

\section{ORNL/TM-2002/86}

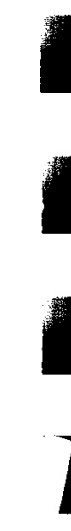

1

S. Deng

X. Li

Y. J. Weitsman

UT-BATTELLE 


\section{DOCUMENT AVAILABILITY}

Reports produced after January 1, 1996, are generally available free via the U.S. Department of Energy (DOE) Information Bridge.

Website http://www.osti.gov/bridge

Reports produced before January 1,1996 , may be purchasedby members of the public from the following source.

NationalTechnical Information Service

5285 Port Royal Road

Springfield, VA 22161

Telephone703-605-6000 (1-800-553-6847)

TDD703-487-4639

Fax 703-605-6900

E-mailinfo@ntis.fedworld.gov

Web site http://www.ntis.gov/supporVordernowabout.htrn

Reports are available to DOE employees, DOE contractors, Energy Technology Data Exchange (ETDE) representatives, and International Nuclear Information System (INIS) representativesfrom the following source.

Office of Scientific and Technical Information

P.O. Box 62

Oak Ridge, TN 37831

Telephore 865-576-8401

Fax 865-576-5728

E-mail reports@adonis.osti.gov

Website http://www.osti.gov/contact.html

This report was prepared as an account of work sponsored by an agency of the United States Government. Neither the United States Government nor any agency thereof, nor any of their employees, makes any warranty, express or implied, or assumes any legal liability or responsibility for the accuracy, completeness, or usefulness of any information, apparatus, product, or process disclosed, or represents that its use would not infringe privately owned rights. Reference herein to any specific commercial product, process, or service by trade name, trademark, manufacturer, or otherwise, does not necessarily constitute or imply its endorsement, recommendation, or favoring by the United States Government or any agency thereof. The views and opinions of authors expressed herein do not necessarily state or reflect those of the United States Government or any agency thereof. 


\title{
ASPECTS OF THE MECHANICAL BEHAVIOR OF STITCHED T300 MAT/URETHANE 420 IMR COMPOSITE
}

\author{
S. Deng, ${ }^{*}$ X. Li, ${ }^{*}$ and Y. J. Weitsman*, ${ }^{*}$ \\ *Department of Mechanical and Aerospace Engineering and Engineering Science, The University of Tennessee, \\ Knoxville, TN 37996 \\ ${ }^{\dagger}$ Metals and Ceramics Division, Oak Ridge National Laboratory, Oak Ridge, TN 37831
}

October 2002

\author{
Prepared by \\ OAK RIDGE NATIONAL LABORATORY \\ Oak Ridge, Tennessee 37831 \\ managed by \\ UT-BATTELLE, LLC \\ for the \\ U.S. DEPARTMENT OFENERGY \\ under contract DE-AC05-00OR22725
}


-

I

I

I

I

,

।

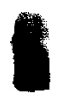

I

I

I

I

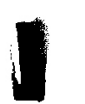

I

I

I

I

I 


\section{CONTENTS}

Page

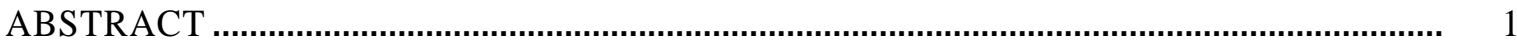

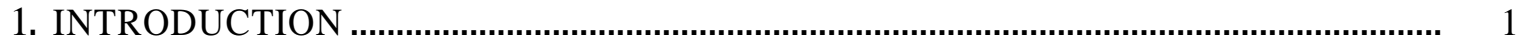

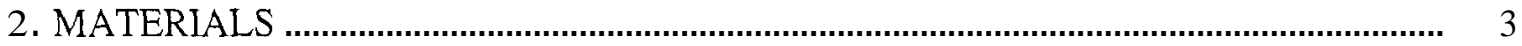

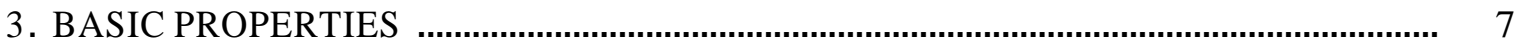

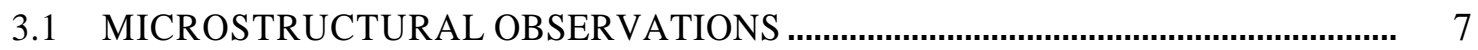

3.2 SPECIMEN PREPARATION ….............................................................................. 7

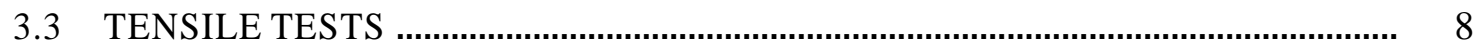

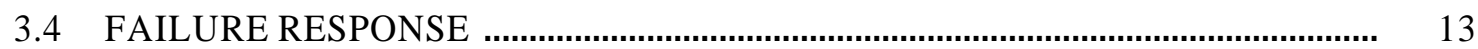

3.5 ANALYTICAL EVALUATION OF PLY PROPERTIES .......................................... 13

3.5.1 Preliminaries .................................................................................................. 13

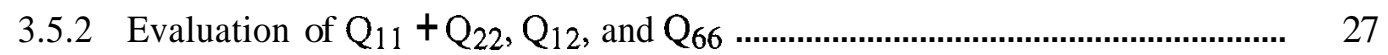

3.5.3 Predictions for Other Orientations ................................................................ 28

3.6 EVALUATION OF Q11 AND Q22 .................................................................... 29

4. TIME-DEPENDENT DEFORMATION OF CROSSPLY LAYUPS .................................. 31

4.1 EXPERIMENTAL PROGRAM AND DATA ….................................................... 31

$4.1 .1 \quad$ Tensile Tests ............................................................................................... 31

4.1.2 Creep and Recovery Tests .............................................................................. 31

4.1.3 Additional Tests ....................................................................................... 34

4.2 DATA REDUCTION ....................................................................................... 36

4.2.1 Creep and Recovery ................................................................................. 36

4.2.2 Long-Term Representation of Creep Data ..................................................... 41

5. PREDICTIONS FOR CROSSPLY BEHAVIOR …............................................................ 47

5.1 EFFECT OF LOAD ORIENTATION ANGLE ON CREEP ....................................... 47

5.2 CREEP UNDER TWO-STEP STRESS INPUT …................................................... 49

6. THE TIME-DEPENDENT AND NONLINEAR RESPONSE OF QUASI-ISOTROPIC

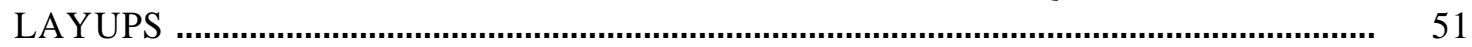

6.1 MATERIALS AND TESTING PROGRAM …......................................................... 51

6.2 LINEAR RANGE OF LAMINATE RESPONSE ................................................... 52

6.2.1 Tensile Properties of [0/90/45/-45]S Laminates ............................................. 52

6.3 STRESS-STRAIN BEHAVIOR IN THE NONLINEAR RANGE ................................55

6.3.1 Crossply Composite .................................................................................... 55

6.3.2 Quasi-Isotropic Composite ........................................................................... 56

6.3.3 Basic Nonlinear Properties and an Approximate Model .................................... 59

6.4 TIME-DEPENDENT RESPONSE ......................................................................... 68

6.4.1 Data .......................................................................................................... 68

6.4.2 Data Reduction .......................................................................................... 68

6.4.3 Correlation Between Tensile Response and Creep Behavior ............................ 70

6.4.4 Prediction of Creep Behavior of Quasi-Isotropic Composites Based on Crossply Viscoelastic Characterization...................................................... 71

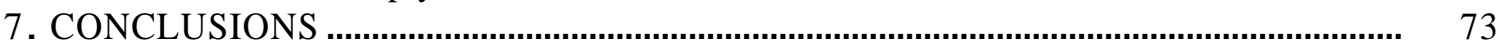

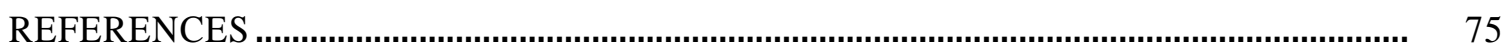

Appendix A. POWER-LAW PARAMETERS ................................................................ A-1

Appendix B. OPTIMALDETERMINATION OFLINEAR PARAMETERS $A_{\mathrm{i}}$ AND
NONLINEAR PARAMETERS $\tau_{\mathrm{i}}$ OF THE PRONY SERIES .......................... B- $\mathrm{B}-1$ 
Appendix C. THE MODELING OF PLASTIC NONLINEARITY IN POLYMERIC COMPOSITES

C-1

Appendix D. OPTIMAL NONLINEAR LEAST-SQUARE DATA FITTING SCHEME TO DETERMINE THE PLASTIC PARAMETERS $a, \boldsymbol{A}$, AND $n$

D-1

Appendix E. A MATHEMATICAL DEMONSTRATION FOR THE DEPARTURE FROM QUASI-ISOTROPY CAUSED BY NONLINEARITY

E-1 


\section{LIST OF FIGURES}

Figure

Micrographs of cross section with fibers at $0 / 90^{\circ}:(a)$ at lower magnification, dark areas indicate fiber tows; $(b)$ at higher magnification showing individual fibers within each tow

Schematic diagram for the cutting of the oriented specimens ...........................

Modulus vs orientation angle ...................................................................... 10

Poisson's ratio vs orientation angle .............................................................

Tensile strength vs orientation angle ........................................................... 11

Failure strain vs orientation angle .............................................................. 12

Typical stress-strain response to failure at various orientation angles $\left([ \pm 45]_{6 \mathrm{~T}}\right)$

Photographs of failed specimens after uniaxial tensile loading in horizontal direction: (a)failed $0^{\circ}$ specimens; $(b)$ an enlarged portion close to main crack

Micrographs of cross-section of $0^{\circ}$ fracture surface: (a)at higher magnification; ( $b$ ) at lower magnification

Photographs of failed specimens after uniaxial tensile loading in horizontal direction: (a)failed $30^{\circ}$ specimens; $(b)$ an enlarged portion close to main crack

Micrograph of a $30^{\circ}$ specimen in the vicinity of the main crack region .............

Photographs of failed specimens after uniaxial tensile loading in horizontal direction: (a)failed $45^{\circ}$ specimens; $(b$ )an enlarged portion close to main crack

Photographs of failed specimens after uniaxial tensile loading in horizontal direction: (a)failed $-45^{\circ}$ specimens; $(b)$ an enlarged portion close to main crack

Photographs of failed specimens after uniaxial tensile loading in horizontal direction: (a)failed $60^{\circ}$ specimens; $(\boldsymbol{b})$ an enlarged portion close to main crack

Photographs of failed specimens after uniaxial tensile loading in horizontal direction: (a)failed $70^{\circ}$ specimens; $(b$ )an enlarged portion close to main crack

Micrograph of a $70^{\circ}$ specimen around the main crack region

Photographs of failed specimens after uniaxial tensile loading in horizontal direction: (a)failed $90^{\circ}$ specimens; $(b)$ an enlarged portion close to main crack

A unidirectionally reinforced ply with the principal axes of symmetry and state of stresses

Unidirectionally reinforced plies orientated at angles Band $\theta+\frac{\pi}{2}$ with loading applied relative to the common direction $x$ and $y$ 
21 Variation of tensile stiffness within the linear range of stress-strain response vs loading orientation for $[ \pm 45]_{3 \mathrm{~S}}$ crossply laminates and comparison with predictions of classical laminate theory

Poisson's ratio vs loading orientation for $[ \pm 45]_{3 S}$ crossply laminates and comparison with predictions of classical laminate theory

24 Schematic drawing of the creep and recovery response of viscoelastic material: (a) step load input; ( $\boldsymbol{b}$ ) strain output

Average values and standard deviations for 5-h creep data of $45^{\circ}$ coupons at $23^{\circ} \mathrm{C}$ and their power-law fits for various stress levels

Average values and standard deviations during 15-h recovery, following

5 -h creep, and their power-law predictions under various stress levels for $45^{\circ}$ coupons at $23^{\circ} \mathrm{C}$

Creep and recovery data collected on a multigaged $[ \pm 45]_{3 S}$ coupon exhibiting nonuniform deformation within a test specimen

$X$-ray images showing damage in $[ \pm 45]_{3 S}$ composite $\left(\phi=45^{\circ}\right)$ at various stress levels

$\mathrm{X}$-ray images showing damage after creep loading in $[45 /-45]_{3 \mathrm{~S}}$ composite $\left(\phi=30^{\circ}\right)$ at various stress levels

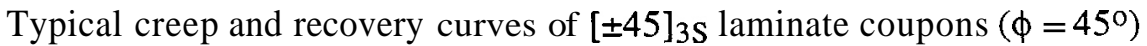
at $23^{\circ} \mathrm{C}$ under various stress levels

Typical creep and recovery curves of $[ \pm 45]_{3 \mathrm{~s}}$ laminate coupons $\left(\phi=45^{\circ}\right)$ at $73^{\circ} \mathrm{C}$ under various stress levels

Comparison of the typical creep-recovery curves under the same stress level

$31 \mathrm{MPa}$ at different temperatures, showing the effect of temperature on the creep deformation

Comparison of the creep and recovery curves under different creep durations, showing the influence of creep time on the permanent deformation.

34 Plot of permanent residual strain vs applied stress for $45^{\circ}$ coupons at $23^{\circ} \mathrm{C}$ with different creep durations, showing the influence of stress and creep time on the permanent deformation

Plot of permanent residual strain vs applied stress for 45" coupons at different temperatures, showing the influence of stress and temperature on the permanent deformation

Plot of permanent residual strain vs applied stress for test coupons with three orientation angles, showing the influence of loading orientation on the permanent deformation

Typical creep data (upper plot) and the modified viscoelastic portion (lower plot)

Typical creep data and the power-law prediction with shift factor $\left(\phi=45^{\circ}\right.$, 5-h creep, $50^{\circ} \mathrm{C}$ ) 
42 Comparison of creep data from three replicate specimens with theoretical predictions for stress-strain response within the linear range $\left(\phi=15^{\circ}\right.$,

5-h creep, $23^{\circ} \mathrm{C}$ )

Comparison of creep data from three replicate specimens with theoretical

predictions for stress-strain response within the linear range $\left(\phi=34^{\circ}\right.$, 5-h creep, $23^{\circ} \mathrm{C}$ )

Creep and recovery data of $0^{\circ}$ coupons under stress levels of $168 \mathrm{MPa}$ and $350 \mathrm{MPa}\left(\phi=0^{\circ}, 5 \mathrm{~h}\right.$ creep, 15 -h recovery, $\left.23^{\circ} \mathrm{C}\right)$

Experimental data and model prediction under a two-step load history for $[ \pm 45]_{3 \mathrm{~S}}$ coupons at $23^{\circ} \mathrm{C}$

Illustration of quasi-isotropic laminates with layup misalignment

Influence of laminate layup misalignment on the stiffness of quasi-isotropic

Typical stress-strain curves of crossply composite, with loads applied

Typical stress-strain curves of quasi-isotropic stitched composite at various orientations at $50^{\circ} \mathrm{C}$

Typical stress-strain curves of quasi-isotropic composite at various orientations at $73^{\circ} \mathrm{C}$

Comparison of stress-strain curves of quasi-isotropic composite with two different loading orientations $\left(\phi=0^{\circ}\right.$ and $\left.22.5^{\circ}\right)$ at $120^{\circ} \mathrm{C}$ Longitudinal and transverse strains vs stress for quasi-isotropic and $\left[ \pm 45^{\circ}\right]_{3 \mathrm{~S}}$ coupons at $120^{\circ} \mathrm{C}$

Schematic drawing of strain compatibility requirements for composite laminates

Predicted and recorded values of longitudinal and transverse strains for the laminates and loading conditions noted in Fig. 55

Predictions of the anisotropic response of quasi-isotropic laminate beyond

the linear range, under loading at various orientations about

the fiber direction for quasi-isotropic laminates loaded at various orientations about the fiber direction and for $[ \pm 45]_{3}$ s laminates

Maximal and minimal values of transverse plastic strain in the individual plies of a quasi-isotropic laminate loaded at 22.5" about the 0 " fiber direction Typical creep-recovery
orientations at $73^{\circ} \mathrm{C}$.

Typical creep-recovery curves of quasi-isotropic composite with two orientations at $120^{\circ} \mathrm{C}$.

64 Typical creep-recovery curves of quasi-isotropic composite with different loading orientations at $23^{\circ} \mathrm{C}$. 


\section{LIST OF TABLES}

Table

Page

1 The properties of T300 stitched mat/420 IMR urethane and neat resin (ACC data) ............................................................................................

2 Tensile data for T300 stitched mat/STR-420 urethane IMR .............................

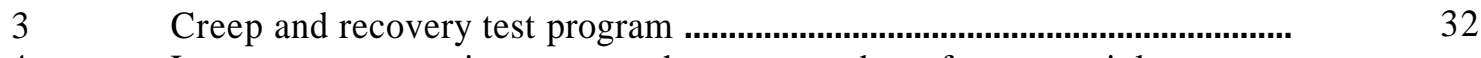

$4 \quad$ Least-square error in correspondence to number of exponential parameters ................................................................................................. 44

5 Prony series parameters of fit to the early 5-h creep data in Fig. 20(a) ......... 44

$6 \quad$ Creep and recovery test program .............................................................. 52

7 Tensile data for quasi-isotropic composite coupons loaded at various orientations .....................................................................................

8 Parameters used for the simulations of the creep and recovery results

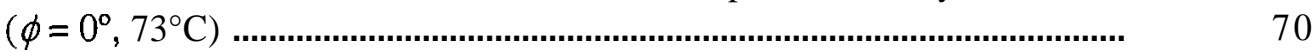

9 Parameters used for the simulations of the creep and recovery results $\left(\phi=22.5^{\circ}, 73^{\circ} \mathrm{C}\right)$
Best-fit power-law parameters $D_{0}, D_{1}$, and $n$ for creep data at $31 \mathrm{MPa}$

A. 1 Best-fit power-law parameters $D_{\mathrm{O}}, D_{1}$, and $n$ for creep data at $31 \mathrm{MPa}$ and several temperatures.

A.2 Best-fit power-law parameters $D_{0}, D_{1}$, and $n$ for creep data at $46.5 \mathrm{MPa}$ and several temperatures........................................................................ 
-

I

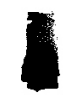

I

I

I

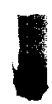

1

I

1

I

I

I

1

I

1

I

1 


\title{
ASPECTS OF THE MECHANICAL BEHAVJOR OF STITCHED T300 MAT/URETHANE 420 IMR COMPOSITE
}

\author{
S. Deng, $\mathbf{X}$. Li, and $\boldsymbol{Y}$.J. Weitsman
}

\begin{abstract}
This report presents experimental and analytical results concerning the behavior of crossply and quasi-isotropic laminates manufactured of stitch-bonded T300/urethane 420 IMR polymeric composites. Based on extensive creep and recovery data at various levels of stress and temperature, as well as on strain-to-failure information, it was possible to arrive at empirical expressions relating deformation to the previous input as well as to input duration. These expressions were incorporated within the formalisms of viscoelasticity and laminate theory to illuminate some basic underlying mechanistic aspects of the material at hand, thereby enabling the prediction of anticipated response under more complex stress and temperature inputs.
\end{abstract}

\section{INTRODUCTION}

Stitched T300/urethane 420 IMR composite is a candidate material for application in the automotive industry. This material consists of strands of T300 carbon fibers that are injected with urethane polymeric resin. Composites are formed by the light stitching of pairs of unidirectionally reinforced plies that are oriented perpendicularly to each other. Stitch lines run at 45" about the fiber direction and are spaced at $5 \mathrm{~mm}$ apart. Sets of crossply pairs are also laid up at $\pm 45^{\circ}$ to each other to form quasi-isotropic laminates. Details of the processing of these materials are provided elsewhere. ${ }^{1-3}$

This report forms one part of an extensive study on the durability of polymeric composites for automotive applications that aims at the establishment of design criteria for these materials. The specific purpose of this report is to provide an understanding of some basic aspects that underlie the mechanical behavior of the material at hand. In this respect, the results presented here are a continuation of a previously published report. ${ }^{4}$ The issues discussed in the present report include basic lamina material properties, as well as time-dependent behavior and nonlinear response of both crossply and quasi-isotropic layups.

A comprehensive account of various other aspects of the mechanical response of this composite is provided elsewhere. ${ }^{1-3}$ 
-

I

I

I

I

I

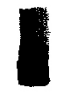

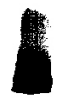

I

I

I

I

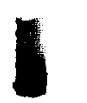

1

I

1

I

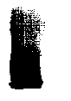




\section{MATERIALS}

Several plaques, with in-plane dimensions of $610 \mathrm{~mm}$ by $610 \mathrm{~mm}$, were provided by the Automotive Composite Consortium (ACC). The plaques were made of T300 stitch-bonded mat/420 IMR urethane with $[0 / 90]_{3 S}$ and $[0 / 90]_{6}$ layups, while three additional plaques consisted of $[0 / 90 / \pm 45]_{\mathrm{s}}$ quasi-isotropic layups. The average thickness of the crossply plaques was $3 \mathrm{~mm}$; that of the quasi-isotropic plaques varied between 2 and $2.4 \mathrm{~mm}$. The stitched T300 mats were injected with urethane resin in a rapid injection molding process. Overall fiber volume fraction ranged between $41 \pm 4 \%$. The matrix and the fiber tow configuration is detailed in Figs. 1 $(a)$ and $(b){ }^{*}$ Stitching was applied to each [0/90] pair of layers, with stitches spaced at $5 \mathrm{~mm}$ apart to minimize the relative movement of the fiber strands during processing. Test coupons with dimensions of $203.2 \mathrm{~mm}$ by $25.4 \mathrm{~mm}$ were cut from the above plaques at various orientations $\phi$ about the fiber direction on the top ply, and crossply glass fiber/epoxy tabs, $1.6 \mathrm{~mm}$ thick, were attached to these coupons in some circumstances.

Several mechanical properties are listed in Table 1.

*See also Fig. 23. 


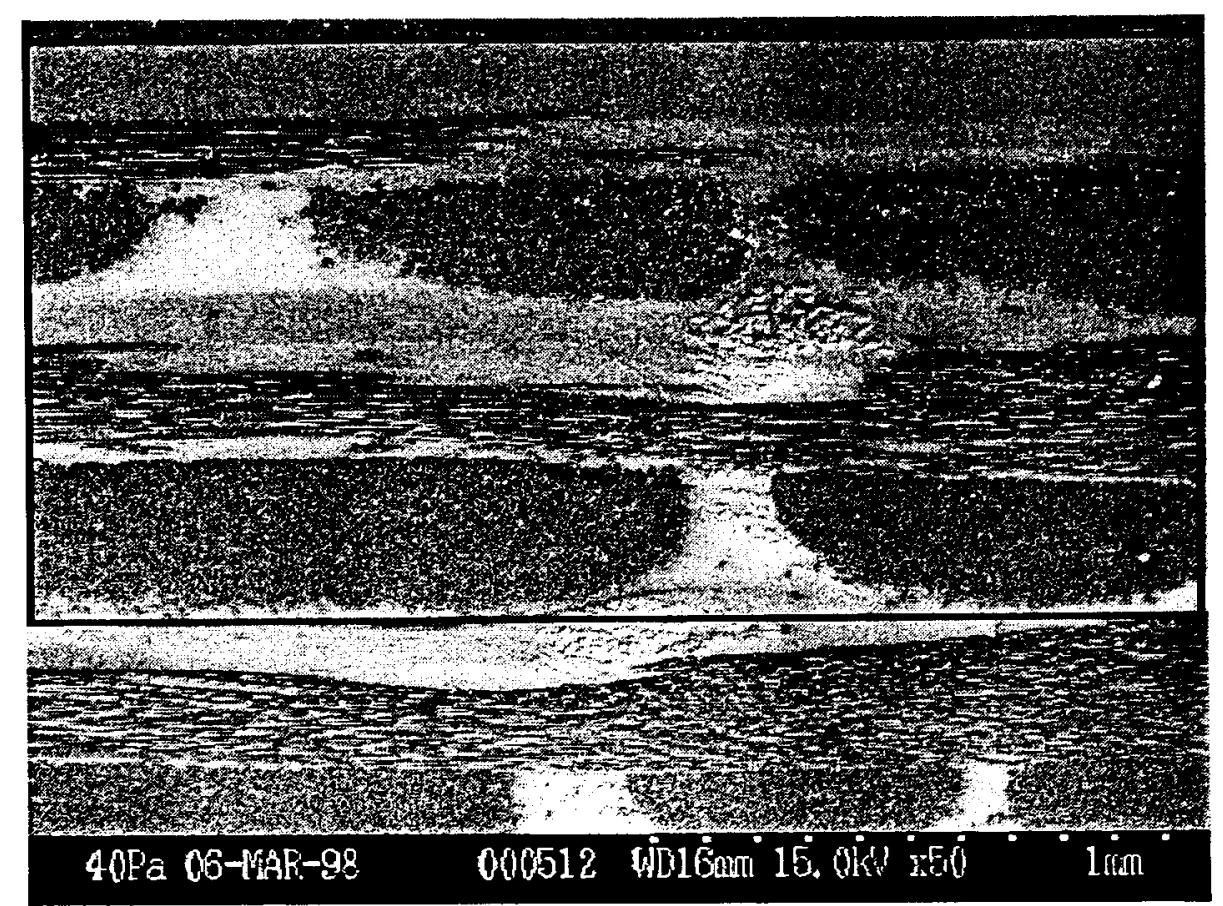

(a)

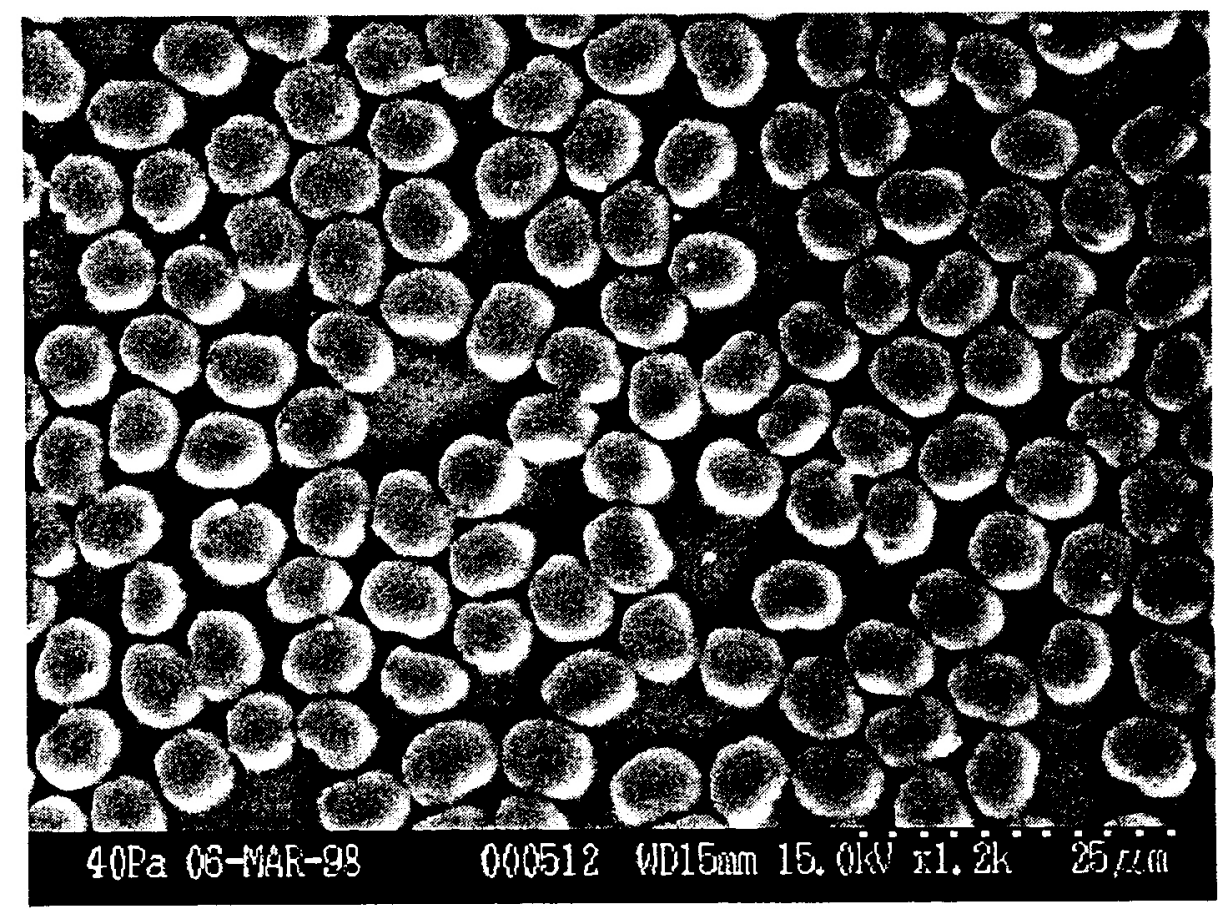

(b)

Fig. 1. Micrographs of cross section with fibers at $0 / 90^{\circ}$ : (a) at lower magnification, dark areas indicate fiber tows; (b) at higher magnification showing individual fibers within each tow. 
Table 1. The properties of T300 stitched mat/420 IMR urethane and neat resin (ACC data)

\begin{tabular}{lc}
\hline & Composite (tensile properties) \\
Fiber volume fraction & $39.0 \%$ to $44.3 \%$ (by weight) \\
Strength $\left(0^{\circ} / 90^{\circ}\right)$ & $477 \mathrm{MPa}$ \\
Modulus & $46.7 \mathrm{GPa}$ \\
Poisson's ratio & 0.05 \\
Failure strain & $\mathbf{1 . 0 1 \%}$ \\
& Neat resin (tensileproperties) \\
Strength & $68.2 \mathrm{MPa}$ \\
Modulus & $3.58 \mathrm{GPa}$ \\
Poisson's ratio & 0.385 \\
Failure strain & $2.64 \%$ \\
\hline \multicolumn{1}{c}{${ }^{a} \mathrm{~A}$ value of $2 \mathrm{GPa}$ was employed in the sequel, based on data obtained at }
\end{tabular}
ORNL. 
I 


\section{BASIC PROPERTIES}

\subsection{MICROSTRUCTURAL OBSERVATIONS}

Two small samples were cut off from the crossply plaque along $0^{\circ}$ and $90^{\circ}$ fiber directions. The sample cross section was polished with alumina powder up to $1 \mu \mathrm{m}$. Micrographs were obtained from scanning electron microscopes (SEMs) and stored in digital format, as shown in Fig. 1. Figure 1(a) gives a low-magnification image where the dark area of the tow appears on the lighter background of the urethane resin. In the larger magnification image, exhibited in Fig. 1(b), individual fibers can be observed within the urethane matrix within the tow.

Particle analysis was performed on a Macintosh Centries 610 computer using the public domain NIH image program (version 1.60). Twenty micrographs similar to those shown in Fig. 1 $(b)$ were used to determine the fiber volume fraction within the tow, resulting in an average fiber volume fraction of $66.5 \%$ in that region. The average volume fraction of the tow within the composites was found to be $64.5 \%$, which results in the overall fiber volume fraction of approximately $\mathbf{4 2 . 9 \%}$.

\subsection{SPECIMEN PREPARATION}

Forty-two crossply specimens, each measuring $203 \mathrm{~mm}$ long and $25 \mathrm{~mm}$ wide, were cut from the aforementioned plaques. The specimens were cut at different orientations, according to the cutting scheme shown in Fig. 2. After cutting, the specimens were dog-bone shaped with a nominal central width of $20 \mathrm{~mm}$.

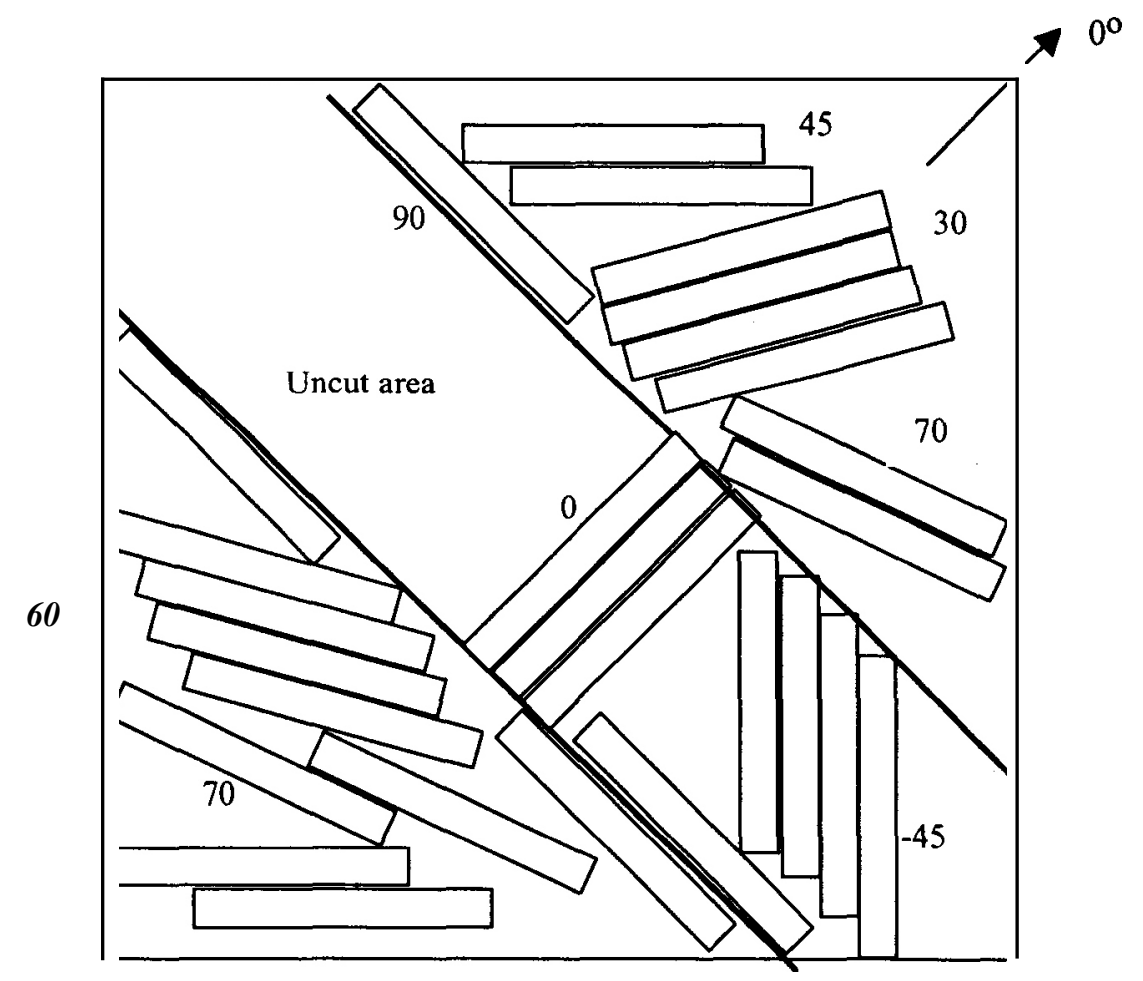

Fig. 2. Schematic diagram for the cutting of the oriented specimens. 


\subsection{TENSILE TESTS}

All tensile tests were performed on an 810 MTS machine. For the crossply samples, two extensometers were used to measure longitudinal tensile strains on both sides of the specimen. In addition, two strain gages were mounted transversely to the loading direction with M-Bond 200 adhesive to measure transverse strain on both sides of the specimen. In accordance with the American Society for Testing and Materials (ASTM) D3039, 5 the tests were carried out under displacement control at a loading rate of $1.27 \mathrm{~mm} / \mathrm{min}$. The measurements on the opposing faces of the test coupons were intended to detect the amount of bending that may be present due to layup asymmetry (such as in the $[0 / 90]_{6}$ plaques) or due to any other layup imperfections.

Results of the modulus, Poisson's ratio, tensile strength, and failure strain measurements are summarized in Table 2 and plotted in Figs. 3 to 7 for crossply specimens cut at various orientation angles. Although these results contain a degree of scatter, they nevertheless agree with the premise that they should exhibit symmetry about the 45" angle. The values plotted in Figs. 3 and 4 apply to the linear range of stress-strain response.

Typical stress-strain behavior to failure is shown in Figs. $7(a)$ for the $[ \pm 45]_{6 \mathrm{~T}}$ and $7(b)$ for the $[ \pm 45]_{3 S}$ layups. Note again the similarity in the behavior of coupons oriented at the paired angles of $\left(0^{\prime} ; 90^{\circ}\right),\left(30^{\prime \prime} ; 60^{\circ}\right)$, and $\left(+45^{\circ} ;-45^{\circ}\right)$.

Table 2. Tensile data for T300 stitched mat/STR-420 urethane $\mathrm{IMR}^{a}$

\begin{tabular}{|c|c|c|c|c|c|}
\hline $\begin{array}{c}\begin{array}{c}\text { Orientation } \\
\text { (deg) }\end{array} \\
\end{array}$ & Specimen ID & $\begin{array}{c}\text { Stiffness } \\
(\mathrm{GPa})\end{array}$ & Poisson's ratio & $\begin{array}{l}\text { UTS } \\
\text { (MPa) }\end{array}$ & $\begin{array}{c}\text { Failure strain } \\
(\%)\end{array}$ \\
\hline \multirow[t]{6}{*}{0} & C7-25 & 40.1 & $\mathrm{~N} / \mathrm{A}$ & 536.4 & 1.27 \\
\hline & & 48.7 & N/A & & 1.05 \\
\hline & C7-26 & 43.5 & 0.040 & 506.9 & 1.10 \\
\hline & & 51.0 & 0.062 & & 0.95 \\
\hline & C7-27 & 40.7 & 0.024 & 498.5 & 1.08 \\
\hline & & 46.6 & 0.116 & & 1.10 \\
\hline Average & & 45.1 & 0.061 & 513.9 & 1.09 \\
\hline \multirow[t]{8}{*}{30} & c7-5 & 13.8 & N/A & 166.9 & N/A \\
\hline & & 15.9 & N/A & & N/A \\
\hline & c7-4 & 13.1 & 0.592 & 158.1 & 6.95 \\
\hline & & 13.4 & 0.752 & & 7.21 \\
\hline & C7-6 & 12.8 & 0.509 & 159.1 & 5.69 \\
\hline & & 15.2 & 0.773 & & 5.86 \\
\hline & c 7-3 & 12.5 & 0.672 & 163.5 & 5.62 \\
\hline & & 14.8 & 0.900 & & 4.51 \\
\hline Average & & 14.0 & 0.700 & 161.9 & 5.97 \\
\hline
\end{tabular}


Table 2. (continued)

\begin{tabular}{|c|c|c|c|c|c|}
\hline Orientation & Specimen ID & $\begin{array}{c}\text { Stiffness } \\
(\mathbf{G P a})\end{array}$ & Poisson's ratio & $\begin{array}{c}\text { UTS } \\
\text { (MPa) }\end{array}$ & $\begin{array}{c}\text { Failure strain } \\
(\%)\end{array}$ \\
\hline \multirow[t]{8}{*}{45} & C7-23 & 11.0 & $\mathrm{~N} / \mathrm{A}$ & 145.5 & 5.50 \\
\hline & & 12.0 & N/A & & NIA \\
\hline & C7-24 & 10.0 & 0.729 & 141.9 & 6.10 \\
\hline & & 11.5 & 0.750 & & 5.10 \\
\hline & $\mathrm{C} 7-2$ & 10.8 & 0.759 & 139.9 & 4.00 \\
\hline & & 12.9 & 0.807 & & 4.10 \\
\hline & C7-1 & 12.5 & 0.760 & 135.2 & 4.50 \\
\hline & & 12.6 & 0.776 & & 6.10 \\
\hline Average & & 11.7 & 0.764 & 140.6 & 5.06 \\
\hline \multirow[t]{8}{*}{-45} & C7-14 & 10.3 & N/A & 131.0 & 4.30 \\
\hline & & 10.9 & N/A & & N/A \\
\hline & C7-13 & 9.6 & 0.660 & 133.1 & 4.84 \\
\hline & & 9.6 & 0.780 & & 4.35 \\
\hline & C7-11 & 9.5 & 0.770 & 133.8 & 5.50 \\
\hline & & 10.6 & 0.672 & & 5.70 \\
\hline & C7- 12 & 8.8 & 0.630 & 127.4 & 4.90 \\
\hline & & 10.7 & 0.820 & & 4.70 \\
\hline Average & & 10.0 & 0.722 & 131.3 & 4.90 \\
\hline \multirow[t]{8}{*}{60} & C7- 18 & 14.5 & $\mathrm{~N} / \mathrm{A}$ & 179.3 & 5.62 \\
\hline & & 14.0 & $N / A$ & & NIA \\
\hline & C7- 17 & 13.3 & 0.703 & 186.7 & 4.95 \\
\hline & & 14.0 & 0.694 & & 4.76 \\
\hline & C7-20 & 12.5 & 0.671 & 163.7 & 7.66 \\
\hline & & 13.0 & 0.660 & & 8.59 \\
\hline & C7- 19 & 12.3 & 0.770 & 171.3 & 5.67 \\
\hline & & 14.5 & 0.749 & & 5.15 \\
\hline Average & & 13.5 & 0.708 & 175.3 & 6.06 \\
\hline \multirow[t]{8}{*}{70} & c $7-7$ & 23.4 & N/A & 248.2 & 3.10 \\
\hline & & 19.0 & $\mathrm{~N} / \mathrm{A}$ & & 3.00 \\
\hline & C7-2 1 & 17.2 & 0.600 & 209.5 & 3.02 \\
\hline & & 18.5 & 0.503 & & 3.18 \\
\hline & C7-22 & 18.9 & 0.614 & 236.2 & 3.01 \\
\hline & & 21.3 & 0.531 & & 3.03 \\
\hline & c $7-8$ & 19.7 & 0.695 & 231.3 & 2.81 \\
\hline & & 23.0 & 0.500 & & 2.52 \\
\hline Average & & 20.1 & 0.574 & 231.3 & 2.96 \\
\hline
\end{tabular}


Table 2. (continued)

\begin{tabular}{cccccc}
\hline $\begin{array}{c}\text { Orientation } \\
(\mathbf{d e g})\end{array}$ & Specimen ID & $\begin{array}{c}\text { Stiffness } \\
\mathbf{( G P a )}\end{array}$ & Poisson's ratio & $\begin{array}{c}\text { UTS } \\
\text { (MPa) }\end{array}$ & $\begin{array}{c}\text { Failure strain } \\
\text { (\%) }\end{array}$ \\
\hline 90 & C7-16 & 44.1 & N/A & 477.1 & 1.18 \\
& & 38.6 & N/A & & 1.18 \\
& C7-10 & 43.9 & 0.068 & 428.3 & 1.00 \\
& & 42.7 & 0.051 & & 1.00 \\
& C7-15 & 50.8 & 0.082 & 500.3 & 1.00 \\
& & 47.4 & 0.045 & & 1.00 \\
& c7-9 & 48.5 & 0.086 & 536.1 & 1.08 \\
Average & & 44.7 & 0.038 & & 1.18 \\
\hline
\end{tabular}

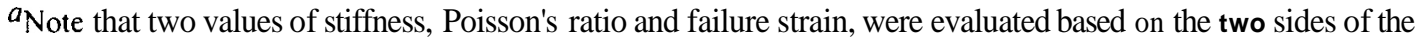
specimen. N/A indicates that the value either was not measured or exceeded the capacity of the extensometer.

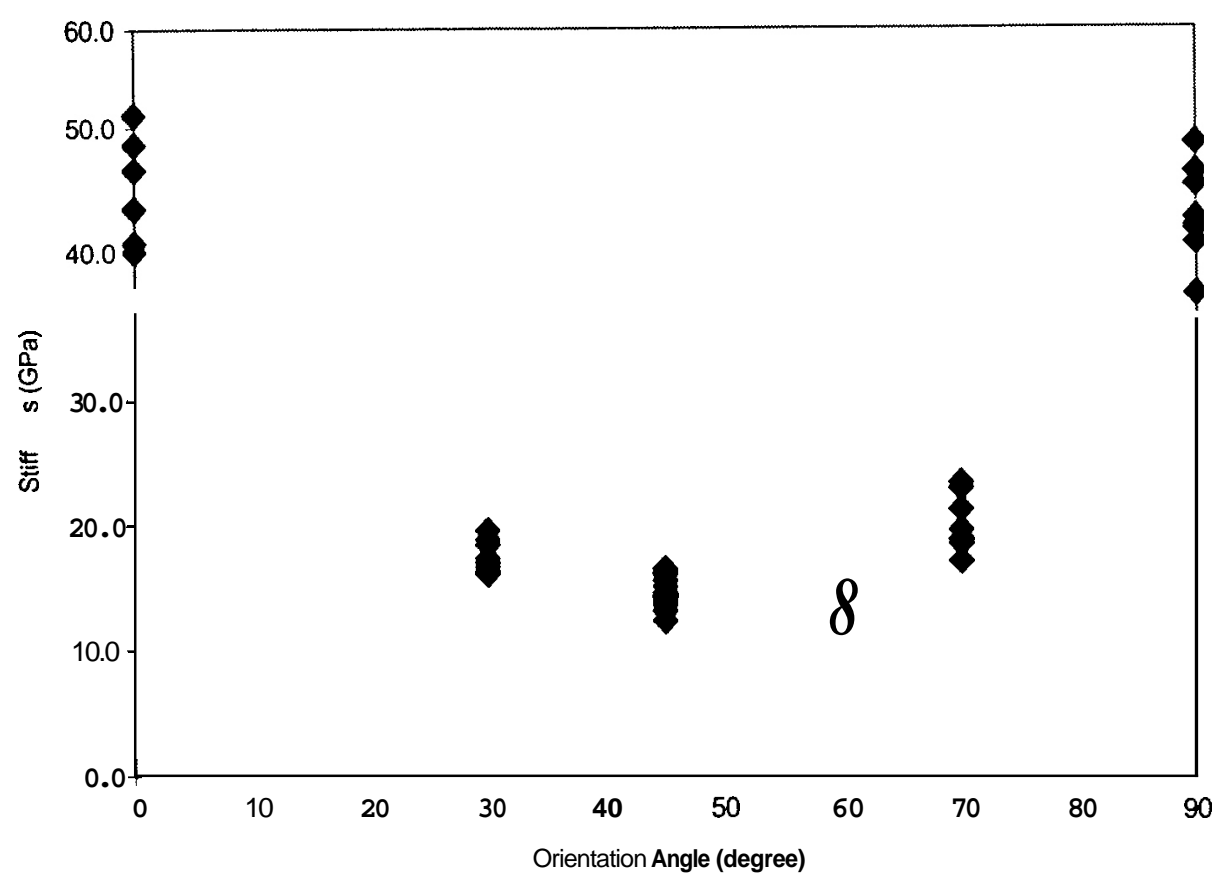

Fig. 3. Modulus vs orientation angle. Data scatter is partly due to the bending about specimens' midplanes. 


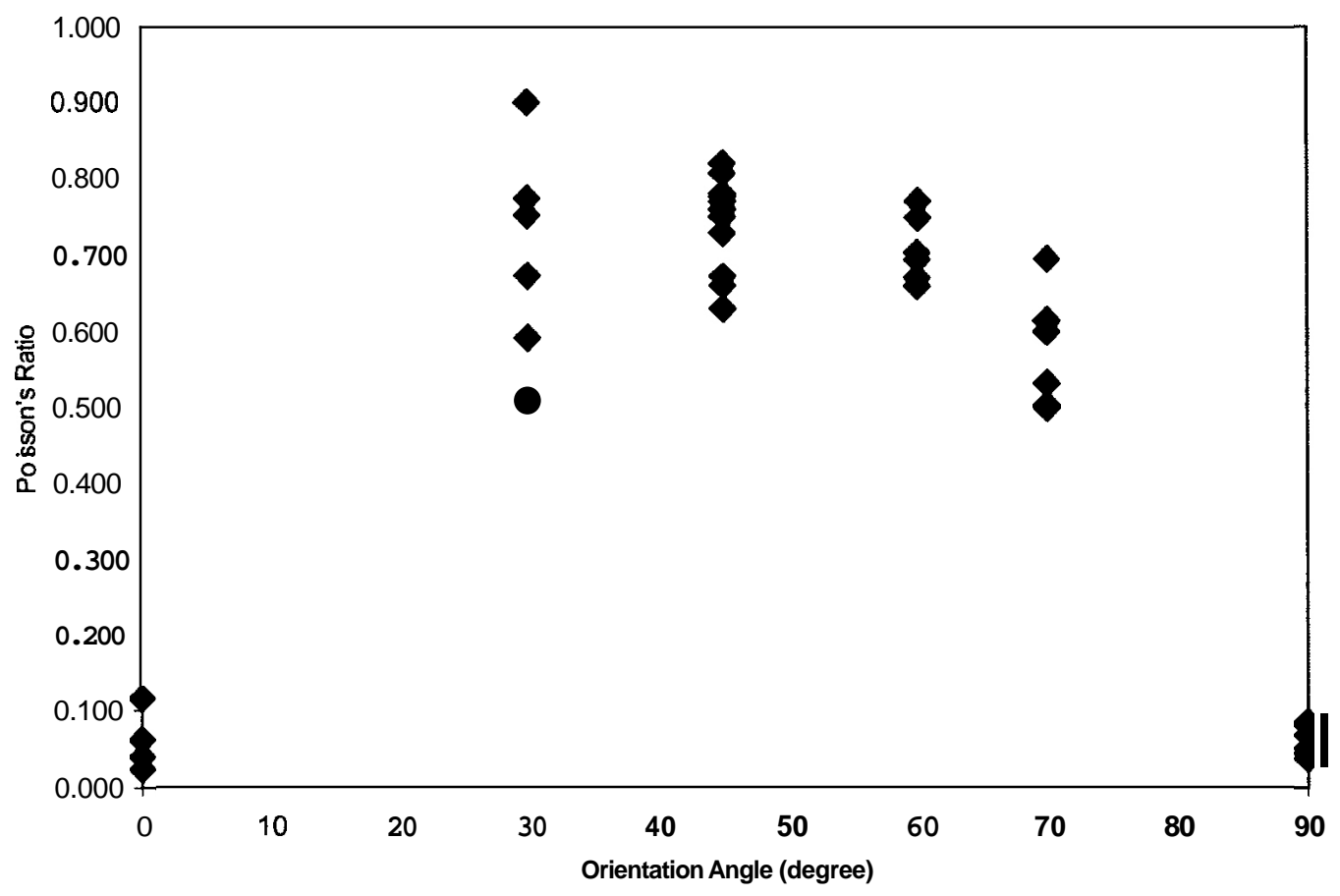

Fig. 4. Poisson's ratio vs orientation angle. Data scatter is partly due to the bending about specimens' midplanes.

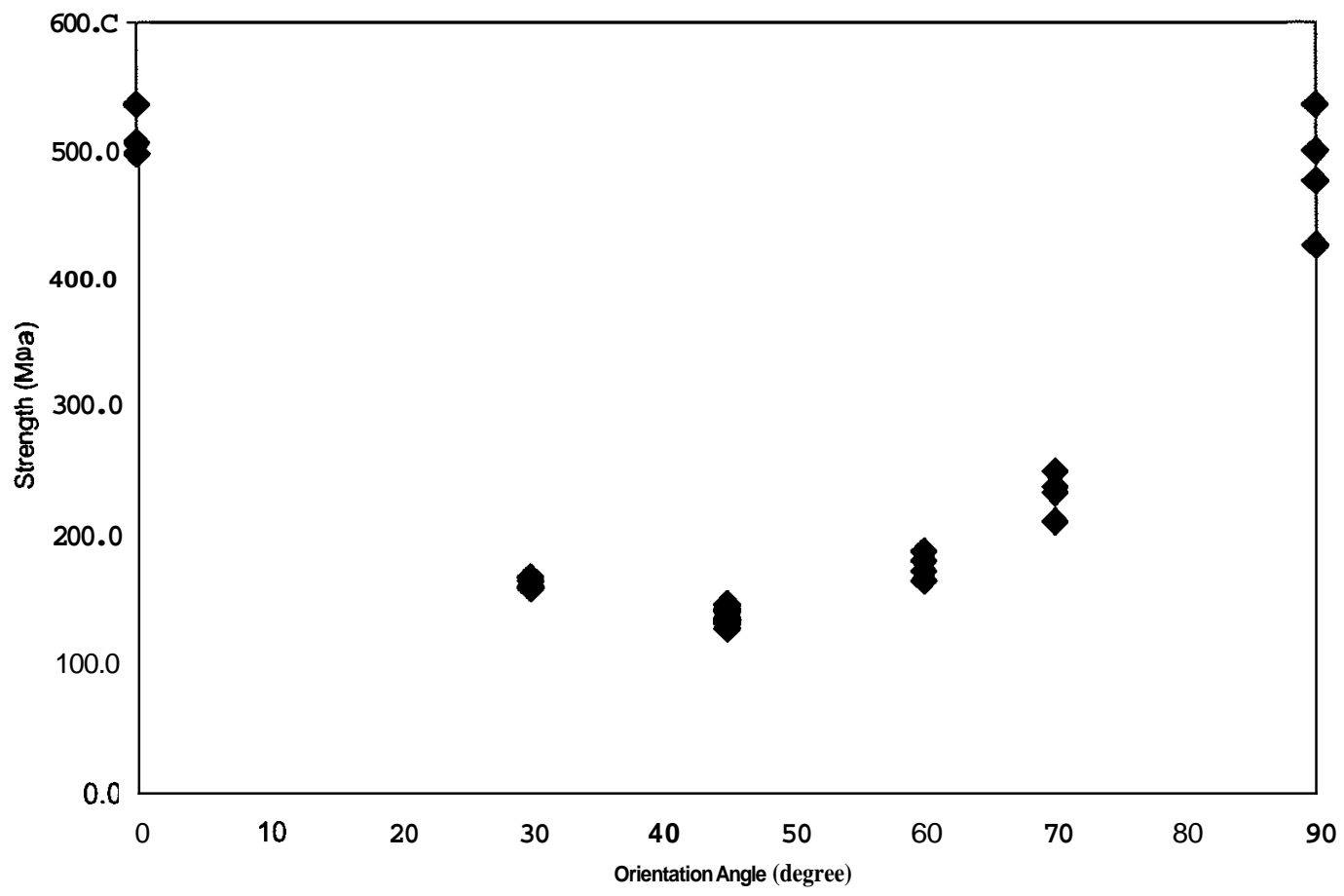

Fig. 5. Tensile strength vs orientation angle. 


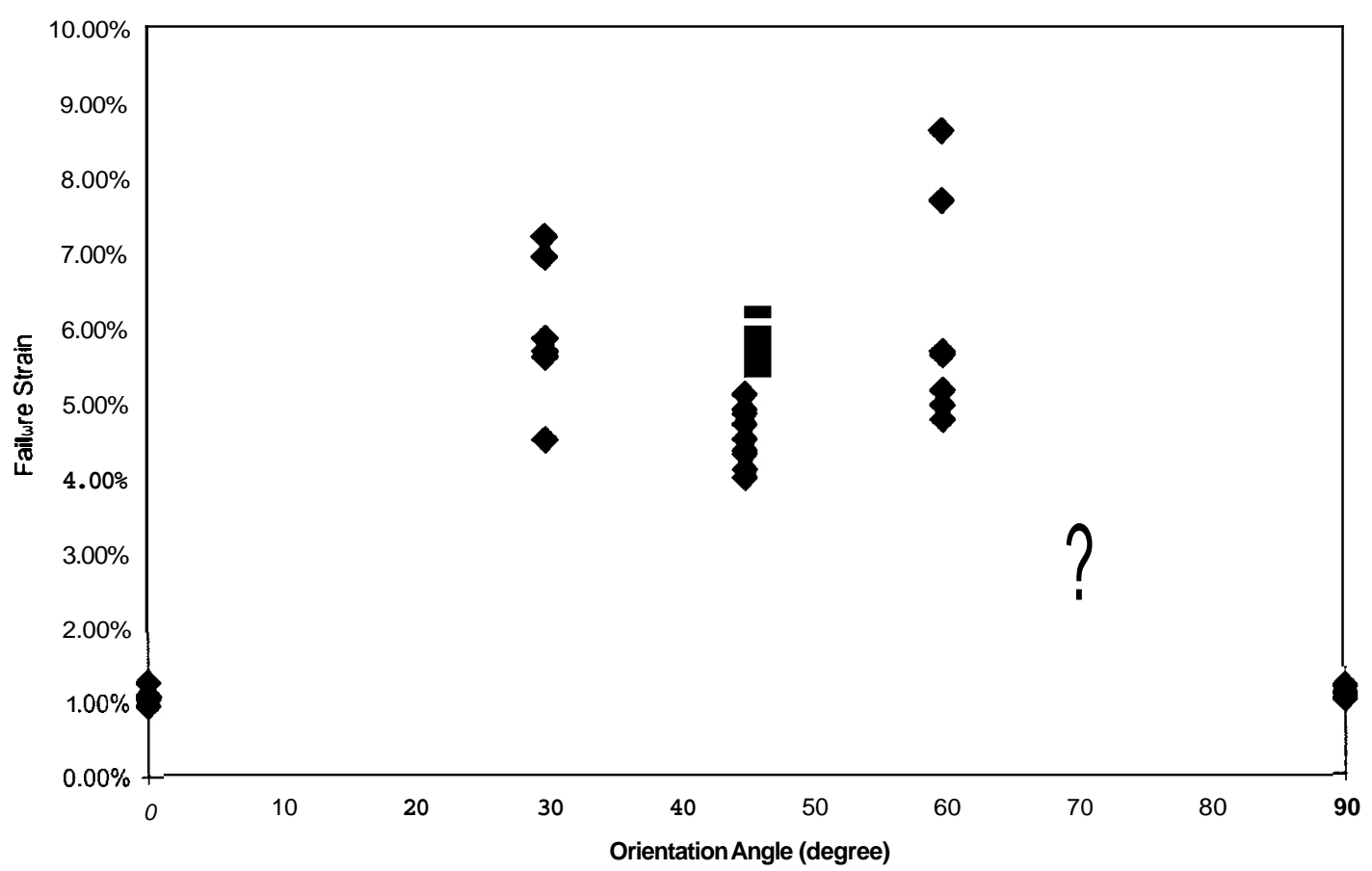

Fig. 6. Failure strain vs orientation angle.

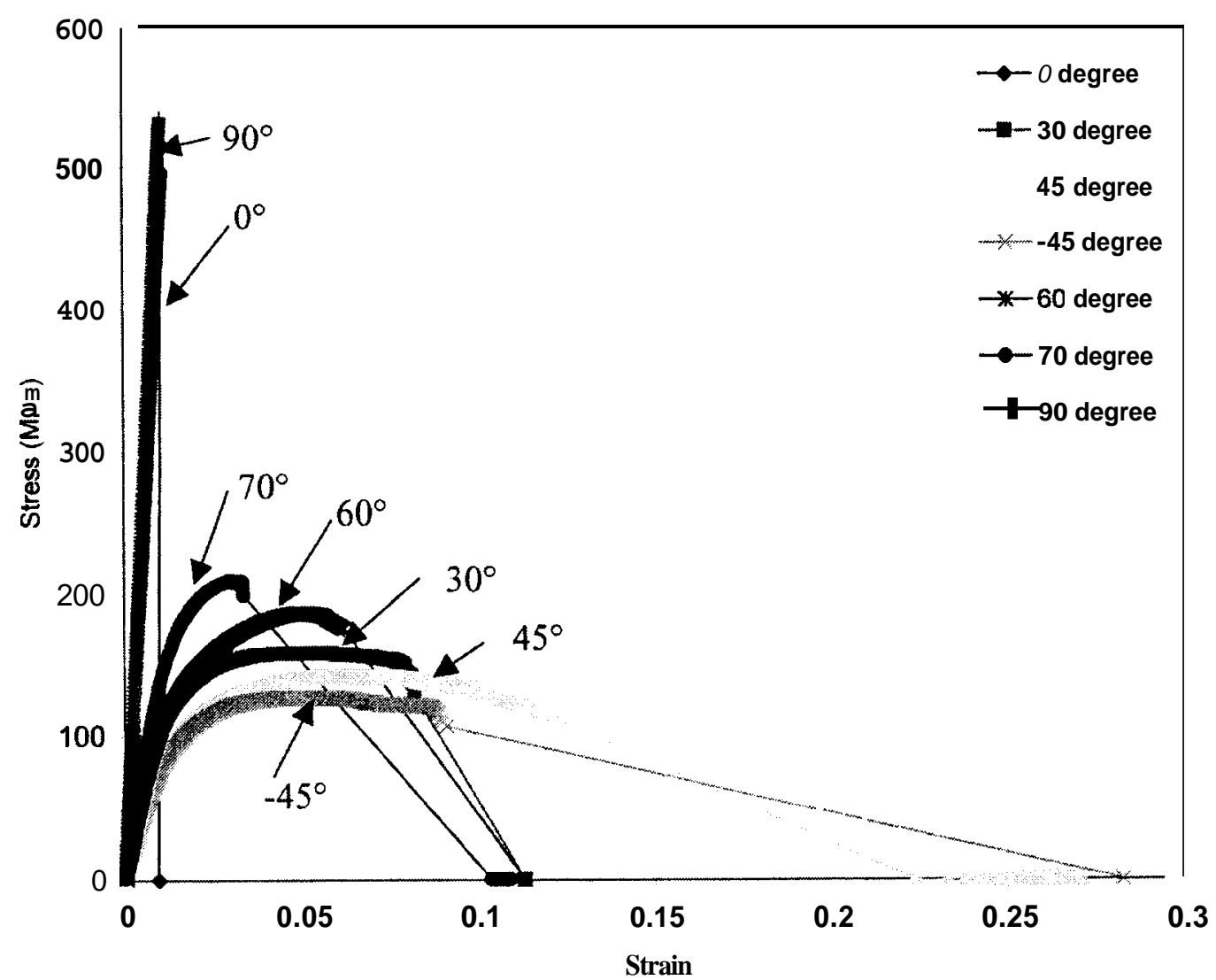

Fig. 7(a). Typical stress-strain response to failure at various orientation angles $\left([ \pm 45]_{6 \mathrm{~T}}\right)$. 


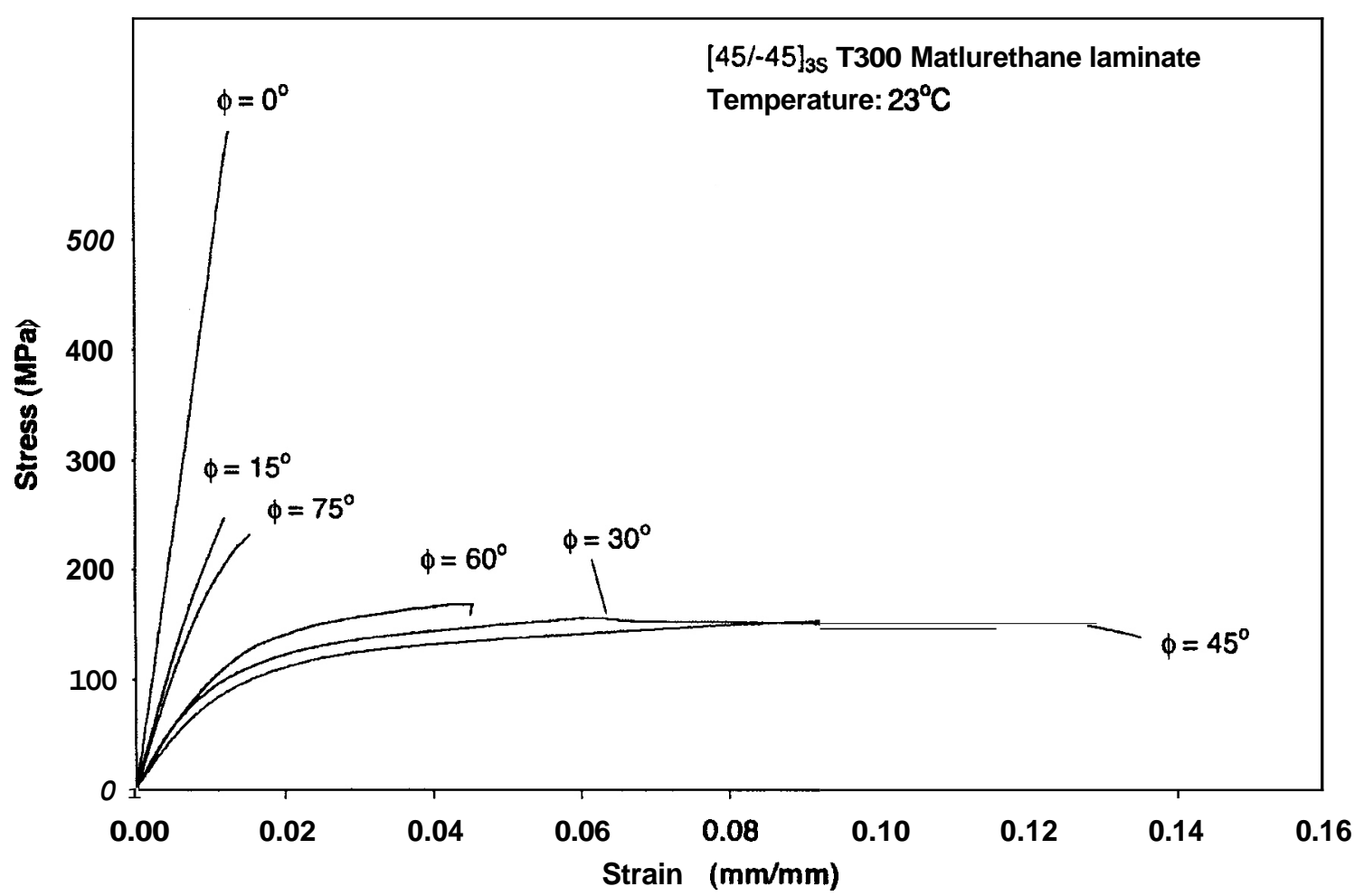

Fig. $7(b)$. Typical stress-strain curves of $[ \pm 45]_{3 s}$ with loads applied at various orientations about the $0^{\circ}$ fiber direction.

\subsection{FAILURE RESPONSE}

Photos and micrographs of the failed crossply specimens are shown in Figs. 8 to 18. Note that almost "clean breaks" appear for the coupons orientated at $0^{\circ}$ and at $90^{\circ}$ (Figs. 8 and 18); rough failure surfaces, which involve fiber pull-out, occur at all other angles. Nevertheless, the failure surfaces remain channeled parallel to the fiber directions, with negligible interference by the stitching orientation.

\subsection{ANALYTICAL EVALUATION OF PLY PROPERTIES}

\subsubsection{Preliminaries}

In the analysis performed here, the basic properties of the individual ply are recovered from the foregoing crossply data through the employment of micromechanics and laminated plate theory.

The main purpose of this analysis is to determine if classic laminate plate theory, which applies in the linear-elastic range of response of laminates formed of plies that are reinforced by straight unidirectionally oriented fibers, remains valid for the current circumstance of a stitched, fiber-strand reinforced composite. 

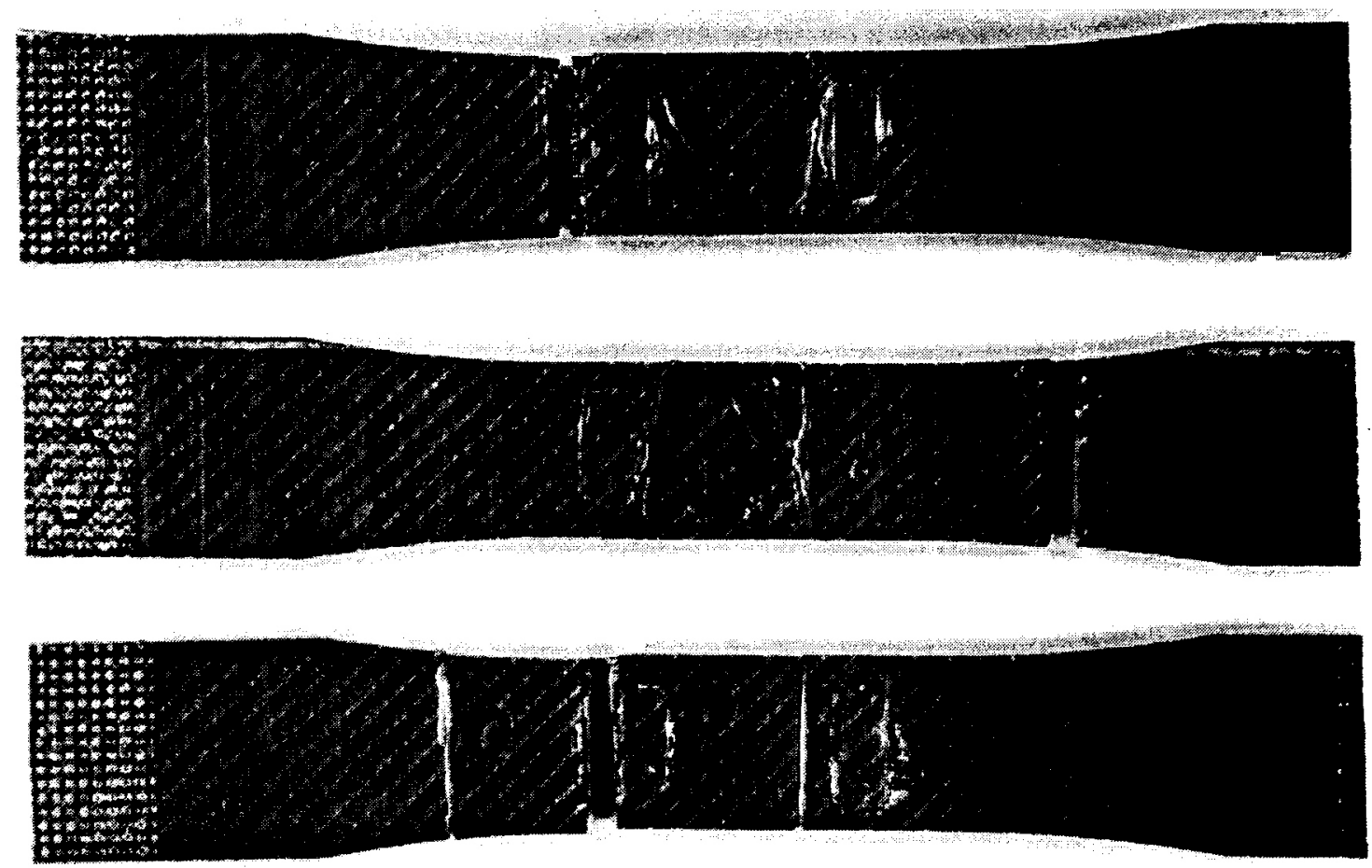

(a)

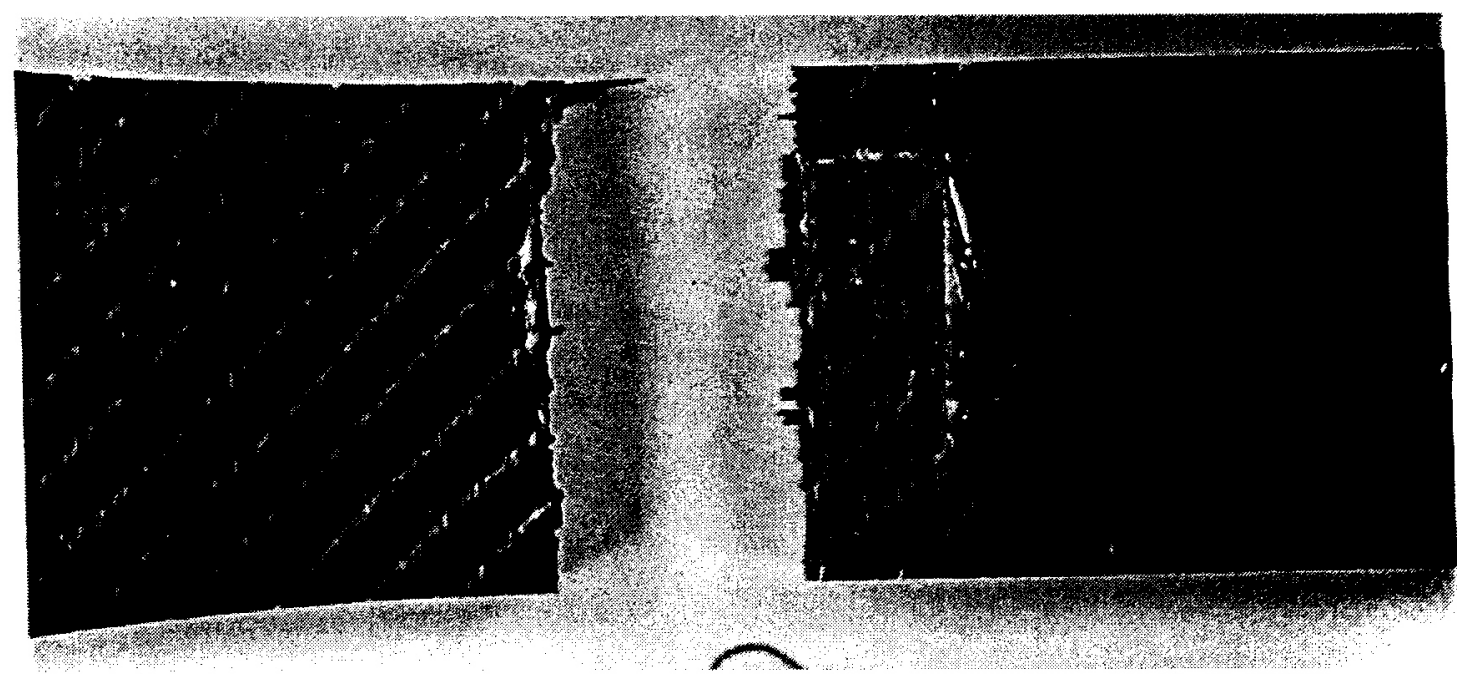

(b)

Fig. 8. Photographs of failed specimens after uniaxial tensile loading in horizontal direction: $(a)$ failed $0^{\circ}$ specimens; $(b)$ an enlarged portion close to main crack. 


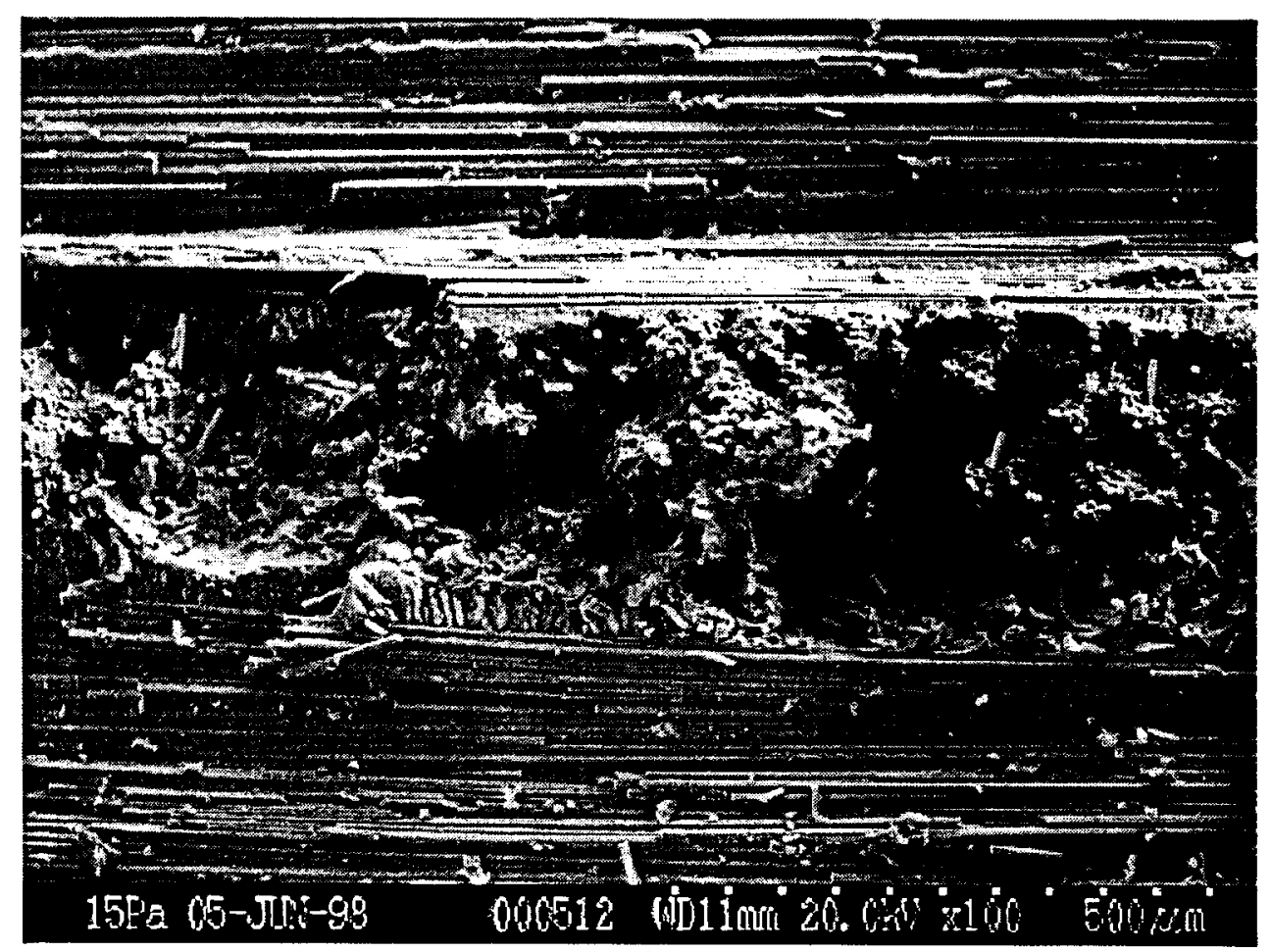

(a)

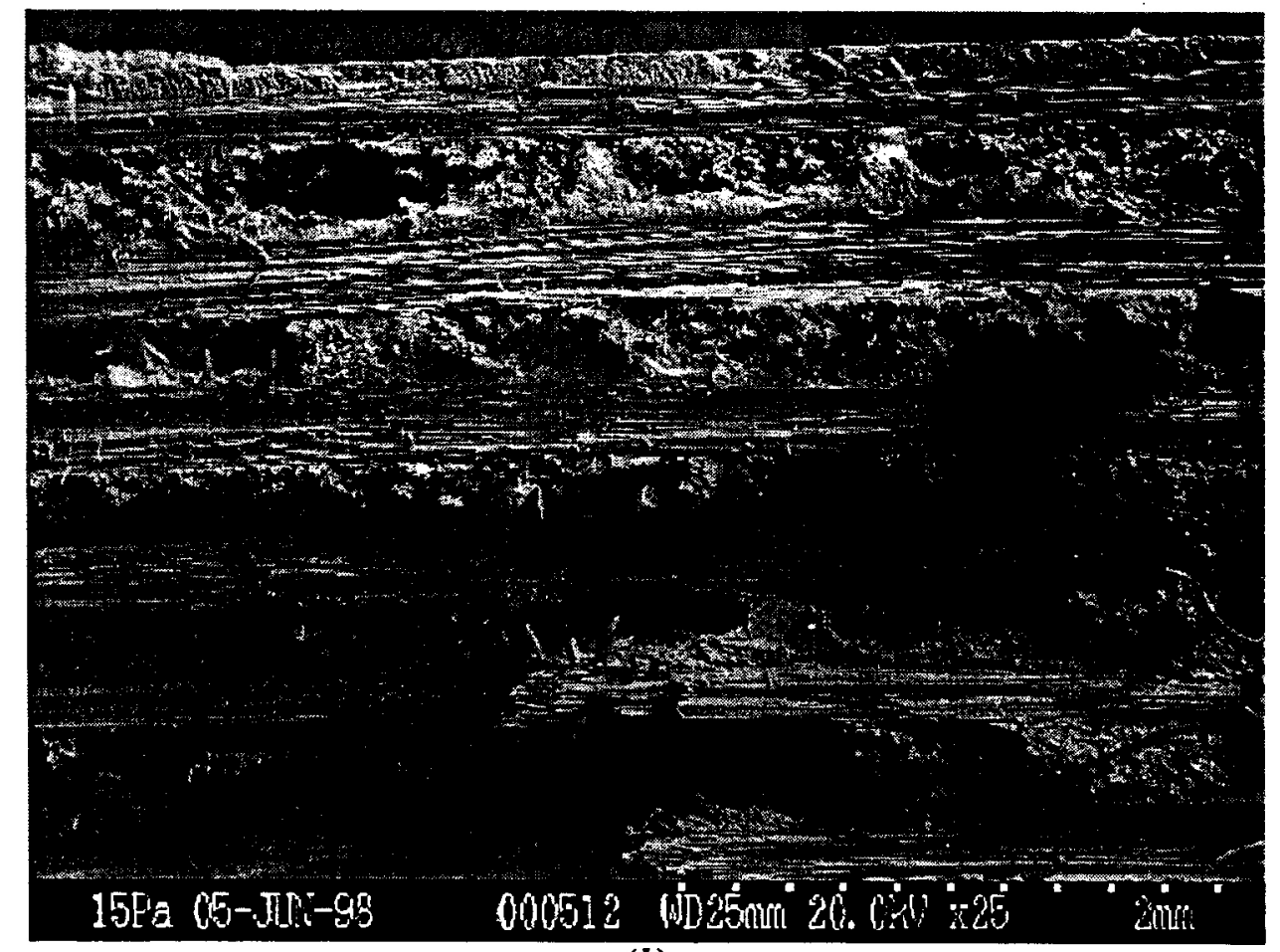

(b)

Fig. 9. Micrographs of cross-section of $0^{\circ}$ fracture surface: (a)at higher magnification; $(b)$ at lower magnification. 


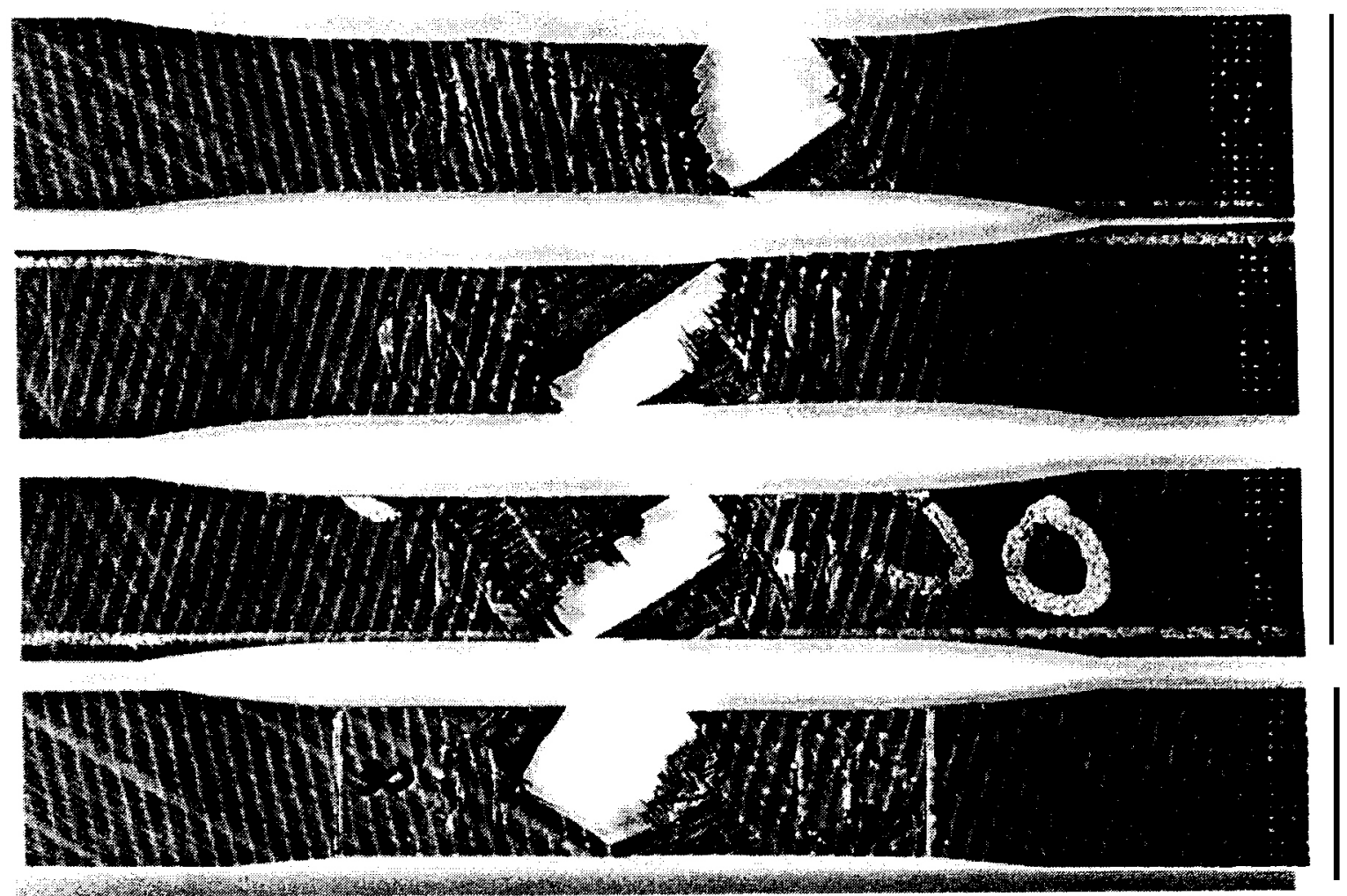

(a)

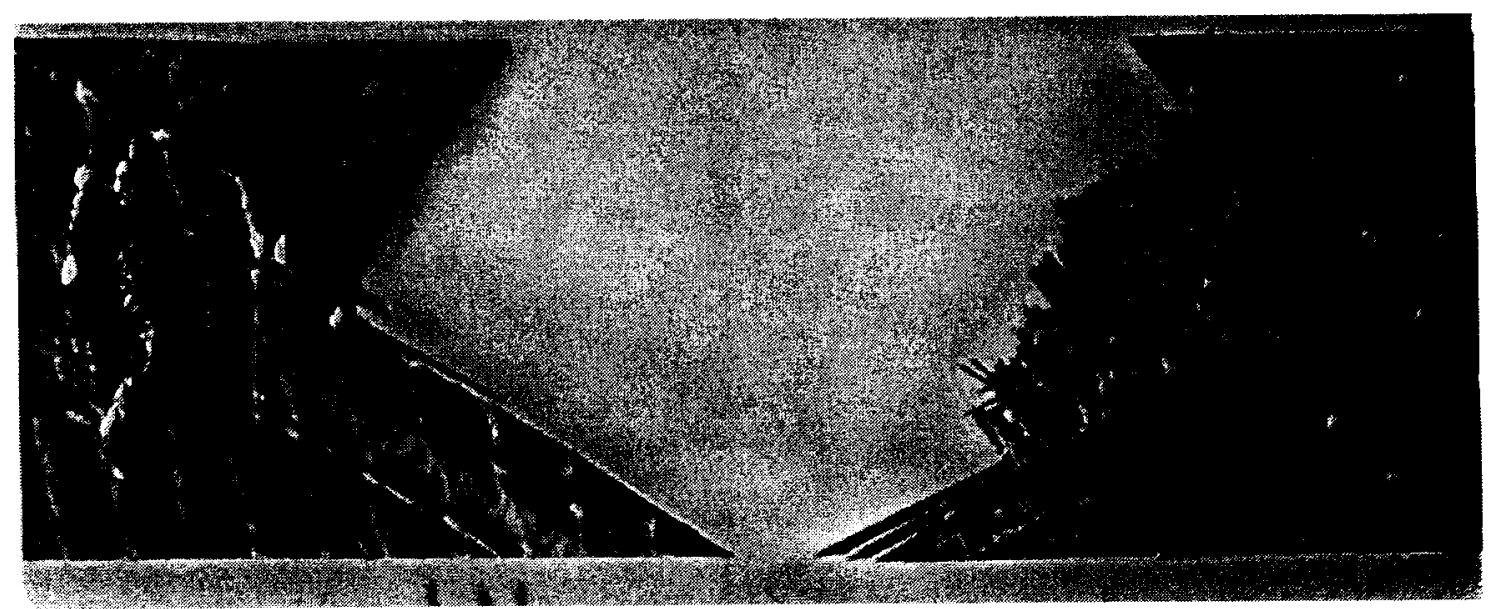

(b)

Fig. 10. Photographs of failed specimens after uniaxial tensile loading in horizontal direction: ( $a$ ) failed $30^{\circ}$ specimens; ( $b$ ) an enlarged portion close to main crack. 


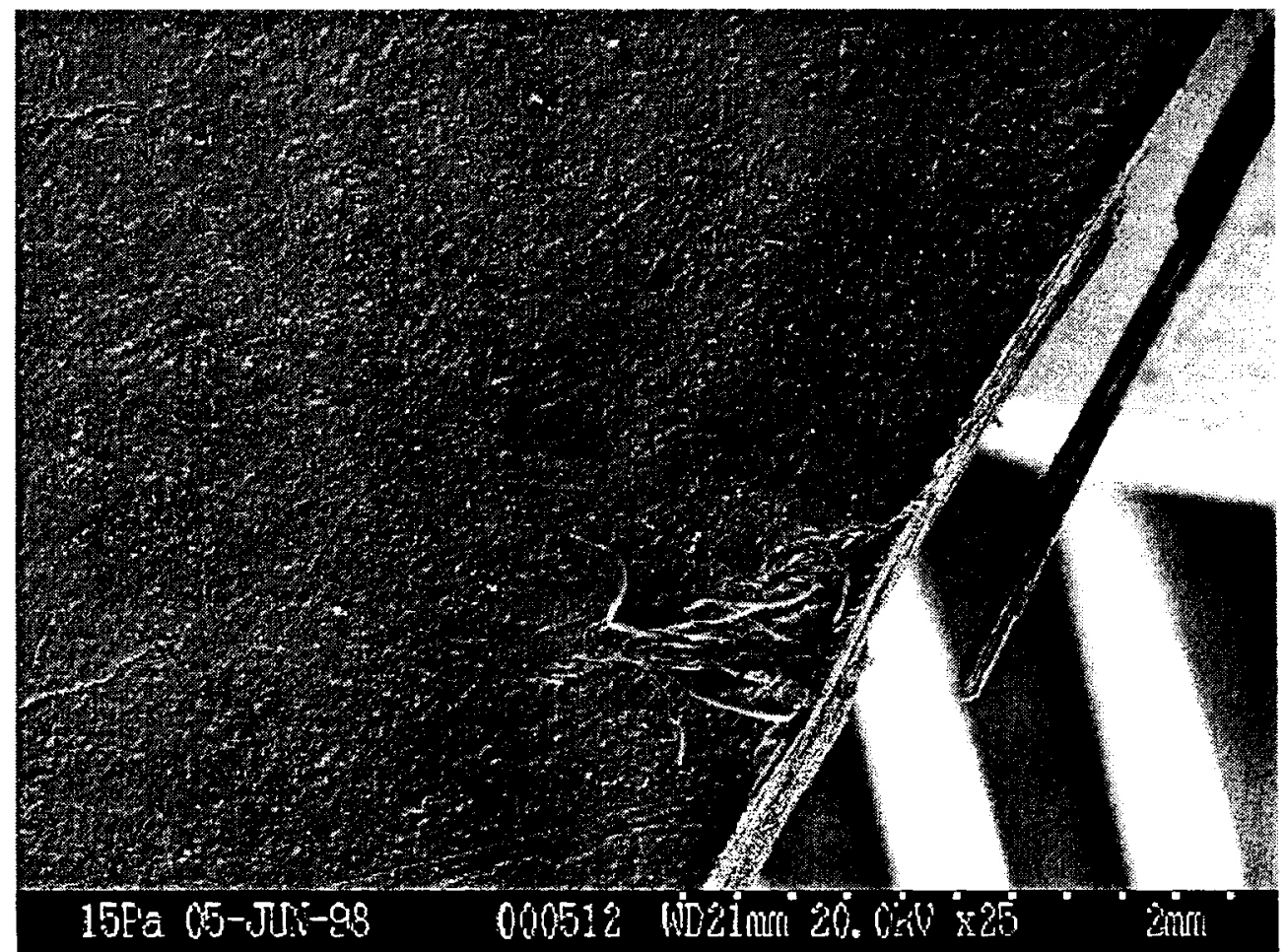

Fig. 11. Micrograph of a $30^{\circ}$ specimen in the vicinity of the main crack region. Secondary cracks were observed (note: specimen was loaded in vertical direction). 

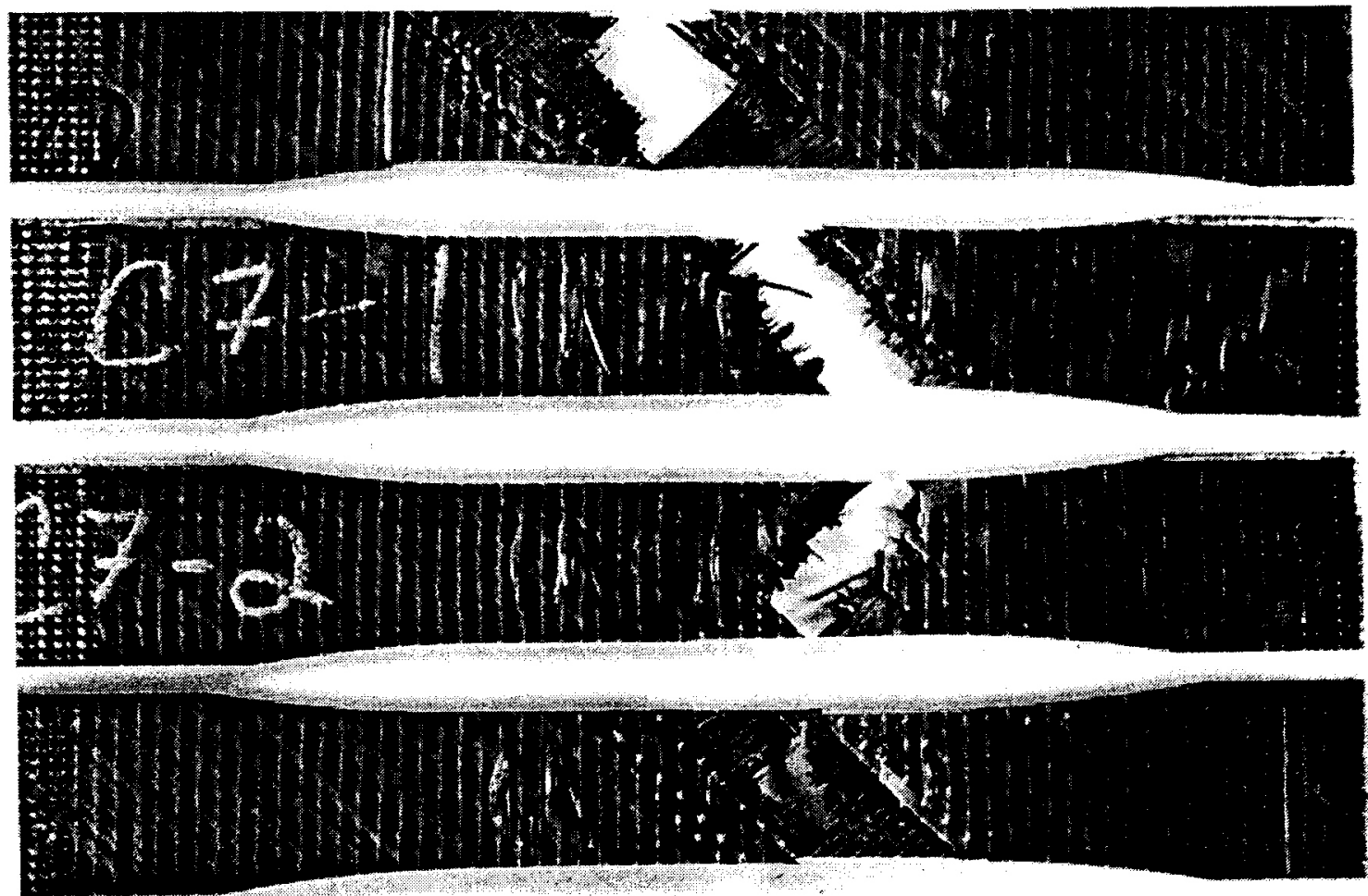

(a)

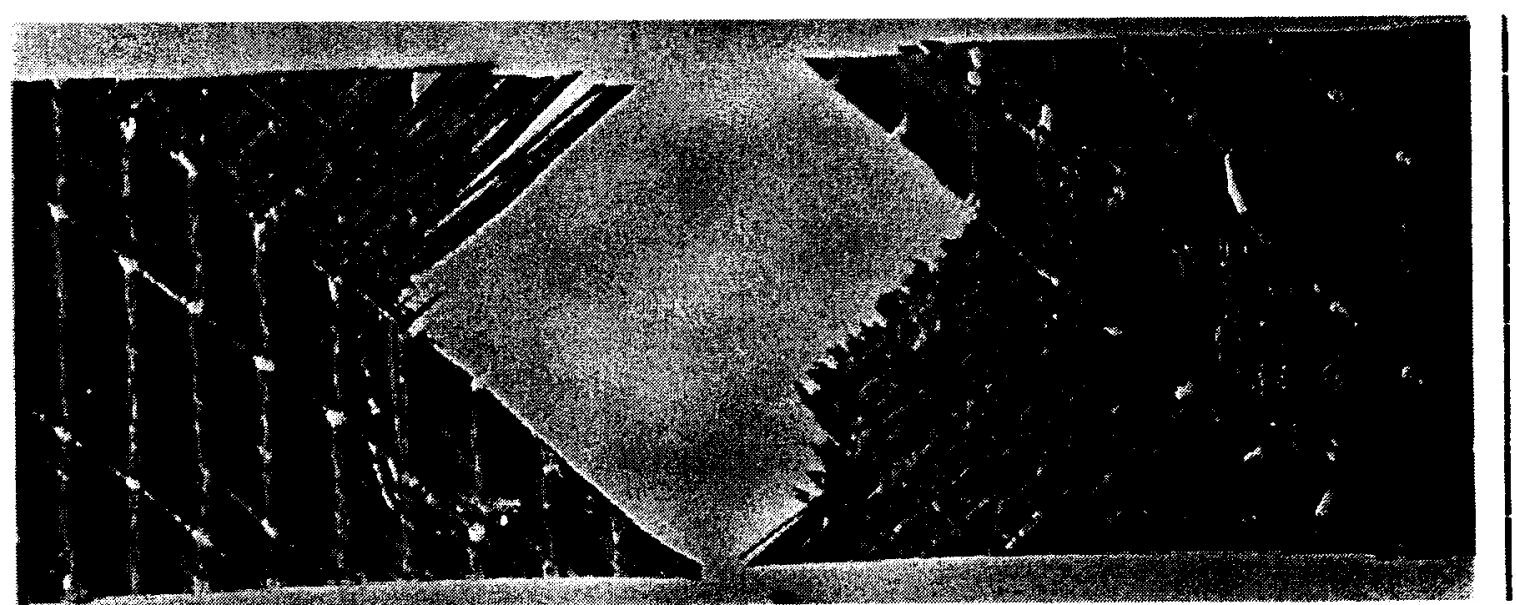

(b)

Fig. 12. Photographs of failed specimens after uniaxial tensile loading in horizontal direction: (a)failed $45^{\circ}$ specimens; (b) an enlarged portion close to main crack. 


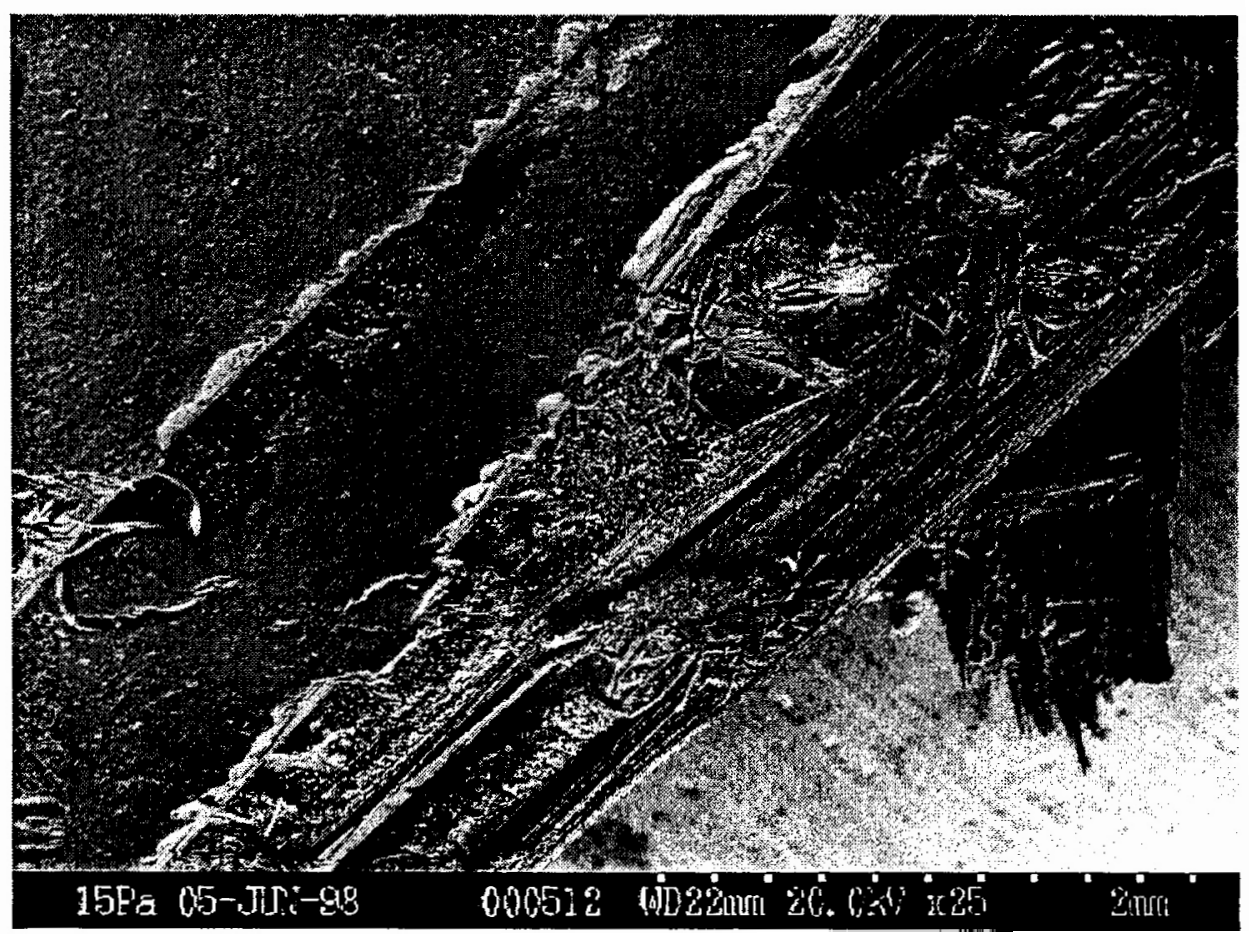

Fig. 13. Micrograph of a $45^{\circ}$ specimen around the main crack region. Secondary cracks were observed (note: specimen was loaded in vertical direction). 


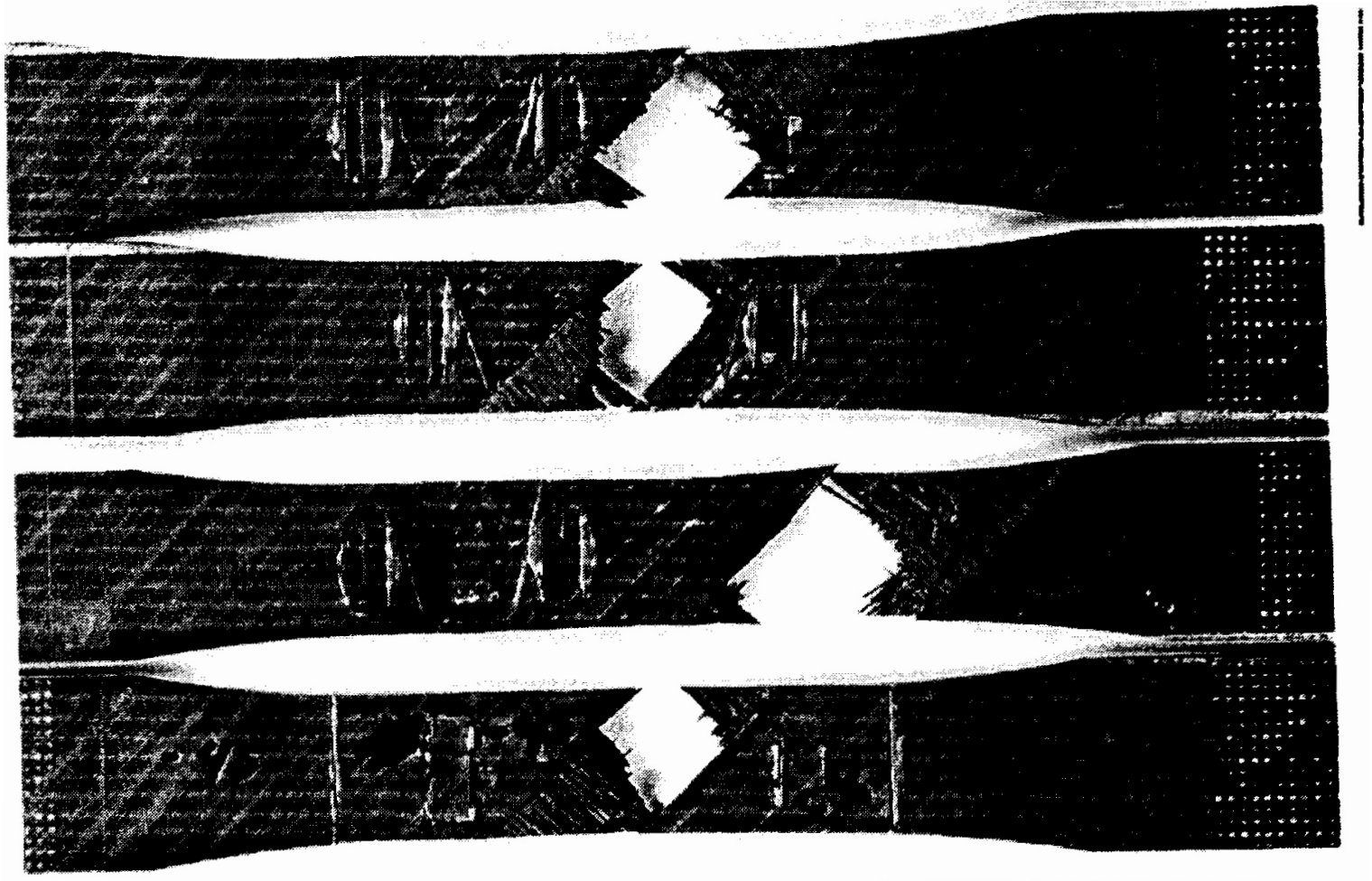

(a)

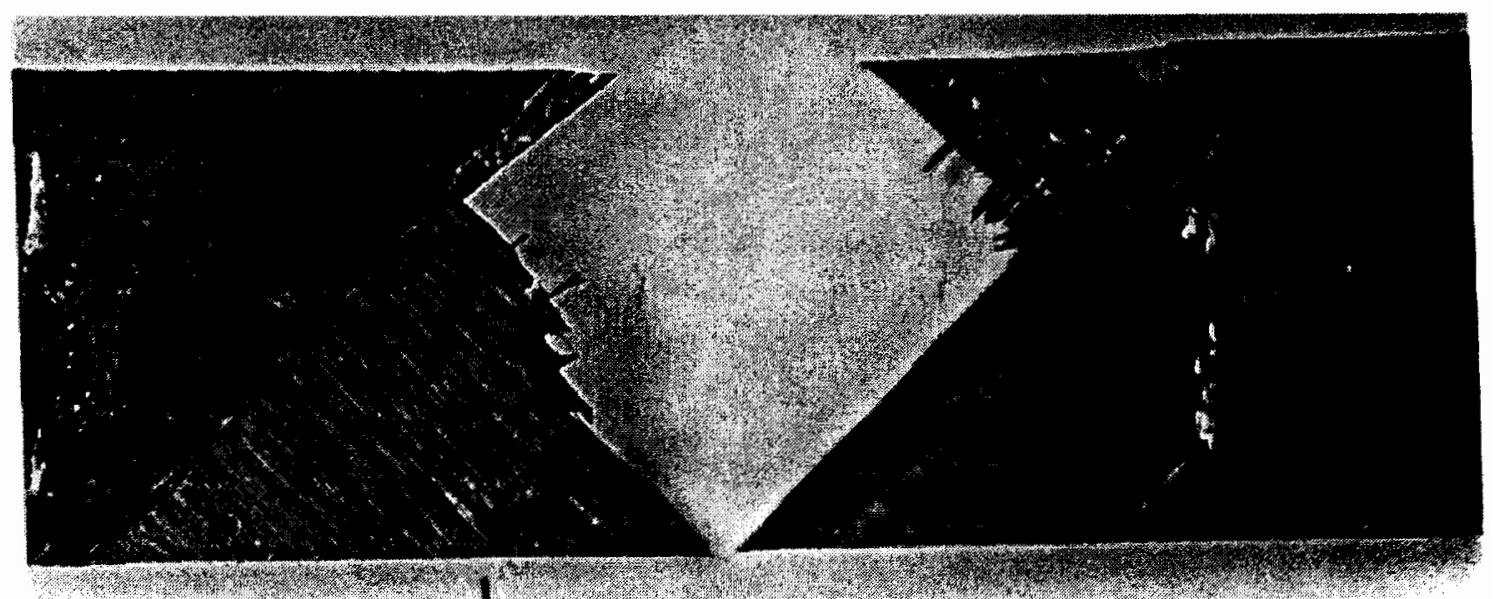

(b)

Fig. 14. Photographs of failed specimens after uniaxial tensile loading in horizontal direction: ( $a$ ) failed $-45^{\circ}$ specimens; $(b)$ an enlarged portion close to main crack. 


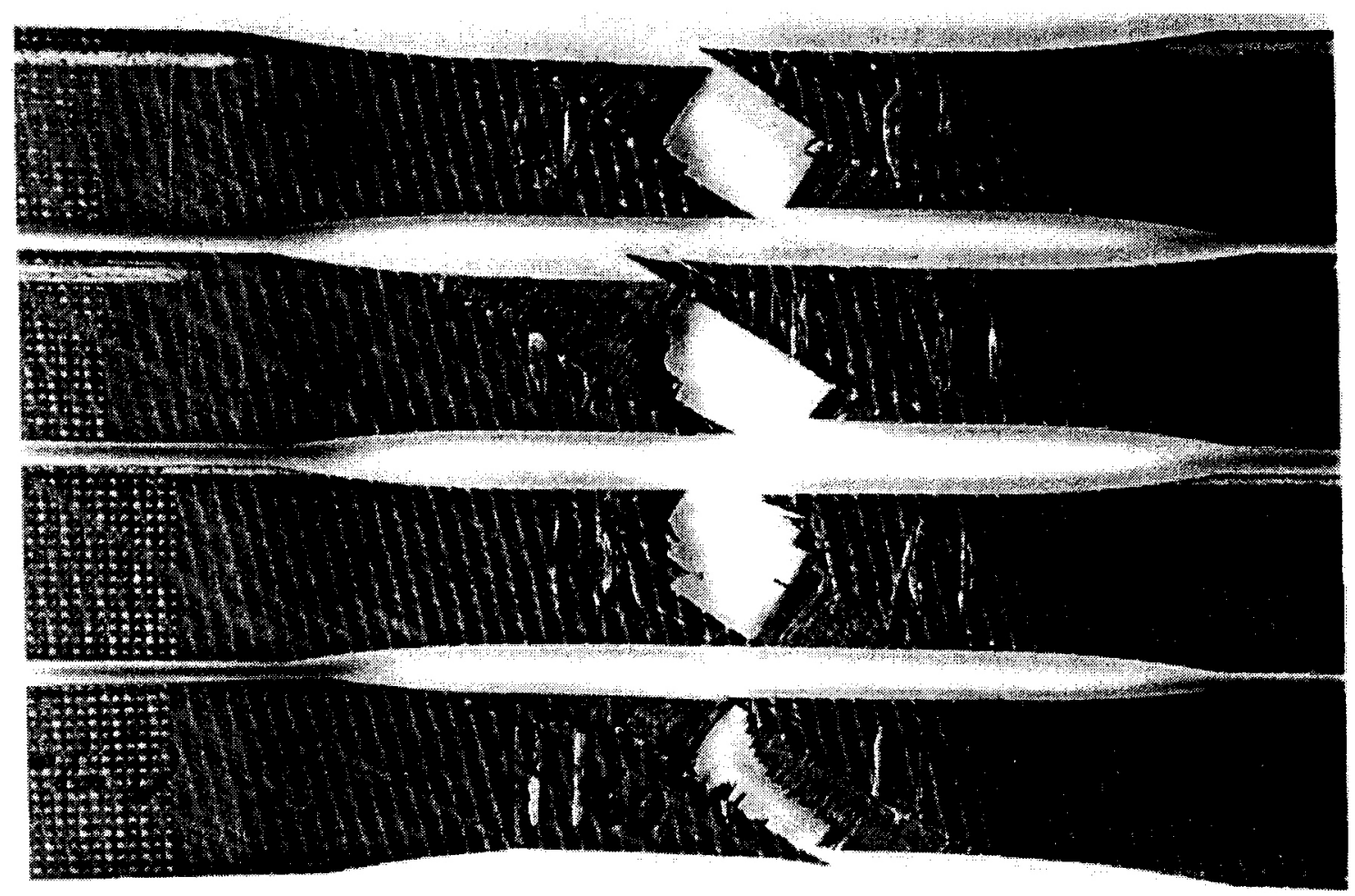

(a)

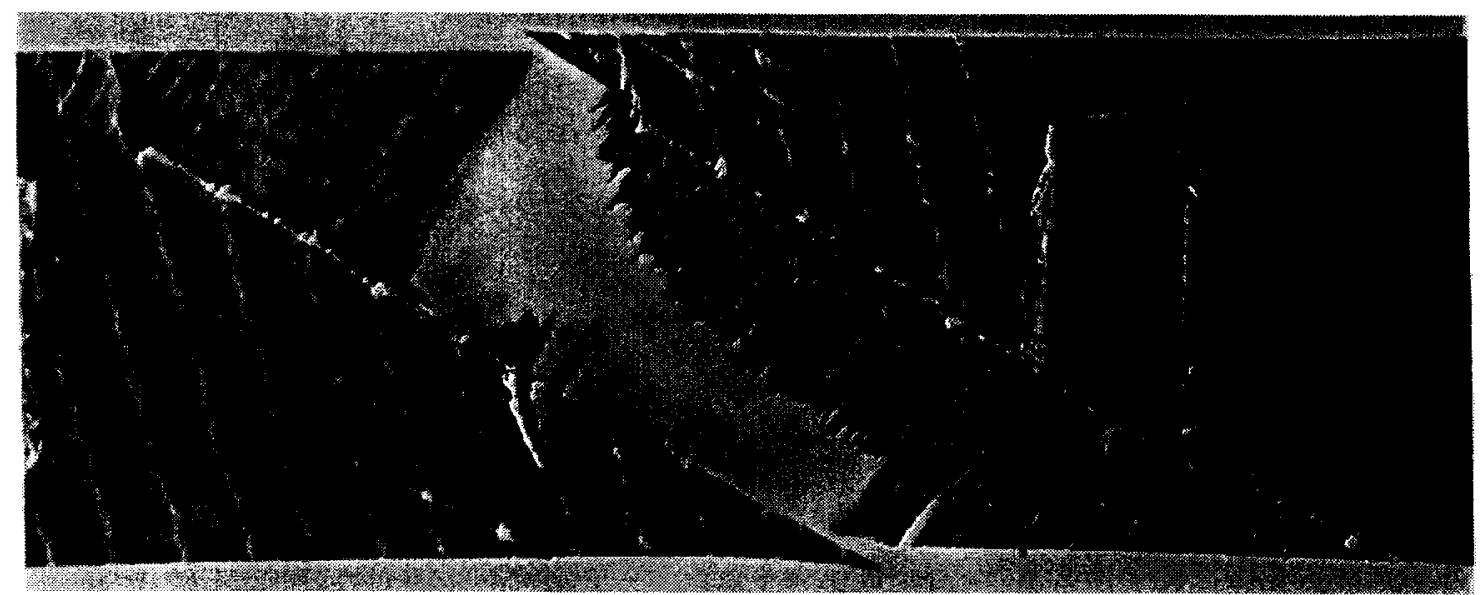

(b)

Fig. 15. Photographs of failed specimens after uniaxial tensile loading in horizontal direction: (a)failed $60^{\circ}$ specimens; $(b)$ an enlarged portion close to main crack. 

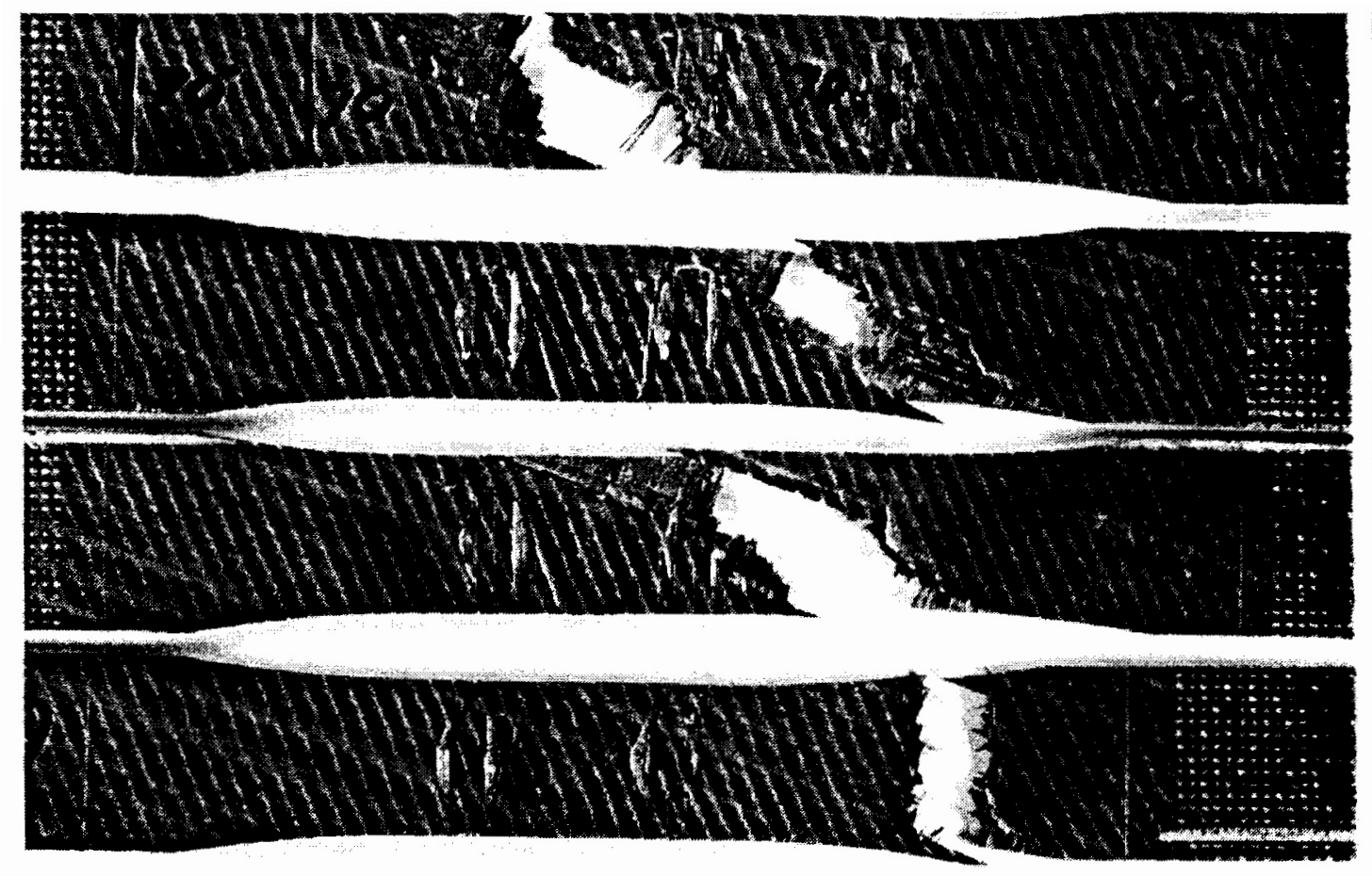

(a)

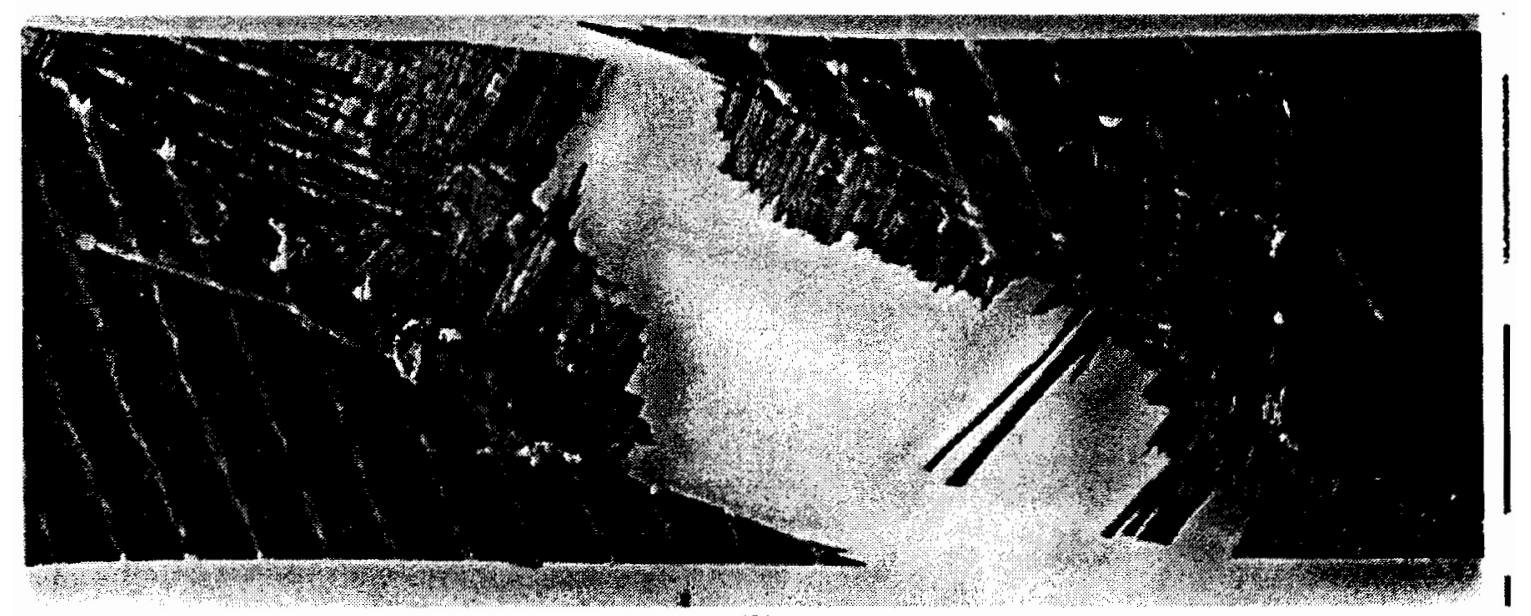

(b)

Fig. 16. Photographs of failed specimens after uniaxial tensile loading in horizontal direction: (a)failed $70^{\circ}$ specimens; (b) an enlarged portion close to main crack. 


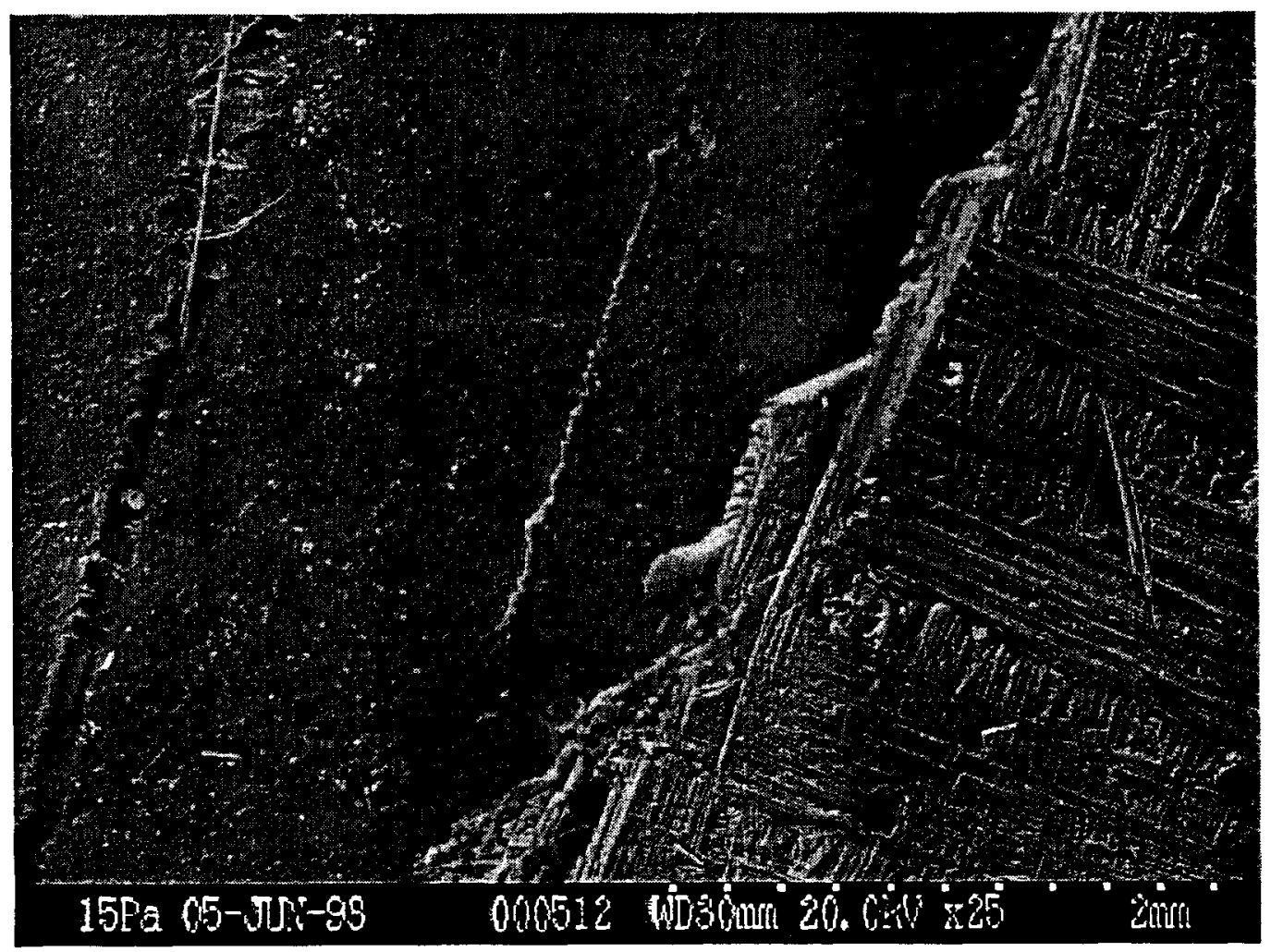

Fig. 17. Micrograph of a $70^{\circ}$ specimen around the main crack region. Secondary cracks were observed (note: specimen was loaded in vertical direction). 

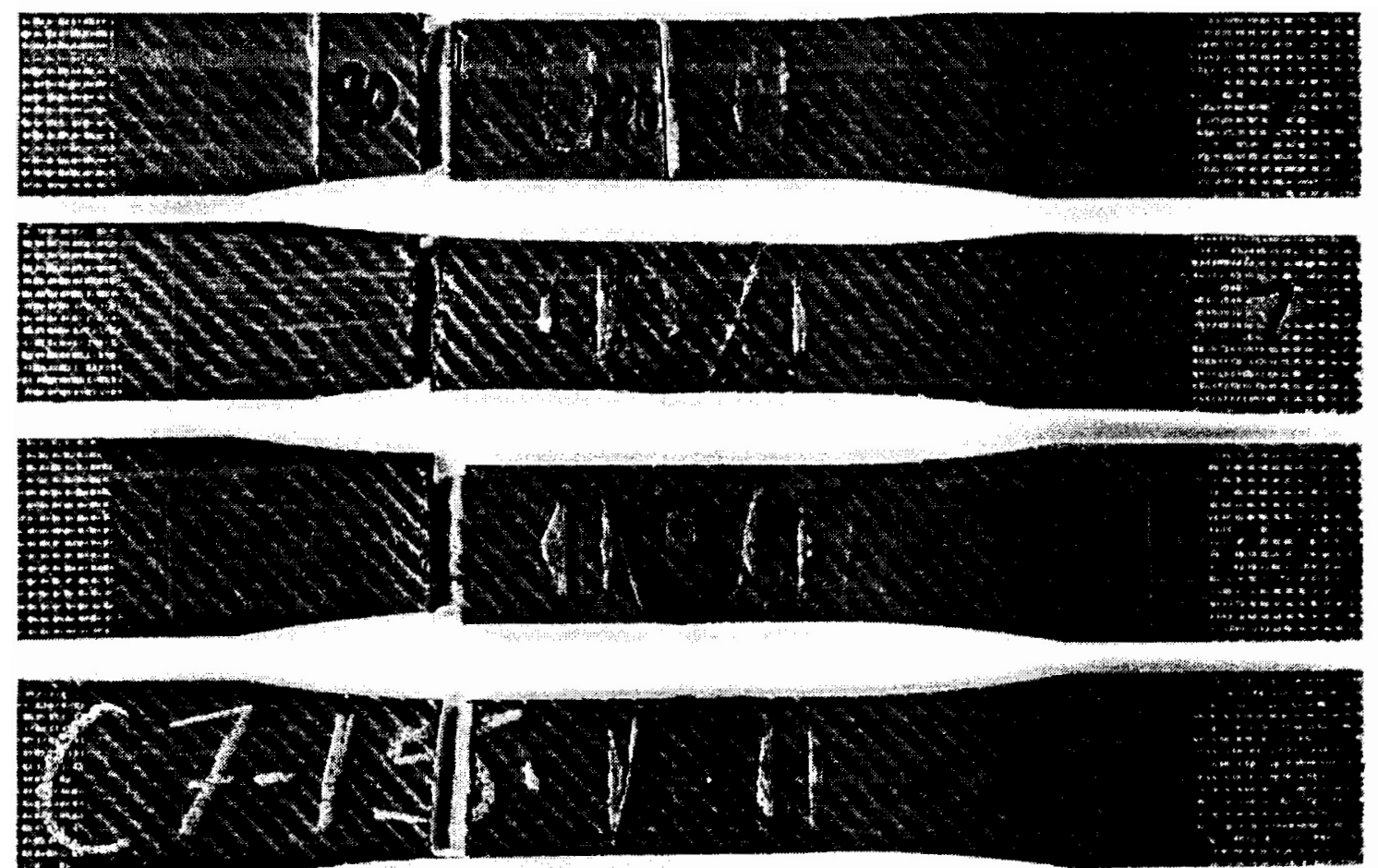

(a)

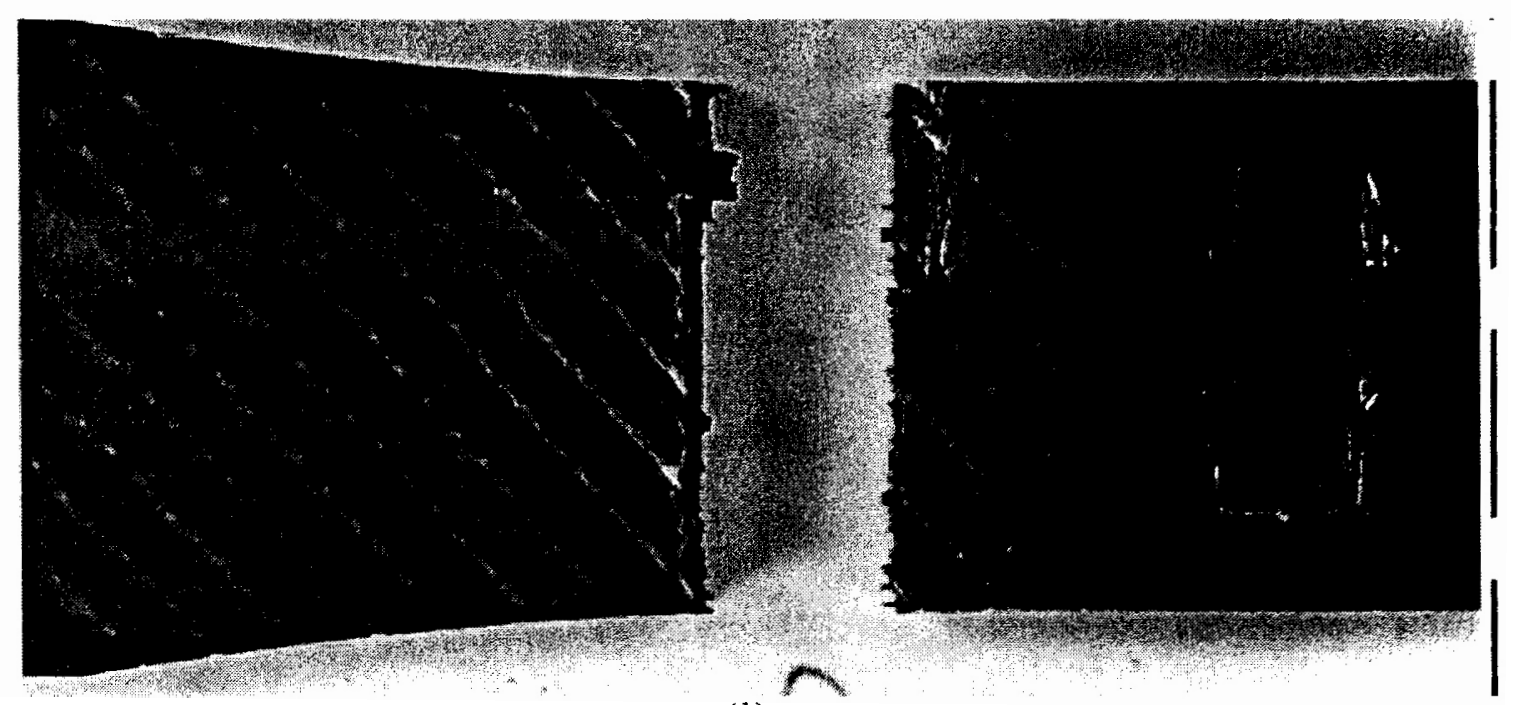

(b)

Fig. 18. Photographs of failed specimens after uniaxial tensile loading in horizontal direction: (a) failed $90^{\circ}$ specimens; (b) an enlarged portion close to main crack. 
The basic linear-elastic properties of a unidirectionally reinforced lamina are the four in-plane, plane stress stiffnesses $Q_{11}, Q_{12}, Q_{22}$, and $Q_{66}$ that relate stresses to strains in coordinate system $\mathrm{X}_{1}$ and $\mathrm{Y}_{1}$, which coincides with the principal directions of ply symmetry, as shown in Fig. 19. Accordingly, one has6

$$
\begin{aligned}
& \sigma_{1}=Q_{11} \varepsilon_{1}+Q_{12} \varepsilon_{2} . \\
& \sigma_{2}=Q_{12} \varepsilon_{1}+Q_{22} \varepsilon_{2} . \\
& \tau_{6}=Q_{66} \gamma_{6} .
\end{aligned}
$$

The above stiffnesses can be related in terms of the longitudinal and transverse moduli $E_{1}$ and $E 2$ as follows:

$$
\begin{aligned}
& Q_{11}=\frac{E_{1}}{1-v_{12} v_{21}} . \\
& Q_{22}=\frac{E_{2}}{1-v_{12} v_{21}} . \\
& Q_{12}=\frac{v_{21} E_{1}}{1-v_{12} v_{21}}=\frac{v_{12} E_{2}}{1-v_{12} v_{21}} \\
& Q_{66}=G_{12} .
\end{aligned}
$$

In the above, $v_{12}$ is the Poisson's ratio that relates strain in the direction of $Y_{1}$ due to stress in the direction of $\mathrm{X}_{1}$ and $v_{21}$ for the reverse case.
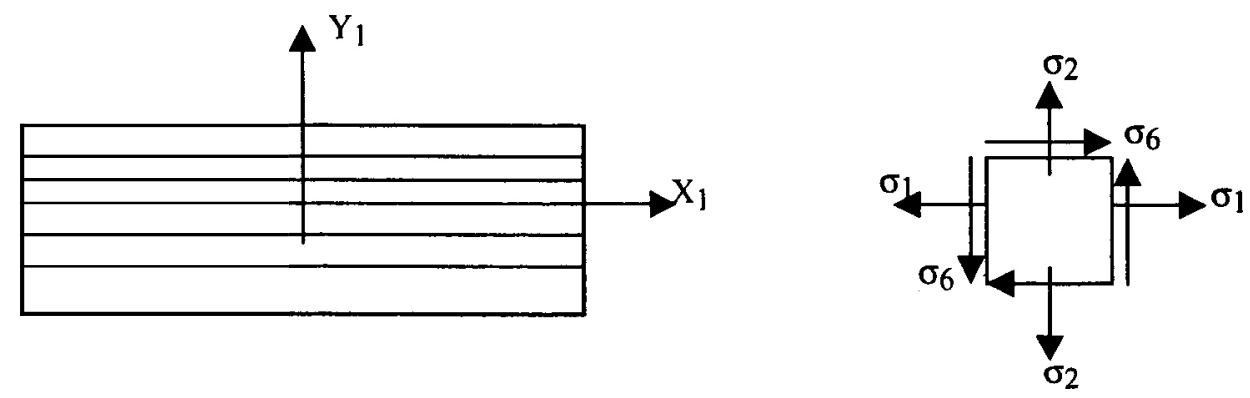

Fig. 19. A unidirectionally reinforced ply with the principal axes of symmetry and state of stresses.

When the lamina principal axes $\left(\mathrm{X}_{1}, \mathrm{Y}_{1}\right)$ do not coincide with the loading direction $(x, y)$ (as shown in Fig. 20), the stress-strain relations with respect to axes $\mathrm{x}$ and $y$ take the following form:

$$
\left\{\begin{array}{l}
\sigma_{x} \\
\sigma_{y} \\
\tau_{s}
\end{array}\right\}=\left[\begin{array}{lll}
\bar{Q}_{11} & \bar{Q}_{12} & \bar{Q}_{16} \\
\bar{Q}_{12} & \bar{Q}_{22} & \bar{Q}_{26} \\
\bar{Q}_{16} & \bar{Q}_{26} & \bar{Q}_{66}
\end{array}\right]\left\{\begin{array}{l}
\varepsilon_{x} \\
\varepsilon_{y} \\
\gamma_{s}
\end{array}\right\},
$$

where the oriented stiffnesses are related to the principal stiffnesses through tensorial transformation. For an orientation angle $\theta$, measured positive counterclockwise from the $\mathrm{x}$-axis to $\mathrm{X}_{1}$-axis, as shown in Fig. 20, the transformation relations read ${ }^{6}$ as follows: 

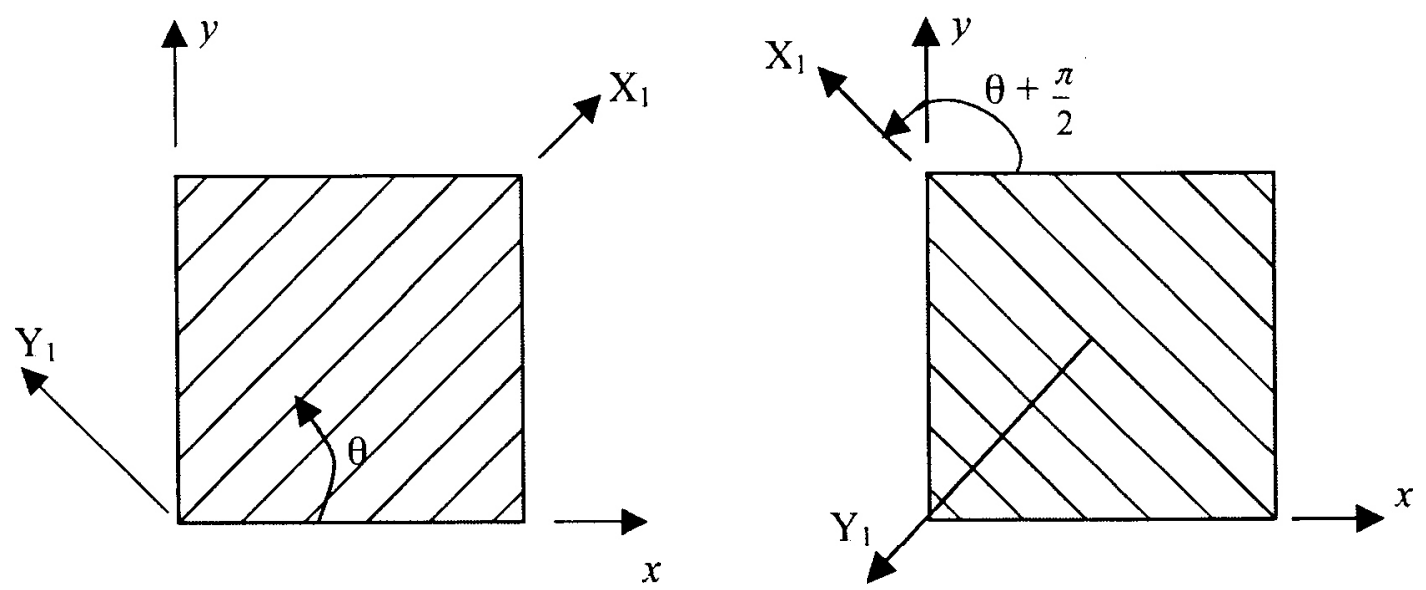

Fig. 20. Unidirectionally reinforced plies orientated at angles Band $\theta+\frac{\pi}{2}$ with loading applied relative to the common direction $x$ andy.

$$
\begin{aligned}
& \bar{Q}_{11}=m^{4} Q_{11}+n^{4} Q_{22}+2 m^{2} n^{2} Q_{12}+4 m^{2} n^{2} Q_{66}, \\
& \bar{Q}_{22}=n^{4} Q_{11}+m^{4} Q_{22}+2 m^{2} n^{2} Q_{12}+4 m^{2} n^{2} Q_{66}, \\
& \bar{Q}_{12}=m^{2} n^{2} Q_{11}+m^{2} n^{2} Q_{22}+\left(m^{4}+n^{4}\right) Q_{12}-4 m^{2} n^{2} Q_{66}, \\
& \bar{Q}_{16}=m^{3} n Q_{11}-m n^{3} Q_{22}+\left(m n^{3}-m^{3} n\right) Q_{12}+2\left(m n^{3}-m^{3} n\right) Q_{66}, \\
& \bar{Q}_{26}=m n^{3} Q_{11}-m^{3} n Q_{22}+\left(m^{3} n-m n^{3}\right) Q_{12}+2\left(m^{3} n-m n^{3}\right) Q_{66}, \\
& \bar{Q}_{66}=m^{2} n^{2} Q_{11}+m^{2} n^{2} Q_{22}-2 m^{2} n^{2} Q_{12}+\left(m^{2}-n^{2}\right)^{2} Q_{66},
\end{aligned}
$$

in which, $m=\cos \theta$ and $n=\sin \theta$. For the angle $\theta+\frac{\pi}{2}$, the above equations can be reproduced by letting $m=-n$ and $n=m$. Straightforward manipulation of Eq. ( 4 )yields the following expressions for the stiffnesses $\boldsymbol{A}$, of symmetric, balanced, crossply laminates oriented at an angle $\boldsymbol{\theta}$ about the $x-y$ coordinate system:

$$
\begin{aligned}
& A_{11}=A_{22}=\frac{n_{p}}{2} h_{o}\left[\left(m^{4}+n^{4}\right)\left(Q_{11}+Q_{22}\right)+4 m^{2} n^{2}\left(Q_{12}+2 Q_{66}\right)\right], \\
& A_{12}=\frac{n_{p}}{2} h_{o}\left[2 m^{2} n^{2}\left(Q_{11}+Q_{22}\right)+2\left(m^{4}+n^{4}\right) Q_{12}-8 m^{2} n^{2} Q_{66}\right], \\
& A_{16}=-A_{26}=\frac{n_{p}}{2} h_{o}\left[\left(m^{3} n-m n^{3}\right)\left(Q_{11}+Q_{22}\right)+2\left(m n^{3}-m^{3} n\right)\left(Q_{12}+2 Q_{66}\right)\right], \\
& A_{66}=n_{2} h_{p} h_{o}\left[2 m^{2} n^{2}\left(Q_{11}+Q_{22}\right)-4 m^{2} n^{2} Q_{12}+2\left(m^{2}-n^{2}\right)^{2} Q_{66}\right],
\end{aligned}
$$

where $h_{\mathrm{o}}$ is the lamina thickness, and $n_{\mathrm{p}}$ is the total number of plies.

Consequently, when subjected to a uniaxial load $N_{x}$, the longitudinal stiffness and the Poisson's ratio of the laminate are given by 


$$
E_{x}=\frac{1}{n_{p} h_{o}}\left(\frac{N_{x}}{\varepsilon_{x}}\right)=\frac{1}{n_{p} h_{o}}\left(A_{11}-\frac{A_{12}^{2} A_{66}+A_{66} A_{16}^{2}-2 A_{12} A_{16} A_{26}}{A_{22} A_{66}-A_{16}^{2}}\right),
$$

and

$$
v_{x y}=-\frac{\varepsilon_{y}}{\varepsilon_{x}}=\frac{A_{12} A_{66}-A_{16} A_{26}}{A_{22} A_{66}-A_{16}^{2}}
$$

Note that Eqs. (5), (6), and (7) contain the combined values of $Q_{11}+Q_{22}$, rather than $Q_{11}$ and $Q_{22}$ separately. This is a peculiarity that applies to symmetric, balanced, crossply laminates.

\subsubsection{Evaluation of $Q_{11}+Q_{22}, Q_{12}$, and $Q_{66}$}

Two laminate orientations, $\phi=0^{\circ}$ and $\phi=45^{\circ}$, were used to backtrack the lamina properties. The experimental data (reported in Table 2) gave average values of $E,,^{\prime \prime}=45.1 \mathrm{GPa}, v_{x}^{0}=0.061$, $E_{x}^{45}=11.7 \mathrm{GPa}$, and $v_{x v}^{4 t}=0.764$. For the case of $\phi=45^{\circ}$, Eqs. (6) and (7) reduce to

$$
E_{x}^{45}=\frac{1}{4}\left(Q_{11}+Q_{22}\right)+\frac{1}{2}\left(Q_{12}+2 Q_{66}\right)-\frac{\left[\frac{1}{2}\left(Q_{11}+Q_{22}\right)+Q_{12}-2 Q_{66}\right]^{2}}{Q_{11}+Q_{22}+2 Q_{12}+4 Q_{66}},
$$

and

$$
v_{x y}^{45}=\frac{Q_{11}+Q_{22}+2\left(Q_{12}-2 Q_{66}\right)}{Q_{11}+Q_{22}+2\left(Q_{12}+2 Q_{66}\right)}
$$

For $\phi=0^{\circ}$, one obtains

$$
E_{x}^{0}=\frac{1}{2}\left(Q_{11}+Q_{22}\right)-\frac{2 Q_{12}^{2}}{Q_{11}+Q_{22}},
$$

and

$$
v_{x y}^{0}=\frac{2 Q_{12}}{Q_{11}+Q_{22}}
$$

Equations (8) to (1 1) yield four expressions for the three unknowns $Q_{11}+Q_{22}, Q_{12}$, and $Q_{66}$. In view of the unavailability of unidirectionally reinforced samples, these expressions, together with the experimental data for $E_{x}^{45}, v_{x y}^{45}, E$,", and $v_{x}^{0}$, employed in combinations of three sets at a time, yielded the following average values for the above three unknowns: $Q_{11}+$ $Q_{22}=91.7 \mathrm{GPa}, Q_{12}=3.1 \mathrm{GPa}$, and $Q_{66}=3.3 \mathrm{GPa}$, with an uncertainty of approximately $\pm 5 \%$ due to layup variabilities. 


\subsubsection{Predictions for Other Orientations}

It is now possible to employ the foregoing values of $Q_{11}+Q_{22}, Q_{12}$, and $Q_{66}$ together with Eqs. (5) to (7) to predict the laminate moduli and Poisson's ratio at all orientations $\phi$. These predictions are shown in Figs. 21 and 22, where the average value of data recorded for $\phi=30^{\circ}, 60^{\circ}$, $70^{\circ}$, and $90^{\prime \prime}$ are shown to fit almost exactly with the predicted values.

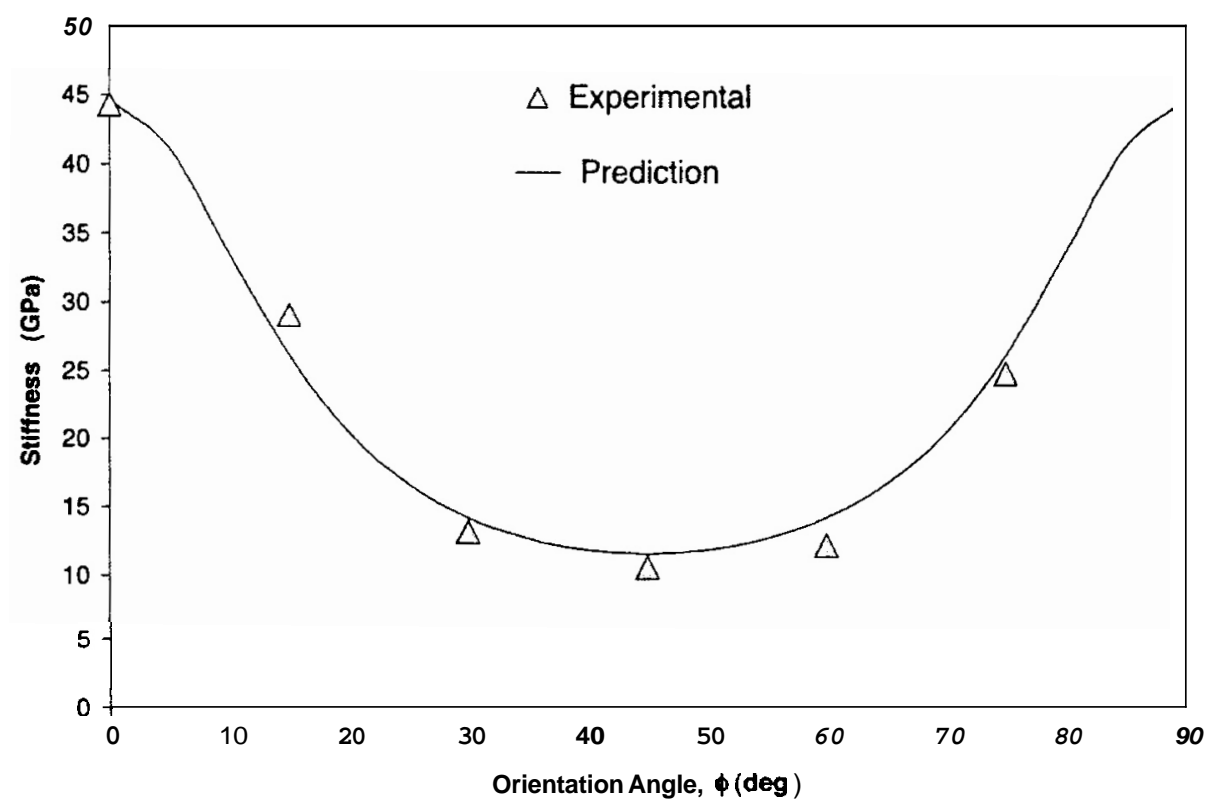

Fig. 21. Variation of tensile stiffness within the linear range of stress-strain response vs loading orientation for $[ \pm 45]_{3 \mathrm{~s}}$ crossply laminates and comparison with predictions of classical laminate theory.

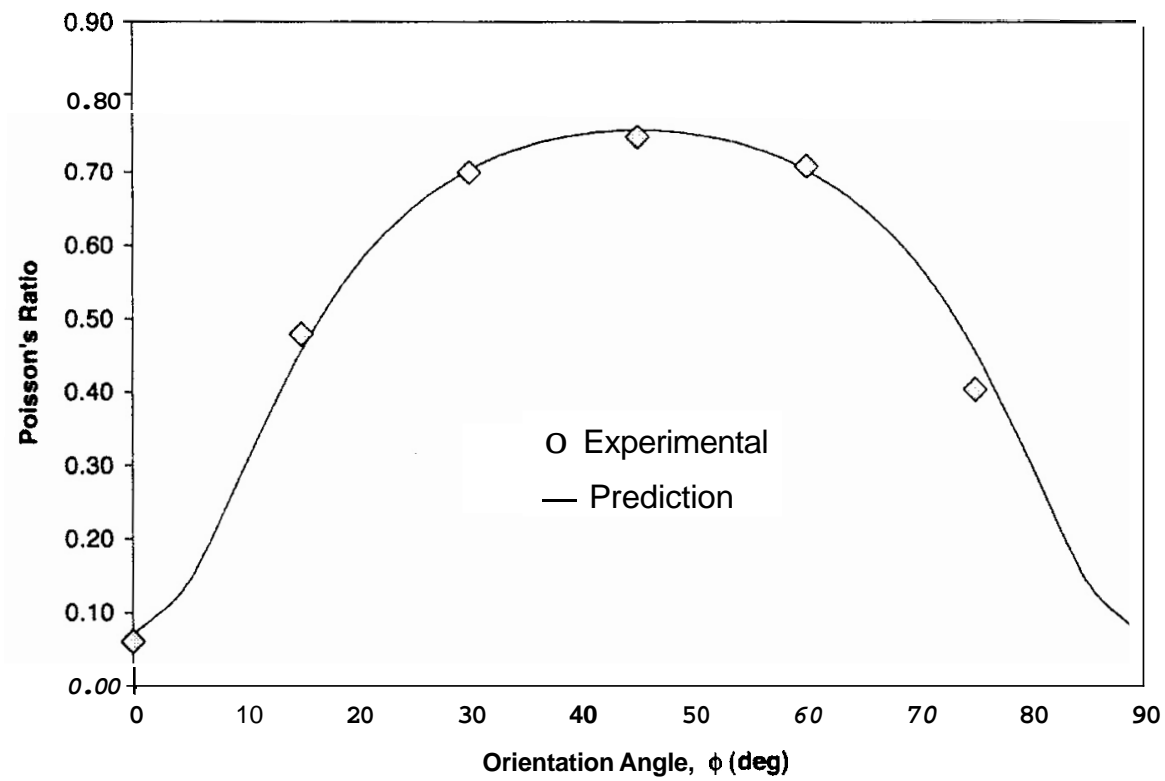

Fig. 22. Poisson's ratio vs loading orientation for $[ \pm 45]_{35}$ crossply laminates and comparison with predictions of classical laminate theory. 


\subsection{EVALUATION OF $Q_{11}$ AND $Q_{22}$}

As noted earlier, a peculiarity associated with symmetric, balanced, crossply laminates precludes the evaluation of $Q_{11}$ and $Q_{22}$ individually, though it is still possible to calculate their sum from laminate stress-strain data. For that purpose, the following properties were considered for the individual fiber and matrix phases: ${ }^{4}$

T300 fiber: $E_{1 f}=221 \mathrm{GPa}, E_{2 f}=13.8 \mathrm{GPa}$, and $\boldsymbol{v}_{12}^{f}=0.2$. Urethane matrix: $E,,=2 \mathrm{GPa}$ and $v_{,}=0.385$.

Furthermore, as noted earlier, one has $V_{\text {Tow }}=64.5 \%$ with $V_{f, \text { Tow }}=66.5 \%$. Thereby, $V_{m, T o w}$ $=33.5 \% ; V_{m \text {,outside tow }}=35.5 \%$ (thus, $V_{f}=42.9 \%, V_{m}=57.1 \%$ ).

Micromechanics considerations state that to a high degree of accuracy it is possible to assess the longitudinal modulus and Poisson's ratio of the unidirectionally reinforced composite ply by the rule of mixture. Thus,

$$
\begin{gathered}
E,=V_{f} E_{1 f}+V_{m} E_{m}=96.9 \mathrm{GPa} ; \\
v_{12}=V_{f} \nu_{12}^{f}+V_{m} \nu_{m}=0.31 .
\end{gathered}
$$

Turning to the transverse modulus $\boldsymbol{E 2}$, the following assumptions are employed: (1) the fibers within the tow region are hexagonally arrayed, and (2) the two regions and the resin regions outside the tow are arrayed in series, as sketched in Fig. 23. Consequently, the transverse modulus within the tow region is evaluated according to the Halpin-Tsai expression:?

$$
E_{2, \text { Tow }}=E_{m} \frac{1+\xi \chi V_{f, T o w}}{1-\chi V_{f, T o w}}
$$

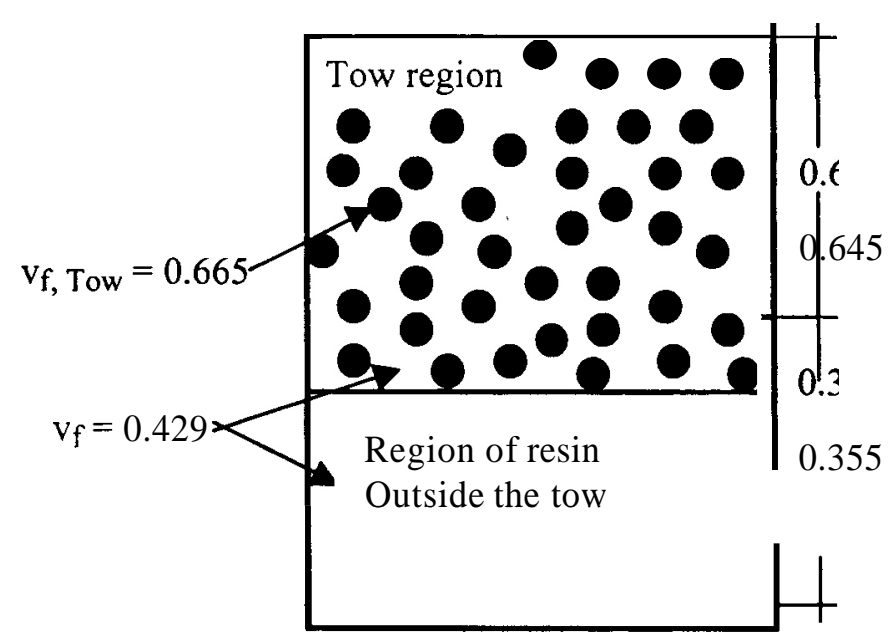

Fig. 23. The idealized model for the evaluation of $\boldsymbol{E}_{\mathbf{2}}$. The quantity $\mathrm{v}_{\mathrm{f}, \mathrm{Tow}}$ denotes the fiber volume fraction within the tow region, and $v_{f}$ is the fiber volume fraction within the composite. 
Thus, letting $\mathrm{d}$ denote fiber diameter and $\mathrm{h}$ the distance between the centers of neighboring fibers, one has $(d / h)^{2}=2 \sqrt{3} V_{f, \text { Tow }} / \pi$, resulting in $\mathrm{d}=0.856 \mathrm{~h}$. This, in turn, yields the following values for the auxiliary quantities $\mathrm{V}_{\mathrm{mp}}$, Tow,$\left\{\right.$, and $\chi: \mathrm{V}_{\mathrm{mp}, \text { Tow }}=0.012, \xi=0.024$, and $\chi=$ 0.858 , whereby $\mathrm{E}_{2 \text {, Tow }}=2.34 \mathrm{GPa}$. The transverse modulus $E 2$ is now obtainable from the inverse rule of mixtures, which applies to phases arrayed in series; namely,

$$
\frac{1}{E_{2}}-\underset{E_{2 . T o w}}{V_{\text {Tow }}}+\frac{V_{m, \text { outside tow }}}{E_{m}}=\frac{0.645}{2.34}+\frac{0.355}{2} \text {, }
$$

resulting in $E 2=2.25 \mathrm{GPa}$. The quantities $Q_{11}$ and $Q_{22}$ can now be computed from

$$
Q_{11}=\frac{E_{1}}{1-v_{12} v_{21}}, \quad Q_{22}=\frac{E_{2}}{1-v_{12} v_{21}}, \quad v_{21}=\frac{E_{2}}{E_{1}} v_{12}
$$

The above equations yield $Q_{11}=95.7 \mathrm{GPa}, Q_{22}=2.24 \mathrm{GPa}$, whereby $Q_{11}+Q_{22}=$ $97.94 \mathrm{GPa}$. The latter result is close to, but not identical with, the average experimental value of 91.7 GPa. Reapportioning $Q_{11}$ and $Q_{22}$ through the factor of $91.7 / 97.94$, we finally get $Q_{11} \cong$ $89.6 \mathrm{GPa}$ and $Q_{22}=2.1 \mathrm{GPa}$. 


\section{TIME-DEPENDENT DEFORMATION OF CROSSPLY LAYUPS}

\subsection{EXPERTMENTAL PROGRAM AND DATA}

\subsubsection{Tensile Tests}

Tension-to-failure tests were conducted using an 810 MTS system at a constant rate of $1.016 \mathrm{~mm} / \mathrm{min}(0.04 \mathrm{in} . / \mathrm{min})$ at temperatures of $23^{\circ} \mathrm{C}$ and $120^{\circ} \mathrm{C}$. Longitudinal and transverse strains were recorded by strain gages and extensometry. The longitudinal strains vs stress at $23^{\circ} \mathrm{C}$ were shown earlier in Fig. 7.

\subsubsection{Creep and Recovery Tests}

Creep and recovery tests consisted of the application of a step stress of amplitude $\sigma_{\mathrm{o}}$ and its subsequent removal after a time $t_{0}$. Creep and recovery strains were recorded during the time intervals $0<t<t_{\mathrm{O}}$ and $t_{\mathrm{O}}<t<r t_{\mathrm{O}}$, respectively. The values of $y$ varied between 2 and 15 . The resulting stress and strain histories are sketched in Fig. 24.

Replicate tests were performed at various levels of $\sigma_{0}$, with several durations $t_{\mathrm{o}}$ and $r t_{\mathrm{o}}$, at different levels of temperature and at various fiber orientations. These are listed in Table 3, where $\phi$ denotes orientation in degrees, and $T$ is the temperature in degrees Celsius.

Typical results, accompanied by standard deviation scatter bands, are exhibited in Figs. 25 and 26 for $T=23^{\circ} \mathrm{C}, t_{\mathrm{o}}=5 \mathrm{~h}, r t_{\mathrm{o}}=20 \mathrm{~h}$ (i.e., $15 \mathrm{~h}$ of recovery time) and various levels of $\sigma_{\mathrm{o}}$. Note the increase in data scatter with stress level $\sigma_{0}$. Such an increase was also observed at higher test temperatures.

The abovementioned data scatter can be attributed to the inherent nature of multiphase materials where flaws and voids are randomly distributed. However, in the present case, those characteristics were compounded by the nonuniformity typical of the material at hand. As noted earlier, variances introduced during the manufacturing process resulted in localized nonuniformity in fiber and void volumes, resin impregnation, and fiber orientations. A somewhat extreme circumstance is exhibited in Fig. 27, where creep and recovery strains were recorded at various stations along the same test coupon. In this case, the onset of localized damage, in the form of nonuniformly distributed matrix cracks, resulted in vast discrepancies in the recorded strain data. The effects of stress, temperature, load duration, and load orientation on the time-dependent response of the composite at hand will be detailed in Sect. 4.2.1.
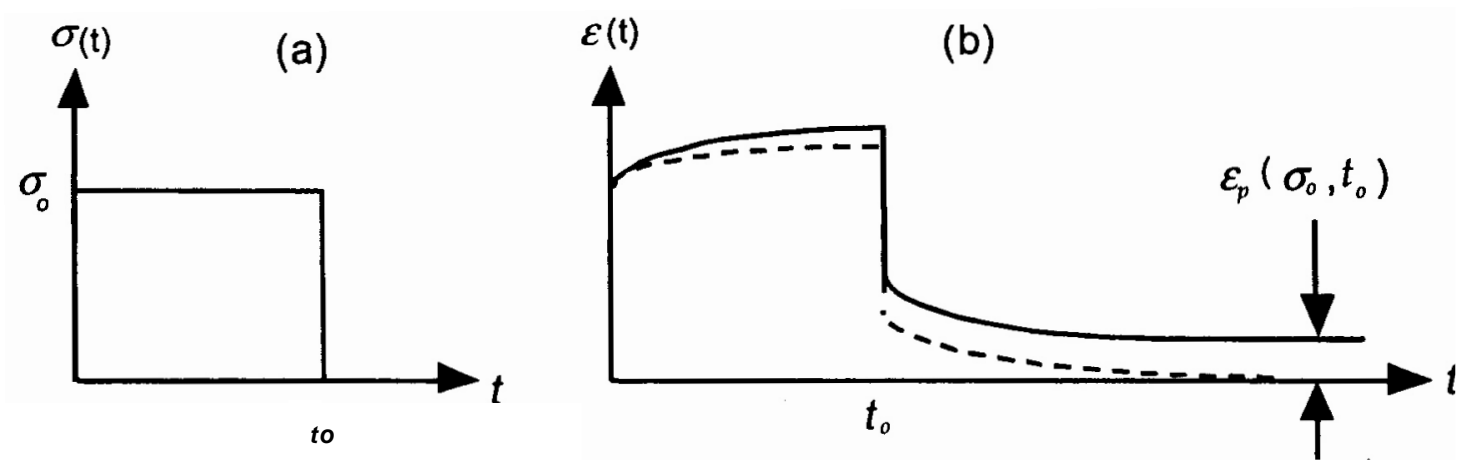

Fig. 24. Schematic drawing of the creep and recovery response of viscoelastic material: (a)step load input; (b) strain output. Solid line accounts for the permanent deformation, and the dashed line is the recoverable, viscoelastic component. 
Table 3. Creep and recovery test program

\begin{tabular}{|c|c|c|c|c|c|}
\hline $\begin{array}{c}\text { Creep stress } \\
\sigma_{0}(\mathrm{MPa})\end{array}$ & $\begin{array}{l}\text { Creep/recovery } \\
\text { times } t_{\mathrm{g}} /(r-1) t_{0}\end{array}$ & $\begin{array}{c}\text { Number of } \\
\text { test } \\
\text { specimens }\end{array}$ & $\begin{array}{l}\text { Creep stress } \\
\sigma_{0}(\mathrm{MPa})\end{array}$ & $\begin{array}{c}\text { Creep/recovery } \\
\text { times } t_{\mathrm{o}} /(r-1) t_{0} \\
(\mathbf{h})\end{array}$ & $\begin{array}{c}\text { Number of } \\
\text { test } \\
\text { specimens }\end{array}$ \\
\hline \multicolumn{3}{|c|}{$\phi=45^{\circ}, \mathrm{T}=23^{\circ} \mathrm{C}$} & \multicolumn{3}{|c|}{$\phi=45^{\circ}, T=120^{\circ} \mathrm{C}$} \\
\hline 31 & $1 / 15$ & 3 & 31 & $5 / 15$ & 3 \\
\hline 31 & $5 / 15$ & 5 & 31 & $24 / 48$ & 1 \\
\hline 31 & $24 / 48$ & 3 & 46.5 & $5 / 15$ & 4 \\
\hline 46.5 & $1 / 15$ & 3 & 46.5 & $24 / 48$ & 2 \\
\hline 46.5 & $5 / 15$ & 3 & 62 & $5 / 15$ & 3 \\
\hline 46.5 & $24 / 48$ & 3 & 62 & $24 / 48$ & 1 \\
\hline 62 & $0 / 15$ & 2 & \multicolumn{3}{|c|}{$\phi=34^{\circ}, T=23^{\circ} \mathrm{C}$} \\
\hline 62 & $1 / 15$ & 3 & 32.8 & $5 / 15$ & 3 \\
\hline 62 & $5 / 15$ & 6 & 32.8 & $24 / 48$ & 3 \\
\hline 62 & $24 / 48$ & 3 & 49.2 & $5 / 15$ & 3 \\
\hline 77.5 & $0 / 15$ & 2 & 49.2 & $24 / 48$ & 3 \\
\hline 77.5 & $1 / 15$ & 3 & 65.5 & $5 / 15$ & 3 \\
\hline 77.5 & $5 / 15$ & 3 & 65.5 & $24 / 48$ & 3 \\
\hline 77.5 & $24 / 48$ & 3 & 82 & $5 / 15$ & 3 \\
\hline 93 & $0 / 15$ & 2 & 96 & $5 / 15$ & 3 \\
\hline 93 & $1 / 15$ & 3 & \multicolumn{3}{|c|}{$\phi=340, \mathrm{~T}=50^{\circ} \mathrm{C}$} \\
\hline 93 & $5 / 15$ & 4 & 32.8 & $5 / 15$ & 2 \\
\hline 93 & $24 / 48$ & 3 & 49.2 & $5 / 15$ & 2 \\
\hline 108.5 & $1 / 15$ & 3 & \multicolumn{3}{|c|}{ 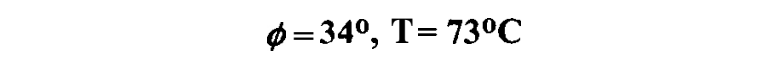 } \\
\hline 108.5 & $5 / 15$ & 4 & 32.8 & $5 / 15$ & 1 \\
\hline 108.5 & $24 / 48$ & 4 & \multicolumn{3}{|c|}{$\phi=15^{\circ}, T=23^{\circ} \mathrm{C}$} \\
\hline & $\phi=45^{\circ}, \mathrm{T}=50^{\circ} \mathrm{C}$ & & 31 & $24 / 48$ & 1 \\
\hline 31 & $5 / 15$ & 3 & 50.4 & $5 / 15$ & 3 \\
\hline 46.5 & $5 / 15$ & 3 & 50.4 & $24 / 48$ & 5 \\
\hline & $\phi=45^{\circ}, T=7^{\circ} \mathrm{C}$ & & 75.6 & $5 / 15$ & 3 \\
\hline 31 & $1 / 15$ & 3 & 75.6 & $24 / 48$ & 3 \\
\hline 31 & $5 / 15$ & 3 & 100.8 & $5 / 15$ & 3 \\
\hline 31 & $24 / 48$ & 3 & 100.8 & $24 / 48$ & 4 \\
\hline 46.5 & $1 / 15$ & 3 & 126 & $5 / 15$ & 3 \\
\hline 46.5 & $5 / 15$ & 4 & 126 & $24 / 48$ & 3 \\
\hline 46.5 & $24 / 48$ & 4 & 151 & $5 / 15$ & 4 \\
\hline 62 & $1 / 15$ & 2 & 151 & $24 / 48$ & 4 \\
\hline 62 & $5 / 15$ & 3 & & & \\
\hline 62 & $24 / 48$ & 2 & \multicolumn{3}{|c|}{$\phi=0^{\circ}, T=23^{\circ} \mathrm{C}$} \\
\hline 77.5 & $1 / 15$ & 1 & 168 & $5 / 15$ & 4 \\
\hline 77.5 & $5 / 15$ & 3 & 350 & $5 / 15$ & 2 \\
\hline 77.5 & $24 / 48$ & 2 & \multicolumn{3}{|c|}{$\phi=0^{\circ}, T=7^{\circ} \mathrm{C}$} \\
\hline 93 & $1 / 15$ & 2 & 226 & $5 / 15$ & 1 \\
\hline 93 & $5 / 15$ & 6 & \multicolumn{3}{|c|}{$\phi=0^{\circ}, T=120^{\circ} \mathrm{C}$} \\
\hline 93 & $24 / 48$ & $\underline{2}$ & 395 & $5 / 15$ & 1 \\
\hline
\end{tabular}




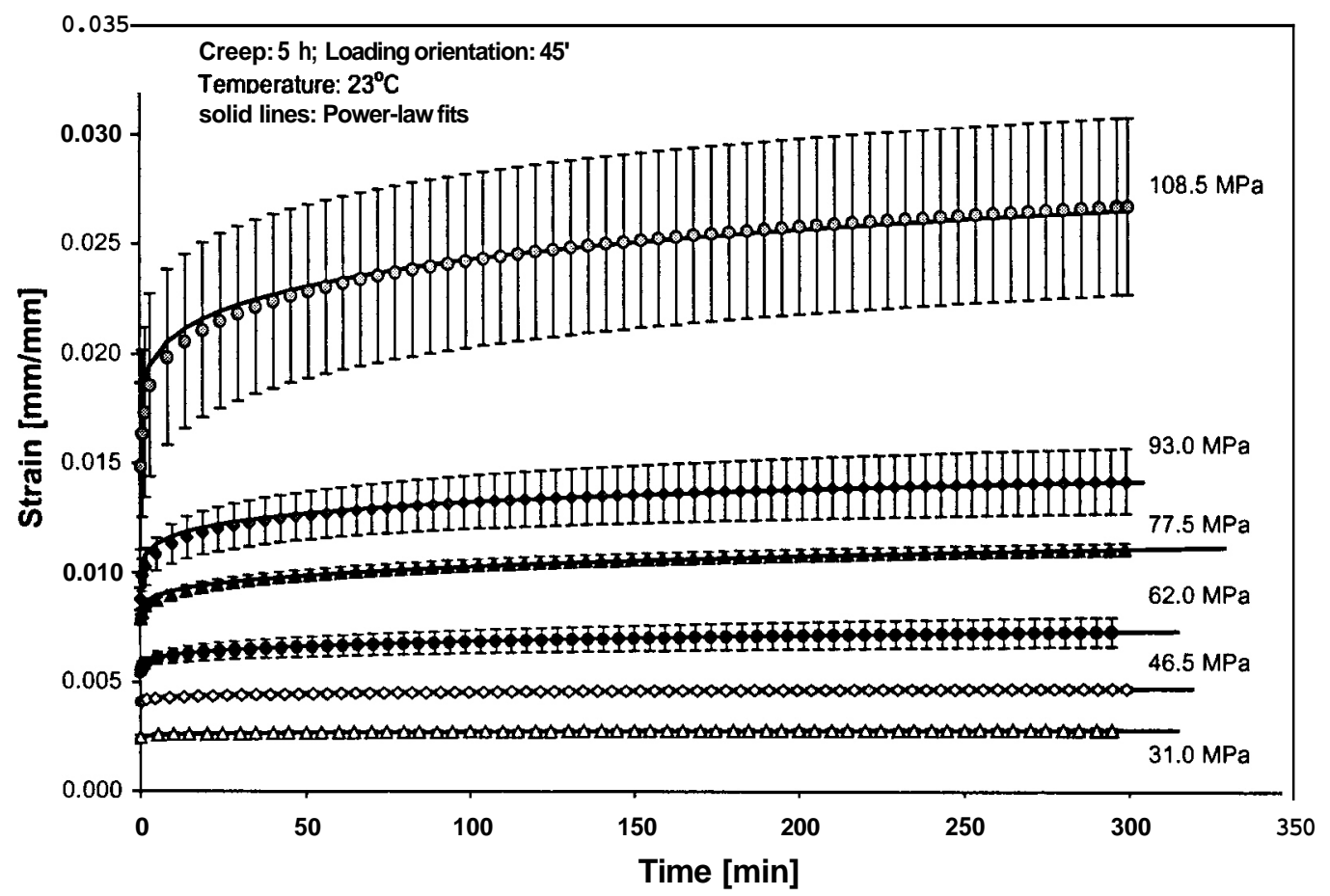

Fig. 25. Average values and standard deviations for 5-h creep data of $45^{\circ}$ coupons at $23^{\circ} \mathrm{C}$ and their power-law fits for various stress levels.

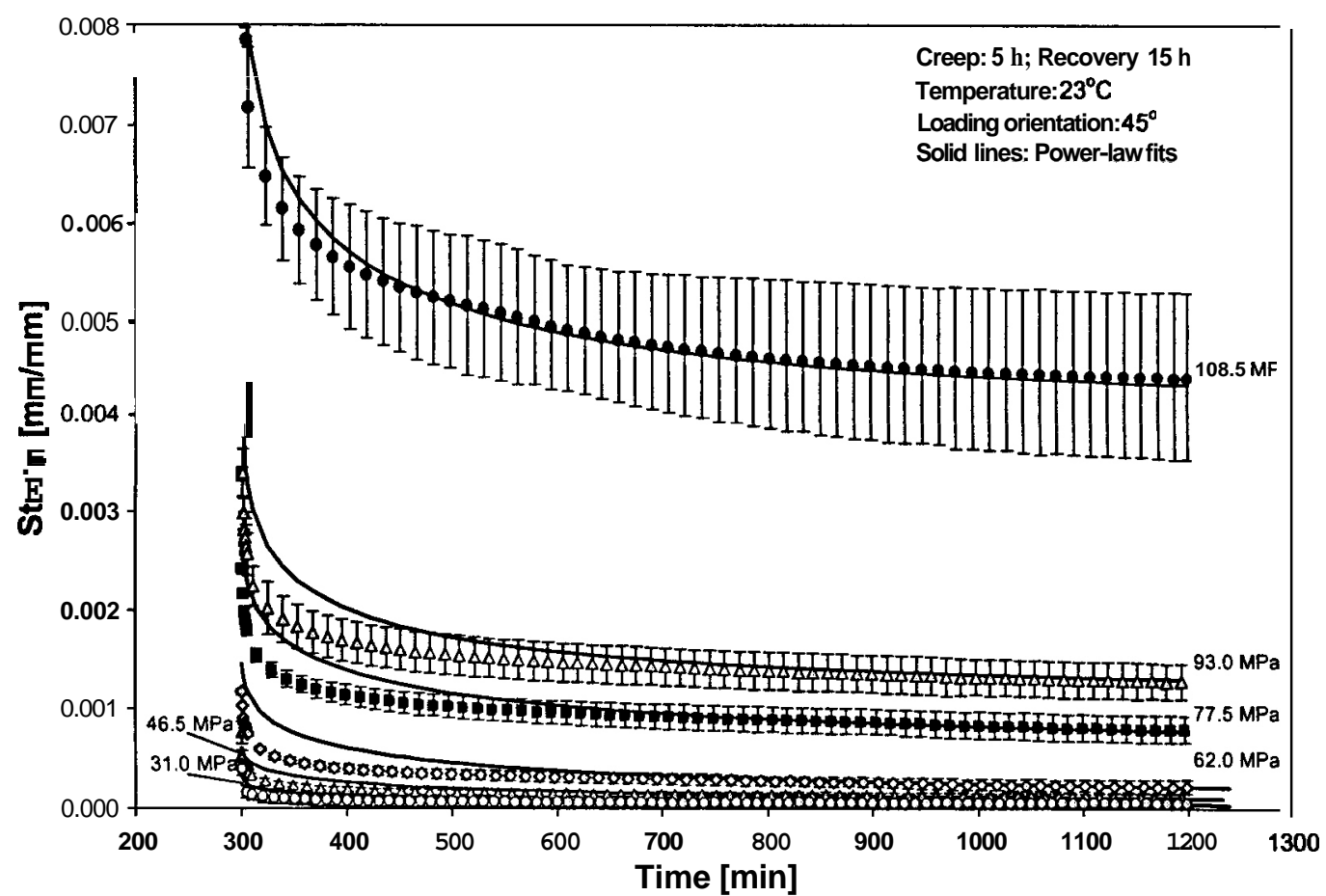

Fig. 26. Average values and standard deviations during 15-h recovery, following 5-h creep, and their power-law predictions under various stress levels for $45^{\circ}$ coupons at $23^{\circ} \mathrm{C}$. 


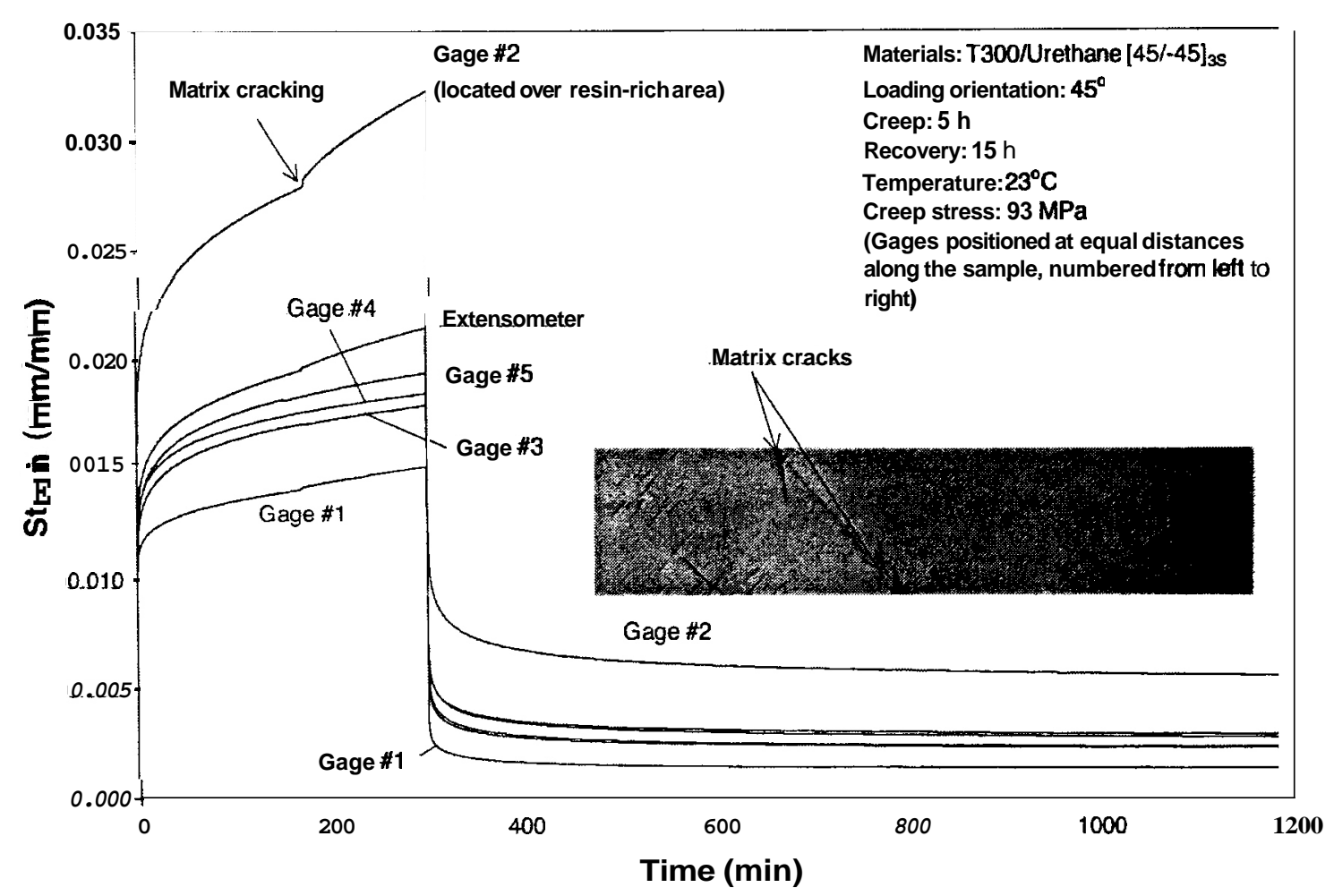

Fig. 27. Creep and recovery data collected on a multigaged $[ \pm 45]_{35}$ coupon exhibiting nonuniform deformation within a test specimen.

\subsubsection{Additional Tests}

Further tests included the X-ray photographic inspection of damage within test samples at increasing levels of applied stress, such as shown in Figs. 28 and 29, and the effect of coupon width on the stress-strain-to-failure response. As may be expected, in the latter case (which is not
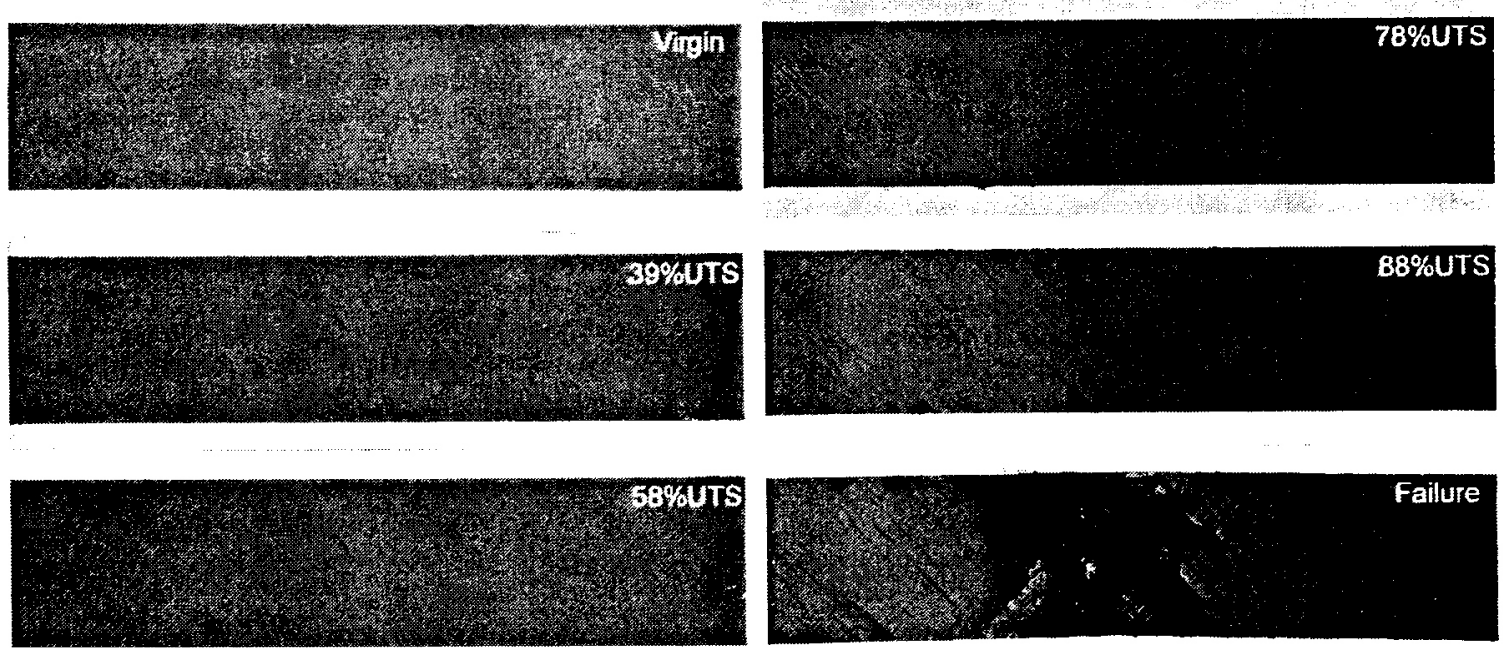

Fig. 28. $X$-ray images showing damage in $[ \pm 45]_{3 S}$ composite $\left(\phi=45^{\circ}\right)$ at various stress levels (in \%UTS, UTS = $155 \mathrm{MPa}$ ). 

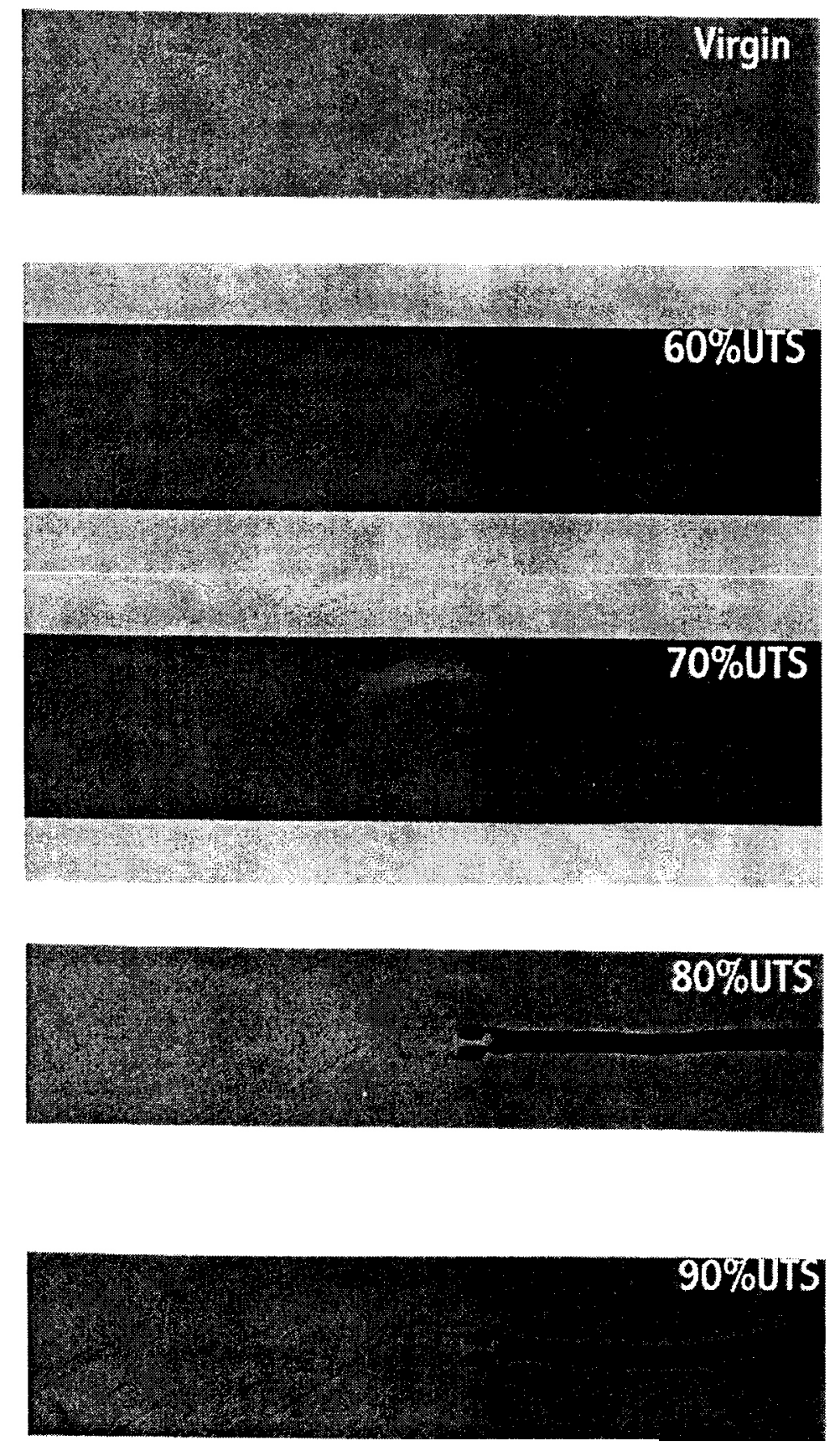

Fig. 29. X-ray images showing damage after creep loading in $[45 /-45]_{3 S}$ composite $\left(\phi=30^{\circ}\right)$ at various stress levels (in \%UTS). 
shown here) the foregoing response became stiffer with increasing coupon width because of the larger confinement provided by the wider tabs.

\subsection{DATA REDUCTION}

\subsubsection{Creep and Recovery}

The extensive data base for creep and recovery strains, listed in Table 3, could be expressed empirically as a sum, $\boldsymbol{E}=\varepsilon_{\mathrm{V}}+\varepsilon_{p}$, of a fully recoverable viscoelastic component $\boldsymbol{\varepsilon}_{\mathrm{Y}}$ and a permanent component $\varepsilon_{p}$. The viscoelastic component could be related in power-law form, namely

$$
E,=\left(D_{o}+D_{1} t^{n}\right) \sigma_{o}
$$

most generally, $s_{l}=f\left(\sigma_{o, t, T, \phi)}\right.$, where $t$ refers to time under load. Also, it may be anticipated that $D_{0}, D_{1}$, and perhaps also $n$, vary with $\sigma_{0}, T$, and $\phi$.

Typical results, confined to $\phi=45^{\circ}$, are exhibited in Figs. 30-33. These and similar results for other angles $\phi$, which are depicted in Figs. 34-36, yield the following empirical expression for the permanent strain $\varepsilon_{p}$ :

$$
\varepsilon_{p}=A\left(t / t_{1}\right)^{0.22} \exp \left[13.32\left(T / T_{R}\right)+24.2\left(\sigma / \sigma_{R}\right)\right] F(\theta),
$$

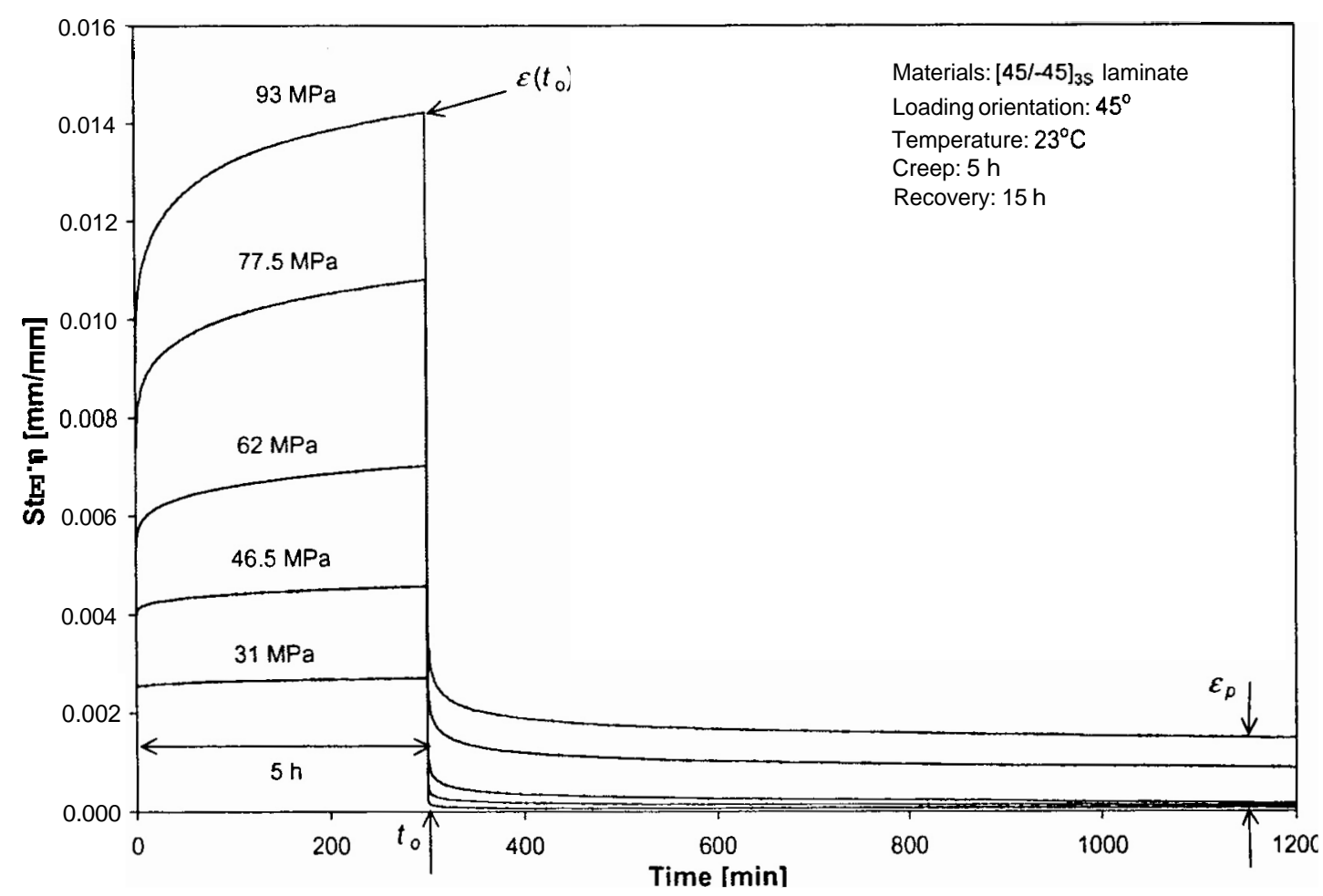

Fig. 30. Typical creep and recovery curves of $[ \pm 45]_{3 S}$ laminate coupons $\left(\phi=45^{\circ}\right)$ at $23^{\circ} \mathrm{C}$ under various stress levels. 


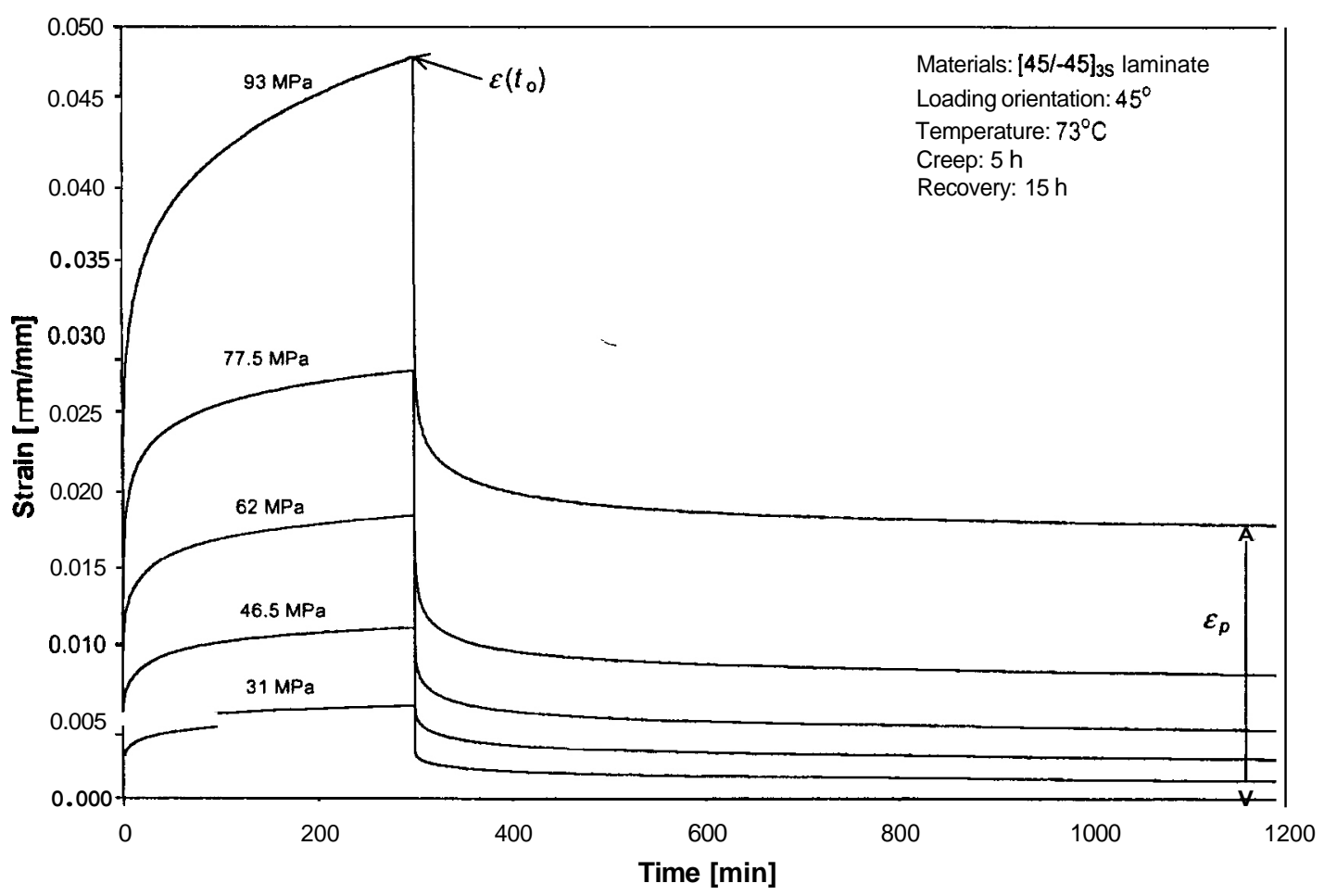

Fig. 31. Typical creep and recovery curves of $[ \pm 45]_{3 S}$ laminate coupons $\left(\phi=45^{\circ}\right)$ at $73^{\circ} \mathrm{C}$ under various stress levels.

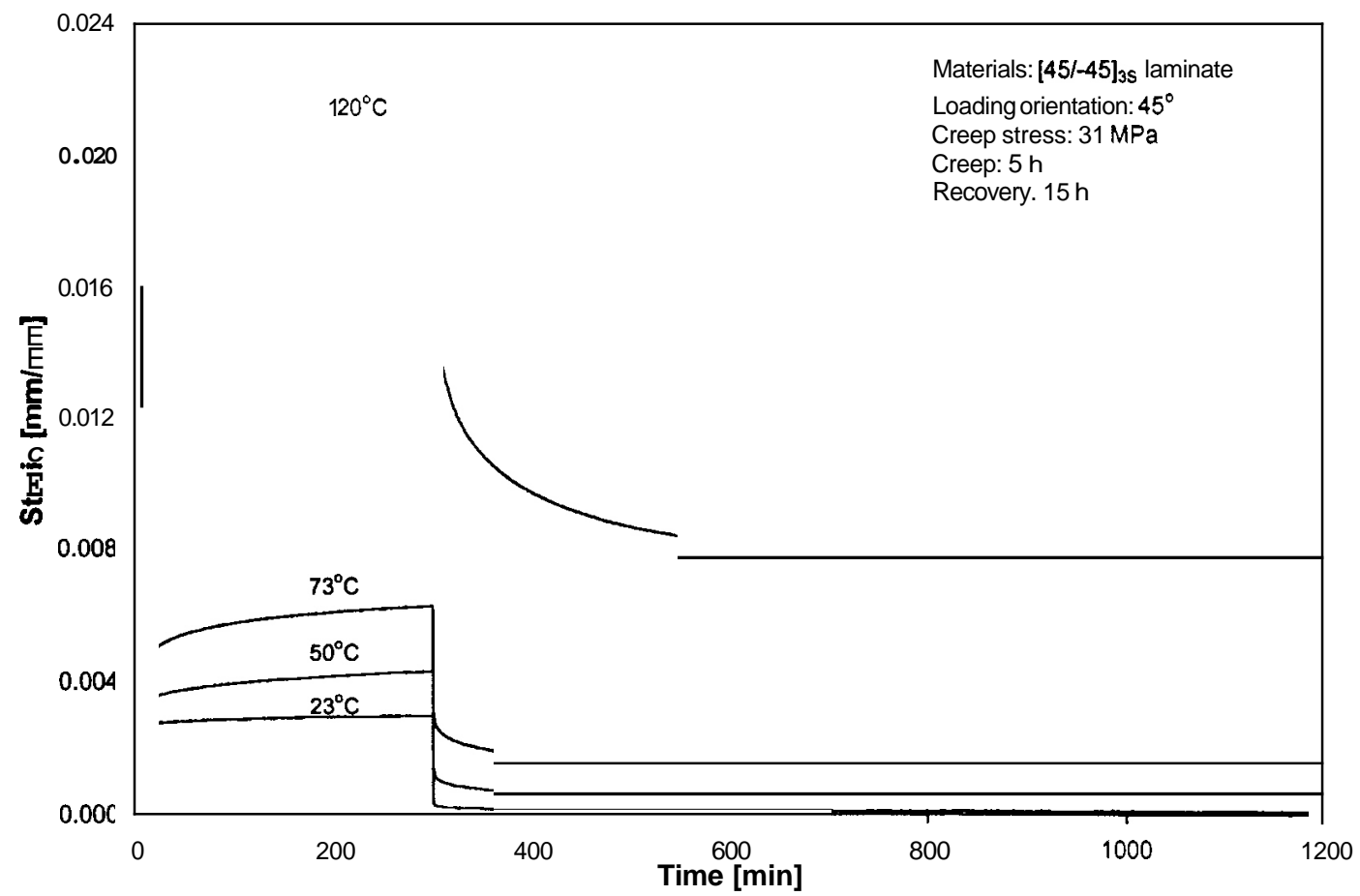

Fig. 32. Comparison of the typical creep-recovery curves under the same stress level $31 \mathrm{MPa}$ at different temperatures, showing the effect of temperature on the creep deformation. 


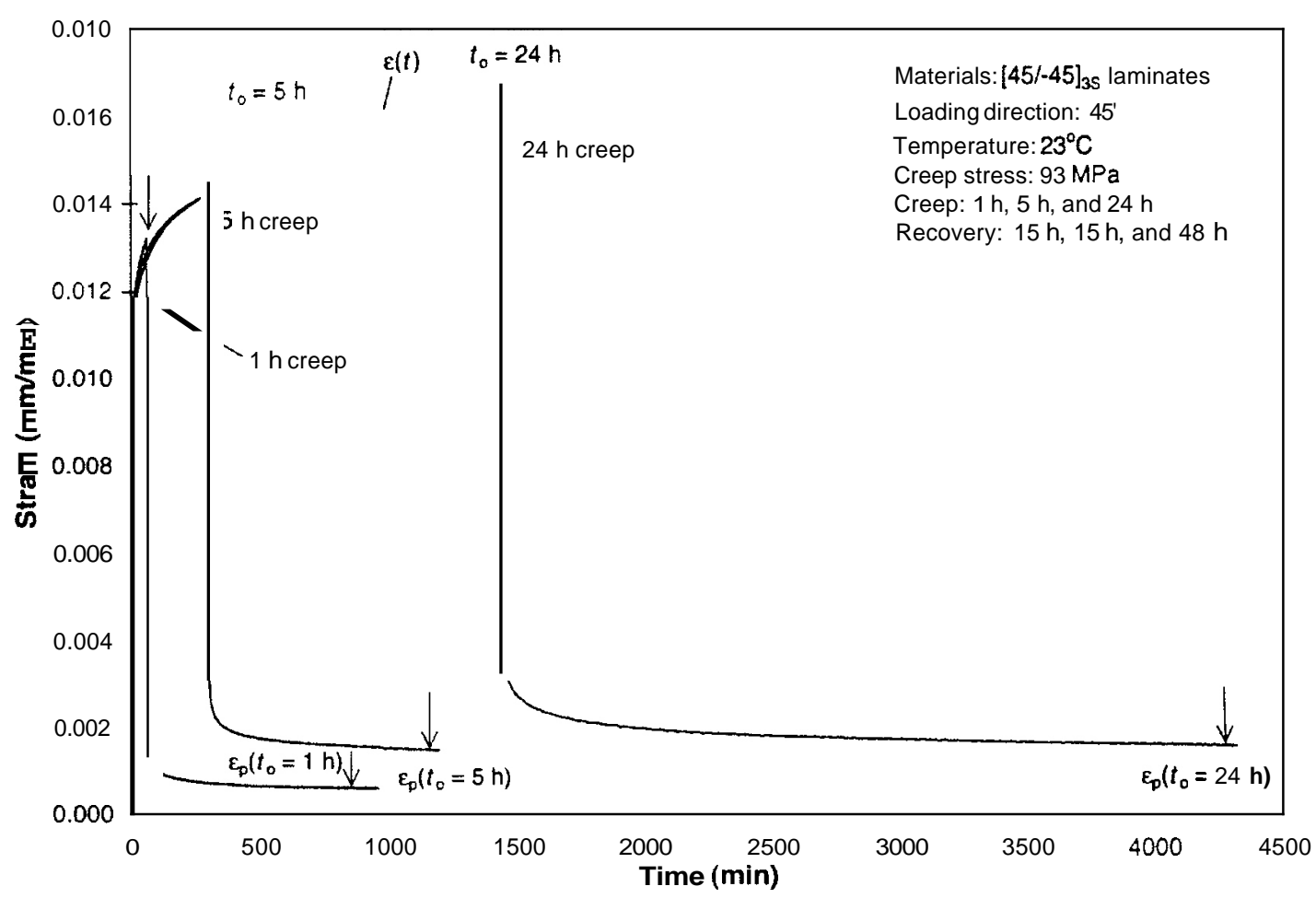

Fig. 33. Comparison of the creep and recovery curves under different creep durations, showing the influence of creep time on the permanent deformation.

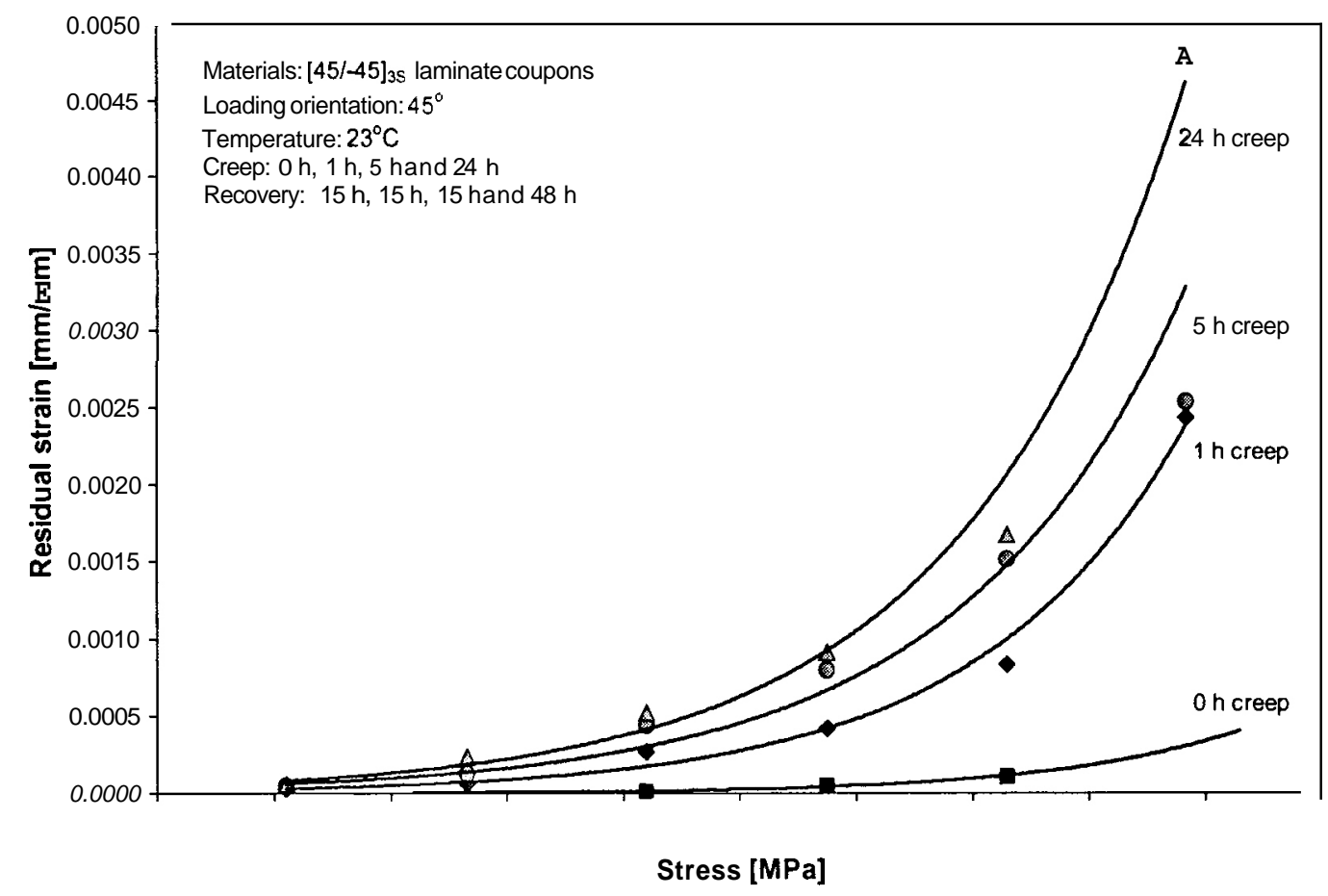

Fig. 34. Plot of permanent residual strain vs applied stress for $45^{\circ}$ coupons at $23^{\circ} \mathrm{C}$ with different creep durations, showing the influence of stress and creep time on the permanent deformation. 


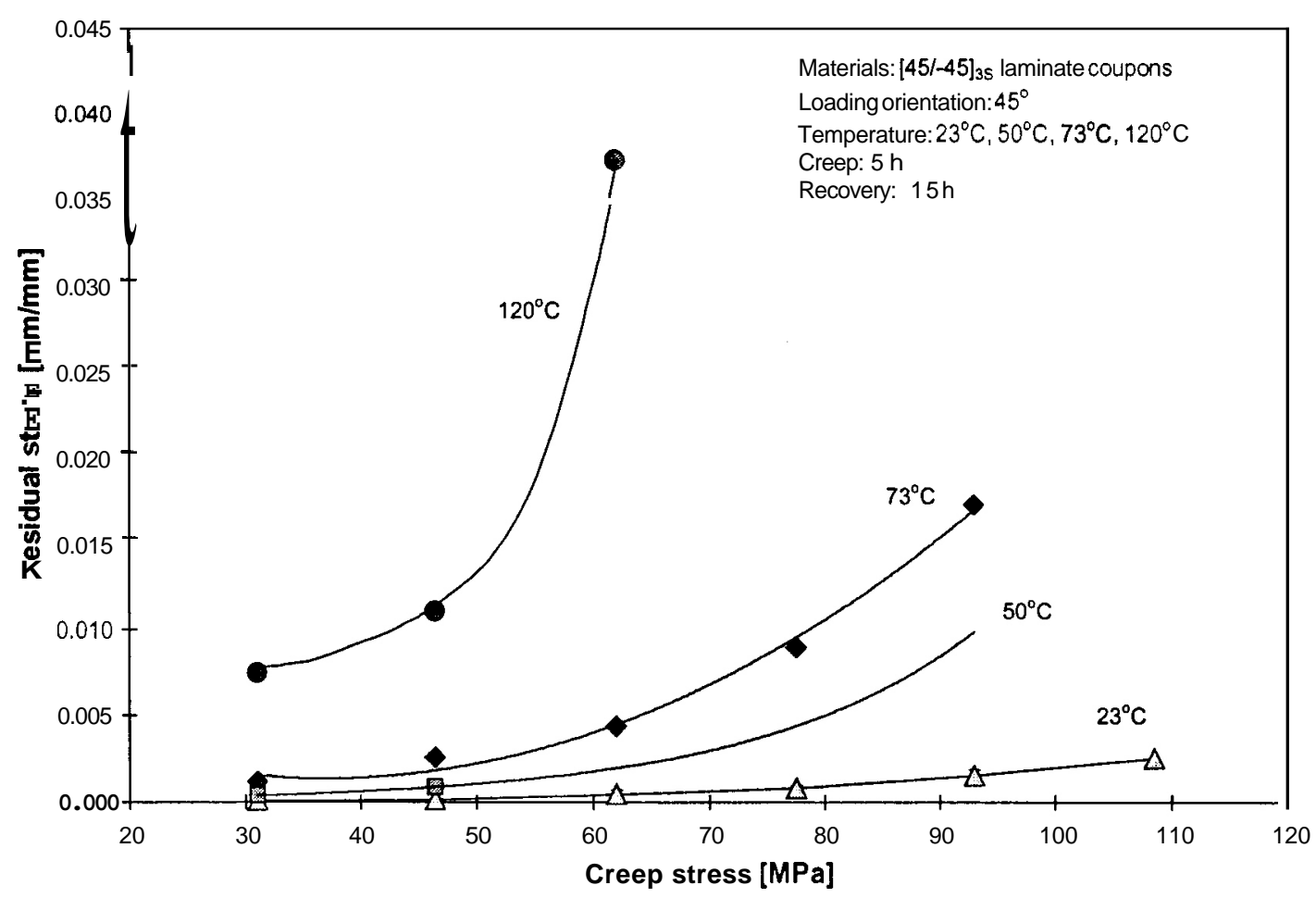

Fig. 35. Plot of permanent residual strain vs applied stress for $45^{\circ}$ coupons at different temperatures, showing the influence of stress and temperature on the permanent deformation.

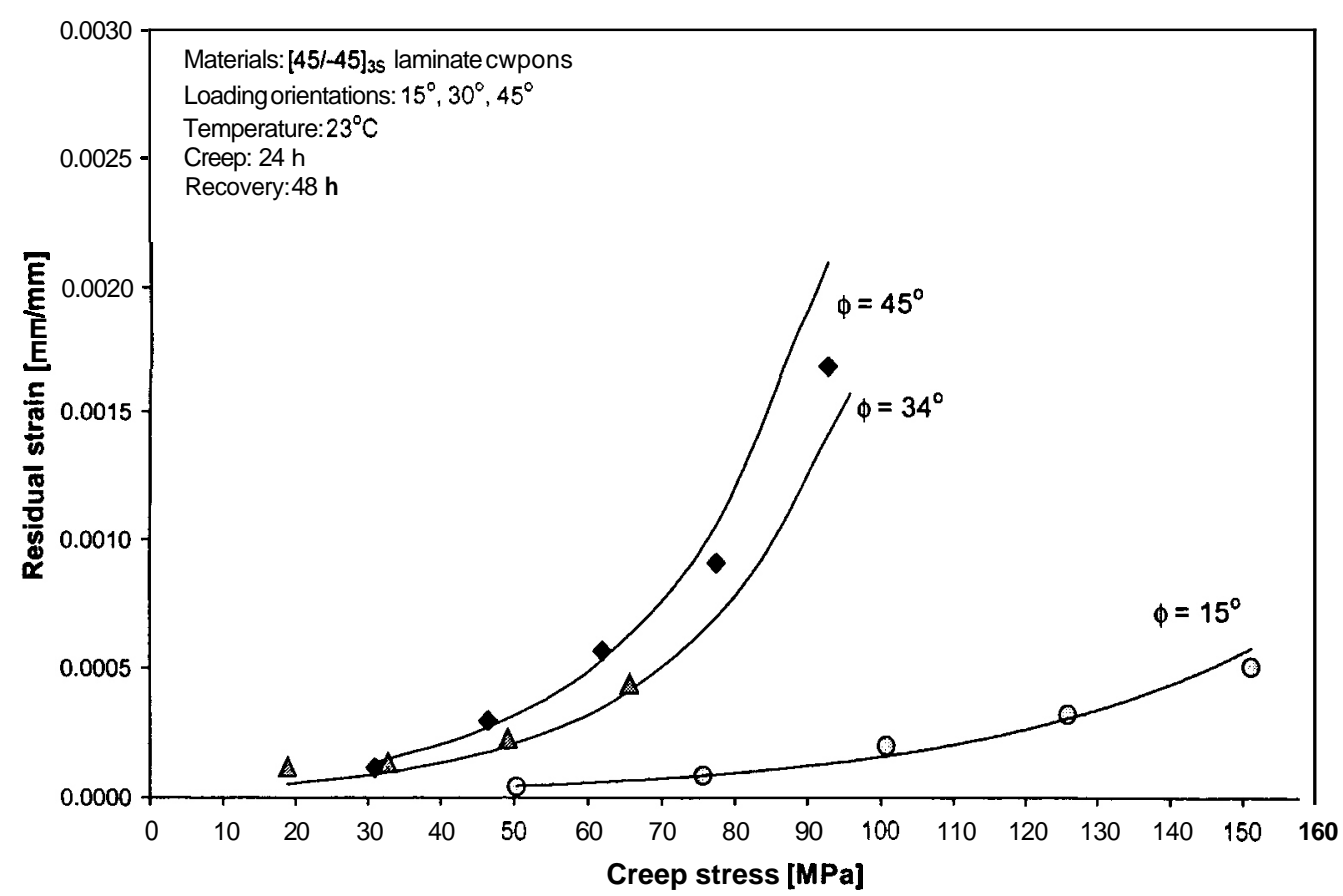

Fig. 36. Plot of permanent residual strain vs applied stress for test coupons with three orientation angles, showing the influence of loading orientation on the permanent deformation. 
where

$$
F(\theta)=1.1643 \cdot\left(1-\frac{|\theta|}{45}\right)+1.3257 \cdot\left[1-\left(\frac{\theta}{45}\right)^{2}\right]-1.49 \cdot\left(1-\left|\frac{\theta}{45}\right|^{3}\right)
$$

In the above, $8=45^{\circ}$ - @ (indegrees), where $\phi$ is the orientation angle. Also $t$ is time in minutes, $\sigma$ is the creep stress in megapascals, Tis temperature in degrees Kelvin, $A$ is a dimensionless constant $=-3 \times 10^{-11}, t_{1}=60 \mathrm{~min}, T_{R}=296^{\circ} \mathrm{K}$, and $\sigma_{R}=550 \mathrm{MPa}$, which is the tensile strength of the $0^{\circ}$ specimen at $23^{\circ} \mathrm{C}$. Accordingly, the recovery strain is given by

$$
E, .=D_{1}\left[t^{n}-\left(t-t_{o}\right)^{n}\right] \sigma_{o}+\varepsilon_{p}\left(t_{o}, T, \sigma_{o}, \phi\right), \quad t>t_{0} .
$$

Note that, by hypothesis, no further permanent deformation occurs after load removal at time $t_{\mathrm{o}}$.

The essential role of $\varepsilon_{p}$ in the fitting of creep and recovery data is exhibited in Fig. 37.

Restricting attention to 5 -h creep data for $\left[ \pm 45^{\circ}\right]_{3 S}$ coupons, followed by 24 -h recovery, it was possible to fit the stress and temperature dependence of the power-law parameters by the following expressions, upon using averaged values for the creep parameters:

$$
\mathcal{E}=\left\{D_{o}+D_{1}[t \cdot a(T)]^{n}\right\} \sigma_{o}+\varepsilon_{p},
$$

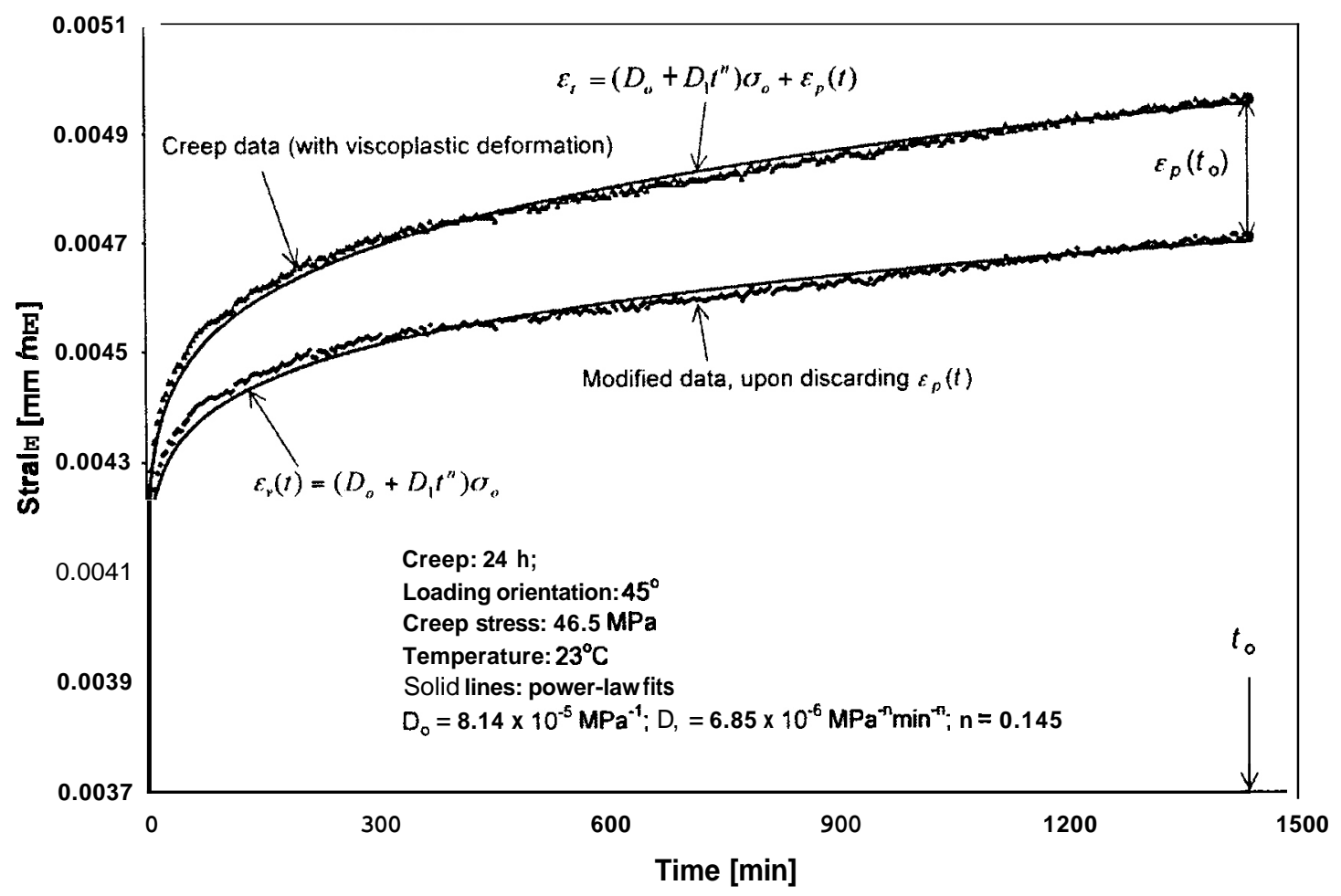

Fig. 37. Typical creep data (upper plot) and the modified viscoelastic portion (lower plot). Comparisons with power-law prediction are shown by the solid lines $\left(\phi=45^{\circ}, 24-\mathrm{h}\right.$ creep, $\left.23^{\circ} \mathrm{C}\right)$. 
where $n=0.25, D_{\mathrm{o}}=D_{\mathrm{o}}(T)=(7.02+0.05037) \times 10^{-5} \mathrm{MPa}^{-1}\left(\mathrm{Tin}{ }^{\circ} \mathrm{C}, 23^{\circ} \mathrm{C}<\mathrm{T}<73^{\circ} \mathrm{C}\right), D_{1}=$ $[1.61+0.05713(\sigma-31) \mathrm{H}(\sigma-31)] \times 10^{-6} \mathrm{MPa}^{-\mathrm{n}} \min ^{-\mathrm{n}}$ and the "shift factor," $a(T)=\exp [74(1-$ $\left.\left.T_{\mathrm{R}} / T\right)\right]\left(\right.$ Tin $\left.{ }^{\circ} \mathrm{K}\right)$. Here $\mathrm{H}(\cdot)$ denotes the unit step function.

An example for the utilization of Eq. (21) in fitting the elevated modified temperature data is shown in Fig. 38.

It must be emphasized that in view of the aforementioned substantial sample-to-sample variations, all the above parametric values, including those listed in Eq. (18), are scattered by about $10-15 \%$ around their averages.

\subsubsection{Long-Term Representation of Creep Data}

As noted previously, the values of the power-law parameters and their dependence on stress and temperature were based on 5-h creep data. It turned out that, to obtain optimal fits for either longer or shorter creep times, it was necessary to employ different values of $D_{0}, D_{1}$, and $n$. Specifically, $D_{1}$ had to be increased, while $n$ needed to be decreased, with creep time $t_{0}$ (see Tables A. 1 and A.2 in Appendix A). This observation pointed out the inadequacy of the threeparameter power law in serving as a model to predict the time-dependent response of the composite under consideration. For example, consider the data for 24-h creep time followed by an additional 48-h recovery period shown in Fig. 39. The optimal power law parameters, determined so as to fit the first 5-h creep data alone, yielded increasing overestimates of subsequent creep and recovery data, as shown in Fig. 39 for the overall data. Conversely, employment of the 24-h power-law parameters provided an improved match against data as shown in Fig. 40. It was thus attempted to fit the creep and recovery data by means of a Prony series, namely

$$
\varepsilon_{\mathrm{v}}=A_{o}+\sum_{i=1}^{n} A_{i}\left(1-e^{-t / \tau_{i}}\right)
$$

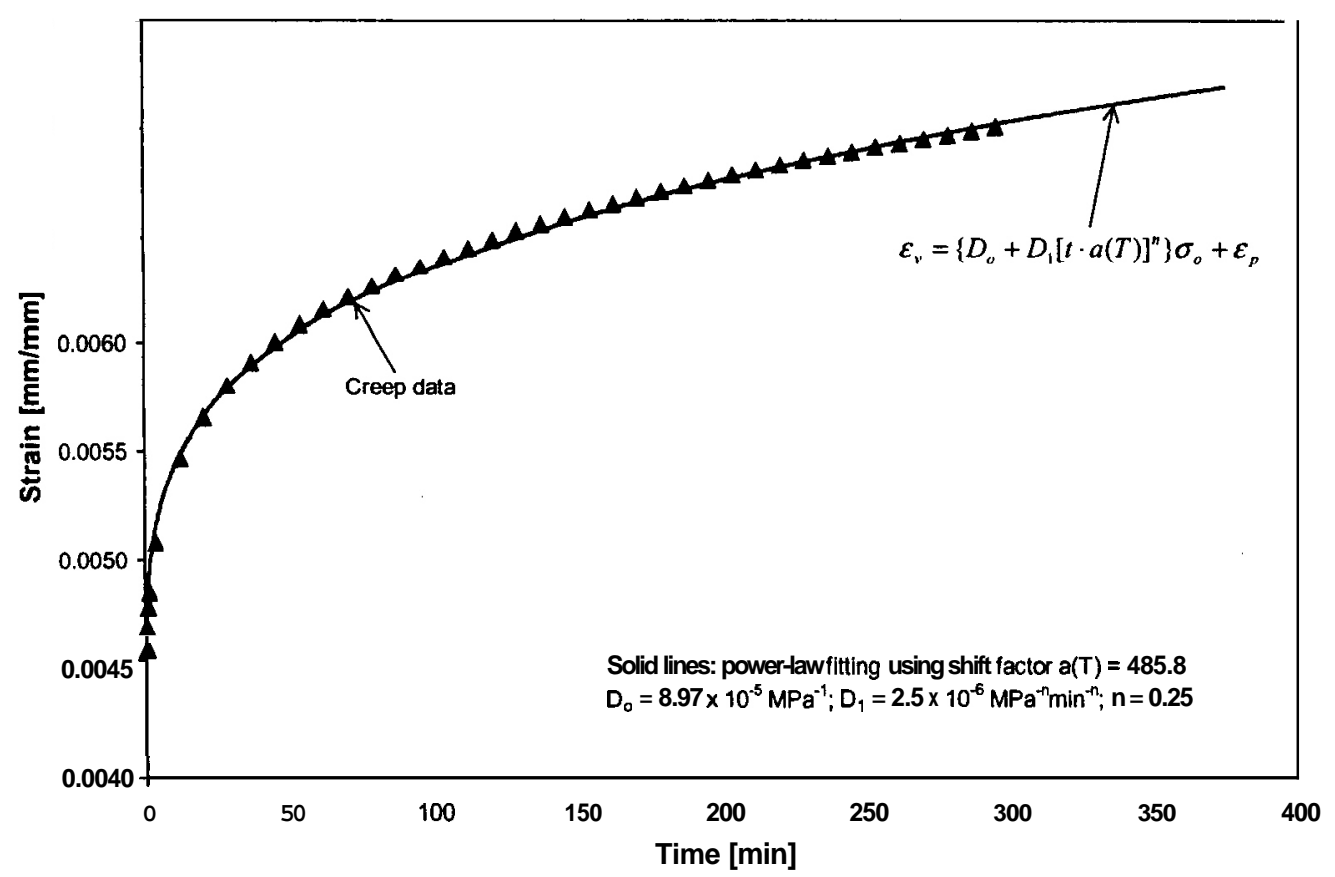

Fig. 38. Typical creep data and the power-law prediction with shift factor $\left(\phi=45^{\circ}, 5-h\right.$ creep, $50^{\circ} \mathrm{C}$ ). 


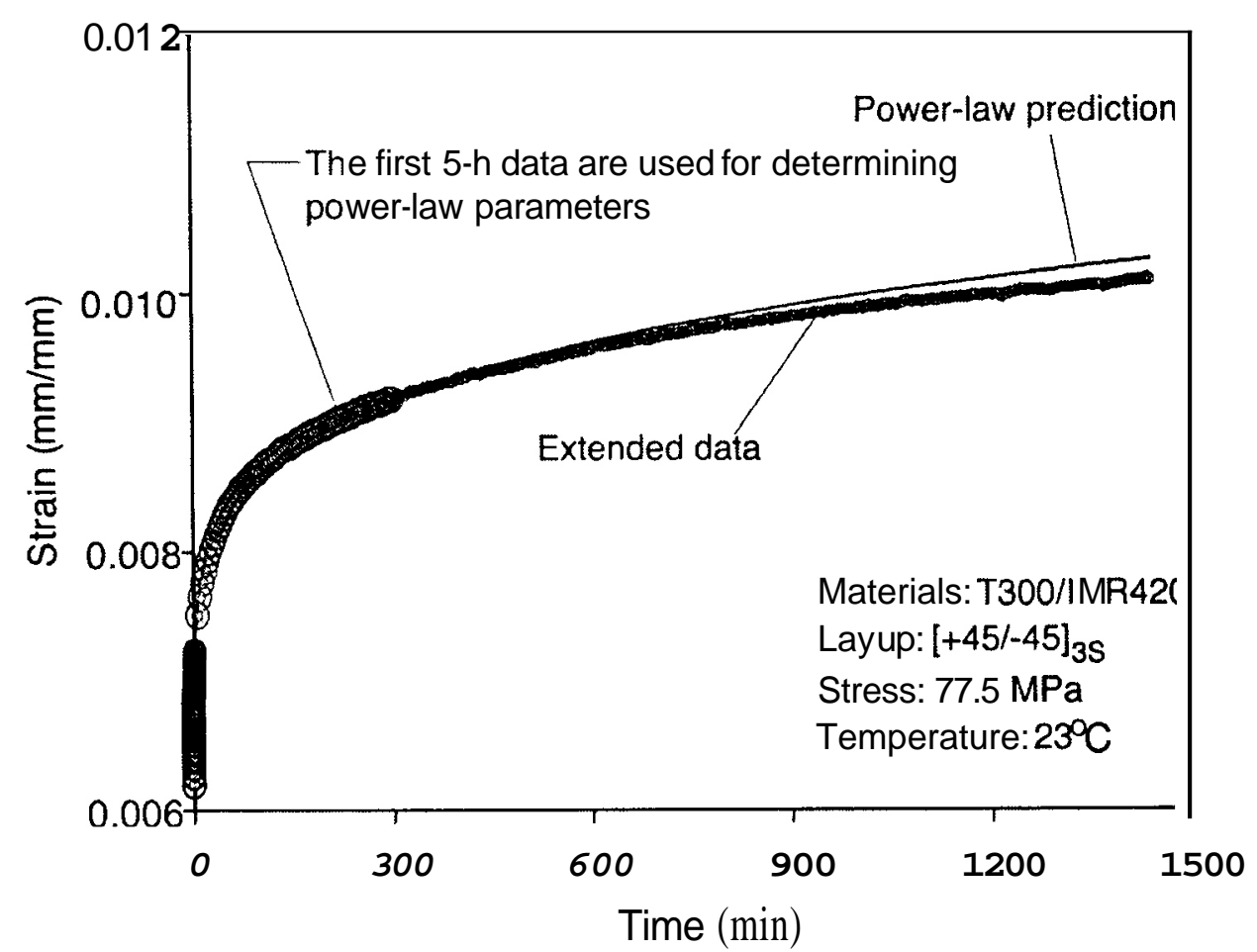

(a)

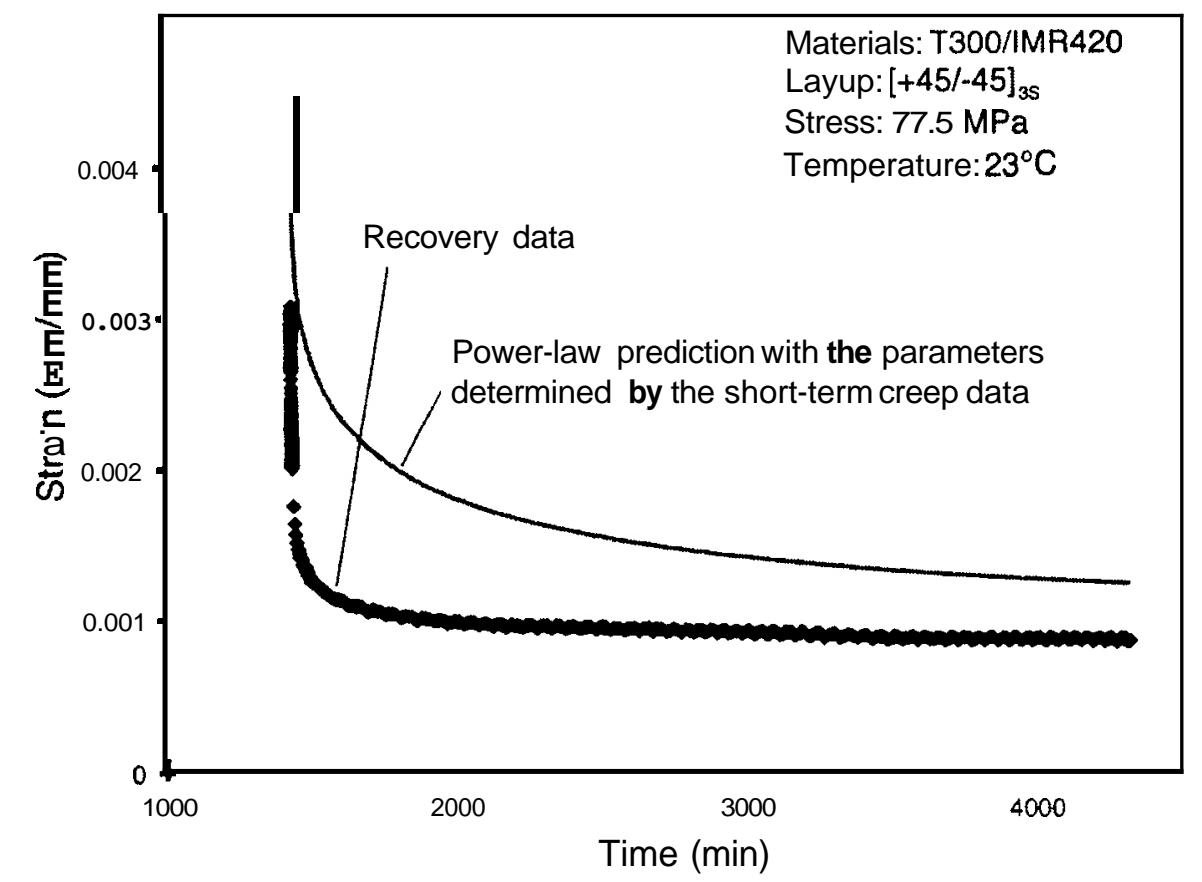

(b)

Fig. 39. Creep and recovery data and corresponding power-law fits: (a)creep, (b) recovery. 


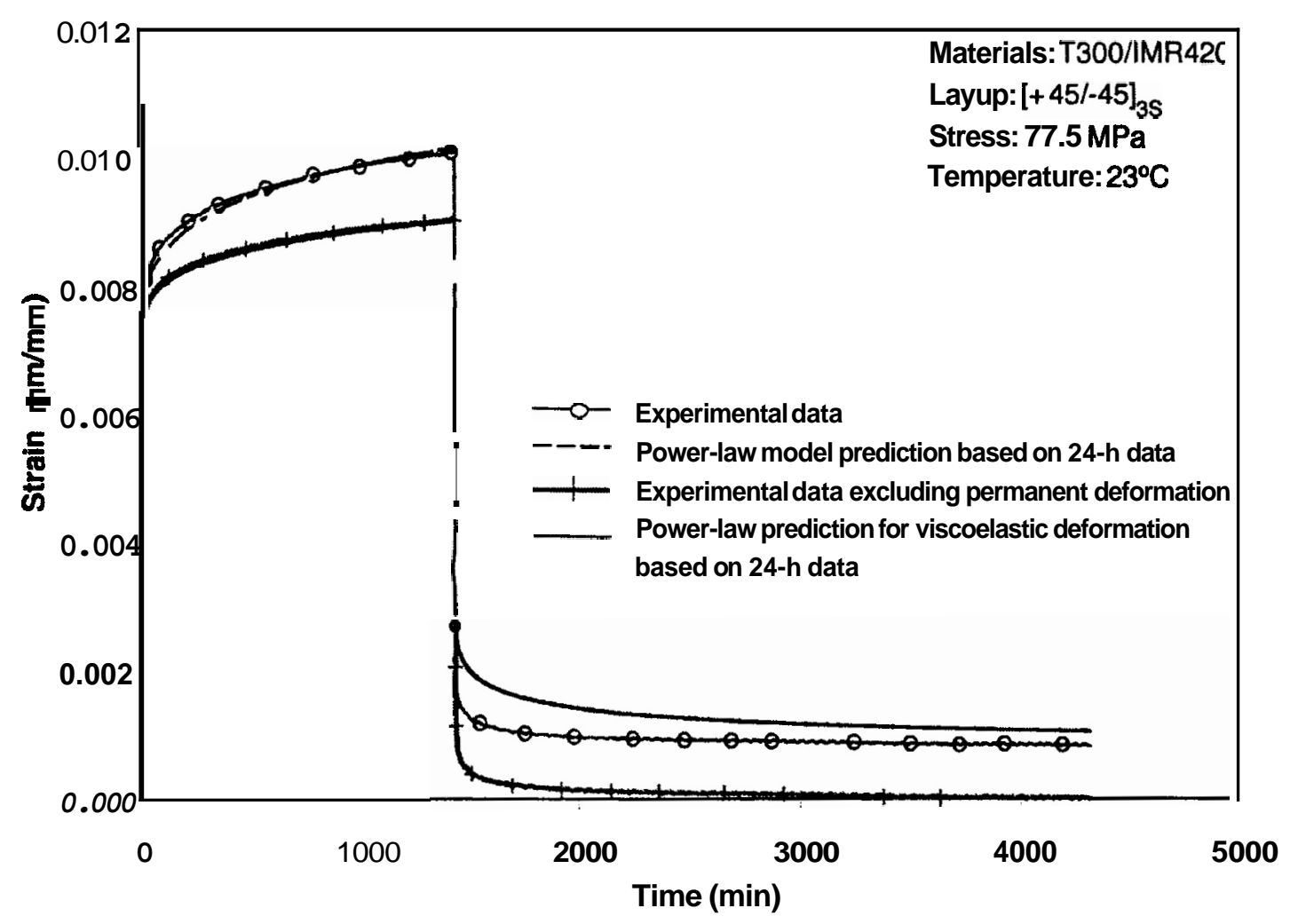

Fig. 40. Experimental creep and recovery data and modified power-law fits.

which contains a larger number of independent parameters. The above representation, which involves $n+1$ amplitudes $A_{i}(i=0, \ldots n)$ and $n$ retardation times $\tau_{i}(i=1, \ldots n)$, can be rewritten as

$$
\left\{\varepsilon_{v}\right\}=A_{o}+[D]_{M N}\{A\}_{N},
$$

where $D_{k L}=1-\exp \left(-\mathrm{t}_{k} / \tau_{L}\right)$.

Obviously, $A,=\varepsilon_{\mathrm{v}}(0)$. Thus, $M$ data points, corresponding to times $t=t_{k}$ are to be matched against $2 \mathrm{n}$ parameters $A_{i}$ and $\tau_{i}$. For attaining the best fit, it is necessary to have $M>2 \mathrm{n}$.

The "linear" parameters $A_{i}$ may be determined by correlating Eqs. (22) and (23) with experimental data, once the "nonlinear" parameters $\tau_{i}$ are known. This can be achieved by employment of the Gauss elimination procedure and optimal regression in the sense of leastsquare error. An overdetermined system $M>\mathbf{2 n}$ generates smoother data-fitting curves. Subsequently, the determination of the parameters $\tau_{i}$ was achieved by an iterative, nonlinear optimization scheme for the least-square error. A similar approach is outlined elsewhere.*

Starting with assumed initial values of the nonlinear parameters $\tau_{i}$, the data on the left side of Eq. (23) is utilized to solve for a concurrent set of values of $A_{i}$. With this set of $A_{i}$, the resulting error in the fit serves to guide the adjustment of $\tau_{i}$ for the next iteration. This procedure is repeated utilizing nonlinear least-square methods, such as the steepest descent technique, until convergence is achieved to within a prescribed tolerance.* $\mathbf{A}$ flow chart of the optimization scheme is shown in Appendix B, with the corresponding least-square errors listed in Table 4.

*This tolerance is related to observed, inevitable fluctuations in the recorded data. 
Table 4. Least-square error in correspondence to number of exponential parameters

\begin{tabular}{ccccccc}
\hline $\boldsymbol{i}$ & $\mathbf{3}$ & $\mathbf{4}$ & $\mathbf{5}$ & $\mathbf{6}$ & $\mathbf{7}$ & $\mathbf{8}$ \\
\hline$\Delta\left(\times 10^{-6} \mathrm{~mm} / \mathrm{mm}\right)$ & 0.9210 & 0.4110 & 0.2437 & 0.3450 & 0.2215 & 0.2183 \\
\hline
\end{tabular}

Though not detailed here, data fits with $i \geq 4$ were indistinguishable from each other. Consequently, it was decided that $i=4$ presented the "best" choice. The corresponding Prony series parameters are listed in Table 5.

Obviously, the nine-parameter Prony series generated here provided a better fit with the creep data at hand. More significantly, this representation predicts the creep and recovery behavior rather accurately for durations that extend beyond the time ranges employed for fitting the creep data. This is shown in Fig. 41, where the permanent component of strain $\boldsymbol{E}_{\mathrm{p}}$ was deleted for clarity. This good agreement between data and model presents an improvement over the result shown in Fig. 39.

It is possible to employ the empirical Eq. (21) to incorporate the effects of stress and temperature within the Prony series in Eq. (22). Accordingly, $A_{0}(T)$ should vary like $D_{0}(T)$; all $A_{i}$ should have the same, common, dependence on $\sigma$ as $D_{1}(\sigma)$; and all $\tau_{i}$ are to be decreased by a common shift factor function $a(T)$.

Table 5. Prony series parameters of fit to the early 5-h creep data in Fig. 20(a) $(A,=0.0063 \mathrm{~mm} / \mathrm{mm})$

\begin{tabular}{ccc}
\hline $\boldsymbol{I}$ & $\boldsymbol{A}_{\boldsymbol{i}}$ & \multicolumn{1}{c}{$\boldsymbol{\tau}_{\boldsymbol{i}}$} \\
\hline 1 & 0.0004 & 0.0021 \\
2 & 0.0008 & 1.0956 \\
3 & 0.0007 & 47.3746 \\
4 & 0.0011 & 351.7997 \\
\hline
\end{tabular}




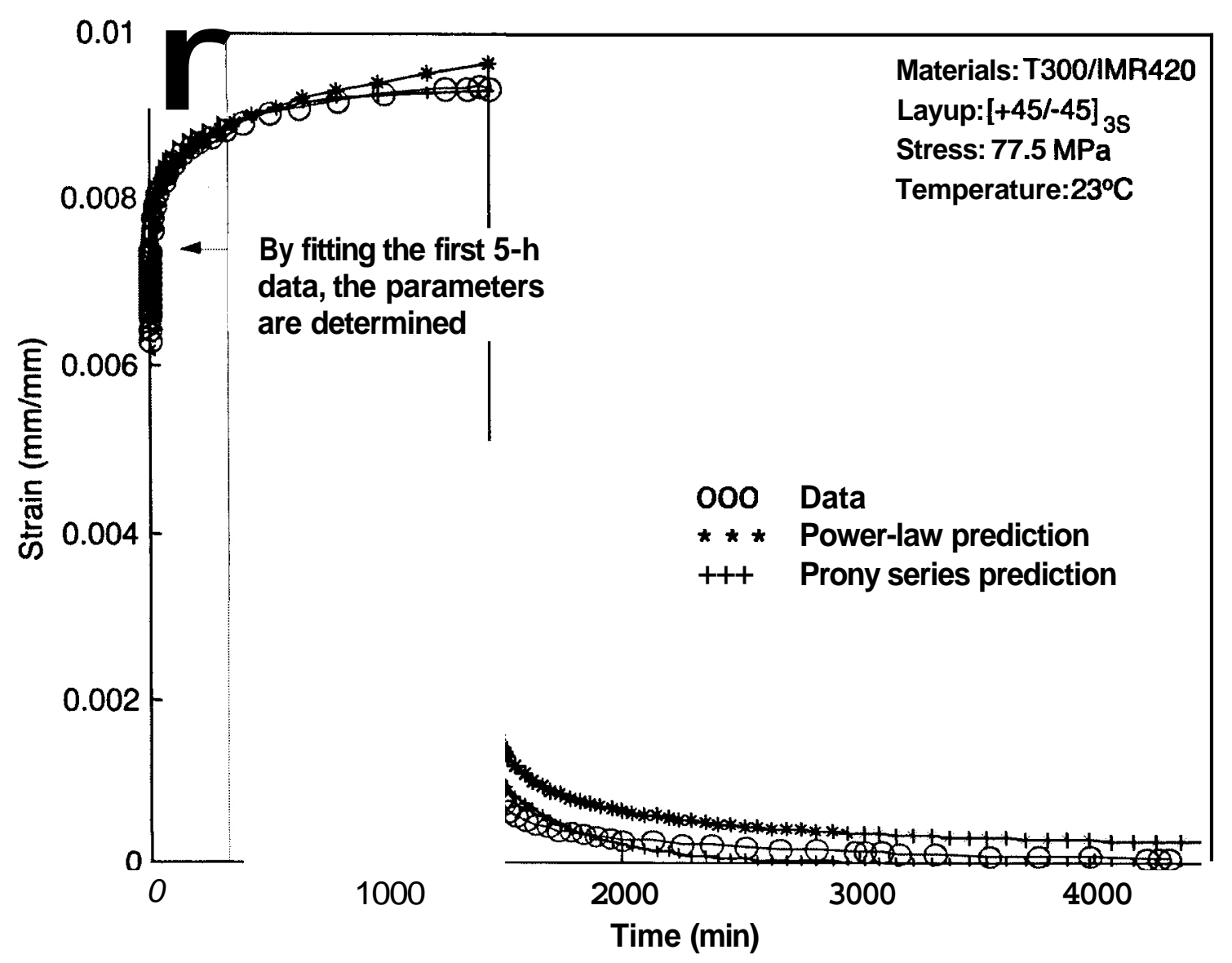

Fig. 41. Comparison of the predictions (Prony series and power-law models) to experimental creep and recovery data. Permanent deformation is excluded. 
D

$\boldsymbol{0}$

D

-

$\mathbf{v}$

$\mathbf{b}$

$\mathbf{D}$

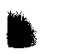

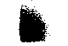

$\mathbf{D}$

$\Delta$

$\mathbf{D}$

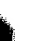

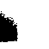




\section{PREDICTIONS FOR CROSSPLY BEHAVIOR}

\subsection{EFFECT OF LOAD ORIENTATIONANGLE ON CREEP}

Inversion of Eq. (8), for $\phi= \pm 45^{\circ}$, gives

$$
\left.\varepsilon_{x}=+\frac{4}{Q_{11}+Q_{22}+2 Q_{12}}+\frac{-1}{\hat{Q}_{66}}\right) \sigma_{x} .
$$

In Eq. (24), only $Q_{22}$ and $Q_{66}$ incorporate the properties of the matrix phase to a significant degree and are thereby time dependent. However, as noted earlier, for balanced crossply layups $Q_{22}$ always appears in combination with $Q_{11}$, in the form of $Q_{11}+Q_{22}$. Furthermore, as shown in Sect. 3.6, $Q_{11}$ exceeds $Q_{22}$ by 2 orders of magnitude. Thus, it is possible to neglect the timedependent variation of $Q_{22}$ and attribute all creep to the temporal dependence of $Q_{66}$. Denote

$$
Q_{66}=Q_{66}(t)=Q_{66}(0)+\Delta Q_{66}(t) .
$$

Comparison of Eqs. (24) and (25) with the power-law expression (17) yields

$$
D_{o}=\frac{1}{4}\left(\frac{4}{Q_{11}+Q_{22}+2 Q_{12}}+\frac{1}{Q_{66}(0)}\right),
$$

where all the foregoing values of $Q_{i j}$, including $Q_{66}(0)$, are given in Sect. 3.5.2. Consequently,

$$
\frac{1}{Q_{66}(t)}=\frac{1}{Q_{66}(0)}+4 D_{1} t^{n}=\frac{1}{Q_{66}(0)}+\left(\frac{4}{Q_{11}+Q_{22}+2 Q_{12}}+\frac{1}{Q_{66}(0)}\right) \frac{D_{1} t^{n}}{D_{o}} .
$$

Substitution of Eq. (27) into Eq. (9) indicated that $v_{x y}^{45}$ decreases but slightly with time. Though not shown here, this result was confirmed experimentally.

With $Q_{66}(t)$ thus determined, the longitudinal creep strain $\varepsilon_{x}(t)$ of any $[\phi /(\phi+\pi / 2)]_{3 S}$ crossply layup orientated by an angle @ about the direction of the uniaxially applied step stress $\sigma_{\mathrm{o}}$, can be calculated using the inverses of Eq. (6).Computations were performed within the linear range of viscoelastic behavior and in the absence of permanent deformation.

Direct substitution of numerical values for $\phi=15^{\circ}$ and $34^{\circ}$ into Eqs. (5) and (6) resulted in the predictive curves for $\boldsymbol{d}(t)$ shown in Figs. $\mathbf{4 2}$ and $\mathbf{4 3}$. These predictions, which employed the average power-law parameters, $D_{0}=8.13 \times 10^{-5} \mathrm{MPa}^{-1}, D_{1}=2.49 \times 10^{-6} \mathrm{MPa}^{-n} \mathrm{~min}^{-n}$, and $n=$ $\mathbf{0 . 2 3 8}$, were compared against several replicate data sets.

Note the very good agreement between predicted and recorded creep behavior exhibited in those figures. Inverting Eq. (10) one obtains

$$
\varepsilon_{x}=\frac{2\left(Q_{11}+Q_{22}\right)}{\left(Q_{11}+Q_{22}\right)^{2}-4 Q_{12}^{2}} \sigma_{x},
$$

whereby all creep, if any, is due to the time dependence of $Q_{22}$. In view of Sect. 3.6, such dependence would cause $\varepsilon_{x}$ to increase by about $0.4 \%$ above its initial value over time. Indeed, the creep and recovery data shown in Fig. $\mathbf{4 4}$ demonstrate the presence of the indiscernible amount of creep at $0^{\circ}$ orientation even at the relatively high stress levels of 168 and $\mathbf{3 5 0} \mathrm{MPa}$. 


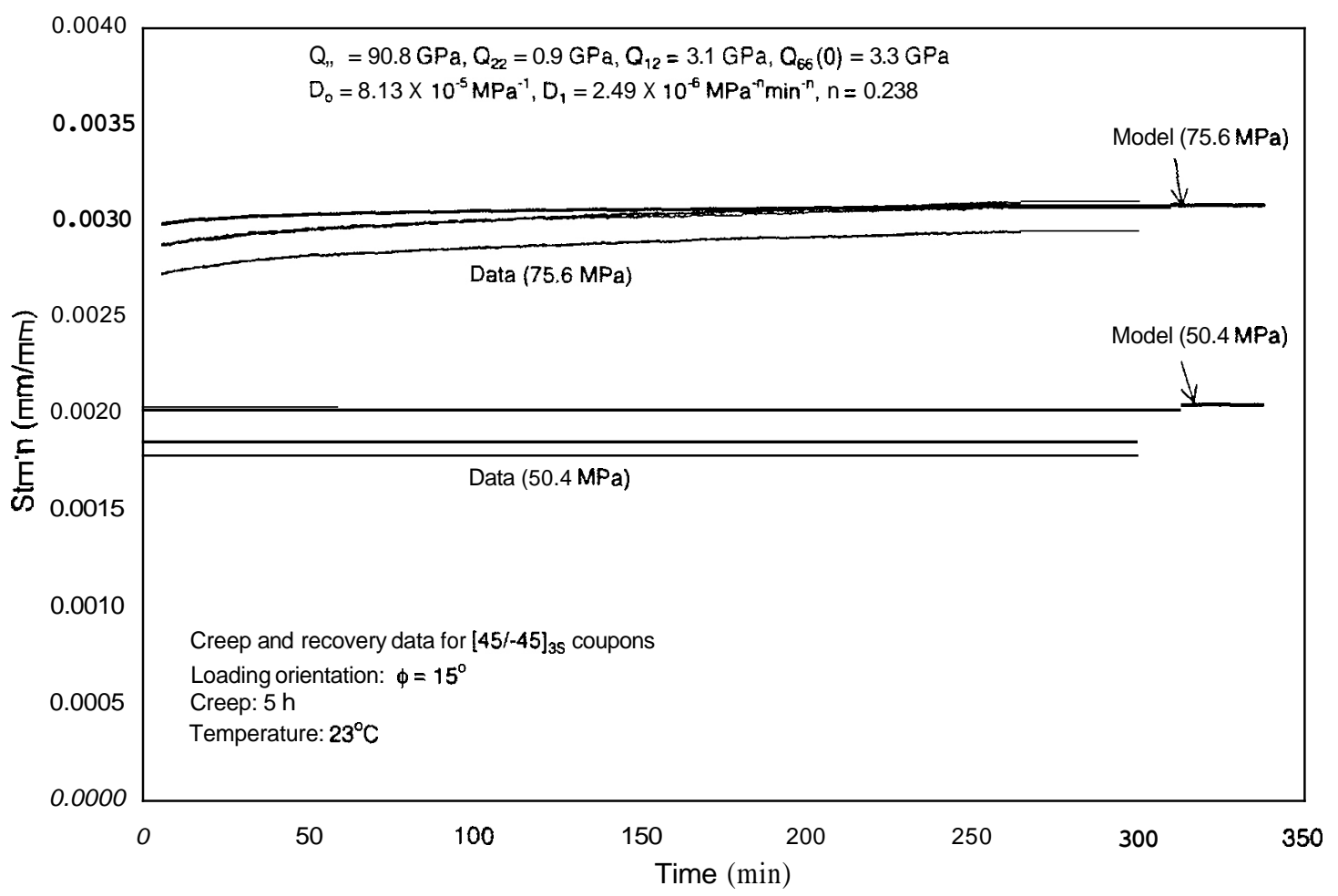

Fig. 42. Comparison of creep data from three replicate specimens with theoretical predictions for stress-strain response within the linear range $\left(\phi=15^{\circ}, 5-\mathrm{h} \mathrm{creep}, 23^{\circ} \mathrm{C}\right)$.

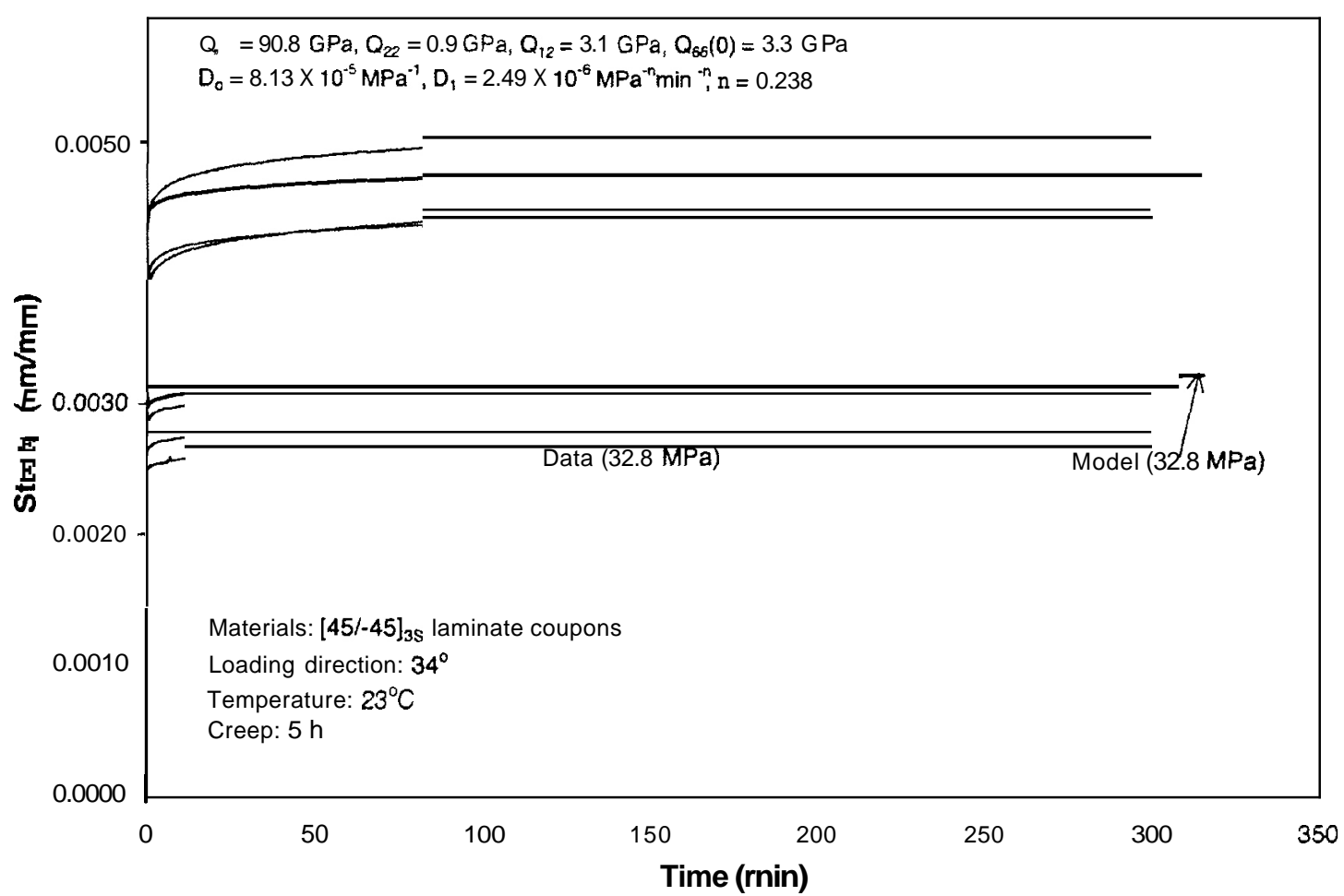

Fig. 43. Comparison of creep data from three replicate specimens with theoretical predictions for stress-strain response within the linear range $\left(\phi=34^{\circ}, 5-\mathrm{h}\right.$ creep, $\left.23^{\circ} \mathrm{C}\right)$. 


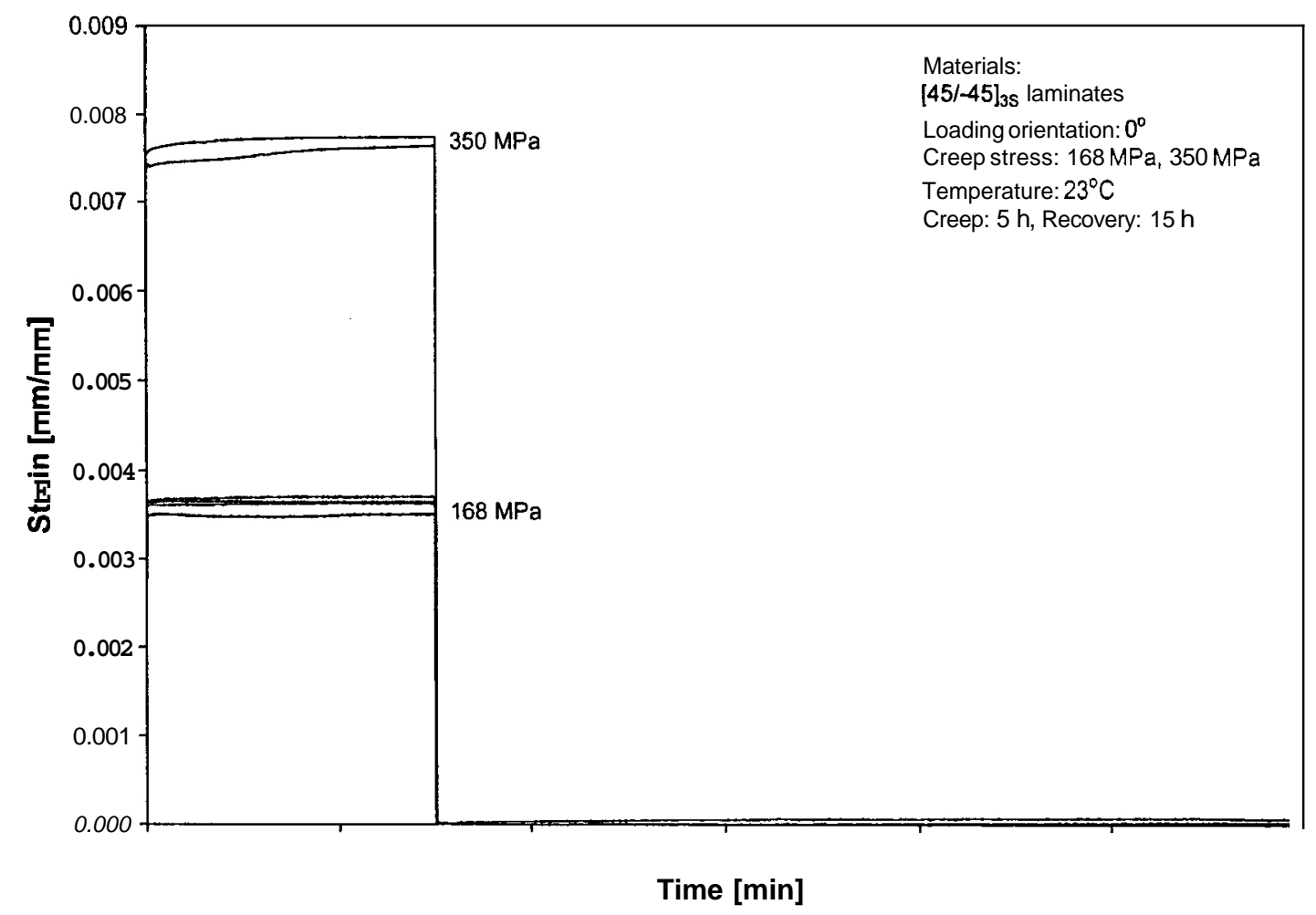

Fig. 44. Creep and recovery data of $0^{\circ}$ coupons under stress levels of $168 \mathrm{MPa}$ and $350 \mathrm{MPa}\left(\phi=0^{\circ}, 5\right.$-h creep, $15-\mathrm{h}$ recovery, $\left.2^{\circ} \mathrm{C}\right)$.

\subsection{CREEP UNDER TWO-STEP STRESS INPUT}

In view of the wide scatter in the response of the composite material at hand, which increases with stress level as shown in Figs. $\mathbf{2 5}$ and 26, it is extremely difficult to predict its behavior under complex inputs in the elevated range of stresses. However, for a limited range of nonlinearity, namely, in the absence of internal damage and permanent deformation, such predictions may still be feasible. For this purpose, consider the case of a two-step stress history applied to a $\left[ \pm 45^{\circ}\right]_{3 S}$ sample:

$$
\begin{aligned}
\sigma & =\sigma_{o}\left[H(t)-H\left(t-t_{o}\right)\right]+\sigma_{1}\left[H\left(t-t_{o}\right)-H\left(t-t_{1}\right)\right] \\
& =\sigma_{o}\left[H(t)-H\left(t-t_{1}\right)\right]+\left(\sigma_{1}-\sigma_{o}\right)\left[H\left(t-t_{o}\right)-H\left(t-t_{1}\right)\right],
\end{aligned}
$$

where, as before, $\mathrm{H}(\cdot)$ denotes the unit step function.

The following specific values were employed in the test program: $\sigma_{0}=31 \mathrm{MPa}, \sigma_{1}=$ 46.5 $\mathrm{MPa}, t_{0}=300 \mathrm{~min}$, and $t_{1}=600 \mathrm{~min}$. The above stress history is shown by the dashed line in Fig. 45.

Consider the power-law representation given in Eq. (17). As can be noted from Tables A.1 and A.2, to attain "best" data fits it is necessary to vary the creep parameters $D_{0}, D_{1}$, and $n$ with the stress level $\sigma$. Specifically, for $\sigma=31 \mathrm{MPa}$, one may employ $D_{\mathrm{o}}=7.85 \times 10^{-5} \mathrm{MPa}^{-1}, D_{1}=$ $2.49 \times 10^{-6} \mathrm{MPa}^{-n} \min ^{-n}$, and $\boldsymbol{n}=\mathbf{0 . 2 3 8}$; for $\sigma=46.5 \mathrm{MPa}$, the suitable parameters are $D_{\mathrm{o}}=8 \times$ 


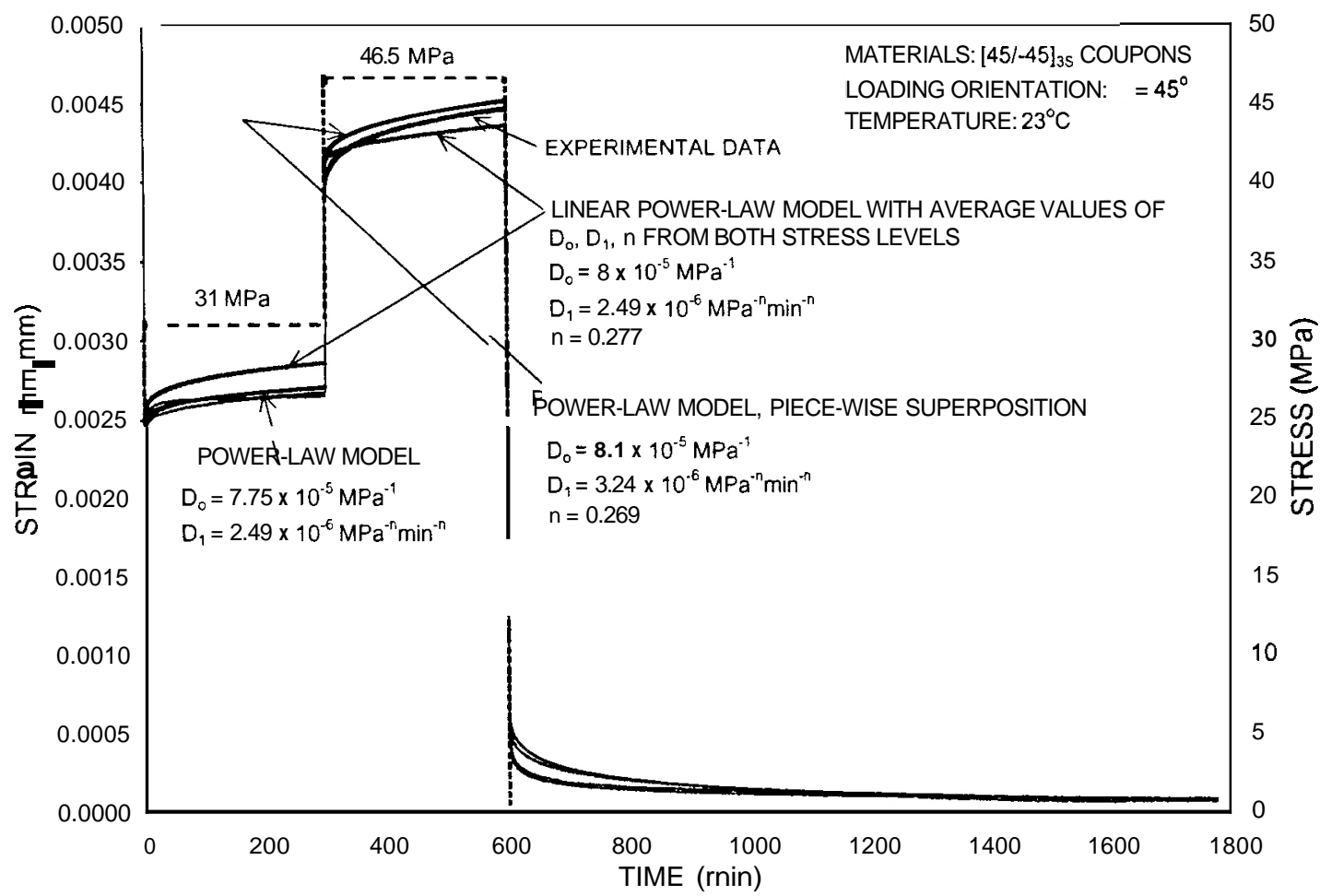

Fig. 45. Experimental data and model prediction under a two-step load history for $[ \pm 45]_{3 \mathrm{~S}}$ coupons at $23^{\circ} \mathrm{C}$.

$10^{-5} \mathrm{MPa}^{-1}, D_{1}=3.24 \times 10^{-6} \mathrm{MPa}^{-\mathrm{n}} \min ^{-\mathrm{n}}$, and $n=0.269$. (The average numerical values of the above parameters are $7.93 \times 10^{-5}, 2.87 \times 10^{-6}$, and 0.253 , respectively.)

A good prediction for the creep and recovery under the above two-step stress history is obtained by superimposing the creep and recovery strains that are due to $\sigma t)=\sigma_{\mathrm{o}}[H(t)-H(t-$ $\left.t_{\mathrm{o}}\right)$ ] with values of $D_{\mathrm{o}}, D_{\mathrm{l}}$, and $n$ that correspond to $\sigma_{\mathrm{o}}=31 \mathrm{MPa}$ and the creep and recovery strains caused by $\sigma(t)=\sigma_{1}\left[H\left(t-t_{\mathrm{o}}\right)-H\left(t-t_{1}\right)\right]$ with values of $D_{\mathrm{o}}, D_{1}$, and $n$ associated with $\sigma_{1}=$ $46.5 \mathrm{MPa}$. This "piecewise superposition" that employs stress-varying creep parameters, ${ }^{9}$ provides a far better agreement with creep data than linear superposition employing average values of creep parameters $D_{0}, D_{1}$, and $n$. Results are shown in Fig. 45. 


\section{THE TIME-DEPENDENT AND NONLINEAR RESPONSE OF' QUASI-ISOTROPIC LAYUPS}

\subsection{MATERIALS AND TESTING PROGRAM}

The quasi-isotropic test coupons were cut at different angles, $\phi$, relative to the fiber direction in the top ply, as shown in Fig. 46.*

Tensile tests were again conducted using an 810 MTS Material Testing System with a loading rate of $1.016 \mathrm{~mm} / \mathrm{min}$ at four different temperatures $\left(23^{\circ} \mathrm{C}, 50^{\circ} \mathrm{C}, 73^{\circ} \mathrm{C}\right.$, and $\left.120^{\circ} \mathrm{C}\right)$. An axial extensometer and several strain gages were used for recording the strains in both the longitudinal and transverse directions of the test coupons. At least three replicate specimens were tested for each case.

Additional test coupons, with the same features as mentioned previously, were employed to conduct creep and recovery tests. The short-term creep and recovery tests were performed on the 810 MTS Material Testing System at various levels of fixed stresses under load control mode. One extensometer and several strain gages were attached to the surfaces of test coupons to record the deformation response during creep loading, followed by recovery on unloading. With one exception, all the foregoing tests involved $24 \mathrm{~h}$ of creep followed by $48 \mathrm{~h}$ of strain recovery. Tests were performed at three temperature levels $\left(23^{\circ} \mathrm{C}, 73^{\circ} \mathrm{C}\right.$, and $\left.120^{\circ} \mathrm{C}\right)$. Residual strain values at the end of the recovery period were considered to represent permanent deformation. The creep and recovery test program is listed in Table 6.

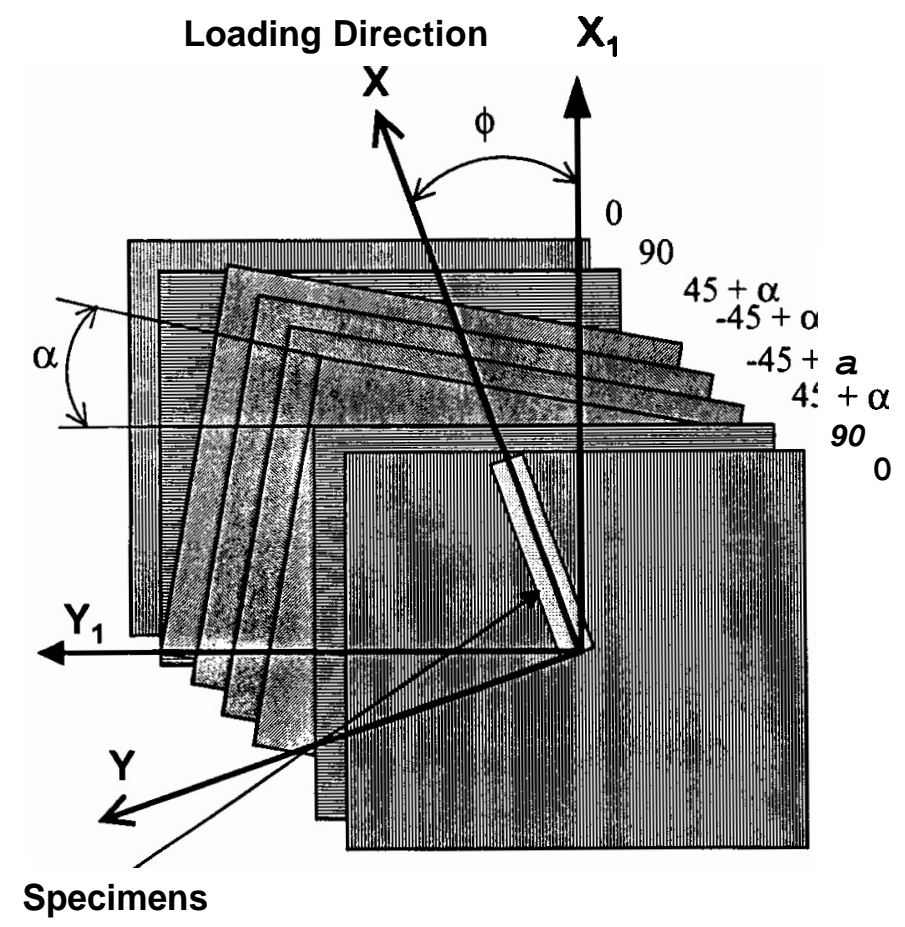

Fig. 46. Illustration of quasi-isotropic laminates with layup misalignment.

*In that figure, some ply groups are misaligned. The observable effects of such misalignment are discussed later. 
Table 6. Creep and recovery test program

\begin{tabular}{|c|c|c|c|c|c|}
\hline $\begin{array}{c}\text { Creep stress } \\
\sigma_{0}(\mathrm{MPa})\end{array}$ & $\begin{array}{l}\text { Creep/recovery } \\
\text { times } t_{0} /(r-1) t_{0} \\
(\mathrm{~h})\end{array}$ & $\begin{array}{c}\begin{array}{c}\text { Number of } \\
\text { test } \\
\text { specimens }\end{array} \\
\end{array}$ & $\begin{array}{c}\text { Creep stress } \\
\sigma_{0}(\mathrm{MPa})\end{array}$ & $\begin{array}{c}\text { Creep/recovery } \\
\text { times } t_{0} /(r-1) t_{0} \\
(h)\end{array}$ & $\begin{array}{c}\begin{array}{c}\text { Number of } \\
\text { test } \\
\text { specimens }\end{array} \\
\end{array}$ \\
\hline \multicolumn{3}{|c|}{$\phi=0^{\circ}, T=73^{\circ} \mathrm{C}$} & \multicolumn{3}{|c|}{$\phi=22.5^{\circ}, T=73^{\circ} \mathrm{C}$} \\
\hline 59.2 & 24148 & 2 & 59.2 & 24148 & 2 \\
\hline 88.8 & $24 / 48$ & 3 & 88.8 & $24 / 48$ & 2 \\
\hline 118.4 & $24 / 48$ & 3 & 118.4 & $24 / 48$ & 2 \\
\hline 148 & $24 / 48$ & 2 & 148 & $24 / 48$ & 2 \\
\hline 177.6 & $24 / 48$ & 2 & 177.6 & $24 / 48$ & 3 \\
\hline \multicolumn{6}{|c|}{$\phi=22.5^{\circ}, T=120^{\circ} \mathrm{C}$} \\
\hline 59.2 & 24148 & 1 & 59.2 & 24148 & 4 \\
\hline 88.8 & 24148 & 1 & 88.8 & $24 / 48$ & 2 \\
\hline 118.4 & 24148 & 1 & 118.4 & $24 / 48$ & 4 \\
\hline 148 & $24 / 48$ & 1 & 148 & $24 / 48$ & 4 \\
\hline 148 & 72148 & 1 & 177.6 & $24 / 48$ & 2 \\
\hline 177.6 & $24 / 48$ & 1 & & & \\
\hline \multicolumn{6}{|c|}{$\phi=90^{\circ}, T=23^{\circ} \mathrm{C}$} \\
\hline 118.4 & 24148 & 1 & 118.4 & $24 / 48$ & 1 \\
\hline 177.6 & $\begin{array}{c}\phi=45^{\circ}, T=23^{\circ} \mathrm{C} \\
24 / 48\end{array}$ & 1 & 148 & $24 / 48$ & 1 \\
\hline & $\phi=45^{\circ}, T=73^{\circ} \mathrm{C}$ & & \multicolumn{3}{|c|}{$\phi=90^{\circ}, T=73^{\circ} \mathrm{C}$} \\
\hline 59.2 & $24 / 48$ & 2 & 59.2 & $24 / 48$ & 2 \\
\hline & & & 118.4 & 24148 & 2 \\
\hline 118.4 & $\begin{array}{c}\phi=\mathbf{6 7 . 5}^{\circ}, \boldsymbol{T}=\mathbf{2 3}^{\circ} \mathrm{C} \\
24 / 48\end{array}$ & 1 & 177.6 & $24 / 48$ & 1 \\
\hline & $\phi=67.5^{\circ}, T=73^{\circ} \mathrm{C}$ & & \multicolumn{3}{|c|}{$\phi=90^{\circ}, T=120^{\circ} \mathrm{C}$} \\
\hline 148 & $24 / 48$ & 2 & 177.6 & $24 / 48$ & 1 \\
\hline 177.6 & $24 / 48$ & 2 & & & \\
\hline
\end{tabular}

\subsection{LINEAR RANGE OF LAMINATE RESPONSE}

\subsubsection{Tensile Properties of $[0 / 90 / 45 /-45]_{S}$ Laminates}

With the foregoing properties at hand, it was possible to evaluate the longitudinal stiffness $E$, of the quasi-isotropic laminate under uniaxial tension. Recalling Eq. (6), one obtains expressions for the in-plane laminate stiffnesses given in Eq. (30), which include an imperfection angle $\alpha$ as shown in Fig. 46. For the quasi-isotropic laminate under consideration, $h_{o}=0.28 \mathrm{~mm}$, and the total number of plies is $n_{\mathrm{p}}=8$.

Obviously, for a perfect quasi-isotropic layup (i.e., with $\alpha=0$ ), $E$, should not depend on load orientation. Nevertheless, actual room temperature experimental data, which are listed in Table 7 and depicted in Fig. 47, indicate the presence of angular dependence in $E$, even within the linear range of stress-strain response. This departure from quasi-isotropy can be traced to reported layup misalignments during the manufacturing process, when adjacent, stitched crossply pairs could not be stacked precisely at $\pm 45^{\circ}$ to each other, as desired.

To assess the effect of such misalignments, consider the circumstance where the inner $\left[ \pm 45^{\circ}\right]$ ply groups were tilted by a common angle $\alpha$ about their proper directions during the 
Table 7. Tensile data for quasi-isotropic composite coupons loaded at various orientations

\begin{tabular}{cccccc}
\hline $\begin{array}{c}\text { Orientation } \\
\begin{array}{c}\text { angle } \\
\text { (deg) }\end{array}\end{array}$ & $\begin{array}{c}\text { Temperature } \\
\left(\mathbf{0}^{\mathbf{0})}\right.\end{array}$ & $\begin{array}{c}\text { Stiffness } \\
\mathbf{( G P a )}\end{array}$ & $\begin{array}{c}\text { Tensile } \\
\text { strength } \\
\mathbf{( M P a})\end{array}$ & $\begin{array}{c}\text { Failure strain } \\
\mathbf{( \% )}\end{array}$ & $\begin{array}{c}\text { Poisson's } \\
\text { ratio }\end{array}$ \\
\hline & & & & & \\
0 & 23 & $30.8 \pm 0.7$ & $306.0 \pm 10.0$ & $0.98 \pm 0.05$ & $0.305 \pm 0.05$ \\
& 50 & $29.8 \pm 1.3$ & $291.6 \pm 43.5$ & $0.94 \pm 0.17$ & \\
& 73 & $31.2 \pm 1.5$ & $284.6 \pm 37.3$ & $0.94 \pm 0.18$ & $0.343 \pm 0.02$ \\
15 & 120 & $26.7 \pm 2.3$ & $260.5 \pm 44.9$ & $0.98 \pm 0.12$ & \\
22.5 & 23 & $28.9 \pm 0.5$ & $239.5 \pm 28.6$ & $0.86 \pm 0.11$ & \\
& 23 & $29.0 \pm 2.7$ & $254.5 \pm 21.3$ & $0.92 \pm 0.10$ & $0.355 \pm 0.05$ \\
& 50 & $32.1 \pm 0.8$ & $306.8 \pm 4.6$ & $0.91 \pm 0.04$ & \\
30 & 73 & $31.4 \pm 1.2$ & $273.5 \pm 12.3$ & $0.87 \pm 0.11$ & $0.393 \pm 0.02$ \\
45 & 120 & $25.8 \pm 4.1$ & $218.1 \pm 27.4$ & $1.00 \pm 0.14$ & \\
67.5 & 23 & $26.9 \pm 0.8$ & $277.7 \pm 5.0$ & $1.09 \pm 0.03$ & \\
& 23 & $32.2 \pm 0.8$ & $295.0 \pm 15.9$ & $0.92 \pm 0.04$ & \\
& 23 & $29.9 \bullet 0.5$ & $289.7 \pm 23.7$ & $1.01 \pm 0.11$ & \\
& SO & $30.6 \pm 0.1$ & $298.8 \pm 9.1$ & $1.04 \pm 0.02$ & \\
90 & 73 & $27.5 \pm 0.4$ & $288.5 \pm 2.1$ & $1.02 \pm 0.05$ & \\
& 120 & $24.3 \pm 0.3$ & $205.2 \pm 4.7$ & $1.16 \pm 0.2$ & \\
& 23 & $30.2 \pm 1.0$ & $294.1 \pm 7.4$ & $0.96 \pm 0.03$ & \\
& SO & $30.7 \pm 2.5$ & $288.9 \pm 5.4$ & $0.92 \pm 0.06$ & \\
\hline
\end{tabular}

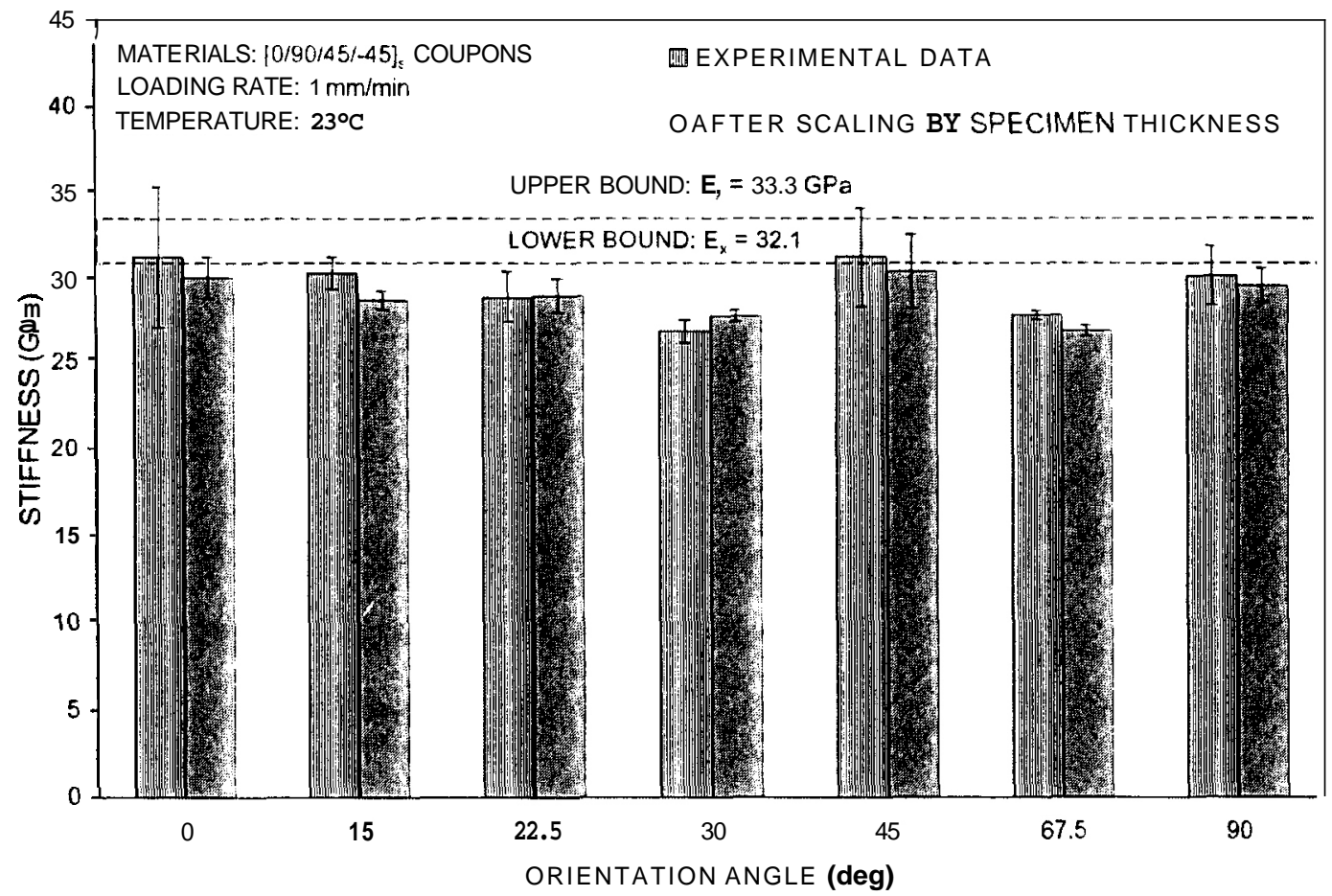

Fig. 47. Stiffness vs orientation angle of quasi-isotropic composite at $23^{\circ} \mathrm{C}$. The dashed line denotes the values for ideal quasi-isotropic laminates. calculated according to laminate theory. 
manufacturing process. as shown in Fig. 46. Straighttorward manipulations of laminate equations ${ }^{10}$ yield the following expressions:

$$
\begin{aligned}
A_{11}= & A_{22}=2 h_{o}\left(Q_{11}+Q_{22}\right)\left\{\cos ^{4} \phi+\sin ^{4} \phi+\frac{1}{2}+\frac{1}{2} \sin ^{2}[2(\alpha+\phi)]\right\}+ \\
& +2 h_{o}\left(Q_{12}+2 Q_{66}\right)\left\{\sin ^{2}(2 \phi)+\cos ^{2}[2(\alpha+\phi)]\right. \\
A_{12}= & 2 h_{o}\left(Q_{11}+Q_{22}-4 Q_{66}\right) \frac{1}{2}\left\{\sin ^{2}(2 \phi)+\cos ^{2}[2(\alpha+\phi)]\right\}+ \\
& +4 h_{o} Q_{12}\left\{\cos ^{4} \phi+\sin ^{4} \phi+\frac{1}{2}+\frac{1}{2} \sin ^{2}[2(\alpha+\phi)]\right\} \\
A_{16}= & -A_{26}=2 h_{o}\left(Q_{11}-Q_{22}-2 Q_{12}-4 Q_{66}\right) \frac{1}{4}\{\sin (4 \phi)-\sin [4(\alpha+\phi)]\} \\
A_{66}= & 2 h_{o}\left(Q_{11}+Q_{22}-2 Q_{12}\right) \frac{1}{2}\left\{\sin ^{2}(2 \phi)+\cos ^{2}[2(\alpha+\phi)]\right\}+4 h_{0} Q_{66}\left\{\cos ^{2}(2 \phi)+\sin ^{2}[2(\alpha+\phi)] ; .\right.
\end{aligned}
$$

As noted in Sect. 3.5.2 and 3.6. the best estmmates for tlie $Q_{i j}$ values are $Q_{11}=89.6, \mathrm{Q}_{22}=2.1$, $\mathrm{Q}_{12}=3.1$, and $\mathrm{Q}_{66}=3.3$ (all in $\mathrm{GPa}$ ).

The resulting departure from quasi-isorropy can be evaluated by combining Eqs. (30) and (6). Results are depicted in Fig. 48, where $E_{x}$ at different orientations $\phi$ is plotted vs the misalignment angle $\alpha$. with $\alpha$ varying between $0^{\circ}$ and $20^{\circ}$. It is evident that departures from quasiisotropy increase with $\alpha$.

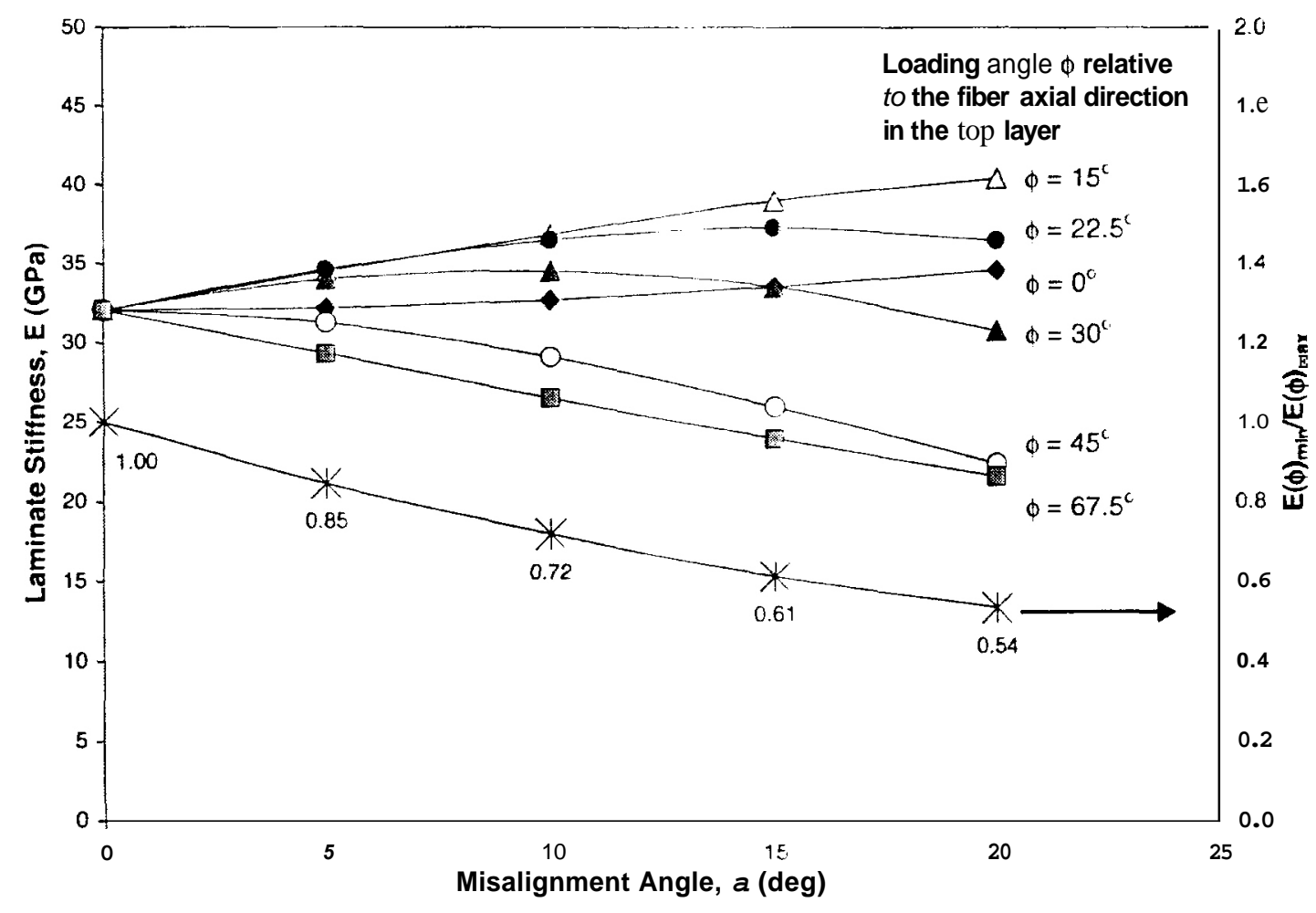

Fig. 48. Influence of laminate layup misalignment on tlie stiffness of yuasi-isotropic composite. 
Note, however. that the results shown in Fig. 48 correspond to the assumed misaligned configuration depicted in Fig. 46. This configuration may or may not correspond to the actual misalignments that occur during the layup process. Due to practical limitations, it is only possible to measure the anpular orientations of the outer layers of the laminate, while the directions of the inner plies may be estimated with some uncertaintv with the aid of X-ray photographs. Nevertheless, an analysis of the idealized misaligned layup shown in Fig. 46 can provide a reasonable estimate for the magnitude of misalignment angles that occurred during the actual layup processes." For the actual ratio of $E_{\min } / E_{\max }$ that was recorded experimentally, it appears that a reasonably good estimate is $a-5^{\circ}$.

\subsection{STRESS-STRAIN BEHAVIOR IN THE NONLINEAR RANGE}

\subsubsection{Crossply Composite}

To explain certain aspects of observed departures from quasi-isotropic response, it is necessary to utilize the nonlinear stress-strain data of crossply laminates. For the crossply composite. the stress-strain response is highly orientation dependent. For loading orientations $\phi=0^{\circ}$ and $90^{\circ}$, which are parallel to fiber directions, the stress-strain curves are nearly linear up to failure, as shown in Fig. 49. However. that linear range diminishes monotonically. and nonlinearity tends to prevail, as the angle between load and fiber direction increases. This angular dependence becomes most pronounced at $\phi=45 "$. The nonlinearity becomes further accentuated with temperature, as shown in Fig. 50.

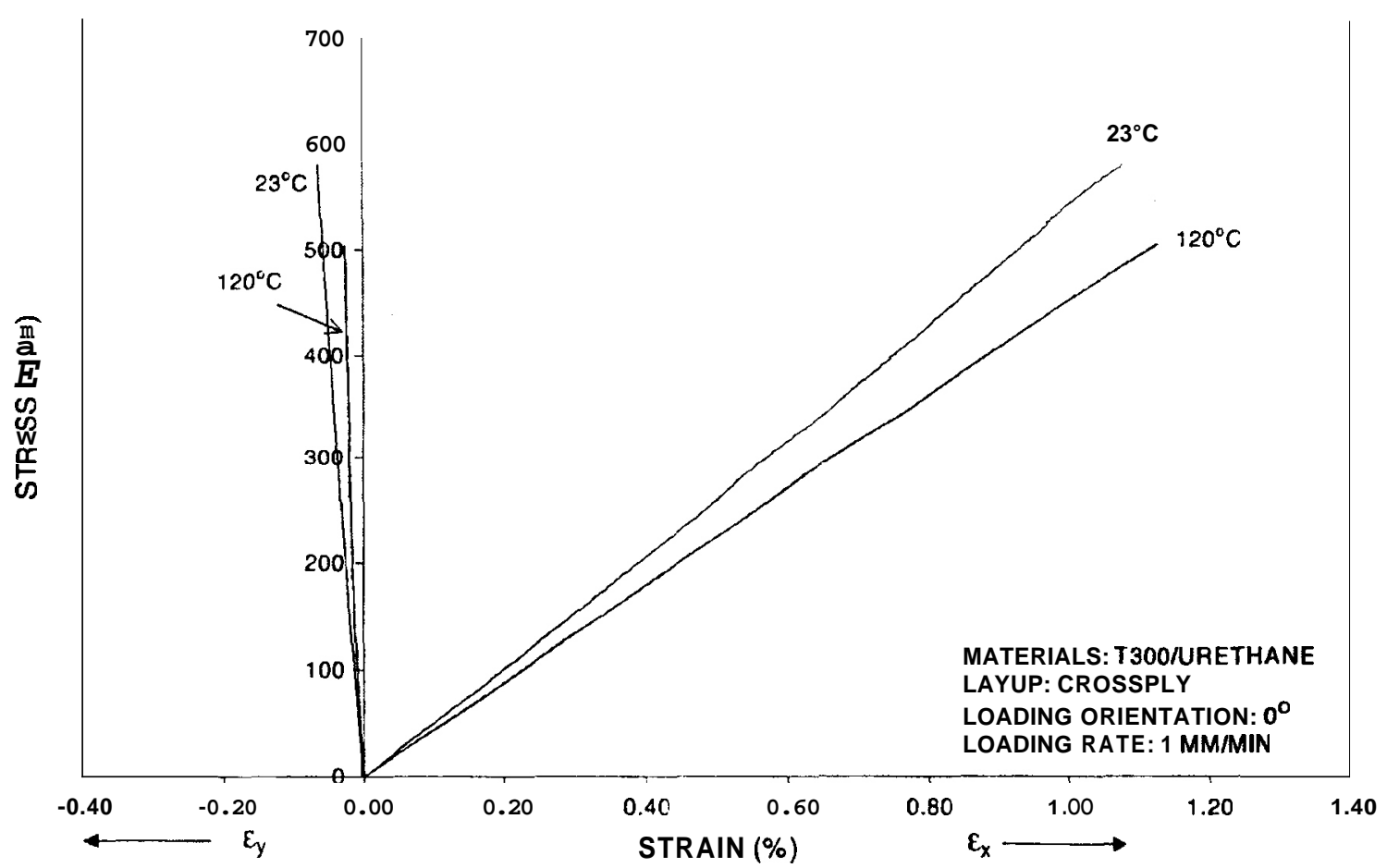

Fig. 49. Typical stress-strain curves of crossply composite, with loads applied at orientation angle $\phi=0^{\circ}$ under two temperatures.

*Although a wide scope of possibilities exists for the locations and orientations of the misaligned plies, the inplane stiffnesses of the laminate are highly insensitive to any particular ordering of those locations within the laminate. 


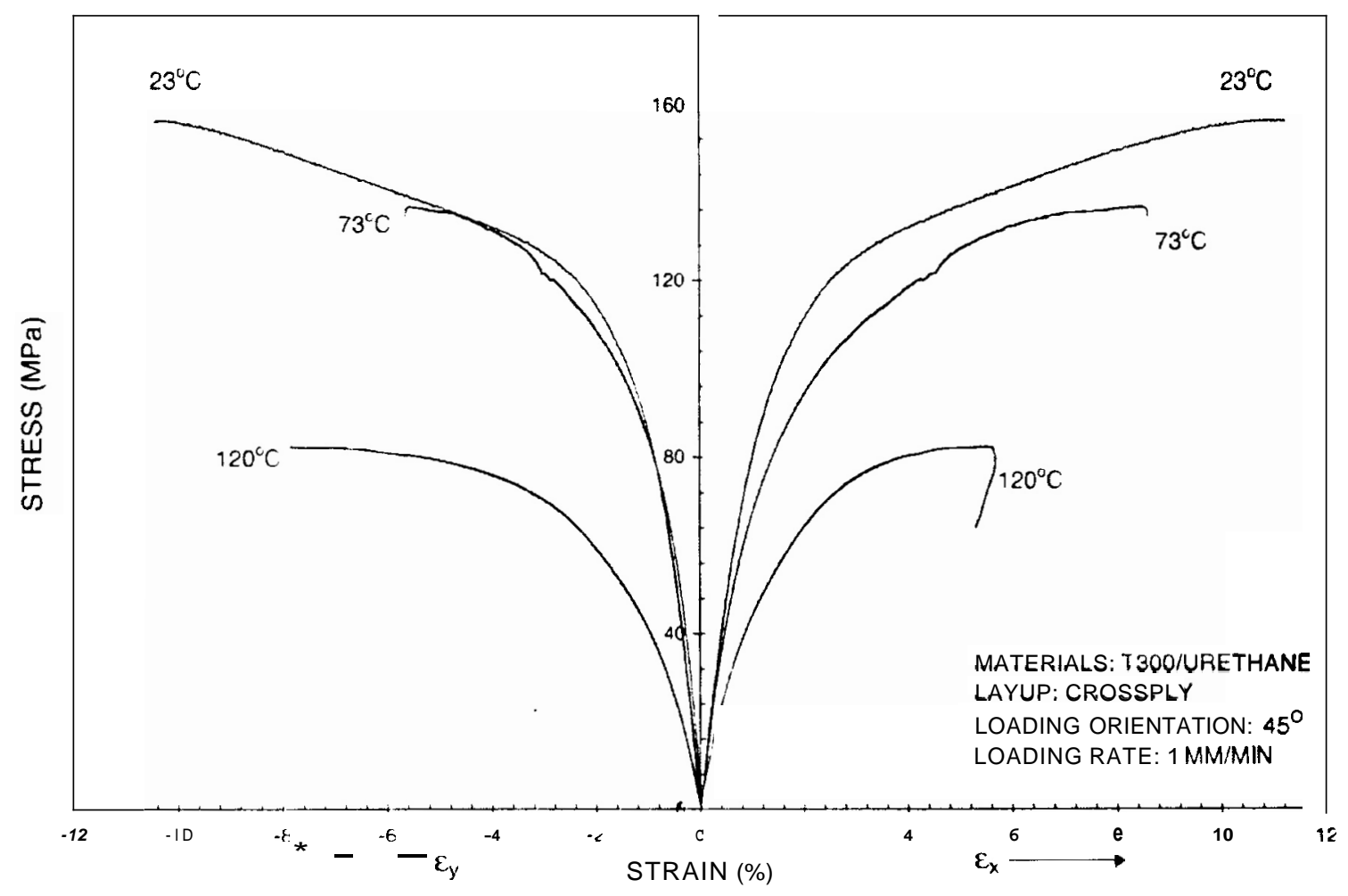

Fig. 50. Typical stress-strain curves of crossply composite. with loads applied at orientation angle $\phi=45^{\circ}$ under three temperatures.

\subsubsection{Quasi-Isot ropic Composite}

The main purpose of this subsection is to provide a rational, mechanics-based. explanation for the consistently observed dependence of the stress-strain response of the quasi-isotropic composite on load orientation at the elevated stress range.

Typical stress-strain to failure curves for quasi-isotropic coupons tested at various orientations are shown in Figs. 51-54. Despite the data scatter that is attributable to layup mismatch angles $\alpha$ as shown in Fig. 46. these figures exhibit consistent departures between the response of coupons tested in orientations $\phi$, such as $0^{\circ}, 45^{\circ}$. and $90^{\circ}$. which are parallel to fiber directions, and the softer behavior of samples tested in intermediate orientations $\phi$ such as $15^{\circ}, 22.5^{\circ}, 30^{\circ}$, and $67.5^{\circ}$. Clearly. the response at angles $\widehat{\phi}$ is nonlinear. with nonlinearity increasing with both stress and temperature. Note that. ideally. all stress-strain curves should coalesce toward a common straight line near the origin. However. this may not occur in all circumstances. because of the aforementioned layup misalignments, as discussed in Sect. 6.2.1. A specific example for a departure between the response at $\phi=0^{\circ}$ and the hehavior at $\widehat{\phi}=22.5^{\circ}$. which emanates from the origin of the stress and strain coordinates. is shown in Fig. 55. Obviously, in this case some of the plies in the sample tested at $\phi=22.5^{\circ}$ are misaligned about their designated quasi-isotropic orientations. and the effects of nonlinearity and misalignment compound each other. Other causes: such as an unequal spacings between fiber strands. can also contribute to the observed disparity. 


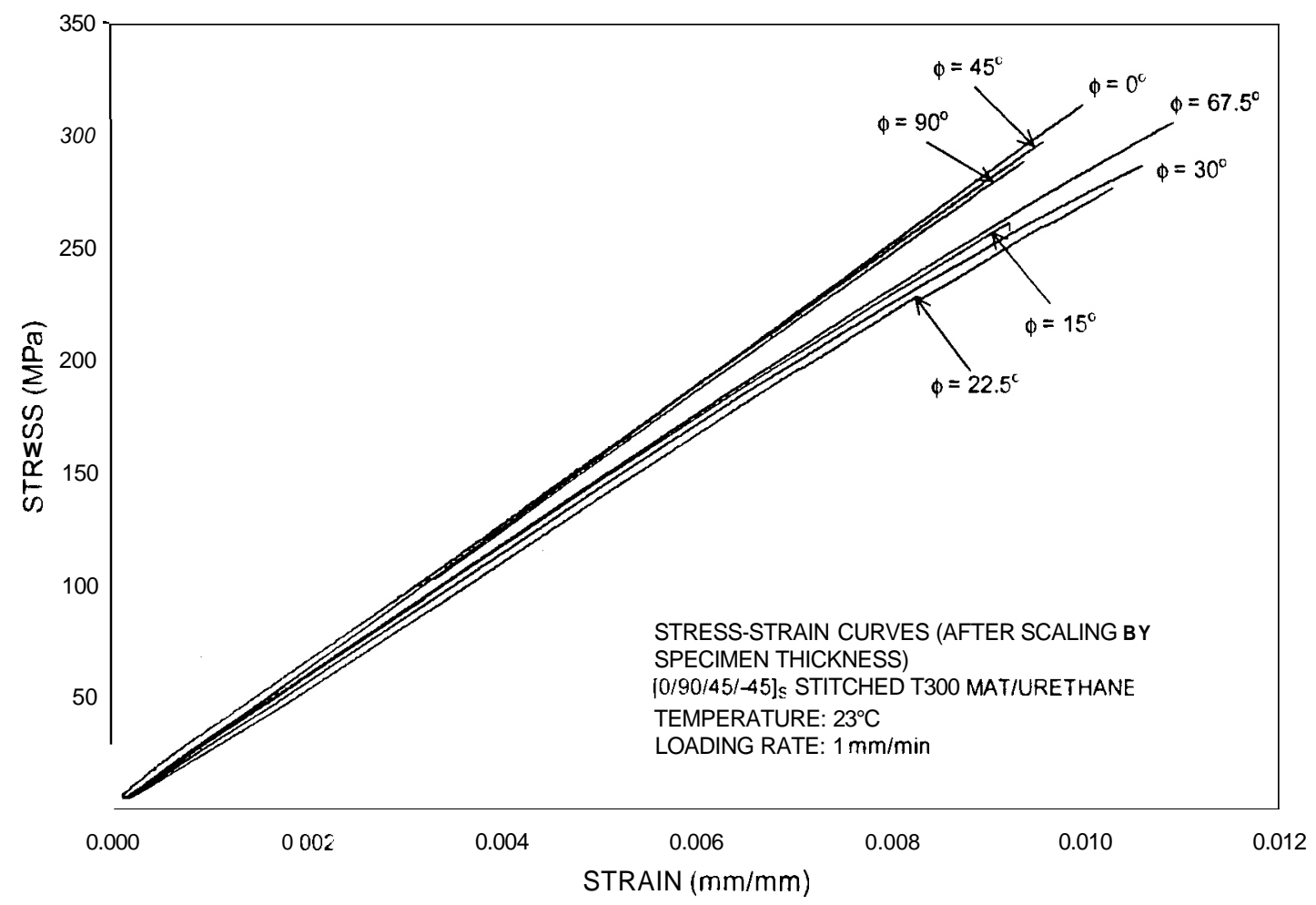

Fig. 51. Typical stress-strain curves of quasi-isotropic composite at various orientations at $23^{\circ} \mathrm{C}$.

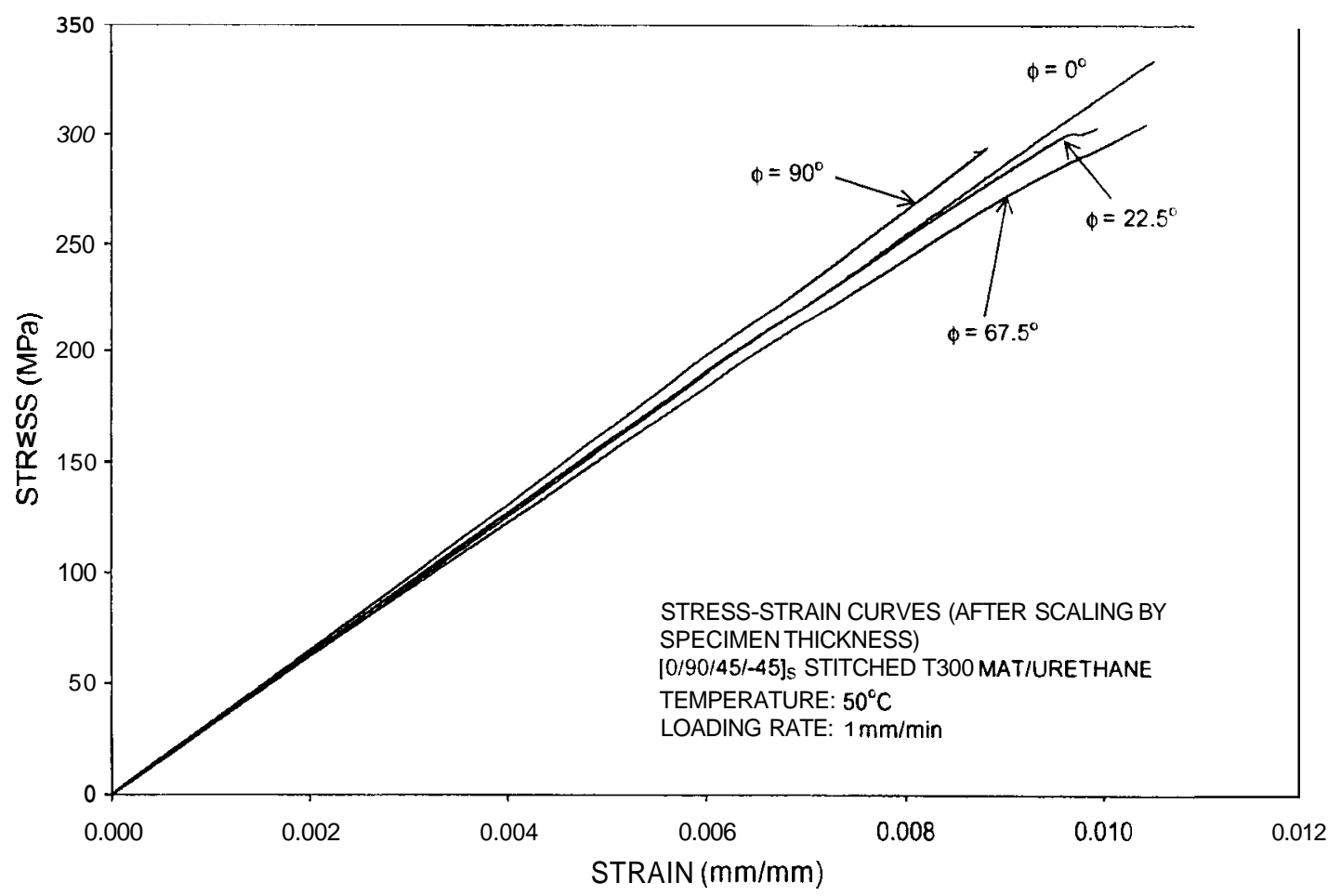

Fig. 52. Typical stress-strain curves of quasi-isotropic stitched composite at various orientations at $50^{\circ} \mathrm{C}$. 


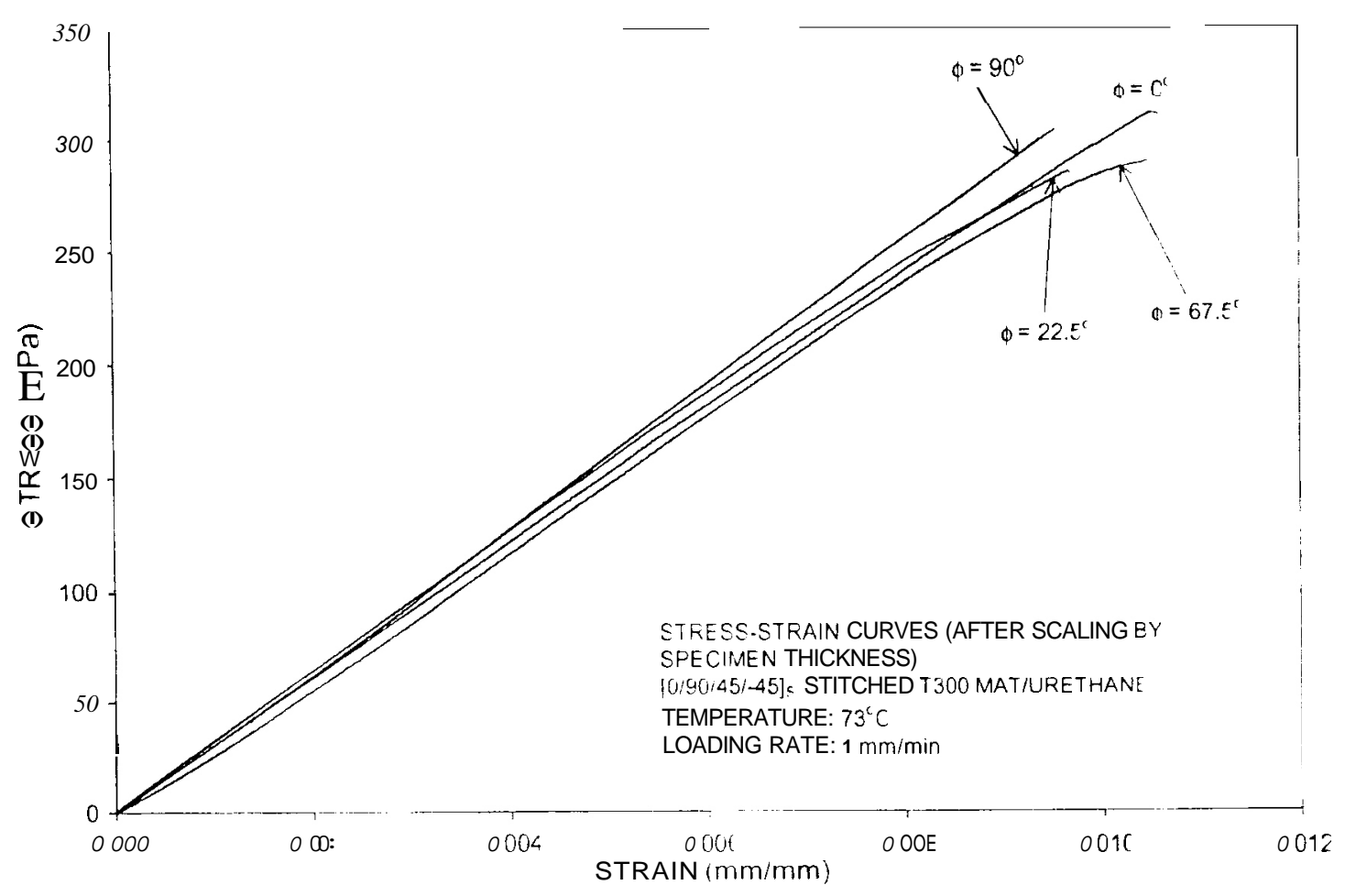

Fig. 53. Iypical stress-strain curves of quasi-isotropic composite at various orientations at $73^{\circ} \mathrm{C}$.

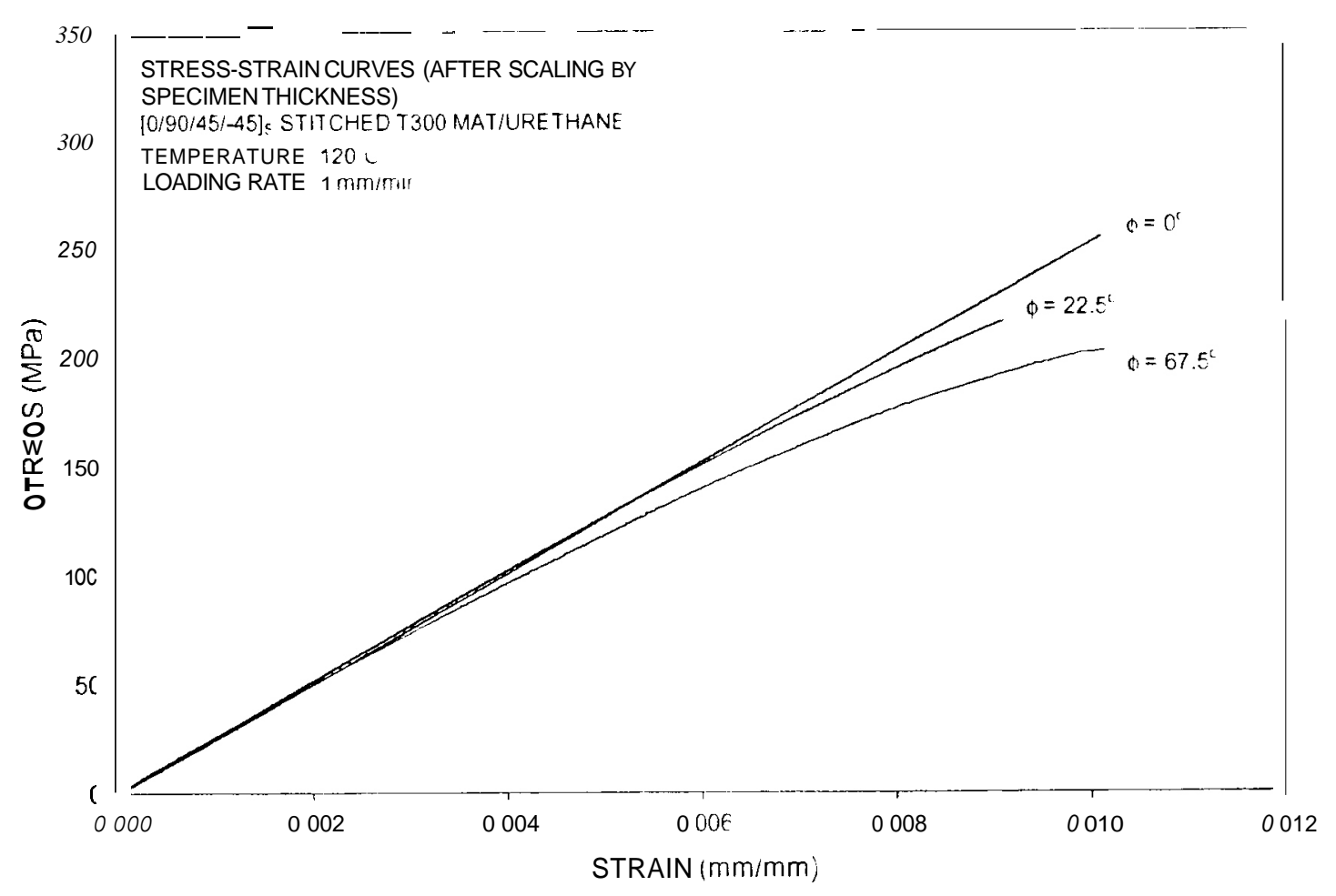

Fig. 54. Typical stress-strain curves of quasi-isotropic composite at various orientations at $120^{\circ} \mathrm{C}$. 


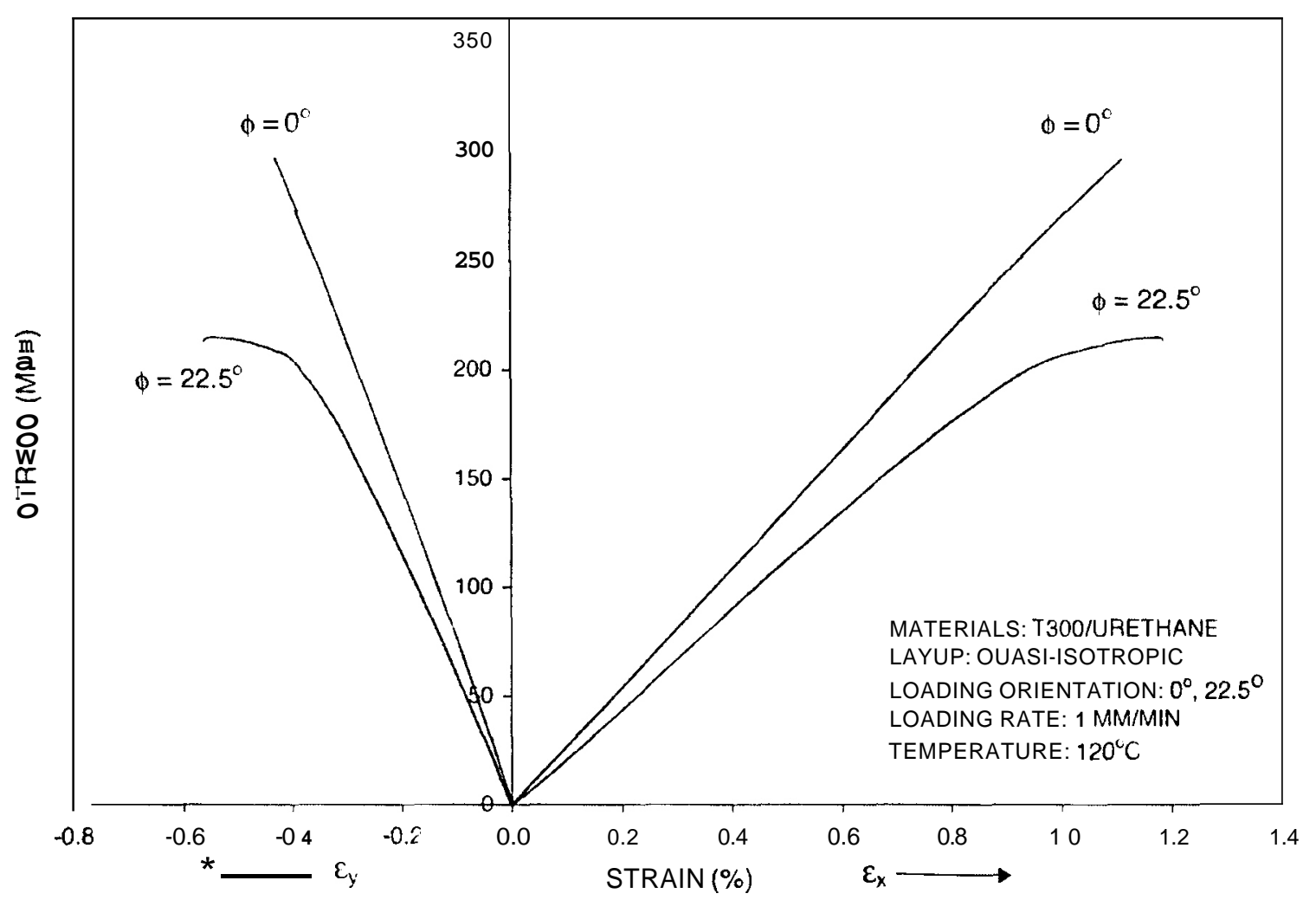

Fig. 55. Comparison of stress-strain curves of quasi-isotropic composite with two different loading orientations $\left(\phi=0^{\circ}\right.$ and $\left.22.5^{\circ}\right)$ at $120^{\circ} \mathrm{C}$.

\subsubsection{Basic Nonlinear Properties and an Approximate Model}

It is possible to account for the nonlinear behavior of fiber-reinforced polymeric composites by means of plasticity and viscoplasticity theories $11-13$ The formulation involves the association of the effective stress $\bar{\sigma}$ with the effective plastic strain $\bar{\varepsilon}^{p}$ within the larger context of plasticity theory. Because a negligible amount of nonlinearity occurs parallel to the fiber direction, $x_{1}$, the normal stress $\sigma_{11}$ is assumed to play no role in $\bar{\sigma}$. Thereby. in a two-dimensional case. the effective stress $\bar{\sigma}$ is associated with shear stress, $\tau_{12}$, and the stress normal to the fiber direction, $\sigma_{22}$, through the expression

$$
\bar{\sigma}=\left[\frac{3}{2}\left(\sigma_{22}^{2}+2 a \tau_{12}^{2}\right)\right]^{1 / 2}
$$

Furthermore. in most circumstances, $\bar{\sigma}$ and $\bar{\varepsilon}^{p}$ were related by the empirical expression $\bar{\varepsilon}^{p}=A \bar{\sigma}^{n}$. The details are reproduced in Appendix C.

The determination of the parameters $a, A$, and $n$ requires the employment of a comprehensive experimental program that utilizes unidirectionally reinforced off-axis plies, at various offaxis orientations, $\theta$, although it appears that balanced $\pm \theta$ angle plies could also be utilized. Unfortunately, such samples were not available for the composite at hand.

It was therefore decided to assess the values of $a, A$. and $n$ from the quasi-isotropic data by means of an approximate approach and subsequently verify the validity of those parameters by employing them to predict the nonlinear response of the $[ \pm 45]_{3 S}$ crossply samples, utilizing an 
incremental computational method. The rationale behind the current approach is that because the quasi-isotropic layups exhibited only a limited amount of plasticity, a nonincremental representation of their nonlinear stress-strain behavior would simplify the evaluation of the parameters $a, A$, and $n$. while keeping the errors within acceptable limits. However. in view of the significant nonlinearity in the response of the $[ \pm 45]_{35}$ crossply samples. the prediction of their behavior by means of the more accurate model would establish the validity of the aforementioned parametric values.

For a single. off-axis. unidirectional composite under monotonically increasing load $N_{\mathrm{x}}$, the increment of the total strain can be decomposed into elastic and plastic portions:

$$
\begin{aligned}
& d \varepsilon_{x}=d \varepsilon_{x}^{\epsilon}+d \varepsilon_{x}^{\prime} \quad \\
& d \varepsilon_{y}=d \varepsilon_{y}^{\iota}+d \varepsilon_{y}^{\prime} .
\end{aligned}
$$

As mentioned earlier. the stress-strain response of the quasi-isotropic composite exhibited only small-10-moderate nonlinearity. as shown in Fig. 56. Thereby. it was decided to avoid a stepby-step. incremental. laminate analysis for this layup and. as an approximation. to integrate Eq. (31) directly, thereby obtaining for each individual ply

$$
\begin{gathered}
\varepsilon_{x}=\bar{s}_{11} \sigma_{x}+[h(\theta)]^{n+1} A \sigma_{x}{ }^{n}: \\
\mathcal{E}_{y}=\bar{s}_{12} \sigma_{x}+v_{x y}^{p}[h(\theta)]^{n+1} A \sigma_{x}{ }^{n}
\end{gathered}
$$

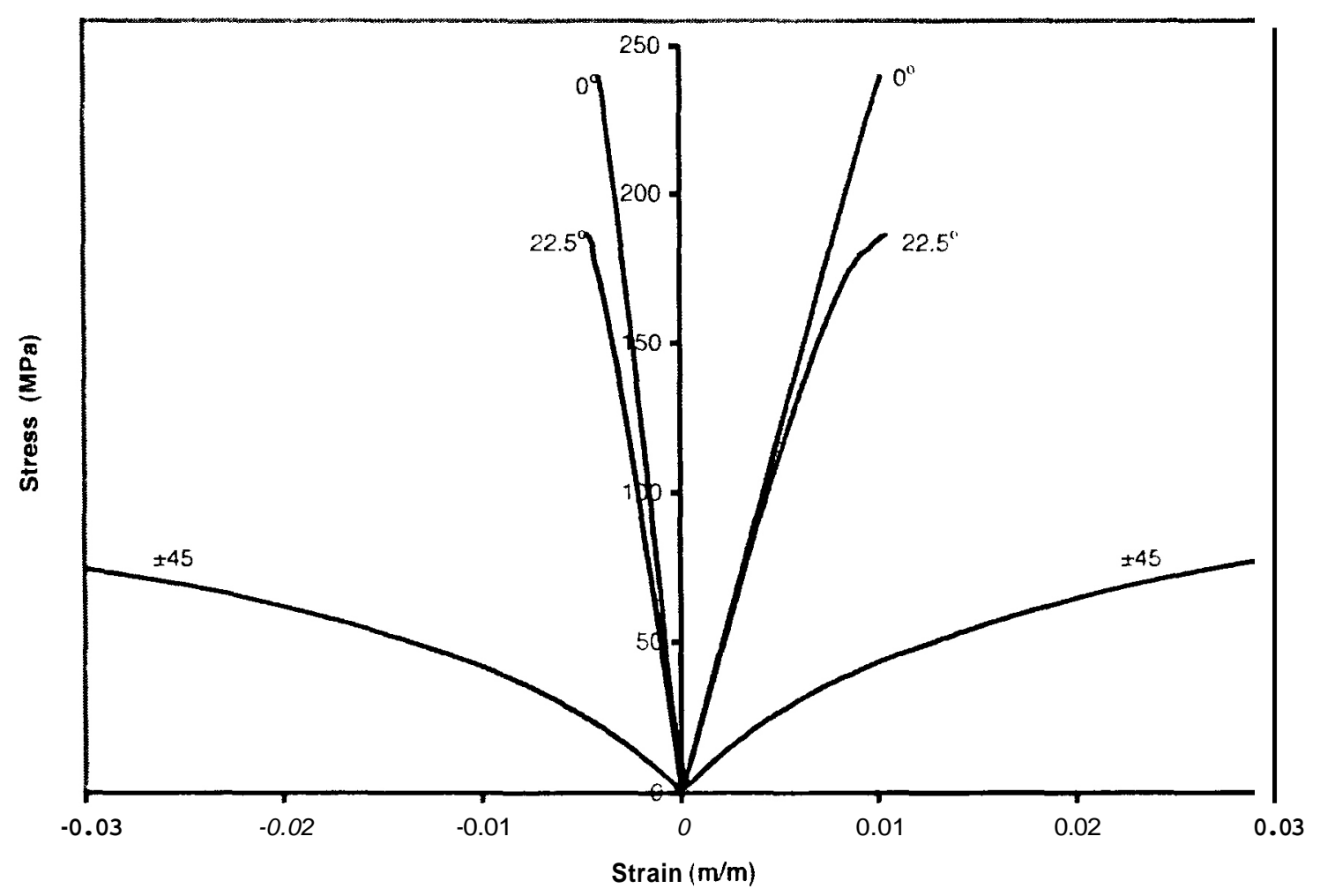

Fig. 56. Longitudinal and transverse st rains vs stress for quasi-isotropic and $\left[ \pm 45^{\circ}\right]_{3 S}$ coupons at $120^{\circ} \mathrm{C}$. 
In Eqs. (32) and (33), $\bar{s}_{11}$ and $\bar{s}_{12}$ are the off-axis elastic compliance components ofunidirectional lamina. while $A, n$. and $h(\theta)$ are the plastic parameters and transformation function detailed in Appendix C and given in Eq. (C.13). Furthermore. the "plastic Poisson's ratio" $v_{x y}^{p}$ can be expressed as ${ }^{8}$

$$
v_{x}^{p}=-\frac{1-2 \mathrm{a}}{2 a+\tan ^{2} \theta}
$$

In view of the fact that the longitudinal plastic strain must have a common value for each and every ply in the laminate at all stress levels. as shown in Fig. 57, Eq. (32) yields

$$
[h(\theta)]_{1}^{n+1} A \sigma_{x .1}^{n}=[h(\theta)]_{2}^{n+1} A \sigma_{x . .2}^{n}=\cdots=[h(\theta)]_{N}^{n+1} A \sigma_{x, N}^{n}=\varepsilon_{x}^{p}
$$

where $N$ is the number of plies of the laminate. For plies of equal thickness $t$, the average stress $\sigma_{\mathrm{x}}$ is given by

$$
\sigma_{x}=\frac{N_{x}}{H}=\frac{t}{H}\left(\sigma_{x .1}+\sigma_{x .2}+\quad+\sigma_{x, N}\right),
$$

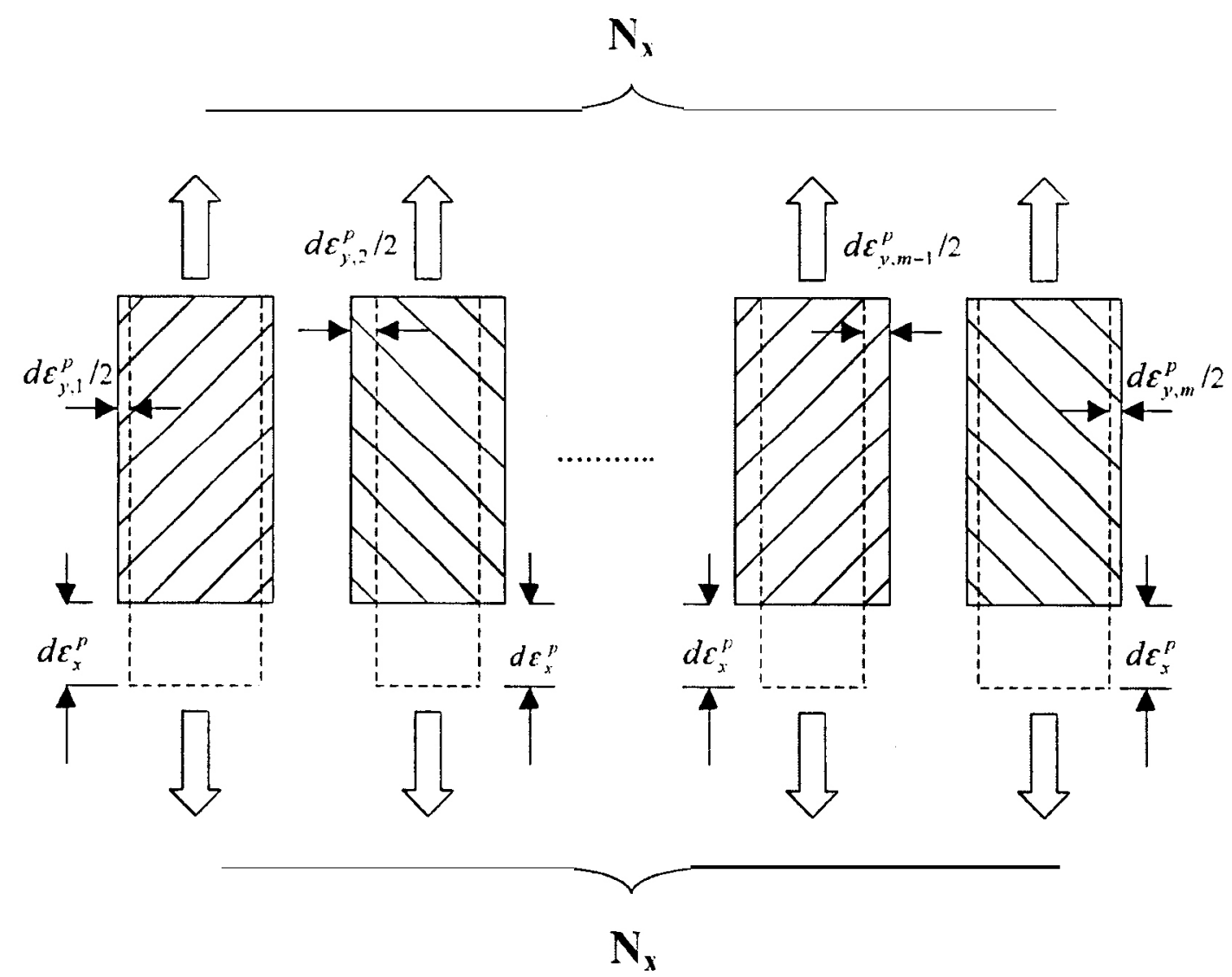

Fig. 57. Schematic drawing of strain compatibility requirements for composite laminates. 
where $H=N r$ is the laminate thickness. and all ply stresses $\sigma_{\mathrm{x} . \mathrm{j}}$ must satisfy Eq. (35). Note that the total number of plies of the laminate is $N=H / t$ : thus. the arerage stress $\sigma_{\mathrm{x}}$ may be expressed as:

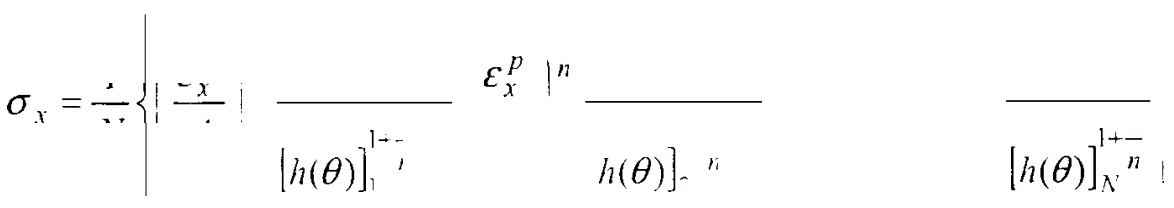

$$
\begin{aligned}
& =\frac{1}{N} \mid \sum_{i=1}^{N} \frac{1}{[h(\theta)]_{i}^{1+\frac{1}{n}}}\left(\frac{\varepsilon_{x}^{p}}{A}\right)^{\frac{1}{n}} .
\end{aligned}
$$

which leads to

$$
\varepsilon_{i}^{p}=N^{n} \frac{A}{\left.\left\{\sum_{i=1}^{N} \mid h(\theta)\right]^{1+\frac{1}{n}}\right\}^{n}} \sigma_{?}^{n}
$$

Similarly, the average value of the 1ransverse plastic strain can be approximated by

$$
\begin{aligned}
\mathcal{E}_{1}^{l} & =\frac{1}{N}\left(\varepsilon_{y, 1}^{p}+\varepsilon_{y \cdot 2}^{p^{\prime}}+\cdots+\varepsilon_{y \cdot N}^{p}\right) \\
& =\frac{1}{N}\left(v_{x y .1}^{p}+v_{x y .2}^{\prime}+\cdots+v_{x y, N}^{p}\right) \varepsilon_{x}^{p}
\end{aligned}
$$

resulting in an averaged "plastic Poisson's ratio"

$$
v_{x !}^{p}=\frac{1}{N} \sum_{i=1}^{N} v_{x !}^{\prime \prime}
$$

The total strain-stress relation may thus be expressed as:

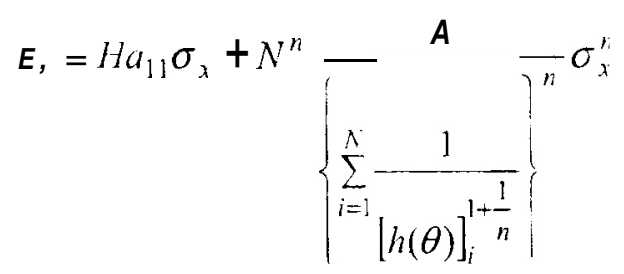




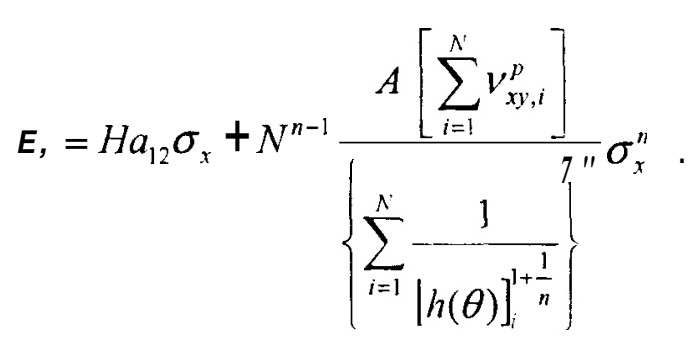

The first terms on the right sides of Eqs. (41) and (42) account for the elastic portions of $\boldsymbol{E}$,. In those equations $a_{11}$ and $a_{12}$ are the well known linear laminate level compliances. Denote the elastic coefficients $\eta_{\mathrm{x}}$ and $\eta_{\mathrm{v}}$ as $\eta_{\mathrm{x}}=H a_{11}$ and $\eta_{\mathrm{v}}=H a_{12}$, and let the plastic coefficients $\xi_{\mathrm{x}}$ and $\xi_{y}$ be

$$
\begin{aligned}
& \xi_{x}=N^{n} \frac{A}{\left\{\sum_{i=1}^{N} \frac{1}{\mid h(\theta)]^{1+\frac{1}{n}}}\right\}^{n}} \\
& \xi_{y}=N^{n-1} \frac{A\left[\sum_{i=1}^{N} v_{x y, i}^{p}\right]}{\left\{\sum_{i=1}^{N} \frac{1}{\mid h(\theta)]_{i}^{1+\frac{1}{n}}}\right\}^{n}}
\end{aligned}
$$

Equations (41) and (42) are then reduced to

$$
\begin{aligned}
& \mathcal{E}_{x}=\eta_{x} \sigma_{x}+\xi_{x} \sigma_{x}^{n} ; \\
& \mathcal{E}_{y}=\eta_{y} \sigma_{x}+\xi_{y} \sigma_{x}^{n}
\end{aligned}
$$

The elastic and plastic coefficients $\eta_{\mathrm{x}}, \eta_{\mathrm{y}}, \xi_{\mathrm{x}}, \xi_{\mathrm{y}}$, and the parameter $\mathrm{n}$ in Eqs. (45) and (46) may be evaluated by fitting experimental data. This was accomplished by means of a nonlinear optimization scheme that was designed to determine the $\eta_{\mathrm{x}}, \eta_{\mathrm{y}}, \xi_{\mathrm{x}}, \xi_{\mathrm{y}}$, and n values that correspond to the best least-square fit against both $\varepsilon_{x}$ and $\varepsilon_{v}$ vs $\sigma_{x}$ data sets. An outline of this scheme is given in Appendix D.

Once the plastic parameter $n$ and coefficients $\xi_{x}$, and $\xi_{v}$ were determined by the aforementioned optimization procedure. the remaining plastic parameters $\mathbf{A}$ and $\boldsymbol{a}$ [the parameter $\boldsymbol{a}$ is embedded in the function $h(\theta)$ ] can be determined by correlating Eqs. (43), (44) and (C.13).*

Note that the present approximation inherently discards any nonlinearity that occurs in the quasi-isotropic composite loaded in any of the fiber directions because by Eq. (C.13), $h(0)=\mathbf{0}$, and thereby both $\xi_{\mathrm{x}}$ and $\xi_{\mathrm{y}}$ vanish. This deficiency results from the assumption inherent in the current approximation that overlooks the requirement of ply-by-ply uniformity of the transverse strain $\mathcal{E}_{\mathrm{y}}$ throughout the laminate. As noted earlier. the above approximation is not admissible for

\footnotetext{
${ }^{*}$ See Appendix $C$ for Eq. (C.13).
} 
crossply laminates loaded in off-axis directions because in those circumstances nonlinearity dominates the response.

The optimization scheme was employed to fit the stress-strain data shown in Fig. 56 for the quasi-isotropic laminates loaded at $22.5^{\circ}$ about the 0 " fiber direction. at $120^{\circ} \mathrm{C}$. The scheme yielded the values of $n=6.619 . a=3.983$, and $\boldsymbol{A}=8.923 \times 10^{-19}\left(\mathrm{MPa}^{-\mathrm{n}}\right)$. The resulting predictions. for both $\sigma_{\mathrm{x}}$ vs $\mathcal{E}_{\mathrm{x}}$ and $\sigma_{\mathrm{x}}$ vs $E_{\text {,.. }}$ are plotted in Fig. 58 where they are compared against the experimental data. In view of the previous remarks. these values are approximate. Nevertheless. if is worth noting that the values of $\eta_{\mathrm{x}}$ and $\eta_{\mathrm{v}}$ came in close agreement with the laminate values $H a_{11}$ and $H a_{22}$.

To assess the validity of the aforementioned approximate values of $n, a$, and $A$, these parameters were employed to predict the response of the $[ \pm 45]_{3} s$ crossply composite by means of a detailed incremental scheme that ascertained uniformity of both longitudinal and transverse strains.

The plasticity strain-stress expression from Appendix $\mathrm{C}$ is

$$
\varepsilon_{x . i}^{p}=[h(\theta)]^{n+1} A \sigma_{x . i}^{\prime \prime}
$$

which can be written as

$$
\sigma_{x . i}=\left\{\frac{1}{[h(\theta)]_{i}^{n+1} A}\right\}^{\prime \prime}\left(\varepsilon_{x, i}^{p}\right)^{\frac{1}{\prime \prime}}
$$

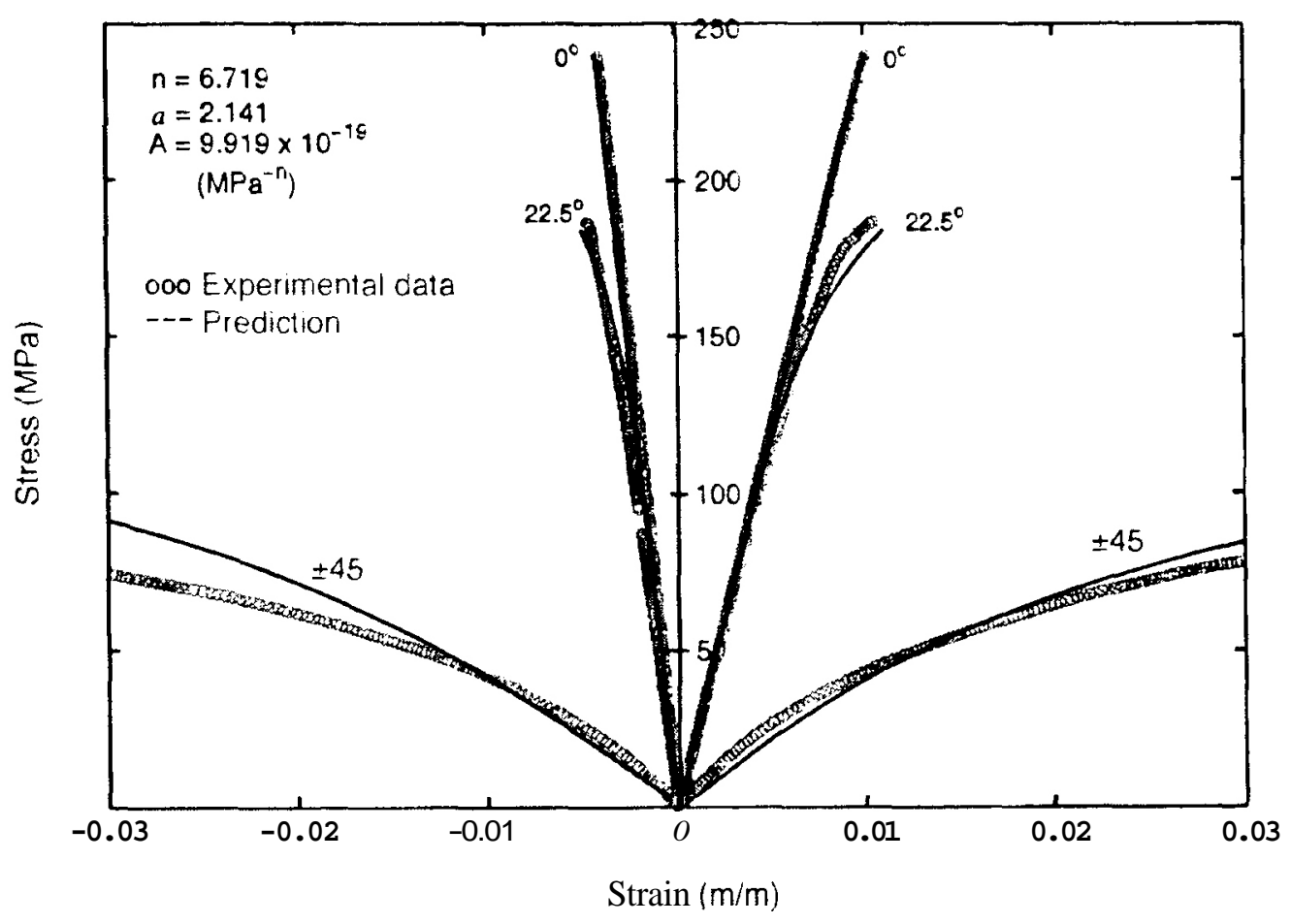

Fig. 58. Predicted and recorded values of longitudinal and transverse strains for the laminates and loading conditions noted in Fig. 55. Predictions based on elasto-plastic behavior with $n=6.719 . \mathrm{a}=2.141$. and $\mathbf{A}=9.919 \times 10^{-19} \mathrm{MPa}^{-n}$. Data for $[ \pm 45]_{3 \mathrm{~S}}$ crossply laminates was included in generating the above values. 
Differentiation of Eq. (47) guves the incremental relationship

$$
d \sigma_{x, i}=\frac{1}{n[h(\theta)]_{i}^{l+\frac{1}{n}} A^{\frac{1}{n}}}\left(\varepsilon_{x, i}^{p}\right)^{\frac{1}{n}-1} d \varepsilon_{x . i}^{p} .
$$

Because, by hypothesis [Eq. (36)], all $\mathcal{E}_{x, i}^{p}$ and $d \varepsilon_{x . i}^{p}$ have common values for all plies. the sumination of all increments $d \sigma_{x . l}$ yields the following expression for the average stress increment:

$$
d \sigma_{3}=\frac{1}{N}\left\{\sum_{i=1}^{N} \frac{1}{n[h(\theta)]_{i}^{1+\frac{1}{n}} A^{\frac{1}{n}}}\right\}\left(\varepsilon_{x}^{p}\right)^{\frac{1}{n-1}} d \varepsilon_{y}^{p}
$$

Consequently, the incremental relationship between laminate level incremental plastic strain $d \varepsilon_{x}^{\mu}$ and stress $d \sigma_{x}$ reads

$$
d \varepsilon_{y}^{l^{\prime}}=\left\{\frac{N n A^{\frac{1}{n}}}{\sum_{i=1}^{N} \frac{1}{[h(\theta)]_{i}^{1+\frac{1}{n}}}}\right\}\left(\varepsilon_{x}^{p}\right)^{1-\frac{1}{n}} d \sigma_{x} .
$$

Note also that in view of Eq. (34), $v_{x 1}^{p}$ has a common value for all plies in the special case of the $\left[ \pm 45^{\circ}\right]_{3 S}$ layups. Consequently. the requirement of uniformity of transverse strains is automatically satisfied in the present circumstance. Equation (50) was solved numerically for stress Increments $\Delta \sigma_{\mathrm{x}}=1 \mathrm{MPa}$. The computations employed the same values of $\boldsymbol{n}, \boldsymbol{a}$, and $\boldsymbol{A}$ as those selected matching the quasi-isotropic data. Results for both $\varepsilon_{\mathrm{x}}$ and $\mathcal{E}_{\mathrm{v}} \mathrm{vs} \sigma_{\mathrm{x}}$ are also shown in Fig. 58, where good agreement is exhibited between computational prediction and experimental data for the crossply composite.

Nevertheless, the current coinputation scheme does not address the requirement that the plastic component of shear stress, namely $\gamma_{x y}^{p}$, should also be common to all plies. It is reasonable to expect that the accounting for this latter requirement would further reduce the level of $\mathbf{a}$, that corresponds to a prescribed level of $E$, thus leading to an even better fit between data and predictions for the response of the $\left[ \pm 45^{\circ}\right]_{3}$ crossply coinposite shown in Fig. 58 .

With regard to the quasi-isotropic specimens, note that the stress-strain data for the $22.5^{\circ}$ load orientation exhibit an abrupt change in slope prior to failure, as can be seen in Fig. 58. A similar behavior was noticed by other researchers, ${ }^{12}$ where such change in slope was attributed to the formation of damage, the representation of which falls beyond the scope of the plasticity formulation used here.

Employing the previous values of $\boldsymbol{a}, \boldsymbol{A}$. and $\boldsymbol{n}$ and the approximate computational scheme, it was possible to predict the departure from quasi-isotropy at increasing stress levels, as loads continue to be directed away from the fiber directions. Results are shown in Fig. 59. 


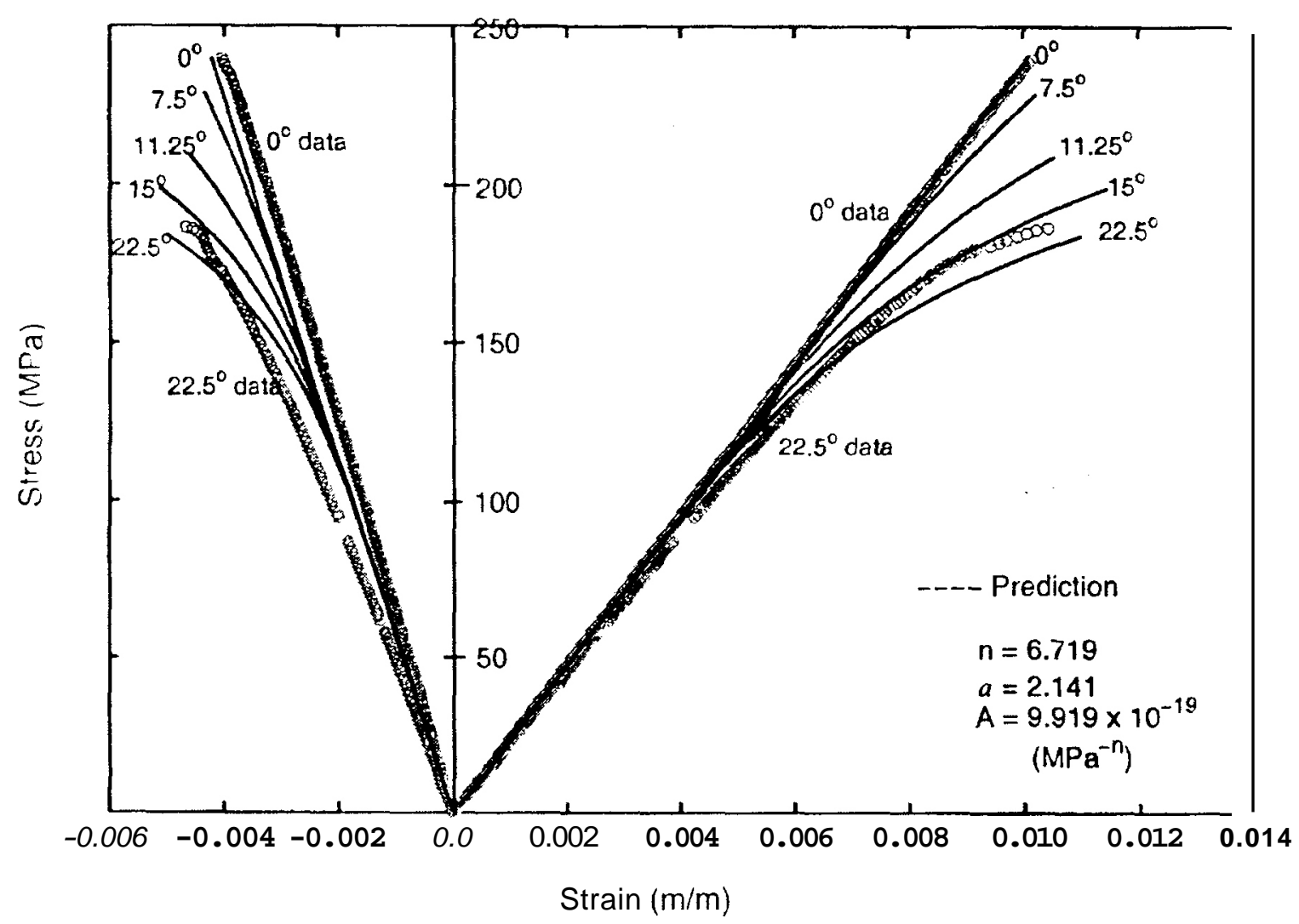

Fig. 59. Predictions of the anisotropic response of quasi-isotropic laminate beyond the lincar range. under loading at various orientations about the fiber direction. Comparative data are shown for $0^{\prime}$ and 22.5 " orientations only.

The plastic components of strain. $\varepsilon^{l}$, and $\varepsilon_{y}^{p}$. are shown in Fig. 60 for both the [0/90/土45]: quasi-isotropic composite, as loads aie directed away from the fiber directions. and for the $[ \pm 45]_{35}$ crossply composite. It can be observed that for the quasi-isotropic composite. the effect of nonlinearity is negligible for stresses below $120 \mathrm{MPa}$. Above $120 \mathrm{MPa}$. nonlinearity becomes significant. and the stress-strain response is no longer isotropic, For the crossply composite. nonlinearity appears to occur even at the low stress range and subsequently induces large in-plane deformation.

An estimate of the error associated with the approximate computation of the quasi-isotropic response at a loading orientation of 22.5". which discarded the required commonality of transverse strains. is exhibited by the curves displayed in Fig. 61. The thin lines in that figure represent the maximum and minimum values of $\varepsilon_{y . i}^{p}$ in individual plies. and the thicker line exhibits the average value of $\varepsilon_{v . l}^{p}$ computed by the approximate method. li can be seen that the width of the error band in terins of strain increases with stress and reaches a range of up to $\pm 20 \%$ at failure. The resulting discrepancy for the $\sigma_{\mathrm{x}}$ vs $\mathcal{E}_{\mathrm{x}}$ plot would obviously be smaller. 


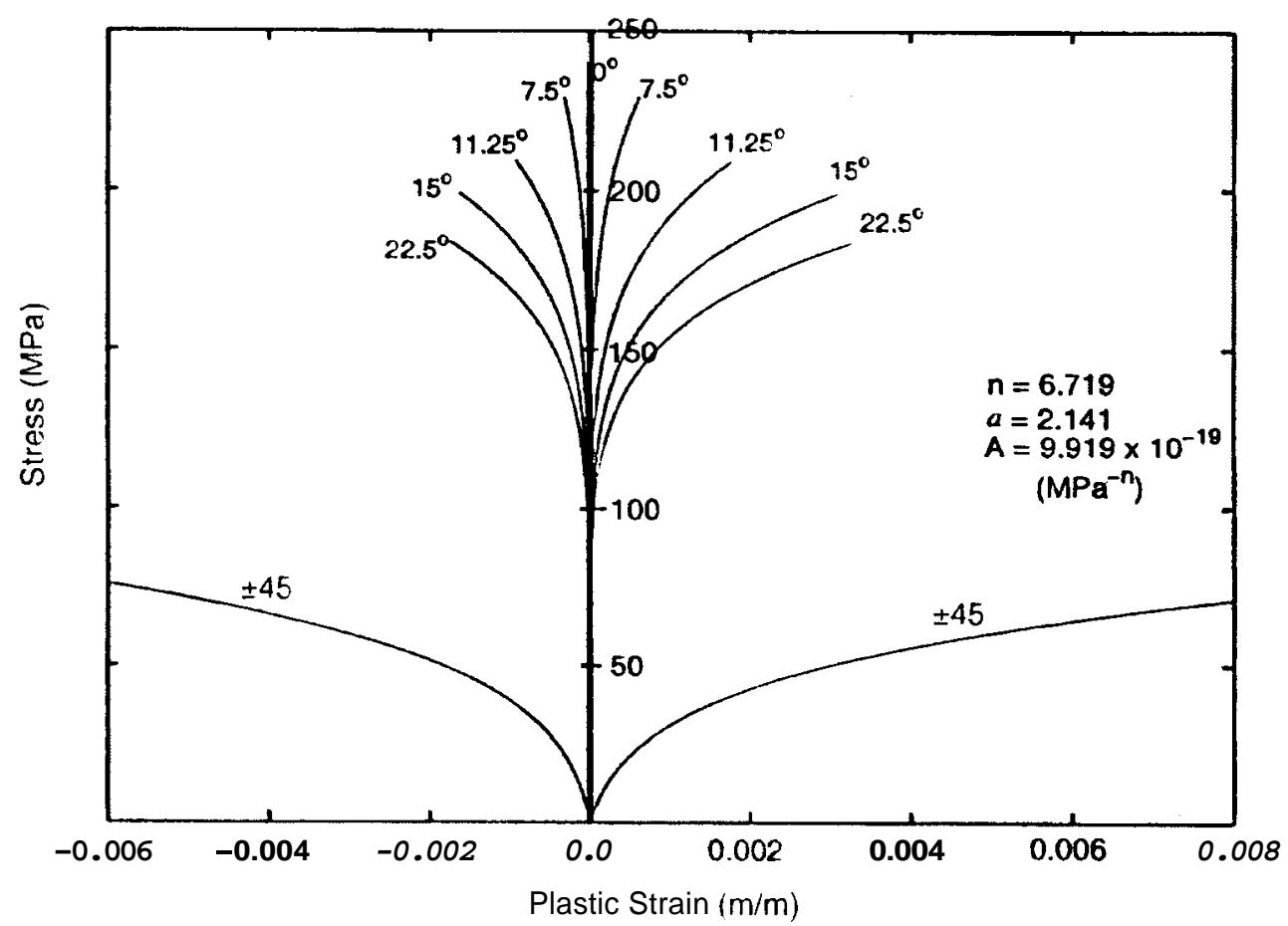

Fig. 60. Predicted values of the longitudinal and transverse components of plastic strains for quasi-isotropic laminates loaded at various orientations about the fiber direction and for $[ \pm 45]_{3 S}$ laminates.

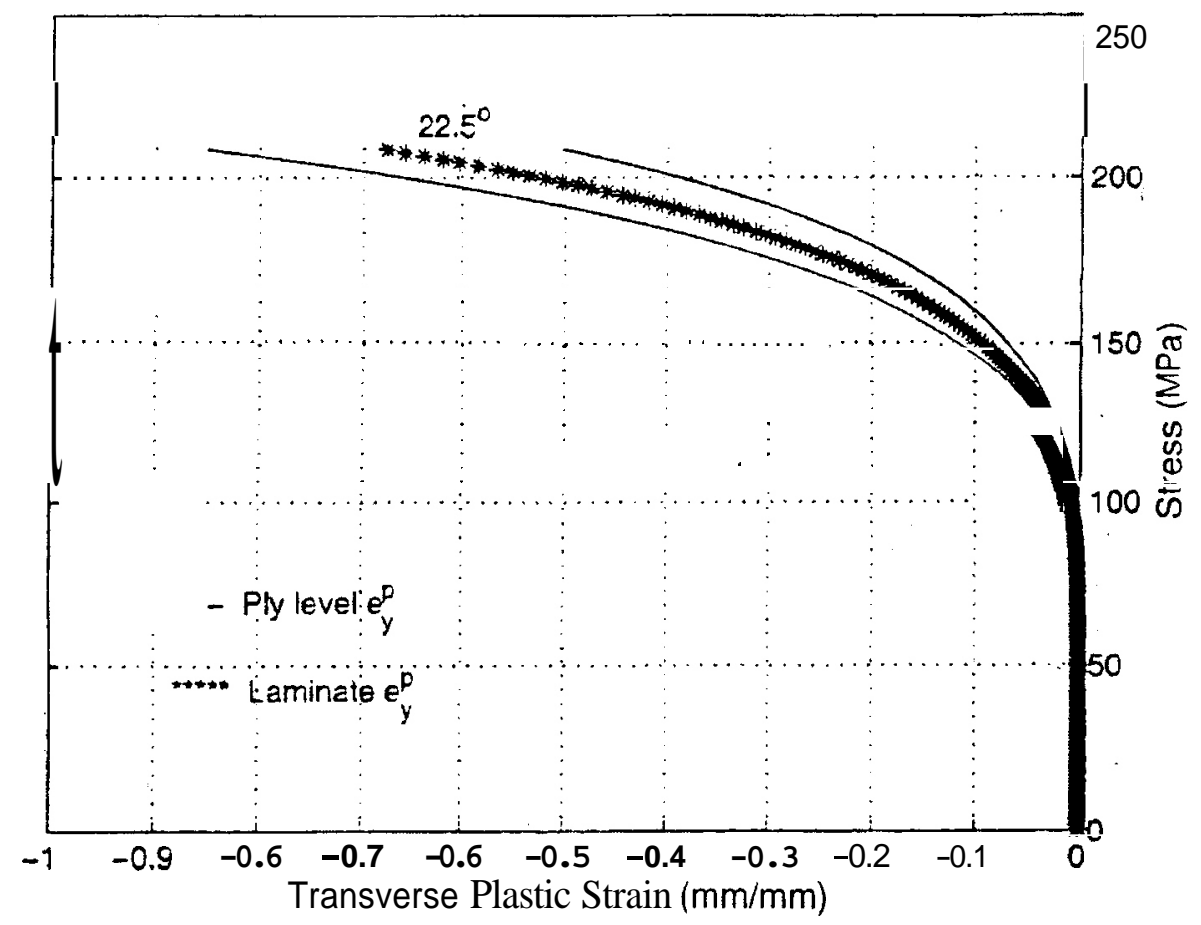

Fig. 61. Maximal and minimal values of transverse plastic strain in the individual plies of a quasi-isotropic laniinate loaded at $22.5^{\circ}$ about the $0^{\circ}$ fiber direction. The disparity provides an error estimate for the approximate scheme. 


\subsection{TIME-DEPENDENT RESPONSE}

\subsubsection{Data}

Similarly to the case of tensile tests. tlie creep and recovery behavior of quasi-isotropic composite coupons was found to depend on the load orientation angle $\phi$. and this dependence was further accentuated with increasing stress amplitudes. Typical creep and recovery curves of quasiisotropic coupons under varnous creep stresses at loading angles $@==0^{\circ}$ and $@=22.5^{\circ}$ are shown in Figs. 62 and 63 , at temperatures of $73{ }^{\circ} \mathrm{C}$ and $120^{\circ} \mathrm{C}$. respectively. Similar results are shown in Fig. 64 for room temperature $\left(23^{\circ} \mathrm{C}\right)$. in which case only five specimens were tested in view of the minimal amount of creep at that temperature level. Nevertheless, it can be seen from the $118.4-\mathrm{MPa}$ tests that even in this case there is a discernible difference between the creep at tie "off-axis" direction of $67.5^{\circ}$ and the case where loads are applied parallel to a fiber directior:. such as $0^{\circ}$ or $90^{\circ}$. Furthermore. Figs. 62- 64 show that the permanent deformation also depends on load orientation angle $\phi$ and Inti-eases with stress and temperature.

\subsubsection{Data Reduction}

By fitting the creep data with a power-law expression. namely

$$
\varepsilon_{1}=\left(D_{0}+D_{1} t^{n}\right) \sigma_{r}
$$

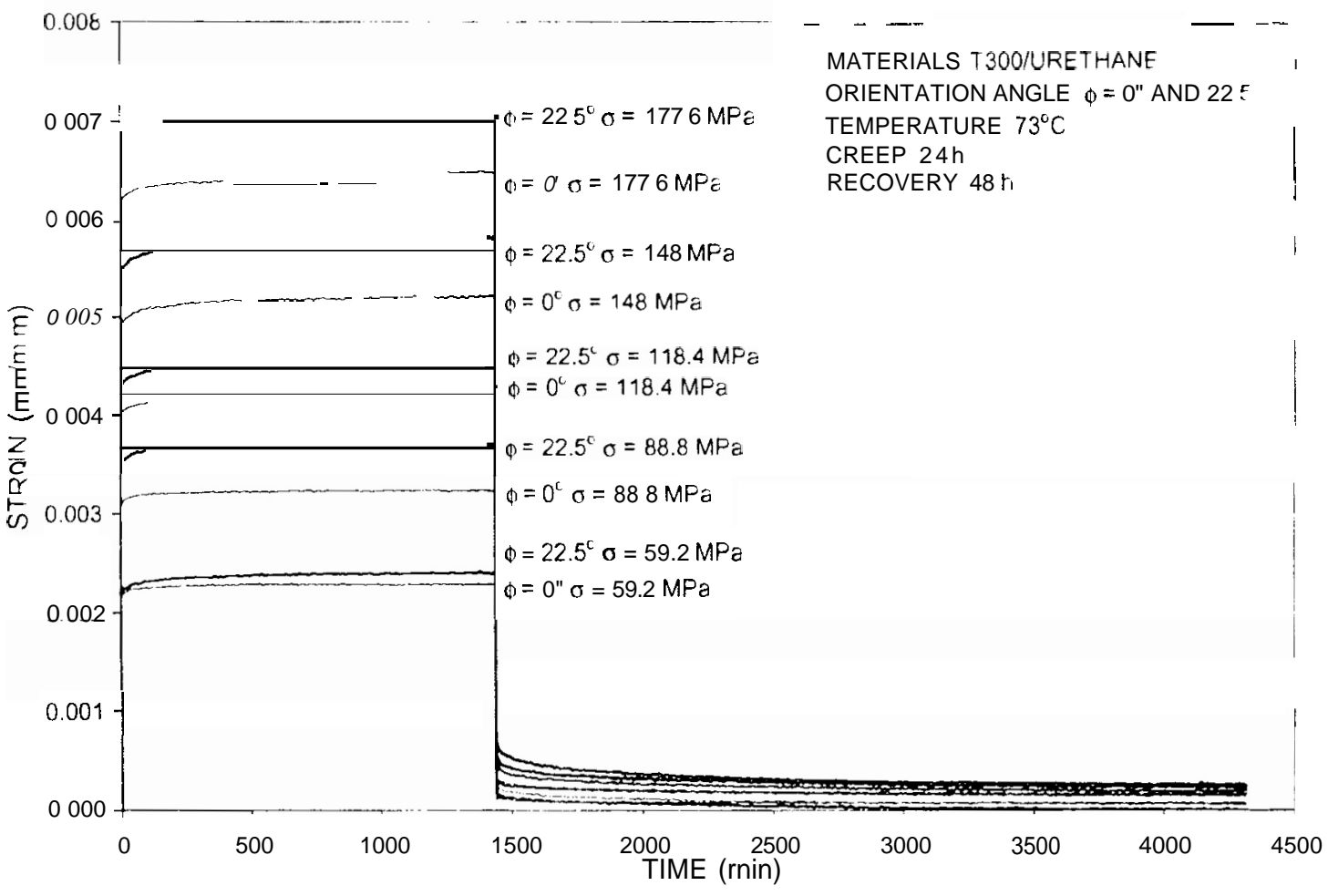

Fig. 62. Typical creep-recosery curves of quasi-isotropic composite with two orientations at $73^{\circ} \mathrm{C}$. 


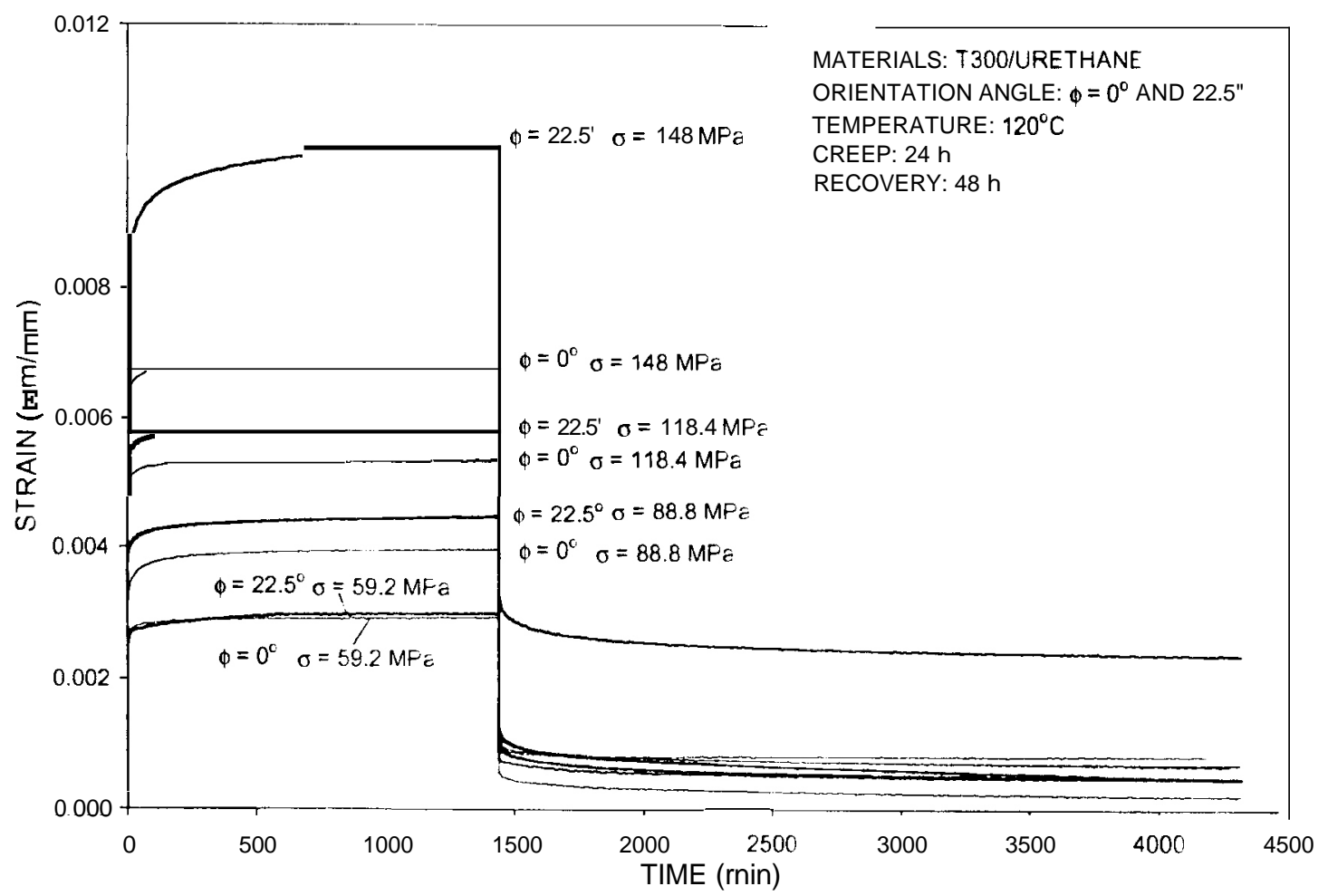

Fig. 63. Typical creep-recovery curves of quasi-isotropic composite with two orientations at $120^{\circ} \mathrm{C}$.

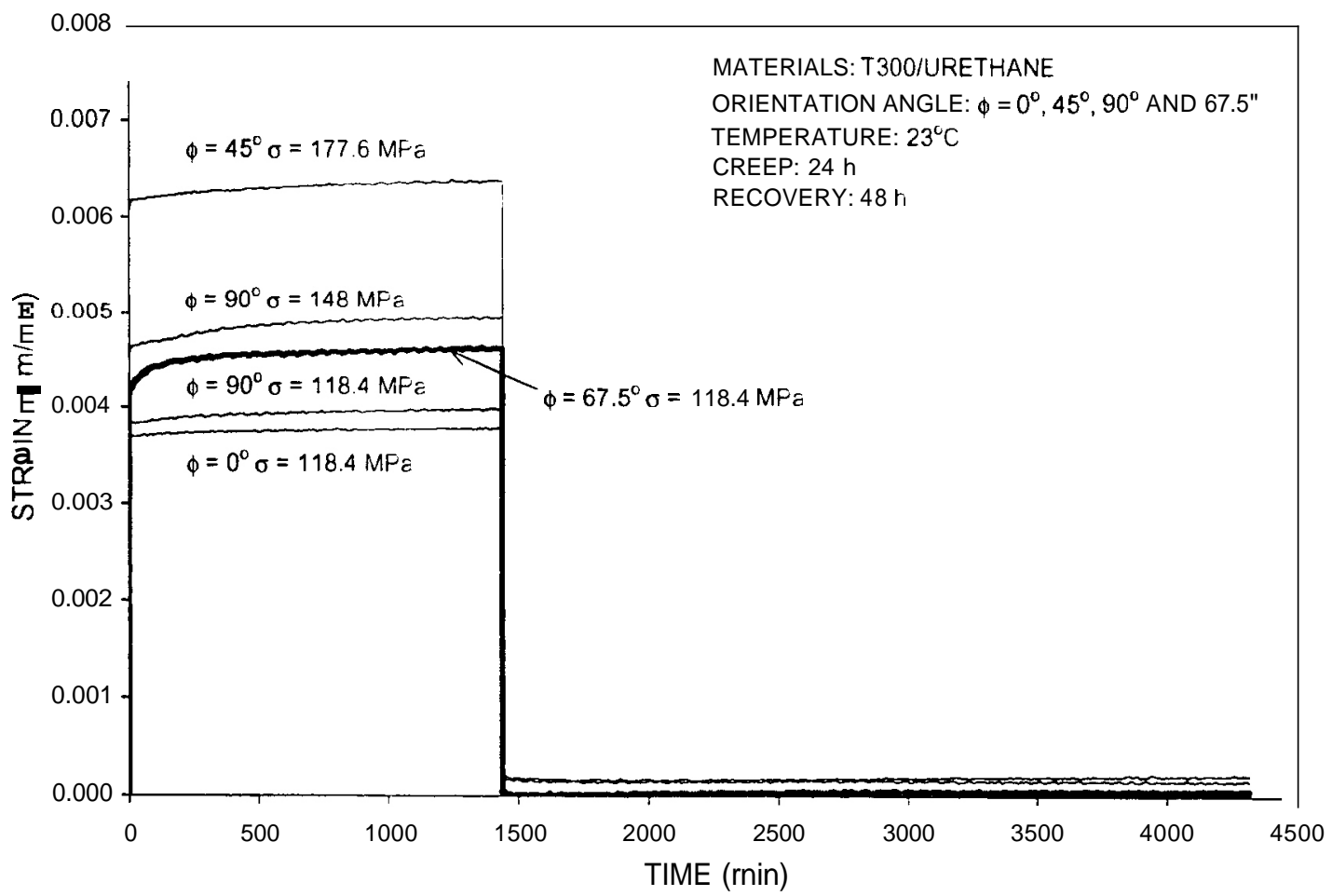

Fig. 64. Typical creep-recovery curves of quasi-isotropic composite with different loading orientations at $23^{\circ} \mathrm{C}$. 
one can obtain the parameters $D_{0}, D_{1}$. and 17 as listed in Tables 8 and Table 9 . These tables suggest that. for these short tests. $D_{1}$.and $D_{1}$ are essentially independent of stress and orientation angle $\phi$. However. the power 17 appears to be higher for $\phi=22.5^{\circ}$ than for $\phi=0^{\circ}$.

\subsubsection{Correlation Retween Tensile Response and Creep Rehavior}

The creep and recovery responses under different loading angles for the quasi-isotropic coupons appear to be consistent with the behavior observed in the tensile tests. Both creep and residual permanent strains were larger at load orientation of $\phi=22.5^{\circ}$ than those that occurred when loads were applied parallel to any of the quasi-isotropic fiber directions. Such difference. can be attributed to Irreversible (plastic) nonlinearity. as depicted by the additional deformation $(\Delta \varepsilon)$ that develops within the coupons loaded at $\phi=22.50$ shown in Fig. 65.

As noted earlier. the quantity $\Delta \varepsilon$ was found to increase with stress and temperature.

\subsubsection{Prediction of Creep Behavior of Quasi-lsotropic Composites Based on Crossply Viscoelastic Characterization}

1-or the quasi-isotropic layup. the In-plane laminate stiffnesses $A_{i j}$ are independent of the loading orientation $\phi$ within the linear range. The following expressions for $A_{i j}$ can be obtained from Eq. (30) upon setting $\alpha=0$ :

$$
\begin{aligned}
& A_{11}=A_{22}=h_{o}\left[3\left(Q_{11}+Q_{22}\right)+2 Q_{12}+4 Q_{66}\right] \\
& A_{12}=h_{o}\left[\left(Q_{11}+Q_{22}\right)+6 Q_{12}-4 Q_{66}\right] . \\
& A_{16}=A_{26}=0 . \\
& A_{66}=h_{0}\left[\left(Q_{11}+Q_{22}\right)-2 Q_{12}+4 Q_{66}\right] .
\end{aligned}
$$

\begin{tabular}{|c|c|c|c|c|c|}
\hline $\begin{array}{c}O_{\prime \prime} \\
(\mathrm{MPa})\end{array}$ & $\begin{array}{l}\text { Creep } \\
\text { time } \\
\text { (h) }\end{array}$ & $\begin{array}{l}\text { Recovery } \\
\text { time } \\
\text { (h) }\end{array}$ & $\begin{array}{c}D_{0} \\
\left(\mathrm{MPa}^{-1}, \times 10^{-5}\right)\end{array}$ & $\begin{array}{c}D_{1} \\
\left(\mathrm{MPa}^{-\mathrm{n}} \min ^{-\mathrm{n}}, \times 10^{-6}\right)\end{array}$ & $n$ \\
\hline 59.2 & 24 & 48 & 3.43 & 1.44 & 0.045 \\
\hline 59.2 & 24 & $4 \mathrm{~h}$ & 3.58 & 2.01 & 0.045 \\
\hline 88.8 & 24 & 48 & 3.34 & 3.31 & 0.050 \\
\hline 88.8 & 24 & 48 & 3.93 & 2.20 & 0.045 \\
\hline 88.8 & 24 & 48 & 3.34 & 2.20 & 0.045 \\
\hline 118.4 & 24 & 48 & 3.51 & 1.78 & 0.045 \\
\hline 118.4 & 24 & 48 & 3.45 & 1.08 & 0.045 \\
\hline 118.4 & 24 & 48 & 3.51 & 2.15 & 0.080 \\
\hline 148 & 24 & 48 & 3.28 & 1.53 & 0.060 \\
\hline 148 & 24 & 48 & 3.84 & 1.48 & 0.060 \\
\hline 177.6 & 24 & 48 & 3.58 & 4.00 & 0.050 \\
\hline 177.6 & 24 & 48 & 2.96 & 6.20 & 0.040 \\
\hline
\end{tabular}

Table 8. Parameters used for the simulations of the creep and recovery results

$$
\left(\phi=0^{\circ}, 7^{\circ} \mathrm{C}\right)
$$


Table 9. Parameters used for the simulations of the creep and recovery results

\begin{tabular}{|c|c|c|c|c|c|}
\hline \multirow[b]{2}{*}{$\begin{array}{c}\sigma_{0} \\
(\mathrm{MPa})\end{array}$} & \multirow[b]{2}{*}{$\begin{array}{l}\text { Creep } \\
\text { time } \\
\text { (h) }\end{array}$} & \multicolumn{3}{|c|}{$\left(\phi=22.5^{\circ}, 73^{\circ} \mathrm{C}\right)$} & \multirow[b]{2}{*}{$n$} \\
\hline & & $\begin{array}{l}\text { Recovery } \\
\text { time } \\
\text { (h) }\end{array}$ & $\begin{array}{c}D_{0} \\
\left(\mathrm{MPa}^{-1}, \times 10^{-5}\right)\end{array}$ & $\begin{array}{c}D_{1} \\
\left(\mathrm{MPa}^{-\mathrm{n}} \min ^{-\mathrm{n}}, \times 10^{-6}\right)\end{array}$ & \\
\hline 59.2 & 24 & 48 & 3.49 & 2.95 & 0.080 \\
\hline 59.2 & 24 & $4 \mathrm{~s}$ & 3.61 & 2.50 & 0.080 \\
\hline 88.8 & 24 & 48 & 3.74 & 3.05 & 0.045 \\
\hline 88.6 & 24 & 48 & 2.93 & 4.80 & 0.055 \\
\hline 118.4 & 24 & 48 & 3.44 & 2.14 & 0.080 \\
\hline 118.4 & 24 & $4 \mathrm{P}$ & 3.70 & 0.65 & 0.080 \\
\hline 148 & 24 & 48 & 3.87 & 3.41 & 0.045 \\
\hline 148 & 24 & 48 & 3.51 & 1.60 & 0.090 \\
\hline 177.6 & 24 & 48 & 3.53 & 1.00 & 0.050 \\
\hline 177.6 & 24 & 48 & 3.53 & 1.68 & 0.045 \\
\hline 177.6 & 24 & $4 \mathrm{P}$ & 3.59 & 2.35 & 0.070 \\
\hline
\end{tabular}

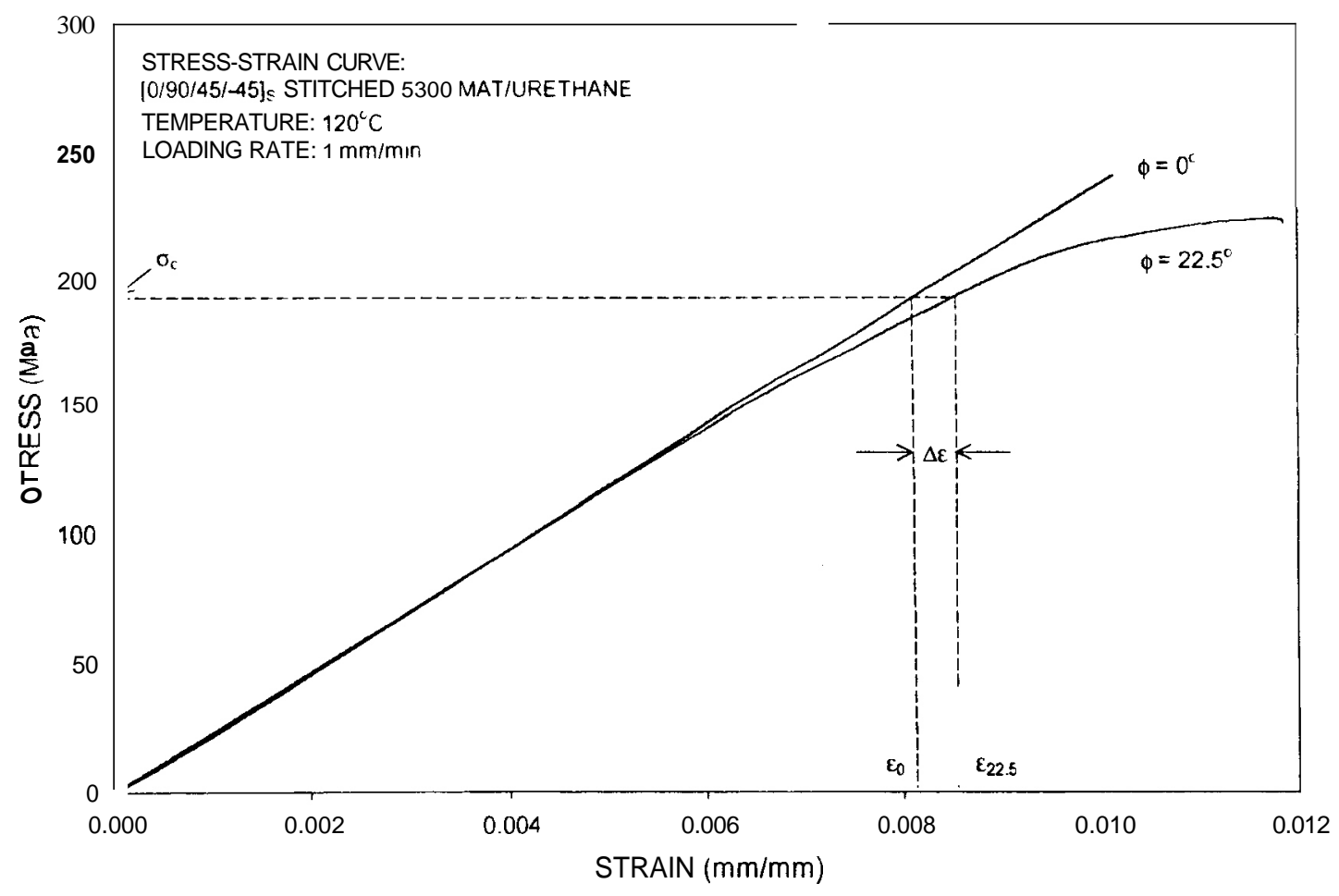

Fig. 65. Typical stress-strain to failure response of quasi-isotropic composite at $120^{\circ} \mathrm{C}$ with loads applied at $\phi=0^{\circ}$ and $\phi=22.5^{\circ}$ about the fiber direction. 
Subsequently, Eq. (6) yields the following relationship between longitudinal strain E,. ana stress $\sigma_{\lambda}$ :

$$
\varepsilon_{x}=n_{p} \frac{3\left(Q_{11}+Q_{22}\right)+2 Q_{12}+4 Q_{0 x}}{\left[3\left(Q_{11}+Q_{22}\right)+2 Q_{12}+4 Q_{66}\right]^{2}-\left[\left(Q_{11}+Q_{22}\right)+6 Q_{12}-4 Q_{66}\right]^{2}} \sigma_{x} .
$$

As noted in Sect. 5.1. it is possible to attribute all time dependence lo $Q_{66}$ and express it by means of Eq. (27).

Upon employing $D_{\mathrm{o}}=4.18 \times 10^{-5} \mathrm{MPa}^{-1}, D_{1}=6.6 \times 10^{-6} \mathrm{MPa}^{-n} \min ^{-\mathrm{n}}$. and $n=0.245 \mathrm{as}$ power-law creep parameters that fall within the range of values that fit the creep data for the crossply composite, it is possible to predict the creep behavior of the quasi-isotropic composite by substituting Eq. (27) into Eq. (53). An example for such a prediction is shown in Fig. 66.

Although the values of the instantaneous strain are subject to some uncertainty that is attributable to sample-to-sample variability in the value of $Q_{11}+Q_{22}$, the predicted time-dependent portion of strain falls parallel to the recorded data. exhibiting excellent agreement with experiinental results.

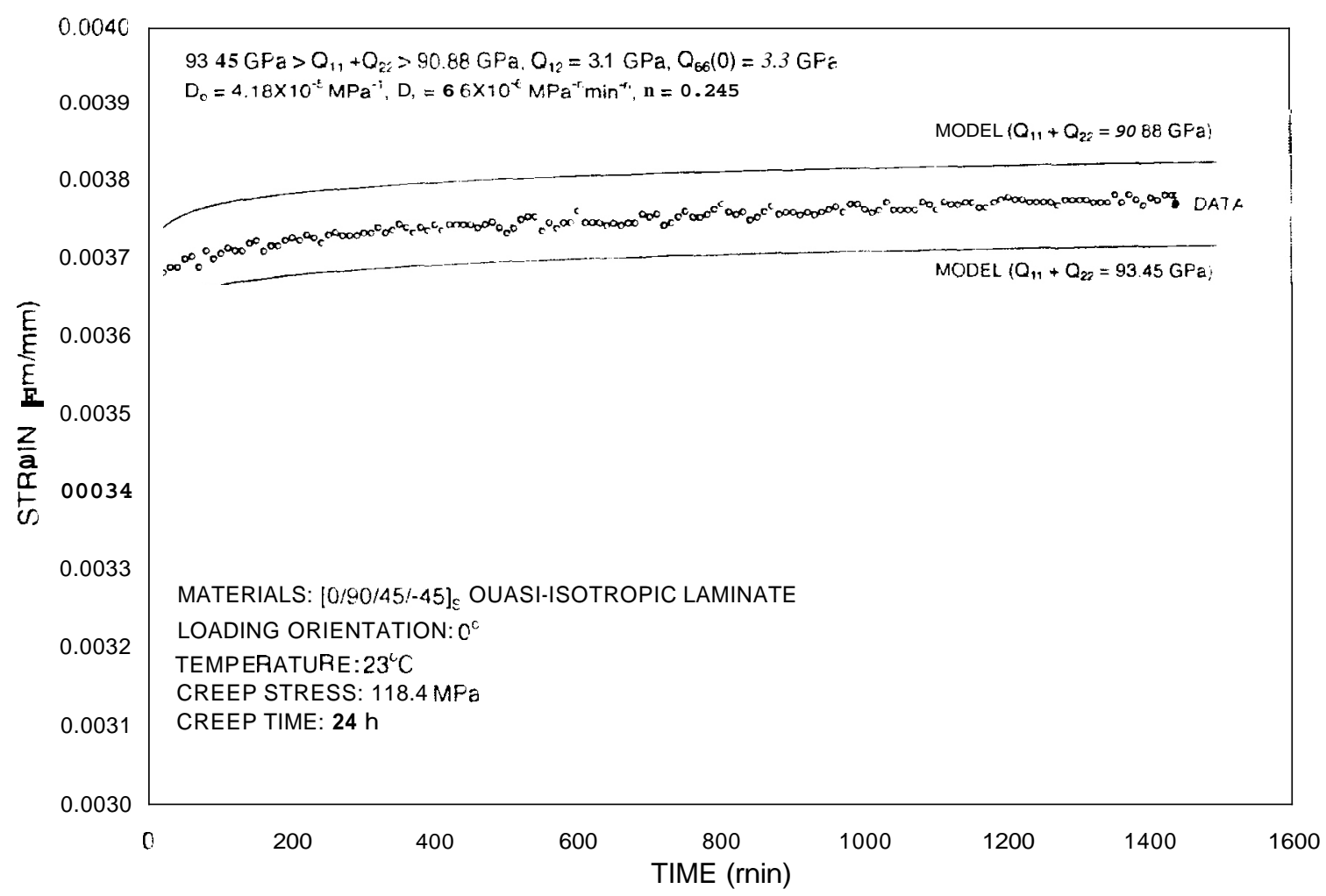

Fig. 66. Pi.tdiction of creep hehav ior of quasi-isotropic composite based on crossply viscoelastic characterization. 


\section{CONCLUSIONS}

The mechanical behavior of stitched T300 mat/urethane 420 IMR composites exhibits a substantial degree of randomness. which most likely results from the presence of multitudes of initial flaws that can be attributed to nonuniformities in resin penetration during the rapid injection process and the nonuniform fiber spacing. The effect of this randomness becomes especially pronounced at elevated stresses and temperatures. Creep under sustained loading, as well as nonlinearity in material response, are caused by the inherent molecular structure of the polymeric phase, but their extents are enhanced by the growth of the abovementioned internal flaws. Because carbon fibers arrest nearly all creep parallel to their directions. this aspect of material behavior is nearly absent in quasi-isotropic laminates. For this same reason. both deformation and creep of crossply layups are highly sensitive to load orientation. This directional dependence of material behavior limits the applicability of crossply laminates to those circumstances where the directions of anticipated design loads are well defined.

In spite of the randomness. it is possible to establish a well-defined safe range for the load carrying capacity of the composite. Within this range, which overlaps the region of linear response, it is possible to predict the behavior of these laminates by means of classical laminate theory in combination with linear viscoelasticity. Note that the light stitching incorporated within the composite has no detrimental effect on its behavior. 
-

-

-

-

-

-

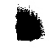

-

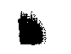

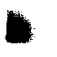

-

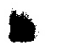

$\mathbf{b}$

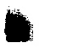

$\mathbf{b}$ 


\section{REFERENCES}

1. J. M. Corum et al., Basic Properties of Reference Crossply Carbon-Fiber Composite, ORNL/TM-2000/29. Oak Ridge National Laboratory, March 2000.

2. J. M. Corum et al., Durability-Based Design Properties of Reference Crossply CarbonFiber Composite, ORNL/TM-2000/322. Oak Ridge National Laboratory, April 2001.

3. J. M. Corum et al., Durability-Based Design Criteria for a Quasi-Isotropic Carbon-Fiber Aunomonive Composite, ORNL/TM-2002/39, Oak Ridge National Laboratory, March 2002.

4. S. Deng and Y. Weitsman, Mechanical Response of Sritched T300 Mat/Urethane 420

IMR composite Laminates; Property/Orientation Dependence and Damage Evolution,

ORNL/TM-2000/103, Oak Ridge National Laboratory Report, February 2000.

5. ASTM Standard D34 10-87. Standard Test Method for Compressive Properties of Unidirectional or Crossply Fiber-Resin Composites. American Society for Testing and Materials.

6. J. Gao and Y. Weitsman. The Tensile Mechanical Properties and Failure Behavior of Srirched T300 Mat/Urethane 420 IMR Composite, The University of Tennessee Report, MAES98-2.0-CM. July 1998.

7. J. C. Halpin, Revised Primer on Composite Materials: Analysis, 2nd ed., Technomic Publishing Co., Stamford, CT, 1992.

8. J. W. Dally and W. F. Riley. Experimental Stress Analysis, McGraw-Hill, lnc., New York, 1991.

9. A. C. Pipkin and T. G. Ropers. "A Non-Linear Integral Representation for Viscoelastic Behavior," J. Mech. Phys. Solids, 16, 1968, pp. 59-72.

10. S. W. Tsai and H. T. Hahn. Introduction to Composite Materials, Technomic Publishing Co.. Stamford, CT, 1980.

11. C. T. Sun and J. L. Chen. "A Simplified Flow Rule for Characterizing Nonlinear Behavior of Fiber Composites." J. Coinp. Mater., 23, October 1989,pp. 1009-1020.

12. C. T. Sun and K. J. Yoon. "Elastic-Plastic Analysis of AS4/PEEK Composite laminate Using a One-Parameter Plasticity Model," J. Comp. Marer., 26(2), 1992, pp. 293-308.

13. R. A. Schapery, "Nonlinear Viscoelastic and Viscoplastic Constitutive Equations Based on Thermodynamics," Mechanics of Time-Dependent Materials, 1(2), 1997, pp. 209-240.

14. V. M. Winn and S. Sridharan, "An Investigation into the Accuracy of a One-Parameter Nonlinear Model for Unidirectional Composites," J. Comp. Mater., 16, 2001, pp. 1491-1507. 
-

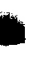

-

-

-

w

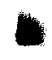

$\checkmark$

b

-

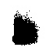

b

b

-

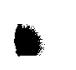

- 


\section{Appendix A. 10WER-LAW PARAMETERS}

Table A.1. Best-fit power-law parameters $D_{0}, D_{1}$, and $n$ for creep data at $31 \mathrm{MPa}$ and several temperatures. Modified values correspond to viscoelastic creep $\mathcal{E}_{v}(t)$ after accounting lor permanent strains $\varepsilon_{p}(t, T . \sigma, \phi)$. (Fits for individual replicate sample data)

\begin{tabular}{|c|c|c|c|c|c|c|c|c|}
\hline \multirow{2}{*}{$\begin{array}{c}\sigma_{\mathbf{0}} \\
(\mathbf{M P a})\end{array}$} & \multirow{2}{*}{$\begin{array}{l}\text { Creep } \\
\text { time } \\
(\mathrm{h})\end{array}$} & \multirow{2}{*}{$\begin{array}{l}\text { Recovery } \\
\text { time } \\
\text { (h) }\end{array}$} & \multicolumn{2}{|c|}{$\begin{array}{c}D_{0} \\
\left(\mathrm{MPa}^{-1} \cdot \times 10^{-5}\right)\end{array}$} & \multicolumn{2}{|c|}{$\begin{array}{c}D_{1} \\
\left(\mathrm{MPa}^{-\mathrm{n}} \min ^{-n}, \times 10^{-6}\right)\end{array}$} & \multicolumn{2}{|l|}{$n$} \\
\hline & & & Unmodified & Modified & Lnmodified & Modified & Unmodified & Modified \\
\hline \multirow{3}{*}{$\begin{array}{c}120^{\circ} \mathrm{C} \\
31\end{array}$} & & & & & & & & \\
\hline & $\begin{array}{l}5 \\
5\end{array}$ & $\begin{array}{l}15 \\
15\end{array}$ & $\begin{array}{l}19.0 \\
22.3\end{array}$ & $\begin{array}{c}19.0 \\
22.3\end{array}$ & $\begin{array}{l}219.0 \\
340.0\end{array}$ & $\begin{array}{l}164.0 \\
215.0\end{array}$ & $\begin{array}{l}0.166 \\
0.110\end{array}$ & $\begin{array}{l}0.135 \\
0.102\end{array}$ \\
\hline & 5 & 15 & 21.3 & 21.3 & 239.0 & 164.0 & 0.135 & 0.110 \\
\hline \multicolumn{9}{|l|}{$73^{\circ} \mathrm{C}$} \\
\hline 31 & $\begin{array}{l}1 \\
1\end{array}$ & $\begin{array}{l}15 \\
15\end{array}$ & $\begin{array}{l}11.0 \\
13.3\end{array}$ & $\begin{array}{l}11.0 \\
13.3\end{array}$ & $\begin{array}{l}27.4 \\
23.1\end{array}$ & $\begin{array}{c}21.4 \\
19.0\end{array}$ & $\begin{array}{l}0.258 \\
0.287\end{array}$ & $\begin{array}{l}0.264 \\
0.296\end{array}$ \\
\hline \multirow[t]{3}{*}{31} & 5 & 15 & 9.58 & 9.58 & 36.4 & 20.0 & 0.167 & 0.210 \\
\hline & c & 15 & 10.4 & 10.4 & 30.3 & 19.0 & 0.210 & 0.220 \\
\hline & $<$ & 15 & 9.45 & 9.45 & 31.1 & 19.2 & 0.206 & 0.230 \\
\hline \multirow[t]{2}{*}{31} & 24 & 48 & 9.03 & 9.03 & 63.3 & 34.2 & 0.138 & 0.150 \\
\hline & 24 & 48 & 10.7 & 10.7 & 37.8 & 25.0 & 0.149 & 0.140 \\
\hline \multicolumn{9}{|l|}{$50^{\circ} \mathrm{C}$} \\
\hline \multirow[t]{3}{*}{31} & 5 & 15 & 10.4 & 10.4 & 11.7 & 10.6 & 0.231 & 0.240 \\
\hline & 5 & 15 & 9.34 & 9.34 & 9.00 & 7.12 & 0.284 & 0.285 \\
\hline & 5 & 15 & 11.5 & 11.5 & 10.7 & 8.03 & 0.281 & 0.290 \\
\hline \multicolumn{9}{|l|}{$23^{\circ} \mathrm{C}$} \\
\hline \multirow[t]{3}{*}{31} & 5 & 15 & 7.74 & 7.74 & 3.44 & 2.58 & 0.205 & 0.198 \\
\hline & 5 & 15 & 8.25 & 8.25 & 1.99 & 1.66 & 0.320 & 0.330 \\
\hline & $\varepsilon$ & 15 & 8.12 & 8.12 & 0.95 & 0.59 & 0.340 & 0.380 \\
\hline \multirow[t]{2}{*}{31} & 24 & 48 & 8.23 & 8.23 & 5.11 & 5.25 & 0.194 & 0.145 \\
\hline & 24 & 48 & 7.65 & 7.65 & 8.85 & 7.88 & 0.101 & 0.101 \\
\hline
\end{tabular}


Table A.2. Best-fit power-law parameters $D_{0}$. $D_{1}$. and $n$ for creep data at $46.5 \mathrm{MPa}$ and several temperatures. Modified values correspond to viscoelastic creep $\mathcal{E}_{v}(t)$ after accounting for permanent strains $\mathcal{E}_{j}(t, 7, \sigma, \phi)$. (Fits for individual replicate sample data)

\begin{tabular}{|c|c|c|c|c|c|c|c|c|}
\hline \multirow[t]{2}{*}{$\begin{array}{c}\sigma_{0} \\
(\mathrm{MPa})\end{array}$} & \multirow{2}{*}{$\begin{array}{l}\text { Creep } \\
\text { lime } \\
\text { (h) }\end{array}$} & \multirow{2}{*}{$\begin{array}{c}\text { Recovery } \\
\text { time } \\
\text { (h) }\end{array}$} & \multicolumn{2}{|c|}{$\begin{array}{c}D_{11} \\
\left(\mathrm{MPa}^{-1} \times 10^{-5}\right)\end{array}$} & \multicolumn{2}{|c|}{ 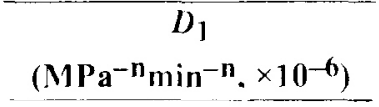 } & \multicolumn{2}{|c|}{$n$} \\
\hline & & & Inmodified & Yondified & Lnmodified & Modified & Linmodified & Modilied \\
\hline \multirow[t]{3}{*}{$\begin{array}{r}120^{\circ} \mathrm{C} \\
46.5\end{array}$} & $\varepsilon$ & $\begin{array}{l}15 \\
15\end{array}$ & $\begin{array}{l}28.8 \\
252\end{array}$ & $\begin{array}{l}28.8 \\
25.2\end{array}$ & $\begin{array}{l}243.0 \\
226.0\end{array}$ & $\begin{array}{l}229.1 \\
202.0\end{array}$ & $\begin{array}{l}0.203 \\
0.203\end{array}$ & $\begin{array}{l}0.12 \\
0.120\end{array}$ \\
\hline & 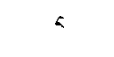 & 15 & 164 & 16.4 & 151.0 & 52.9 & 0.204 & 0.198 \\
\hline & $\varepsilon$ & 15 & 161 & 16.1 & 118.0 & $88^{-}$ & 0.168 & 0.150 \\
\hline $\begin{array}{r}73^{\circ} \mathrm{C} \\
46.5\end{array}$ & 1 & $\begin{array}{l}15 \\
15\end{array}$ & $\begin{array}{l}13.5 \\
126\end{array}$ & $\begin{array}{l}13 . \\
12.6\end{array}$ & $\begin{array}{l}39.6 \\
24.9\end{array}$ & $\begin{array}{l}27.5 \\
14.4\end{array}$ & $\begin{array}{l}0.318 \\
0.227\end{array}$ & $\begin{array}{l}0.332 \\
0.320\end{array}$ \\
\hline 46.5 & $\begin{array}{l}5 \\
5 \\
5\end{array}$ & $\begin{array}{l}15 \\
15 \\
15 \\
15\end{array}$ & $\begin{array}{l}10 . \mathrm{h} \\
10.6 \\
10 . \mathrm{h} \\
10.5\end{array}$ & $\begin{array}{l}10.6 \\
10.6 \\
10.6 \\
10.5\end{array}$ & $\begin{array}{l}57.9 \\
60.9 \\
47.8 \\
47.5\end{array}$ & $\begin{array}{l}25.8 \\
33.0 \\
34.5 \\
28.5\end{array}$ & $\begin{array}{l}0.146 \\
0.130 \\
0.179 \\
0.184\end{array}$ & $\begin{array}{l}0.210 \\
0.155 \\
0.165 \\
0.18 .\end{array}$ \\
\hline 46.5 & $\begin{array}{l}24 \\
24\end{array}$ & $\begin{array}{l}48 \\
48\end{array}$ & $\begin{array}{l}11.5 \\
10.7\end{array}$ & $\begin{array}{l}11.5 \\
10.7\end{array}$ & $\begin{array}{l}107.0 \\
38.3\end{array}$ & $\begin{array}{l}85.9 \\
20.9\end{array}$ & $\begin{array}{l}0.129 \\
0.146\end{array}$ & $\begin{array}{l}0.12 \gamma \\
0.145\end{array}$ \\
\hline \multicolumn{9}{|l|}{$50^{\circ} \mathrm{C}$} \\
\hline 46.5 & $\varepsilon$ & 15 & 9.39 & 9.34 & 12.5 & $11 . \hat{3}$ & 0.265 & 0.245 \\
\hline & $=$ & $\begin{array}{l}15 \\
15\end{array}$ & $\begin{array}{l}8.52 \\
8.97\end{array}$ & $\begin{array}{l}8.5 \% \\
8.9 \%\end{array}$ & $\begin{array}{l}16.2 \\
14.8\end{array}$ & $\begin{array}{l}11.9 \\
12.7\end{array}$ & $\begin{array}{l}0.220 \\
0.249\end{array}$ & $\begin{array}{l}0.230 \\
0.220\end{array}$ \\
\hline \multicolumn{9}{|l|}{$23^{\circ} \mathrm{C}$} \\
\hline 46.5 & 5 & 15 & 8.37 & 8.37 & 3.92 & 3.24 & 0.232 & 0.245 \\
\hline & 5 & If; & 8.30 & 8.30 & 4.94 & 4.59 & 0.244 & 0.24 ? \\
\hline & 5 & IS & 8.99 & 8.99 & 2.61 & 2.68 & 0.286 & 0.268 \\
\hline 46.5 & $\begin{array}{l}24 \\
24 \\
24\end{array}$ & $\begin{array}{l}48 \\
48 \\
48\end{array}$ & $\begin{array}{l}7.73 \\
8.14 \\
7.36\end{array}$ & $\begin{array}{l}7.73 \\
8.14 \\
7.36\end{array}$ & $\begin{array}{l}7.95 \\
7.65 \\
6.95\end{array}$ & $\begin{array}{l}5.75 \\
6.85 \\
6.49\end{array}$ & $\begin{array}{l}0.164 \\
0.164 \\
0.164\end{array}$ & $\begin{array}{l}0.160 \\
0.145 \\
0.155\end{array}$ \\
\hline
\end{tabular}




\section{Appendix B. OPTIMAL DETERMINATION OF LINEAR PARAMETERS $A_{1}$ AND NONLINEAR PARAMETERS $\tau_{\mathrm{i}}$ OF THE PRONY SERIES}

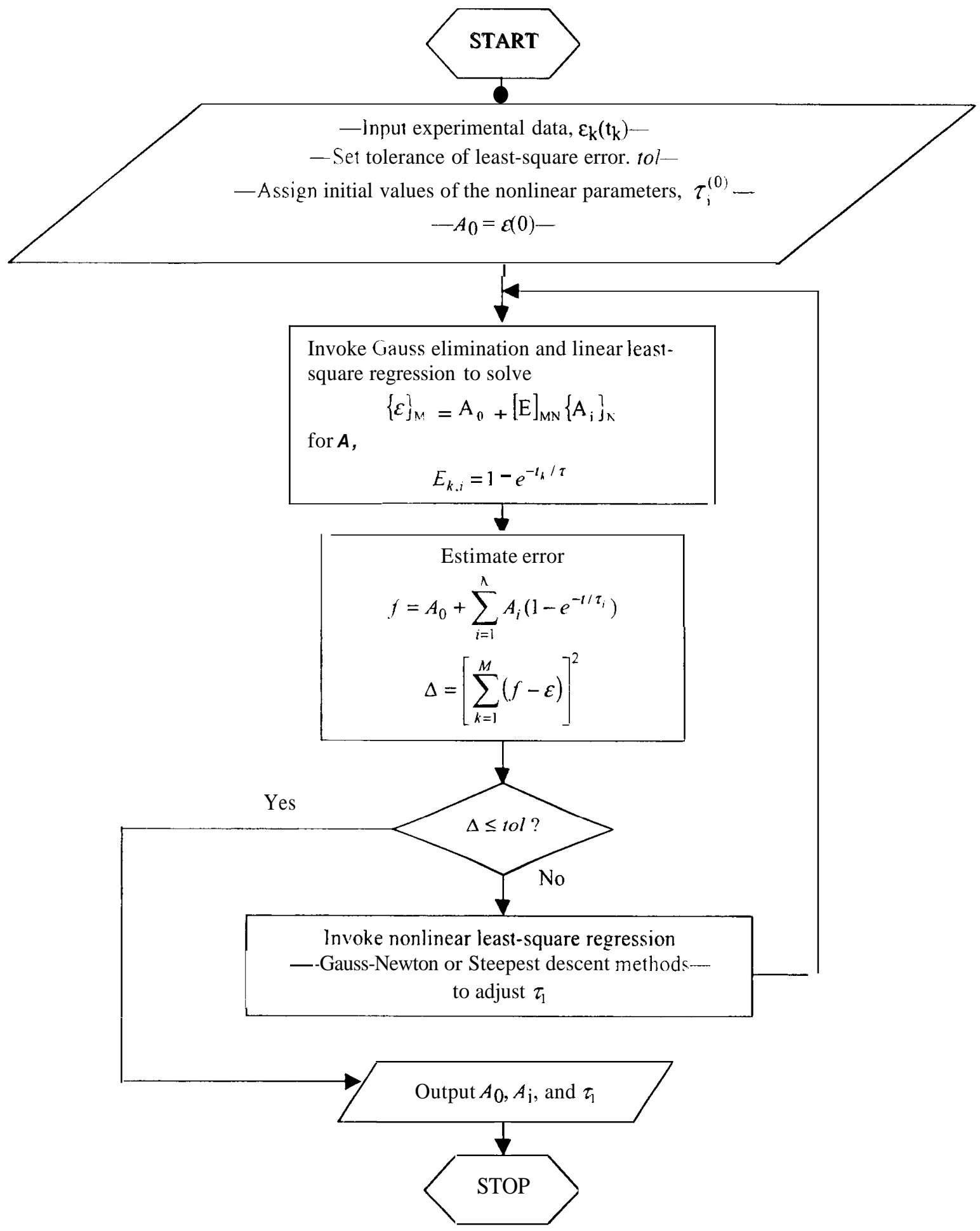

B-1 
0

-

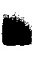

$\mathbf{v}$

-

-

-

-

-

.

-

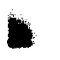

$\Delta$

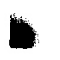

$\bullet$

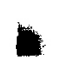

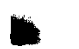

B-2

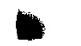




\section{Appendix C. THE MODELING OF PLASTIC NONLINEARITY IN POLYMERIC COMPOSITES}

This appendix summarizes the three-parameter plasticity model proposed by Sun and Chen. ${ }^{1}$ The model assumes the distortional energy in a unidirectionally reinforced composite lamina for the state of plane stress to be given b!

$$
2 f\left(\sigma_{i j}\right)=\sigma_{22}^{2}+2 a \tau_{12}^{2} \leq k
$$

where $a$ is an empirical plastic parameter, $\sigma_{22}$ is the in-plane stress transverse to the fiber direction. and $\tau_{12}$ is the in-plane shear stress. Also $f$ is the yield function. and $k$ represents the yield surface at which plastic flow occurs. The incremental plastic strain is given by:

$$
d \varepsilon_{i j}^{l}=\frac{\partial f}{\partial \sigma_{i j}} d \lambda
$$

In Eq. (C.2), $d \lambda$ is a proportionality factor. termed the plastic multiplier.

Substituting Eq. (C.1) into (C.2) the plastic strain components may be expressed in an expanded form:

$$
\left\{\begin{array}{l}
d \varepsilon_{11}^{p} \\
d \varepsilon_{22}^{p} \\
d \gamma_{12}^{p}
\end{array}\right\}=\left\{\begin{array}{c}
0 \\
\sigma_{22} \\
2 a \tau_{12}
\end{array}\right\} d \hat{\lambda} .
$$

Consider incremental plastic work per unit volume:

$$
d W^{p}=\sigma_{i j} d \varepsilon_{i j}^{p}=2 f d \lambda
$$

Based on equivalent plastic work, a measure of plasticity may be related by effective stress and effective plastic strain, which are defined as

$$
\bar{\sigma}=\sqrt{3 f}, \text { or } f=\frac{u}{n}
$$

and thus

$$
d \bar{\varepsilon}^{p}=\frac{2}{3} \bar{\sigma} d \hat{\lambda}
$$

An empirical model, expressed in power-law form, was found to provide a reasonable representation for the plastic behavior of composites.' Because nonlinearity in the stress-strain response of many composites appears to occur at the onset of loading, one has

$$
\bar{\varepsilon}^{p}=A \bar{\sigma}^{n}
$$


Combining Eqs. (C.1) and (C.5). one obtains

$$
\bar{\sigma}=\left[\frac{3}{2}\left(\sigma_{22}^{2}+2 a \tau_{12}^{2}\right)\right]^{\frac{1}{2}}
$$

Substitution of Eq. (C.8) into (C.7) yields

$$
\bar{\varepsilon}^{p}=A\left[\frac{3}{2}\left(\sigma_{22}^{i}+2 a \tau_{12}^{2}\right)\right]^{\frac{n}{2}}
$$

Equations (C.1) and (C.7) through (C.9) suggest that the plastic response of polymeric composites may be characterized by the three constants $n$. a. and $A$.

For an off-axis unidirectional composite under uniaxial load $N_{\mathrm{x}}$ oriented at an angle $\theta$ about the fiber direction. the stress components relative to the principal directions of symmetry are

$$
\left\{\begin{array}{l}
\sigma_{11} \\
\sigma_{22} \\
\tau_{12}
\end{array}\right\}=\left\{\begin{array}{c}
\cos ^{2} \theta \\
\sin ^{2} \theta \\
-\sin \theta \cos \theta
\end{array}\right\} \sigma_{x}
$$

Also. the plastic strain in the loading direction 15

$$
d \varepsilon_{3}^{\prime}=\cos ^{2} \theta d \varepsilon_{11}^{\prime}+\sin ^{2} \theta d \varepsilon_{22}^{\prime \prime}-\sin \theta \cos \theta d \gamma_{12}^{\prime}
$$

Combination of Eqs. (C.3). (C.10). and (C.11) leads to

$$
\left.d \varepsilon_{r}^{p}=\frac{2}{2} \operatorname{lh}(\theta)\right\}^{F} \sigma_{3} d \lambda
$$

where $h(\theta)$ is given b?

$$
h(\theta)=\left[\frac{3}{2}\left(\sin ^{4} \theta+2 a \sin ^{2} \theta \cos ^{2} \theta\right)\right]^{\frac{1}{2}} .
$$

In conjunction with the transformation function $h(\theta)$, the effective stress and effective plastic strain may also be expressed in 1erms of a, . From Eqs. (C.6), (C.8), and (C.10) one obtains

$$
\bar{\sigma}=h(\theta) \sigma_{x}
$$

and

$$
d \bar{\varepsilon}^{p}=\frac{2}{3} h(\theta) \sigma_{x} d \lambda
$$


Comparison of Eqs. (C.15) and (C.12) yields

$$
d \bar{\varepsilon}^{p}=\frac{d \varepsilon_{x}^{p}}{h(\theta)}
$$

whereby, upon integration

$$
\bar{\varepsilon}^{\prime \prime}=\frac{\varepsilon_{\lambda}^{p}}{h(\theta)}
$$

Substituting Eqs. (C.14) and (C.17) into Eq. (C.7) one obtains

$$
E, "=[h(\theta)]^{n+1} A \sigma_{x}^{n}
$$

Equation (C.IS) expresses the plastic strain-stress relation in an off-axis unidirectional composite under a uniaxial load. This shows that under a certain stress level the corresponding plastic strain is determined by the material plastic properties $n, A$, and a, where a is embedded in $h(\theta)$.

In the case of laminates, all individual plies. oriented at different angles about the load direction. are assumed to undergo the same strains $\boldsymbol{E}, \boldsymbol{E}, .$, and $\gamma_{x}$. To ascertain this commonality of deformation at each stage of loading. with $h(\theta)$ varying from ply to ply, it is necessary to perform an incremental computation because the plastic components of strain vary nonlinearly with stress.

\section{REFERENCES}

1. C. T. Sun and J. L. Chen, "A Simplified Flow Rule for Characterizing Nonlinear Behavior of Fiber Composites," J. Comp. Mater.. 23. October 1989, pp. 1009-1020. 
-

0

$\mathbf{D}$

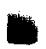

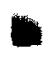

$\mathbf{b}$

0

v

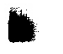

$\mathbf{v}$

$\mathbf{v}$

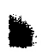

D

$\mathbf{v}$

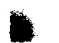

$\mathbf{v}$

c-4

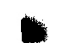




\section{Appendix D. OPTIMAL NONLINEAR LEAST-SQUARE DATA FITTING SCHERIE TO DETERMINE THE PLASTIC \\ PARAMETERS $A, A$, ANDN}

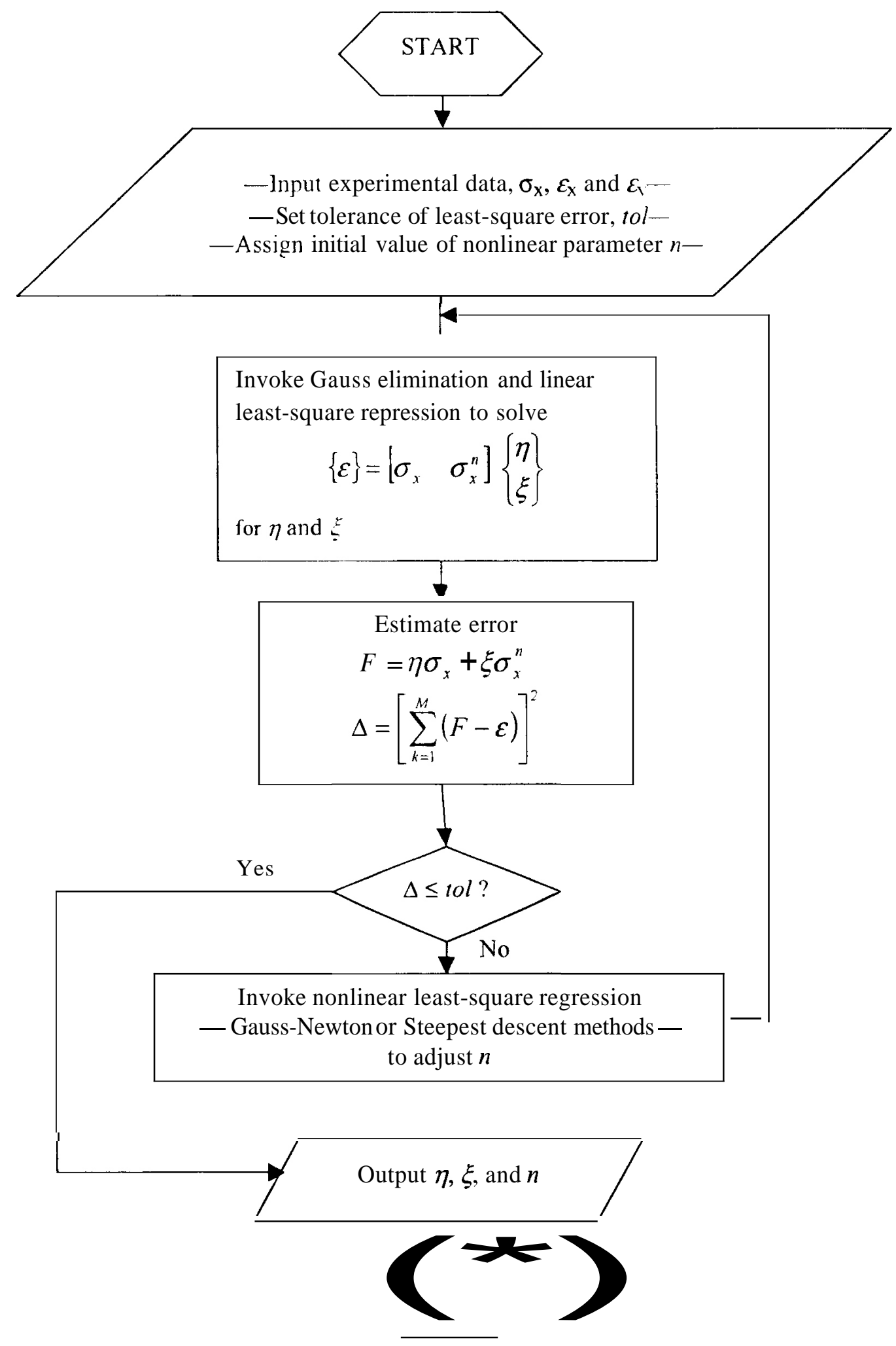

D-1 
b

$\mathbf{s}$

$\boldsymbol{v}$

0

-

b

-

.

$\mathbf{D}$

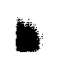

$\mathbf{b}$

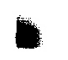

D

v

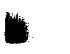

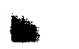

D-2 


\section{Appendix E. A MATHEMATICAL DEMONSTRATION FOR THE DEPARTURE FROM QUASI-ISOTROPY CAUSED BY NONLINEARITY}

Though not supported by experimental data. it is possible to provide a straightforward demonstration for the fact that the respoiise of quasi-isotropic laminates becomes orientation dependent in the nonlinear range of stress-strain behavior by means of a simplified nonlinear formulation.

For this purpose. assume that the basic stress-strain relations of a unidirectional ply are given by

$$
\begin{aligned}
& \sigma_{1}=Q_{11} \varepsilon_{1}+Q_{12} \varepsilon_{2}, \\
& \sigma_{2}=Q_{12} \varepsilon_{1}+Q_{22} \varepsilon_{2}, \\
& \sigma_{6}=f\left(\varepsilon_{6}\right) .
\end{aligned}
$$

Thus. Eq. (E.1) presumes that all nonlinearity dwells in the stress-strain response in shear alone. Obviously, $f\left(\varepsilon_{6}\right)=-f\left(-\varepsilon_{6}\right)$ and $\lim _{\varepsilon_{6} \rightarrow 0} f\left(\varepsilon_{6}\right)=Q_{66}$.

Straightforward manipulations of Eq. (E.1) yield the following expressions for the response of a quasi-isotropic laininate under uniaxial stress applied at an angle $\phi$ about the $X_{1}$ axis:

$$
\begin{aligned}
& \sigma_{\mathrm{x}}=\left\{\frac{1}{2}\left(\mathrm{~m}^{4}+\mathrm{n}^{4}\right)\left(Q_{11}+Q_{22}\right)+2 \mathrm{~m}^{2} \mathrm{n}^{2} Q_{12} \varepsilon_{\mathrm{x}}\right. \\
& \sigma_{\mathrm{x}}=\left[\frac{1}{2}\left(\mathrm{~m}^{4}+\mathrm{n}^{4}\right)\left(Q_{11}+Q_{22}\right)+2 \mathrm{~m}^{2} \mathrm{n}^{2} Q_{12}\right] \varepsilon_{x} \\
&+\left[\mathrm{m}^{2} \mathrm{n}^{2}\left(Q_{11}+Q_{22}\right)+\left(\mathrm{m}^{4}+\mathrm{n}^{4}\right) Q_{12}\right] \varepsilon_{\mathrm{y}} \\
&+m n\left[f\left\{\left(m^{2}-n^{2}\right) \gamma_{x y}+2 m n\left(\varepsilon_{x}-\varepsilon_{y}\right)\right\}-f\left\{\left(m^{2}-n^{2}\right) \gamma_{x y}-2 m n\left(\left(\varepsilon_{x}-\varepsilon_{y}\right)\right\}\right],\right.
\end{aligned}
$$

where $\mathrm{m}=\cos \phi$ and $\mathrm{n}=\sin \phi$.

In the special case that $\phi=22.5^{\circ}$, the above expression reduces to

$$
\sigma_{\mathrm{x}}=\frac{1}{8}\left[3\left(Q_{11}+Q_{22}\right)+2 Q_{12}\right] \varepsilon_{\mathrm{x}}+\frac{1}{8}\left[\left(Q_{11}+Q_{22}\right)+6 Q_{12}\right] \varepsilon_{\mathrm{y}}+\frac{\sqrt{2}}{2} \tilde{f}\left\{\frac{\sqrt{2}}{2}\left(\varepsilon_{x}-\varepsilon_{y}\right)\right\}
$$

While, for $\phi=0^{\circ}$, one obtains

$$
\sigma_{x}=\frac{1}{8}\left[3\left(Q_{11}+Q_{22}\right)+2 Q_{12}\right] \varepsilon_{x}+\frac{1}{8}\left[\left(Q_{11}+Q_{22}\right)+6 Q_{12}\right] \varepsilon_{y}+\frac{1}{2} f\left(\varepsilon_{x}-\varepsilon_{y}\right) .
$$

Note that under uniaxial tension $\varepsilon_{6}=0$ for both $\phi=0^{\circ}$ and $\phi=22.5^{\circ}$.

The essential theme of the above expressions is that they clearly demonstrate that Eqs. (E.3) and (E.4) predict different results. The difference is entirely due to the fact that, in view of the nonlinear character of $f(x), \frac{1}{\alpha} f(a x) \neq f(x)$. It also follows that in the linear range, that is, as $f(x) \rightarrow Q_{66} x$, the aforementioned inequality becomes an equality and quasi-isotropy prevails. 
Nevertheless. it is worth noting that. while demonstrating the departure from quasi-isotrop: due to nonlinearity. 11 can be shown that the current formulation predicts that the response at $22.5^{\prime \prime}$ is stiffer than that at $\phi=0^{\circ}$. Such a prediction is. of course. contradicted by data. 
ORNL/TM-2002/86

\section{INTERNAL DISTRIBUTION}

$\begin{aligned} \text { 1-2. } & \text { R. L. Battiste } \\ 3 . & \text { R. G. Boeman } \\ 4-6 . & \text { J. M. Corum } \\ 7 . & \text { D. L. Erdman } \\ 8 . & \text { J. G. Hansen } \\ 9 . & \text { A. Ionita } \\ \text { 10. } & \text { V. Kunc } \\ \text { 11. } & \text { E. Lara-Curzio } \\ \text { 12. } & \text { R. E. Norris }\end{aligned}$

\author{
13-14. M. B. Ruggles-Wrenn \\ 15. S. Simunovic \\ 16. P. A. Sklad \\ 17. C. C. Southinayd \\ 18. J. M. Starbuck \\ 19. C. D. Warren \\ 20-23. Y. J. Weitsman \\ 24. R. E. Ziegler \\ 25. ORNL Laboratory Records
}

\section{EXTERNAL DISTRIBUT1ON}

26-28. S. Deng, University of Tennessee. Department of Mechanical and Aerospace Engineering, 307 Perkins Hall, Knoxville, TN 37996-2030

29. M. M. Fisher. American Plastics Council. 1300 Wilson Boulevard. Suite 800, Arlington, VA 22209

30. R. B. Freeman, The Budd Company, 1515 Atlantic Boulevard, Auburn Hills. MI 48326

31-60. L. Berger, Automotive Composite Consortium. General Motors, 30500 Mound Road, Mail Code 480-106-710. Box 9055, Warren, MI 48090-9055

61. J. M. Henshaw. Department of Mechanical Engineering, The University of Tulsa. 600 S. College Avenue, Tulsa. OK 74104-3189

62. G. A. Holmes. National Institute of Standards and Technology, Bldg. 224, Room B116, Mail Stop: Room B 108. Gaithersburg? MD 20899

63. D. Kossak. Cambridge Industries, 29333 Stephenson Highway, Madison Heights, MI 48071

64-66. X. Li. University of Tennessee! Department of Mechanical and Aerospace Engineering, 307 Perkins Hall. Knoxville, TN 37996-2030

67. S. R. Reeve, National Composite Center. 2000 Composite Drive, Kettei.ing, OH 45420

68. C. R. Schultheisz. National Institute of Standards and Technology, Building 224, Room A209, Gaithersburg, MD 20899

69. T. D. Seagrave, Bayer Corporation, 100 Bayer Road, Pittsburgh, PA 15205

70. L. V. Smith, Washington State University. School of Mechanics and Materials Engineering, Pullman, WA 99164-2920

71. D. Stewart. Stewart Automotive Research, LLC, 1260 Shotwell Street, Houston, TX 77020

72. X. J. Xin, Department of Mechanical and Nuclear Engineering, Kansas State University, 338 Rathbone Hall, Manhattan, KS 66506-5205

73-76. J. A. Carpenter. U.S. Department of Energy, 1000Independence Avenue, SW, Washington, DC 20585

77. M. Rowlins, U.S. Department of Energy. Oak Ridge Site Office, Oak Ridge, TN 37831

78. S. Diamond, U.S. Department of Energy, 1000 Independence Avenue, SW, Washington, DC 20585 
D

0

v

D

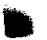

a

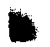

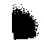

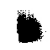

$v$

-

t

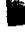

,

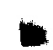

$\checkmark$ 